\title{
TRAINING HUMAN \\ MESENCHYMAL STROMAL CELLS \\ FOR BONE TISSUE ENGINEERING APPLICATIONS
}

JOYCE DOORN 


\section{Members of the committee:}

Chairman: Prof. Dr. G. van der Steenhoven Twente University

Promoter: Prof. Dr. C.A. van Blitterswijk Twente University

Co-promoter: Dr. J. de Boer Twente University

Members: Prof. Dr. J. Engbersen

Twente University

Prof. Dr. J. de Bruijn

Twente University/Queen Mary University

Prof. Dr. K. Le Blanc

Karolinska Institutet

Prof. Dr. J.P.T.M. van Leeuwen Erasmus MC

Dr. K. Dechering Radboud University Nijmegen

\section{Joyce Doorn}

\section{Training human mesenchymal stromal cells for bone tissue engineering} applications

PhD Thesis, University of Twente, Enschede, The Netherlands.

Copyright: Joyce Doorn, Enschede, The Netherlands, 2012. Neither this book nor its parts may be reproduced without written permission of the author.

\section{ISBN: 978-90-365-3312-6}

The research described in this thesis was financially supported by the Smart Mix Program of the Netherlands Ministry of Economic Affairs and the Netherlands Ministry of Education, Culture and Science.

Anna Foundation|NOREF and the Netherlands society for biomaterials and tissue engineering (NBTE) provided financial support for the publication of this thesis.

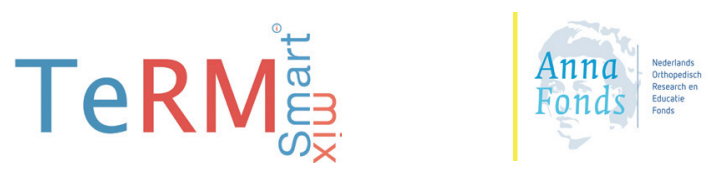




\title{
TRAINING HUMAN MESENCHYMAL STROMAL CELLS FOR BONE TISSUE ENGINEERING APPLICATIONS
}

\section{PROEFSCHRIFT}

\author{
ter verkrijging van \\ de graad van doctor aan de Universiteit Twente, \\ op gezag van de rector magnificus, \\ prof. dr. H. Brinksma, \\ volgens besluit van het College voor Promoties \\ in het openbaar te verdedigen \\ op vrijdag 17 februari 2012 om 12.45 uur
}

door

Joyce Doorn

geboren op 17 Augustus 1983

te Emmeloord 
Promoter: Prof. Dr. Clemens A. van Blitterswijk

Co-promoter: Dr. Jan de Boer 


\section{Contents}

$\begin{array}{lll}\text { Chapter } 1 & \text { General introduction and outline of this thesis } & 7\end{array}$

Chapter 2 Therapeutic applications of mesenchymal stromal cells; 27 paracrine effects and potential improvements

Chapter $3 \quad$ Forskolin enhances bone formation of human mesenchymal $\quad 55$ stromal cells

Chapter 4 Timing rather than the concentration of cAMP correlates with osteogenic differentiation of human mesenchymal stromal cells

Chapter 5 Protein kinase A signaling balances osteogenic and adipogenic differentiation of human mesenchymal stromal cells

Chapter 6 Pro-osteogenic trophic effects by protein kinase A activation in human mesenchymal stromal cells

Chapter 7 Insulin like growth factor-1 enhances proliferation and differentiation of human mesenchymal stromal cells

Chapter 8 Hypoxia mimicing small molecules as a tool to train human mesenchymal stromal cells for revascularization strategies

Chapter 9 General conclusions and discussion

Summary

Samenvatting

Dankwoord

Curriculum Vitae

Publications / Selected abstracts 



\section{CHAPTER 1.}

General introduction and outline of this thesis

The only way to do great work is to love what you do.

- Steve Jobs 


\section{General introduction}

\section{Regenerative medicine}

The increase in human lifespan and the growing population of people aged 65 and above, inevitably leads to an increase in age-associated diseases and disorders, such as osteoporosis (with bone fractures as a result), arthritis, Parkinson's and Alzheimer's disease. Tissue engineering and regenerative medicine offer new possibilities and therapeutic approaches for diseases that currently have no treatment or limited treatment options. Tissue engineering was initially defined as "An interdisciplinary field that applies the principles of engineering and the life sciences toward the development of biological substitutes that restore, maintain, or improve the tissue function" [1] and later on as "The process of creating living, physiological, three-dimensional tissues and organs utilizing specific combinations of cells, cell scaffolds, and cell signals, both chemical and mechanical" [2]. This combination of scaffolds with cells is referred to as cell-based tissue engineering and the field of regenerative medicine includes tissue engineering as well as stem cell therapies that are based on infusions or injections of bare stem cells.

A breakthrough in the field of regenerative medicine came in 2006 with the transplantation of the first full organ, the bladder (figure 1). From 7 patients, researchers isolated muscle and endothelial cells, cultured these on scaffolds for 7 weeks and implanted the engineered construct [3]. Even more exciting was the transplantation of the first tissue-engineered trachea (figure 2). A decellularized donor-derived trachea was used as a scaffold. Then, in vitro-expanded stem cells from the patient were differentiated towards the chondrogenic lineage and seeded into the scaffold using a bioreactor. The inside of the scaffold was lined with epithelial cells and the graft was then used to replace the left main bronchus [4]. No complications occurred and the patient left the hospital 10 days after surgery. More recently, another trachea was engineered with a polymer scaffold as basis, thus using a fully synthetic approach, and a patient with late-stage tracheal cancer was successfully implanted with this tissueengineered trachea.

These examples demonstrate the feasibility and the potential of regenerative medicine, but there

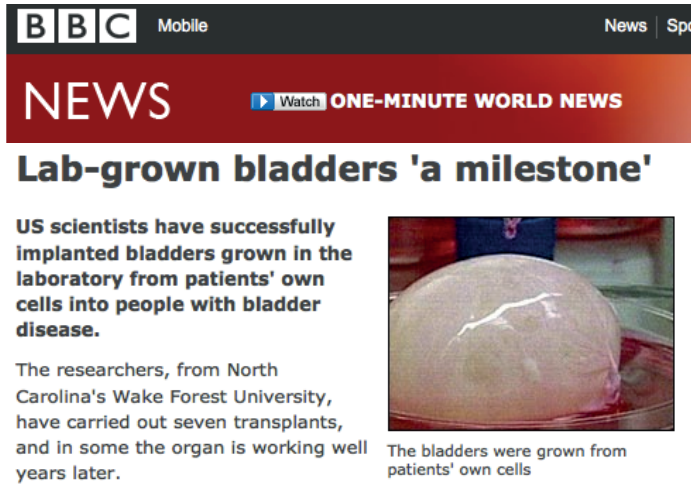

Figure 1. First report on successful implantation of tissue-engineered bladders. In 2006 researchers created and implanted tissue-engineered bladders for the first time, by culturing patient-derived muscle and endothelial cells on scaffolds. (Adapted from news.bbc.com.uk) 


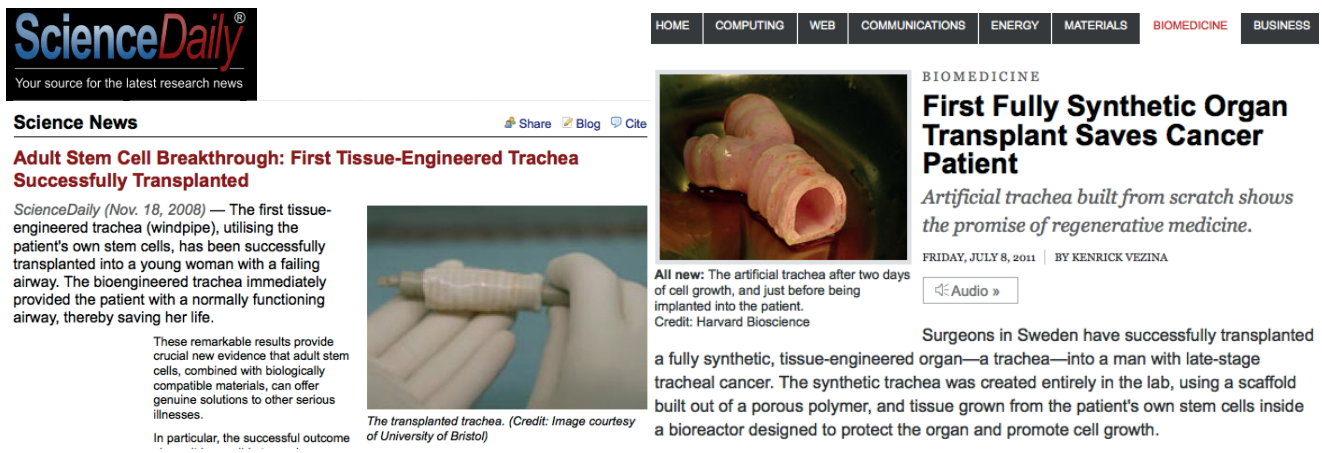

Figure 2. First reports on successful implantation of tissue-engineered tracheas. In 2008, researchers created a trachea by seeding patient-derived cells on a decellularized scaffold from a donor. After culture in a bioreactor the construct was successfully implanted in a patient (left). Subsequently, in 2011, a trachea was constructed and implanted in a similar manner but this time with a polymer scaffold (right). (left; adapted from www.sciencedaily.com, right; adapted from technologyreview. com)

are several challenges left to face. For example, vascularization of large constructs, differentiation of cells or fabrication of multi-tissue organs, such as the kidney or the heart, remain complicated.

\section{Bone}

Bones, which constitute part of the skeleton, are well known for their supportive and protective function, but they also play a role in numerous other processes. As part of the musculoskeletal system, they are involved in locomotion and play an important role in metabolism, by serving as a reservoir of minerals and growth factors [5]. Figure 3 shows the basic composition of bone. The outer part of long bones and the shells of flat bones consist of compact cortical bone, whereas the inner part of long bone is composed of highly porous trabecular, or cancellous, bone. Cortical bone consists of individual osteons with Haversian canals in the middle, which contain nerves and blood vessels and are interconnected by perforating Volkmann canals [6]. Bone matrix is composed of an organic and an inorganic part. The organic part mainly consists of fibril-forming collagen type I, supported by various non-collagenous proteins which are dispersed between the collagen [5]. The inorganic part is first deposited as unmineralized osteoid by osteoblasts, and later mineralized by the deposition of hydroxyapatite crystals, mainly consisting of calcium and phosphate, in between the collagen fibrils. This combination of collagen and crystals provides bone with both its mechanical strength and elastic properties [6]. Based on the alignment of the collagen fibers, bone can be microscopically classified as either woven or lamellar. In lamellar bone, the fibers are highly organized in parallel, concentric sheets, thus providing mechanical strength, whereas in woven bone the fibers are more randomly oriented. This woven bone is 


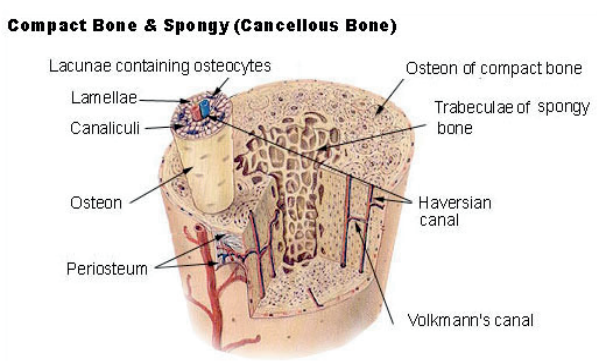

Figure 3. Histology of bone. Bone consists of two types; dense compact bone on the outside and spongy, or cancellous bone, containing the bone marrow, on the inside. Compact bone consists of densely packed osteons, which contain a central canal (the Haversian canal), surrounded by lamellae of matrix. Within these matrix osteocytes are located in lacunae. The Haversian canals are interconnected by Volkmann's canals. (Adapted from the US National Cancer Institute's Surveillance, Epidemiology and End Results (SEER) Program, http://training. seer.cancer.gov/module_anatomy)

center become hypertrophic and start they become apoptotic. The hypertrophic cartilage is invaded by blood vessels, thus allowing osteoprogenitors and hematopoietic stem cells to enter, and within the space left after apoptosis of chondrocytes, later on the bone marrow is formed. At the distal ends of the bone, a secondary ossification center originates, to form the epiphyseal growth plates that allow growth of long bones during development [7].

\section{Cells constituting bone}

Various cell types are part of the bone system. Mesenchymal progenitors, which give rise to the bone cells, reside within the connective tissue between trabeculae, close to blood vessels as well as in the periosteum. Osteoblasts are derived from mesenchymal progenitors and deposit osteoid, which later mineralizes into mature bone. Osteoblasts produce hormones, enzymes (such as alkaline phosphatase) and matrix proteins (such as collagens, bone sialoprotein, osteocalcin and osteonectin) that play a role in the mineralization process. Once osteoblasts become entrapped in the matrix, they differentiate into mature bone cells; osteocytes. Osteocytes occupy spaces called lacunae and are involved in the maintenance of the matrix, calcium homeostasis and the regulation of the bones' response to mechanical stress. Apoptosis of osteocytes is thought to trigger bone turnover and in this way they control local remodeling. Osteoclasts are multinucleated cells that are derived from monocytes in the blood 
A

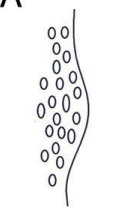

Limb bud

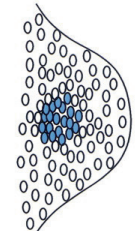

Mesenchymal condensation

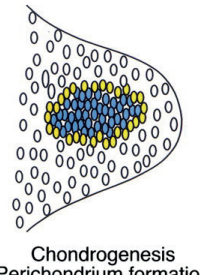

Perichondrium formation

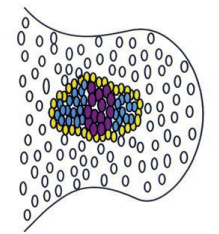

Hypertrophic differentiation Growth plate formation

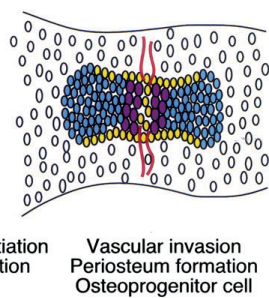

B

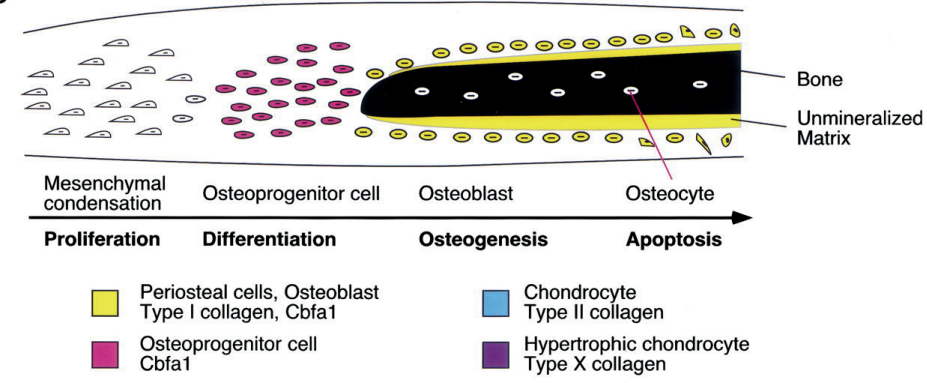

Figure 4. Endochondral and intramembranous bone development. Top; a schematic representation of endochondral ossification. Mesenchymal stromal cells condensate and start to differentiate into chondrocytes in the center, expressing collagen type II and X. At the periphery, chondrocytes become hypertrophic and eventually become apoptotic and calcify. The bone will be infiltrated with blood vessels and invaded by osteoblasts, which deposit new bone matrix. Bottom; a schematic representation of intramembraneous ossification. Mesenchymal progenitors directly differentiate into osteoprogenitor cells and subsequently into osteoblasts. Osteoblasts deposit bone matrix, after which these cells become entrapped and become osteocytes. (Adapted from [92])

stream, and are located in resorption pits called Howship's lacunae. Osteoclasts resorb bone matrix by secreting $\mathrm{H}^{+}$ions to acidify and dissolve the mineral phase, and by secreting various proteases and matrix metalloproteinases that degrade the organic phase. Bone resorption and bone deposition are continuous, parallel processes, and a proper balance between these two processes makes that bone is constantly remodeled [6].

\section{Bone tissue engineering}

The constant remodeling of bone is also the reason for its amazing self-healing capacity. However, in some cases the healing capacity of bone is not sufficient, for example in large defects, non-unions or tumor-resections. In these situations it is necessary to fill the originating bone defect with a graft. Several graft-strategies have been developed, and are currently utilized, each with its own advantages and limitations. Still considered the golden standard is autografting, where bone is harvested from another part of the patient's body (e.g. the iliac crest) and transplanted into the defect. This usually results in very good healing of the defect, but requires a second surgery to harvest the bone, which may be accompanied with complications at the harvest site. In allografting, bone 
is obtained from a cadaver, but this carries the risk of transmitting diseases, and success rates are not as high as with autografting. The third option is a synthetic graft, which can be based on metals, polymers, ceramics or composites. Although metals provide the required mechanical strength, they poorly integrate with the bone, whereas ceramics, such as calcium phosphates, support bone ingrowth, remodeling and may even induce new bone formation, but they lack mechanical properties.

Bone tissue engineering aims to provide an alternative to the approaches described above, and involves harvesting of cells from the patient and an appropriate scaffold. As shown in figure 5 , the patient-derived cells are expanded in vitro to obtain sufficient numbers, combined with growth factors or other osteoinductive molecules, seeded onto a scaffold and implanted back into the patient. The feasibility of this approach has been demonstrated in numerous models, including large animal models and humans, but the amounts of bone obtained in humans are limited and bone tissue engineering has not found its way to the clinic. Goshima et al. were the first to demonstrate bone formation upon ectopic implantation of rat bone marrow cells on calcium phosphate scaffolds in rats [8] and a large amount of in vivo studies in rodents have been performed since [9], as well as a few studies in large animals [10-12]. The first clinical study in humans was reported in 2001 by Quarto et al., who implanted in vitro expanded autologous mesenchymal stromal cells (MSCs) in bone defects of patients for whom conventional treatment had failed. Implantation did not result in complications and after 5-7 months, complete fusion between the host bone and the implant occurred [13, 14]. Successful studies were also reported by Cancedda et al., who showed repair of a fracture in the tibia in three patients, by implantation of expanded autologous MSCs on ceramic scaffolds [15] and by Schimming et al., who implanted periosteal cells from the mandibular on a polymer fleece for maxillary sinus augmentation [16]. In these studies the origin of the newly formed bone was not identified, controls were not included, the results were solely based on radiographs and on data from very few patients, which remain drawbacks of these studies [9]. Several other studies have shown successful bone tissue engineering, although these are all case studies and also

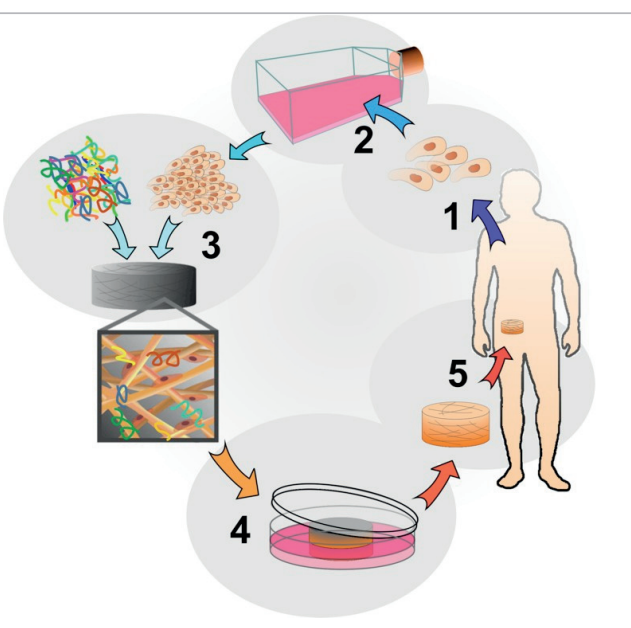

Figure 5. Principle of bone tissue engineering. In cell-based bone tissue engineering, cells are harvested from the patient (1) and expanded in vitro (2). When sufficient amounts of cells are obtained, they are seeded onto the scaffold (4), possibly in combination with osteoinductive molecules (3), and the construct is implanted back into the patient (5). (Adapted from Julian H.S. George, PhD thesis) 
hampered by one or more of the limitations described above. These studies include regeneration of a femur fracture, the alveolar cleft, the mandible and a maxillary defect [17]. The need for larger studies, including controls, was shown by Meijer et al., who demonstrated that in 10 patients who underwent reconstruction of the maxillary sinus, new bone formation was only observed in 1 patient [9]. Improvement of the current protocols is thus warranted.

\section{Scaffold}

In the design of a scaffold for bone tissue engineering several aspects have to be considered. It should be biocompatible and biodegradable, meaning that the material should not evoke an inflammatory response and that the material is resorbed and replaced by body tissue over time. In addition, it should provide sufficient mechanical strength and preferably possess osteoinductive properties, meaning that new bone formation does not only rely on ingrowth of bone, but also spontaneously originates on the inside of the scaffold. The porosity of the scaffold has to allow diffusion of nutrients, but also growth of cells and vascularization and by tuning the surface roughness of the material, attachment and behavior of cells can be influenced. Furthermore, one has to consider its processability and the ability to sterilize it. Metal implants, such as titanium, offer very good mechanical stability, but poorly integrate with the bone and therefore a coating of calcium phosphate is often applied [18]. Calcium phosphate scaffolds itself, which are biodegradable and osteoconductive or -inductive offer very good alternatives [19]. The porosity and the surface roughness of these materials can be tuned in the manufacturing process. On the other hand, the mechanical strength of calcium phosphate ceramics is insufficient, thus the search for better scaffolds remains.

\section{Cell source}

Cells can be obtained from several sources, each with advantages and limitations. Embryonic stem cells (ES cells), induced pluripotent stem cells (iPS cells), adult stem cells, but also more mature, differentiated cells, such as osteoprogenitor cells are all topic of investigations. Although ES and iPS cells have great differentiation and proliferation potential, teratoma formation remains a major concern with the use of these cells [20]. On the other hand, the use of more mature cells is associated with limited proliferation and expansion capacity. Therefore, one of the most interesting cell types for bone tissue engineering is the MSC. First identified by Friedenstein et al. as colony forming unit-fibroblasts (CFU-F) in the bone marrow [21], nowadays known as MSCs, it is now known that these cells can be isolated from virtually any tissue in the adult body, including bone marrow, adipose tissue, trabecular bone, synovium, dental pulp, vascular wall, muscle, kidney, lung, brain, pancreas, umbilical cord and placenta. It is estimated that only $15 \%$ of CFU-Fs have stem cell-like properties [22] and the 


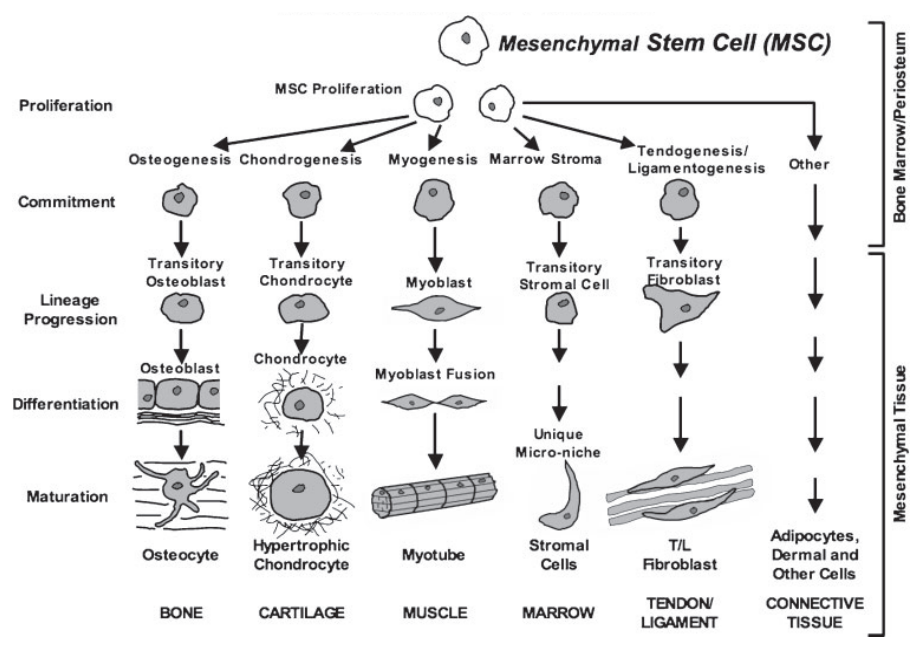

Figure 6. Differentiation potential of mesenchymal stromal cells. MSCs proliferate and have the ability of self-renewal and, in response to extracellular signals commit and differentiate into mature cells of a specific lineage. Initially, MSCs were thought to give rise only to cells of the mesenchyme (osteogenic, chondrogenic and adipogenic lineages), but later these cells were also shown to differentiate into stromal cells, cardiomyocytes, astrocytes, endothelial-like cells, pancreatic and hepatic cells. (adapted from [36])

number of obtained CFU-Fs from a biopsy varies between donors [23]. Isolated CFUFs form a heterogenous population, with different morphologies and variations in the ability to proliferate and differentiate, within and between biopsies from different donors [21,24]. Despite this, the cells are relatively easy to isolate and select based on plastic adherence and show high proliferative capacities in vitro, although proliferation of these cells is not unlimited. Furthermore, as shown in figure 6, they are capable of differentiation towards at least the osteogenic, chondrogenic and adipogenic lineage [25], and more recently differentiation into myocytes [26, 27], endothelial [28, 29], neuronal [30, 31], hepatic [32] and pancreatic [33] cells was also reported. Due to the abundant isolation sites, the fast release of MSCs into the bloodstream upon damage and the fact that MSCs share expression of several surface markers with pericytes, it is now hypothesized that MSCs are pericytes, which stabilize and are located in close proximity to blood vessels [34]. Besides their differentiation potential, MSCs secrete a wide range of cytokines, growth factors and other molecules [35], that have immunomodulatory and regenerative effects [36]. Autoimmune diseases such as graft-versus-host disease and Crohn's disease are thought to benefit from these secreted immunomodulatory factors, and trophic factors, which exert pro-angiogenic, pro-mitogenic, anti-apoptotic and anti-scarring effects, may improve tissue functions after myocardial infarcts or kidney failure.

Another advantage of adult stem cells is that they can be obtained from the adult body, thus in principle an autologous approach is available for every patient. However, 
the performance of cells varies widely between donors [37] and there is debate about the quality of these cells from elderly patients [38]. In addition, in patients with genetic disorders or for example cardiovascular disease, underlying causes may also affect stem cell quality. In these cases, allogeneic cells offer an alternative and usage of these cells also allows off-the-shelve therapies and selection of stem cells with the best performance. Major concerns of allogeneic therapies are of course immune reactions and transmission of diseases.

\section{Signaling pathways involved in differentiation of hMSCs}

In order to enhance the bone forming capacity of human MSCs (hMSCs) in vivo, an improvement of the performance of the cells is required and more knowledge of the signaling pathways that direct proliferation and differentiation of these cells is essential. In vitro differentiation, in vivo bone formation as well as the specific secretion of growth factors can be enhanced by specific culture protocols or chemical treatment of cells [39-42]. The differentiation of hMSCs towards the osteogenic lineage in vitro can be achieved with various stimuli that activate different signaling pathways. Dexamethasone, bone morphogenetic protein-2 (BMP-2) and vitamin D are commonly used to induce osteogenic differentiation of these cells in vitro [43]. The development of mature osteoblasts from MSCs and the various pathways involved is depicted in figure 7. Initial commitment of MSCs towards the osteogenic lineage is characterized by the expression of the transcription factors Runx2 [44] and Osterix [45], whereas early differentiation into osteoblasts is accompanied by expression of alkaline phosphatase (ALP), which is involved in mineralization $[46,47]$. A description of the signaling pathways relevant to this thesis, their mechanisms and their role in osteogenic differentiation are described below.

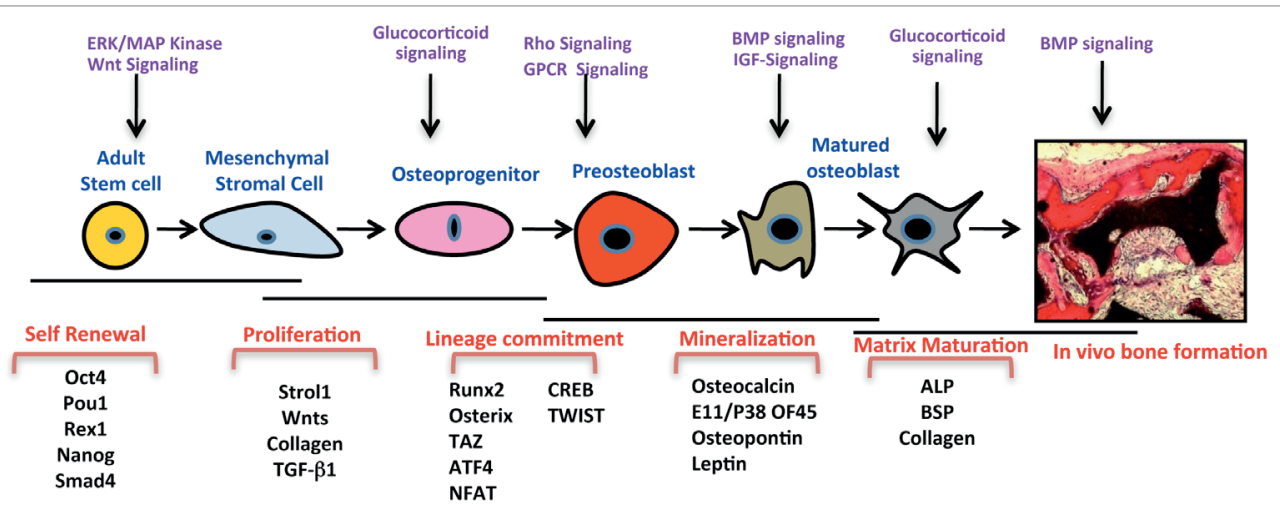

Figure 7. Signaling pathways and factors regulating differentiation of MSCs towards mature osteocytes. Each step of commitment and differentiation of mesenchymal stromal cells is regulated by specific signaling pathways and each phase is characterized by expression of different genes and transcription factors. (Courtesy of R. Siddappa) 


\section{BMP signaling}

BMP signaling is mainly involved in the induction of bone formation as well as in the differentiation of osteoblasts. In a landmark paper by Urist et al., it was shown that demineralized, decellularized bone was able to induce new bone formation [51]. Later on, the responsible BMPs were isolated and purified from bone and cloned [52]. Nowadays, over 20 BMPs have been identified and they are classified as members of the transforming growth factor- $ß$ (TGF- $ß$ ) family [53]. A schematic representation of the BMP signaling pathway is depicted in figure 8. Intracellular effects of BMPs are mediated via two cell surface serine/threonine kinase receptors (BMPR type I and II) [54]. BMPs bind to the type II receptor, which then forms a complex with and results in phosphorylation of the type I receptor. The type I receptor transmits the signal downstream primarily by activation of mothers against decapentaplegic (Smads), but also via the p38 mitogen-activated protein kinase (MAPK), and c-Jun N-terminal kinase (JNK) signaling pathways. Activated receptor Smads (R-Smads) form a complex with co-Smads (Smad4), which then translocates into the nucleus to initiate transcription of target genes, such as the inhibitors of differentiation (Id1 and Id2) $[55,56]$. The precise role of BMPs in the in vitro differentiation of human MSCs remains elusive. BMP6 increases expression of various osteogenic genes and enhances mineralization [57], whereas other BMPs had no effect on alkaline phosphatase, but increased expression levels of bone sialoprotein and osteopontin in hMSCs $[57,58]$. In vivo, all BMPs are potent inducers of bone formation [59] and they are thus used as potent inducers of bone in clinical applications such as spinal fusion and non-unions. However, relatively large amounts of BMPs are required for these applications and this is associated with high costs as well as bone formation outside the defect area.

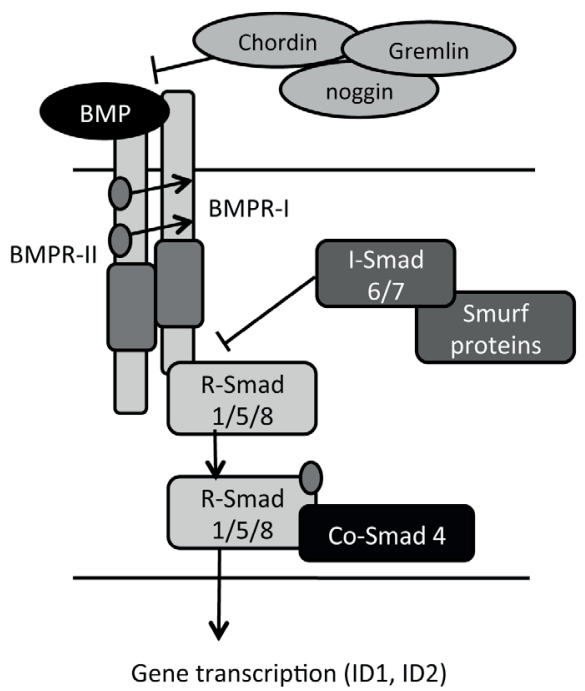

Figure 8. BMP signaling pathway. BMPs bind to the BMP receptor type II (BMPR-II), which co-localizes with the BMP receptor type I (BMPR-I). This complex phosphorylates Receptor-smads (R-smad-1, -5 and -8 ) and the phosphorylated R-Smads form a complex with co-Smad-4. This complex translocates into the nucleus where it activates transcription of target genes. Inhibition of BMP signaling occurs on various levels. Noggin, chordin and gremlin inhibit receptor binding of BMPs, whereas inhibitorySmads (I-Smad-6 and -7) intracellularly function as decoys for R-Smads by binding to the type I receptor. Smurf proteins induce degradation of R-Smads. 


\section{Wnt signaling}

Wnt (wingless-type MMTV integration site family members) signaling is involved in the proliferation and differentiation of MSCs. Wnts can activate both the canonical pathway, also referred to as the $\beta$-catenin dependent pathway or the non-canonical pathway (figure 9). In the canonical pathway, $\beta$-catenin is continuously degraded by a complex of Axin, the adenoematuous polyposis coli (APC) protein, and GSK3 $\beta$. Upon binding of Whts to their specific Frizzled receptors (Fzd) and a low-density lipid protein (LRP) co-receptor this complex is inhibited, thus resulting in stabilization of $\beta$-catenin. $\beta$-catenin then translocates into the nucleus, where it interacts with transcription factors of the lymphoid enhancer-binding factor / T-cell specific family (TCF/LEF) and activates transcription of target genes [60]. Non-canonical pathways are also activated by binding of Wnts to Fzd receptors, but intracellular signals are transmitted via intracellular calcium release and activation of PKC ( $\mathrm{Ca}^{2+}$ dependent pathway) or via JNK [61]. Wnt signaling is inhibited by secreted frizzled-related proteins (sFRPs) and Wnt inhibitory factor-1 (WIF-1) as well as sclerostin and dickkopf-1 (Dkk-1), which function as decoys to the LRP co-receptors [60].
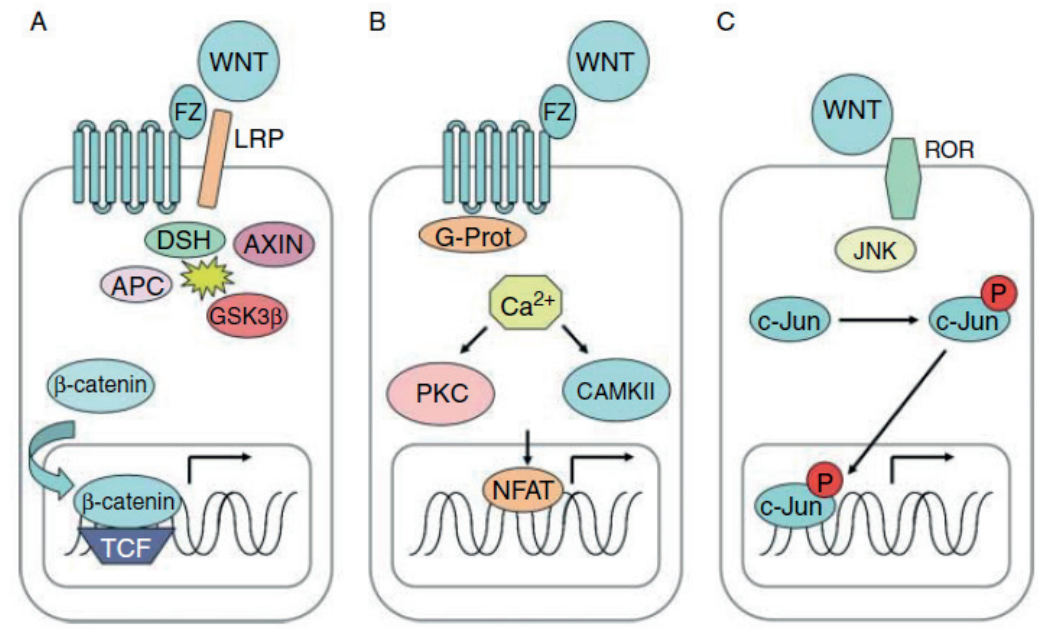

Figure 9. Canonical and non-canonical Wnt signaling pathways. Canonical pathway (a); binding of Wnts to the Fzd receptor and the low-density lipoprotein LRP co-receptor leads to degradation of the $\beta$-catenin degrading APC/Axin/GSK3 $\beta$ complex and results in the stabilization of $\beta$-catenin. B-catenin translocates into the nucleus and binds to the TCF/LEF family of transcription factors, resulting in transcription of target genes. In the non-canonical $\mathrm{Ca}^{2+}$-dependent pathway (b), Wnts bind in a similar manner to the Fzd and LRP receptors, which results in intracellular release of $\mathrm{Ca}^{2+}$ through a Gprotein and subsequent activation of the $\mathrm{Ca}^{2+}$-sensitive kinase calcium/calmodulin-dependent kinase II (CAMKII) or protein kinase C (PKC), which induce transcription factors such as the nuclear factor of activated T-cells (NFAT). In the non-canonical JNK-dependent pathway (c), Wnts bind to either the Fzd receptors or the receptor tyrosine kinase like-orphan receptor (ROR). JNK phosphorylates c-jun, which forms a transcription factor with c-fos and activates transcription of target genes. (Adapted from [93]) 
In various (murine) cell lines it was demonstrated that activation of Wnt signaling results in enhanced osteogenic differentiation, and in vivo experiments also established that Wnt signaling positively correlates with bone mass, via activation of stem cell renewal, osteoblast proliferation and induction of osteoblastogenesis [61]. In human MSCs however, opposing effects were observed. In our own lab it was shown that Wnts enhance proliferation and inhibit osteogenic differentiation of hMSCs in vitro $[62,63]$. In addition, others demonstrated proliferative and anti-osteogenic effects of Wnt3 A [64], although Wnt5A, which activates the non-canonical JNK pathway, did induce osteogenesis [65], suggesting that in hMSCs canonical Wnts stimulate proliferation and non-canonical Wnts stimulate osteogenic differentiation [64].

\section{IGF-signaling}

The insulin-like growth factor (IGF) system contains three ligands (IGF-1, IGF-2 and insulin), their cell surface receptors (the IGF-1 receptor (IGF-1R), the IGF-2 receptor (IGF-2R), the insulin receptor (IR) and hybrid IGF/insulin receptors) and six IGF binding proteins (IGFBPs). Functions of IGF- 1 and -2 are similar, but IGF- 2 is mainly involved in fetal processes, whereas IGF-1 is required for full growth of bones. In the adult body, IGF-1 is more potent and present in higher concentrations. IGF signaling is often referred to as the growth hormone (GH) / IGF-1 axis, due to the regulation of IGF-1 by GH which stimulates systemic production of IGF-1 by the liver. Several cell types also produce IGF-1 locally, under influence of numerous stimuli. IGF activity is regulated by the acid labile subunit (ALS) and six IGF binding proteins (IGFBPs), which form complexes with IGFs to enhance their stability and facilitate their transport but they may also inhibit receptor binding [66]. The IGFs bind with high affinity to the IGF$1 \mathrm{R}$ and the hybrid receptors, whereas insulin binds with high affinity to the IR. The IGF-2R only binds IGF-2 and functions as a clearance receptor to remove IGF-2 from the circulation.

As shown in figure 10, IGF-1 has high affinity for and mainly binds to the IGF-1R, but can also bind hybrid receptors. The IGF-1R mediates downstream effects via the insulin receptor substrate- 1 and -2 (IRS-1, -2) and Akt, which stimulate growth and proliferation. Signaling through the IR primarily mediates metabolic effects whereas signaling through the IGFRs result in growth and proliferation [67].

Actions of IGFs are very diverse. IGF-1 serves as a survival factor for neural cells, and may exert trophic (protective and regenerative) effects in neural disorders as well as in the heart. Furthermore, IGF-1 has mitotic and anti-apoptotic effects [67]. Several mouse models have demonstrated the key role of IGF-1 in bone formation. Disruption of IGF signaling results in decreased bone size [68] and volume as well as defects in mineralization [69], but IGF-1 also promotes osteoclastogenesis, which may be the reason 


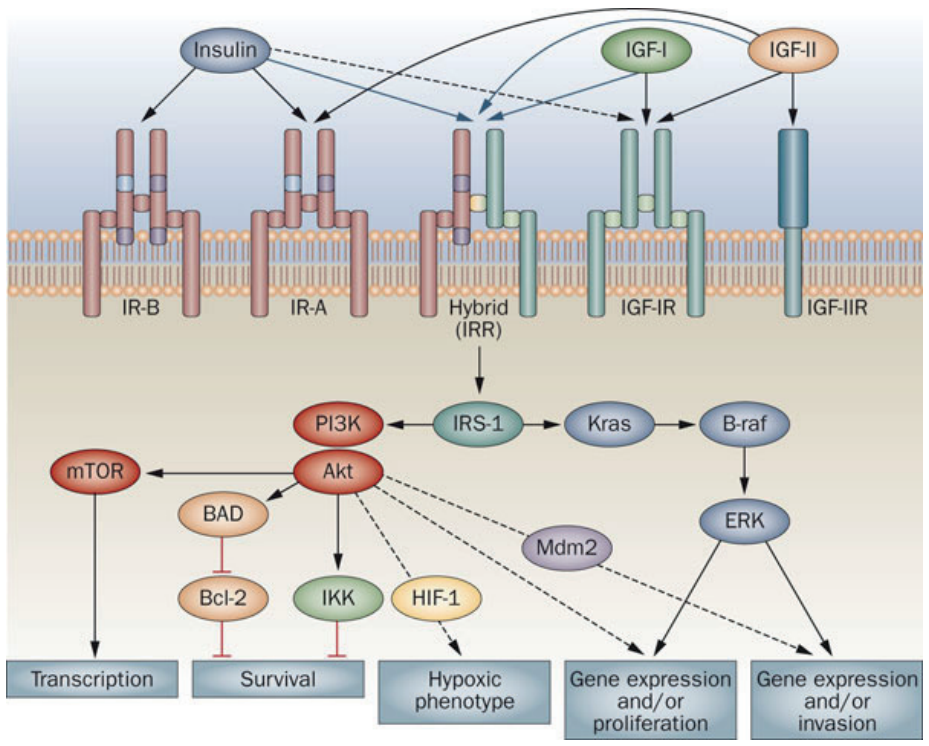

Figure 10. Insulin / IGF signaling pathways and main endpoints. IGF-1 binds with high affinity to the IGF-1R, but may also bind to a hybrid insulin/IGF receptor (IRR). IGF-2 binds to both IGF receptors, hybrid receptors and the insulin receptor type A (IR-A). Receptor binding results in activation of IR substrates (IRS), which activate different downstream pathways. Depending on the activated pathway, IGF or insulin binding results in proliferation, survival or transcription of other genes. (Adapted from [94])

that an increase in bone density was observed in some mouse models [68]. In vitro, IGF1 was shown to increase proliferation, migration and differentiation of osteoblasts [7072], but the effects of IGF-1 on hMSCs are subject of debate. Some studies have shown increased proliferation and osteogenic differentiation upon treatment with rhIGF-1 [73, 74] or adenoviral overexpression [75], whereas others report no effect [76, 77].

\section{GPCR signaling}

GPCRs (G-protein coupled receptors) are seven-transmembrane receptors through which various hormones, such as melatonin, epinephrine, calcitonin, calcitonin generelated peptide, prostaglandins, parathyroid hormone and parathyroid hormone-related peptide transmit their signals. Intracellularly, GPCRs are bound by heterotrimeric proteins (G-proteins), which, depending on the type of protein (Gs, Gi or Gq,) can activate different downstream signaling pathways. Each G-protein contains an $\alpha-, \beta$ and $\gamma$-subunit and binding of a ligand to its specific receptor results in a conformational change that leads to dissociation of the $\alpha$-subunit of the coupled G-protein. In the case of cAMP/PKA signaling, signals are transmitted via Gs proteins. The Gs $s_{\alpha}$ binds to adenylate cyclase, which converts ATP into cAMP and cAMP activates the downstream protein kinase A (PKA) pathway. PKA phosphorylates the transcription factor cAMP responsive element binding protein (CREB), which activates transcription of target genes in the nucleus [78]. For some time, PKA was believed to be the sole mediator of cAMP signaling, 
but around a decade ago, another target of cAMP, the exchange protein directly activated by cAMP (Epac), was identified [79]. Activation of the cAMP/PKA pathway in several cell lines with GPCR ligands was shown to improve osteogenic differentiation [80-82] and in our own lab cAMP was demonstrated to improve differentiation in vitro as well as bone formation in vivo by hMSCs [41]. In contrast, a role for cAMP in adipogenic differentiation was also demonstrated $[83,84]$.

\section{HIF-1 signaling}

Besides osteogenic differentiation, vascularization of the engineered constructs is of key importance for the survival of implanted cells. It was demonstrated that MSCs can differentiate into endothelial-like cells and one approach to enhance vascularization in tissue engineered constructs, is to include endothelial-like MSCs within these constructs. In addition, MSCs secrete high numbers of angiogenic growth factors, such as vascular endothelial growth factor (VEGF). Increased secretion of angiogenic growth factors potentially also induces the formation of blood vessels by both implanted and host cells. The hypoxia inducible factor-1 (HIF-1) pathway plays an important role in these effects. This pathway is activated in low oxygen (hypoxia) cultures, and studies have shown that culture of hMSCs in low oxygen concentrations facilitates secretion of pro-angiogenic growth factors, but also increases survival and engraftment percentages of implanted

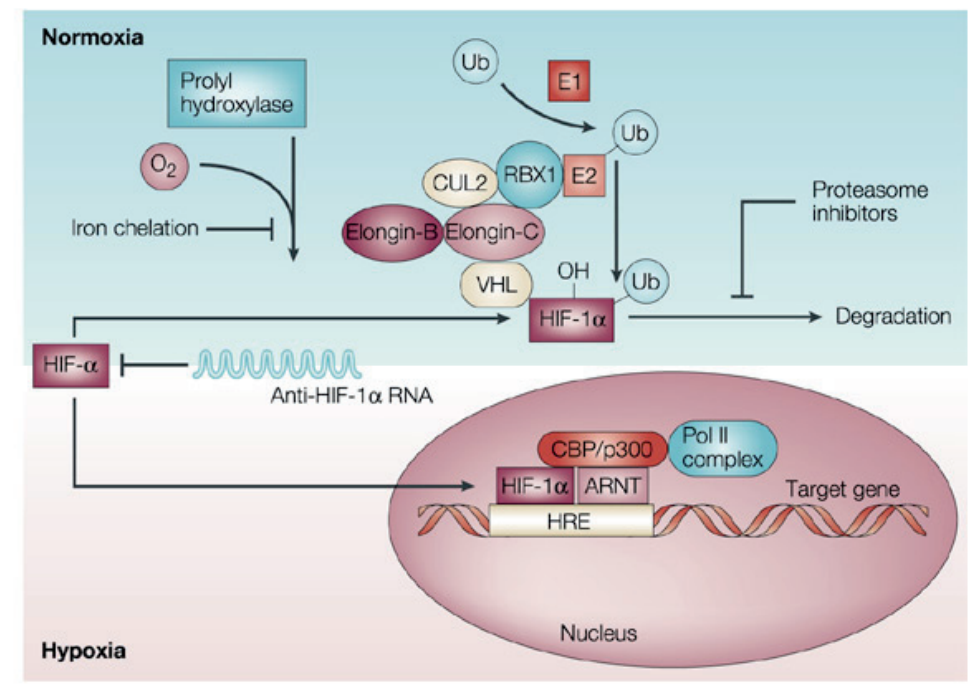

Figure 11. HIF-1 signaling pathway. In the presence of oxygen (top panel), prolyl hydroxylases target the HIF-1 $\alpha$ for ubiquitylation by the Von hippel Lindau (VHL) complex, which makes it a target for degradation. Iron is required for functioning of prolyl hydroxylases and iron chelation thus inhibits their activity. Besides iron, oxygen is also a requirement for the function of prolyl hydroxylases and in the absence of oxygen, HIF- $1 \alpha$ is stabilized and translocates into the nucleus, where it complexes with HIF-1ß (aryl hydrocarbon receptor nuclear translocater (ARNT)), CBP/p300 and the DNA polymerase II (Pol II). This complex initiates transcription of target genes by binding to the hypoxia responsive elements (HREs). (Adapted from [95]) 
cells [85-87]. As depicted in figure 11, in the presence of oxygen, the HIF-1 $\alpha$ subunit is degraded by prolyl hydroxylases (PHDs) [88], but in the absence of oxygen, PHDs are inactive [89]. In this case, HIF-1 $\alpha$ accumulates, translocates into the nucleus and forms a complex with the HIF-1ß subunit and p300/CBP which binds to hypoxia responsive elements (HREs) in the promoter of target genes [90,91]. Many of the genes containing an HRE are endothelial or angiogenic and activation of this pathway in hMSCs may lead to endothelial differentiation of hMSCs and enhanced secretion of angiogenic growth factors.

\section{Physical cues}

Not only soluble molecules or growth factors, but also mechanical and topographic cues can influence the differentiation of hMSCs. For example, McBeath et al. demonstrated that cell shape directs hMSCs into the adipo- or osteogenic lineage via Rho-kinase signaling. When cells were allowed to spread, Rho-kinase was activated which resulted in osteogenic differentiation, whereas rounded cells became adipocytes [48]. Similarly, material hardness affects cell adhesion and specific topographical features may induce osteogenic differentiation, by influencing spreading of cells [49] and mechanical stress, induced by fluid flow, tension or compression may induce RhoA signaling, Wnt signaling and BMP signaling. Depending on the type and strength of the stimulus, mechanical stress can direct hMSCs towards the osteo- or chondrogenic lineage [50]. 


\section{Aims and outline of this thesis}

This thesis has been divided in two parts. As described above, the cAMP/PKA pathway seems to be involved in both adipogenic and osteogenic differentiation, and the goal of the first part of this thesis was to examine the role of the PKA pathway in osteogenic differentiation of hMSCs in more detail. In the second part, it was examined if the trophic factors that are secreted by these cells upon differentiation, are biologically active and if they could play a role in tissue engineering applications.

As described, MSCs secrete a wide range of cytokines, growth factors and other molecules, which can have immunomodulatory as well as regenerative properties. In chapter 2, the currently identified molecules responsible for these processes are listed and current literature on therapeutic applications using these trophic MSCs is reviewed. We have shown before that activation of the PKA pathway in hMSCs, by treatment with the small molecule db-cAMP increases their differentiation in vitro and bone forming capacity in vivo, which is accompanied by increased secretion of bone specific growth factors. The aim of chapter 3 is to optimize PKA activation to obtain optimal differentiation, growth factor secretion and in vivo bone formation, by using different types of PKA activators in various concentrations. Additionally, in chapter 4 PKA activation is further investigated, by examining how various GPCR ligands as well as intermittent stimulation affect differentiation of hMSCs. Since the PKA pathway was suggested to be involved in both adipogenic and osteogenic differentiation of hMSCs, the aim of chapter 5 is to unravel how PKA activation is involved in the balance between these two lineages.

In the second experimental part of this thesis, it is examined if the growth factor secretion by hMSCs can be improved for specific applications. The aim of chapter 6 was to investigate if secreted growth factors could contribute to bone formation in vivo. hMSCs show increased secretion of bone specific growth factors upon treatment with db-cAMP, and we investigated if these are biologically active and affect behavior of surrounding cells. In addition, the pathways involved were examined. One of the growth factors secreted in high amounts after treatment with db-cAMP and also abundantly present in bone is insulin-like growth factor-1 (IGF-1). The aim of chapter 7 was to investigate the effects of this protein on proliferation and differentiation of hMSCs in vitro and to examine if secretion of this protein influences in vivo bone formation.

Besides osteogenic factors, secretion of angiogenic growth factors could enhance vascularization in tissue engineered constructs and in addition, increased secretion of angiogenic factors could improve the performance of infused hMSCs in for example myocardial infarct and kidney failure. Therefore, the aim of chapter 8 was to enhance the secretion of these factors by activation of the hypoxia induced factor-1 (HIF-1) pathway. 
Therefore, a library of small molecules was screened for their ability to activate the HIF-1 pathway, and it was examined which growth factors are secreted upon treatment of hMSCs with these small molecules and to investigate the biological activity of the secreted factors.

Chapter 9 includes general conclusions as well as my discussion based on the results in this thesis, and recommendations for future applications. 


\section{References}

1. Langer R, Vacanti J. (1993) Science 260, 920-926

2. Griffith LG. (2002) Ann N Y Acad Sci 961, 83-95

3. Atala A, Bauer SB, Soker S, Yoo JJ, et al. (2006) The Lancet 367, 1241-1246

4. Macchiarini P, Walles T, Biancosino C, Mertsching H. (2004) J Thorac Cardiovasc Surg 128, 638-641

5. Zaidi M. (2007) Nat Med 13, 791-801

6. Bilezikian JP, Rodan GA, Raisz LGe. Principles of Bone Biology. 2 ed2002.

7. Gilbert SF. Developmental Biology, 6th edition. Associates SMS, editor2000.

8. Goshima J, Goldberg VM, Caplan AI. (1991) Clinical orthopaedics and related research, 298311

9. Meijer GJ, de Bruijn JD, Koole R, Van Blitterswijk CA. (2007) PLoS Med 4, e9

10. Bruder SP, Kraus KH, Goldberg, V.M., Kadiyala, S. The Effect of Implants Loaded with Autologous Mesenchymal Stem Cells on the Healing of Canine Segmental Bone Defects. 1998. p. 985-996.

11. Kon E, Muraglia A, Corsi A, Bianco P, et al. (2000) 49, 328-337

12. Petite H, Viateau V, Bensaïd W, Meunier A, et al. (2000) Nat Biotechnol 18, 959-963

13. Quarto R, Mastrogiacomo M, Cancedda R, Kutepov SM, et al. (2001) The New England journal of medicine 344, 385-386

14. Marcacci M, Kon E, Moukhachev V, Lavroukov A, et al. (2007) Tissue engineering 13, 947-955

15. Cancedda R, Mastrogiacomo M, Bianchi G, Derubeis A, et al. (2003) Novartis Found Symp 249, 133-137,170-174,239-241

16. Schimming R, Schmelzeisen R. (2004) J Oral Maxillofac Surg 62, 724-729

17. Chatterjea A, Meijer G, van Blitterswijk C, de Boer J. (2010) Stem Cells Int 2010, 215-625

18. Barrère F, van der Valk CM, Meijer G, Dalmeijer RAJ, et al. (2003) J Biomed Mater Res B Appl Biomater 67B, 655-665

19. Yuan H, Yang Z, de Bruijn JD, de Groot K, et al. (2001) Biomaterials 22, 2617-2623

20. Jukes JM, Moroni L, van Blitterswijk CA, de Boer J. (2008) Tissue Eng A 14, 135-147

21. Friedenstein AJ. (1980) Haematol Blood Transfus 25, 19-29

22. Wu X, Peters JM, Gonzalez FJ, Prasad HS, et al. (2000) Bone 26, 21-26

23. Castro-Malaspina H, Gay R, Resnick G, Kapoor N, et al. (1980) Blood 56, 289-301

24. Kuznetsov SA, Krebsbach PH, Satomura K, Kerr J, et al. (1997) J Bone Miner Res 12, 13351347

25. Pittenger M, Mackay A, Beck S, Jaiswal R, et al. (1999) Science 284, 143 - 147

26. Dezawa M, Ishikawa H, Itokazu Y, Yoshihara T, et al. (2005) Science 309, 314-317

27. Shake JG, Gruber PJ, Baumgartner WA, Senechal G, et al. (2002) Ann Thorac Surg 73, 19191925

28. Oswald J, Boxberger S, Jørgensen B, Feldmann S, et al. (2004) Stem cells 22, 377-384 
29. Rouwkema J, Westerweel PE, de Boer J, Verhaar MC, et al. (2009) Tissue Eng Part A 15, 20152027

30. Brazelton TR, Rossi FM, Keshet GI, Blau HM. (2000) Science 290, 1775-1779

31. Mezey E, Chandross KJ, Harta G, Maki RA, et al. (2000) Science 290, 1779-1782

32. Weng Y, Lin H, Hsiang Y, Hsieh C, et al. (2003) Adv Exp Med Biol 534, 119-128

33. Moriscot C, de Fraipont F, Richard M-J, Marchand M, et al. (2005) Stem Cells 23, 594-603

34. da Silva Meirelles L, Caplan AI, Nardi NB. (2008) Stem Cells 26, 2287-2299

35. Haynesworth SE, Baber MA, Caplan AI. (1996) J Cell Physiol 166, 585-592

36. Caplan AI, Dennis JE. (2006) J Cell Biochem 98, 1076-1084

37. Siddappa R, Licht R, van Blitterswijk C, de Boer J. (2007) J Orthop Res 25, 1029-1041

38. Alves H, Doorn J, CA vB, De Boer J. (2011) Curr Stem Cell Res Ther,

39. Doorn J, van de Peppel J, van Leeuwen JPTM, Groen N, et al. (2011) Biomaterials 32, 60896098

40. Ren G, Zhang L, Zhao X, Xu G, et al. (2008) Cell Stem Cell 2, 141-150

41. Siddappa R, Martens A, Doorn J, Leusink A, et al. (2008) Proc Natl Acad Sci U S A 105, 72817286

42. Nemeth K, Leelahavanichkul A, Yuen PS, Mayer B, et al. (2009) Nat Med 15, 42-49

43. Siddappa R, Fernandes H, Liu J, van Blitterswijk C, et al. (2007) Curr Stem Cell Res Ther 2, 209220

44. Ducy P, Zhang R, Geoffroy V, Ridall AL, et al. (1997) Cell 89, 747-754

45. Nakashima K, Zhou X, Kunkel G, Zhang Z, et al. (2002) Cell 108, 17-29

46. Hoemann CD, El-Gabalawy H, McKee MD. (2009) Pathol Biol (Paris) 57, 318-323

47. van Straalen J, Sanders, E, Prummel, MF, Sanders, GT. (1991) Clin Chim Acta 201, 27-33

48. Urist. (1965) Science 150, 893-899

49. Reddi AH, Huggins C. (1972) Proc Natl Acad Sci U S A 69, 1601-1605

50. Reddi AH. (2005) Cytokine Growth Factor Rev 16, 249-250

51. Massague J, Wotton D. (2000) EMBO J 19, 1745-1754

52. Katagiri T, Imada M, Yanai T, Suda T, et al. (2002) Genes Cells 7, 949-960

53. Kurabayashi M, Dutta S, Jeyaseelan R, Kedes L. (1995) Mol Cell Biol 15, 6386-6397

54. Friedman MS, Long MW, Hankenson KD. (2006) J Cell Biochem 98, 538-554

55. Diefenderfer DL, Osyczka AM, Reilly GC, Leboy PS. (2003) Connect Tissue Res 44 Suppl 1, 305311

56. Mendes SC, \{Van Den Brink\} I, \{De Bruijn\} JD, \{Van Blitterswijk\} CA. (1998) J Mater Sci Mater Med 9, 855-858

57. Krishnan V, Bryant HU, Macdougald OA. (2006) J Clin Invest 116,

58. Muruganandan S, Roman AA, Sinal CJ. (2008) Cell Mol Life Sci 66, 236-253

59. De Boer J, Siddappa R, Gaspar C, Van Apeldoorn A, et al. (2004) Bone 34, 818 - 826

60. De Boer J, Wang HJ, Van Blitterswijk CA. (2004) Tissue Eng 10, 393-401

61. Boland GM, Perkins G, Hall DJ, Tuan RS. (2004) J Cell Biochem 93, 1210-1230

62. Bilkovski R, Schulte DM, Oberhauser F, Gomolka M, et al. (2010) J Biol Chem 285, 6170-6178 
63. Kawai M, Rosen CJ. (2008) Pediatric Nephrology 24, 1277-1285

64. Annunziata M, Granata R, Ghigo E. (2011) Acta Diabetologica 48, 1-9

65. Wang Y, Nishida S, Elalieh HZ, Long RK, et al. (2006) J Bone Miner Res 21, 1350-1358

66. Zhang M. (2002) J Biol Chem 277, 44005-44012

67. Wildemann B, Burkhardt N, Luebberstedt M, Vordemvenne T, et al. (2007) J Orthop Surg Res 2, 27

68. Li S-H, Guo D-Z, Li B, Yin H-B, et al. (2009) Vet J 179, 430-436

69. Nakasaki M, Yoshioka K, Miyamoto Y, Sasaki T, et al. (2008) Bone 43, 869-879

70. Jeong W-K, Park S-W, Im G-I. (2008) J Biomed Mater Res A 86A, 1137-1144

71. Chen F-M, Chen R, Wang X-J, Sun H-H, et al. (2009) Biomaterials 30, 5215-5224

72. Koch H, Jadlowiec JA, Campbell PG. (2005) Stem Cells Dev 14, 621-631

73. Walsh S. (2003) Bone 33, 80-89

74. Thomas T, Gori F, Spelsberg TC, Khosla S, et al. (1999) Endocrinology 140, 5036-5044

75. Alberts B, Bray D, Lewis J, Raff M, et al. Molecular Biology of the Cell, 3rd edition: New York: Garland Science; 1994.

76. de Rooij J, Zwartkruis FJT, Verheijen MHG, Cool RH, et al. (1998) Nature 396, 474-477

77. Roth JA, Kim B-G, Lin W-L, Cho M-I. (1999) J Biol Chem 274, 22041-22047

78. Kaneki H, Takasugi I, Fujieda M, Kiriu M, et al. (1999) J Cell Biochem 73, 36-48

79. Swarthout JT, D’Alonzo RC, Selvamurugan N, Partridge NC. (2002) Gene 282, 1-17

80. Zhao Y, Ding S. (2007) Proc Natl Acad Sci U S A 104, 9673-9678

81. Yang D-c, Tsay H-j, Lin S-y, Chiou S-h, et al. (2008) PLoS ONE 3, e1540

82. Hu X, Yu SP, Fraser JL, Lu Z, et al. (2008) J Thorac Cardiovasc Surg 135, 799-808

83. Hung S-C, Pochampally RR, Chen S-C, Hsu S-C, et al. (2007) Stem Cells 25, 2363-2370

84. Hung SC, Pochampally RR, Hsu SC, Sanchez C, et al. (2007) PLoS ONE 2, e416

85. Jaakkola P, Mole DR, Tian Y-M, Wilson MI, et al. (2001) Science 292, 468-472

86. Wang GL, Jiang BH, Rue EA, Semenza GL. (1995) Proc Natl Acad Sci U S A 92, 5510-5514

87. Semenza GL. (2003) Nat Rev Cancer 3, 721-732

88. Harris AL. (2002) Nat Rev Cancer 2, 38-47

89. Mcbeath R, Pirone DM, Nelson CM, Bhadriraju K, et al. (2004) Dev Cell 6, 483-495

90. Dalby MJ, Gadegaard N, Tare R, Andar A, et al. (2007) Nat Mater 6, 997-1003

91. Kelly DJ, Jacobs CR. (2010) Birth Defects Res C Embryo Today 90, 75-85

92. Ornitz DM, Marie PJ. (2002) Genes Dev 16, 1446-1465

93. Laudes M. (2011) J Mol Endocrinol 46, R65-R72

94. Clayton PE, Banerjee I, Murray PG, Renehan AG. (2011) Nat Rev Endocrinol 7, 11-24

95. Harris AL. (2002) Nat Rev Cancer 2, 38-47 


\section{CHAPTER 2.}

\section{Therapeutic applications of mesenchymal stromal cells; paracrine effects and potential improvements}

Joyce Doorn ${ }^{1}$

Guido Moll ${ }^{2}$

Katarina Le Blanc ${ }^{2}$

Clemens van Blitterswijk'

Jan de Boer ${ }^{1}$

${ }^{1}$ Department of Tissue Regeneration, MIRA Institute for Biomedical Technology and Technical Medicine, University of Twente, Enschede 7500 AE, The Netherlands.

${ }^{2}$ Department of Laboratory Medicine, Clinical Immunology and Transfusion Medicine, Karolinska Institutet and Hematology Center at Karolinska University Hospital Huddinge, Stockholm, SE-14186, Sweden

Tissue Eng Part B Rev. 2011 Oct 13

It's never too late to be what you might have been.

- George Eliot 


\begin{abstract}
Amongst the various types of cell-to-cell signaling, paracrine signaling comprises those signals that are transmitted over short distances between different cell types. In the human body, secreted growth factors and cytokines instruct, amongst others, proliferation, differentiation and migration. In the hematopoietic stem cell niche, stromal cells provide instructive cues to stem cells via paracrine signaling and one of these cell types, known to secrete a broad panel of growth factors and cytokines are mesenchymal stromal cells (MSCs). The factors secreted by MSCs have trophic, immunomodulatory, anti-apoptotic, and pro-angiogenic properties, and their paracrine profile varies according to their initial licensing by various stimuli. MSCs are currently studied as treatment for inflammatory diseases such as graft-versus-host-disease and Crohn's disease, but also as treatment for myocardial infarct and solid organ transplantation. In addition, MSCs are investigated for their use in tissue engineering applications, in which their differentiation plays an important role, but as we recently demonstrated, their trophic factors may also be involved. Furthermore, a functional improvement of MSCs might be obtained after pre-conditioning or tailoring the cells themselves. Also, the way cells are clinically administered may be specialized for specific therapeutic scenarios. In this review we will first discuss the hematopoietic stem cell niche, in which MSCs were recently identified and are thought to play an instructive and supportive role. We will then evaluate therapeutic applications that currently try to utilize the trophic and/ or immunomodulatory properties of MSCs, and we will also discuss new options to enhance their therapeutic effects.
\end{abstract}




\section{Introduction}

Cell signaling is a complex process of communication between different cells within one or multiple tissues and forms the basis of all cellular activities; proliferation, differentiation, migration and apoptosis are all processes instructed by different signals. Depending on cell contact and the distance between the cells, cell signaling can be divided into different categories;

- In autocrine signaling, signals are transmitted to the producer cell.

- In juxtacrine signaling, cells require direct contact and signals can be transmitted via gap junctions in the membrane.

- In paracrine signaling, signals are transmitted only over short distances via factors that exert their effects locally. These factors are secreted by one cell and are only affecting neighboring cells due to fast degradation, consumption or movement limitation by the extracellular matrix.

- In endocrine signaling, signals are transmitted over long distances, via hormones secreted by organs and glands.

\section{Paracrine signaling between stromal cells and parenchyma}

In the human body, a great amount of tissues release signaling molecules such as growth factors, cytokines and hormones to communicate, instruct and to provide support to surrounding tissues. The interaction between stromal cells and tissues that they support may be a good example of such paracrine interactions. Not only do these cells function as a physical support layer, they also provide cues for proliferation and differentiation. One of the most-studied networks is formed by hematopoietic stem cells (HSCs) and their progeny, and its supportive stromal system. Decades of research on the different anatomic compartments and cellular subtypes revealed that an intricate signaling network exists between the two, which on the one hand allows stromal cells to balance extensive immune activation within their direct proximity, and on the other to exert local homeostatic and instructive cues to hematopoietic, as well as epithelial and other cells types.

Under non-pathological conditions, these cues are tightly regulated, and may provide the basis for paradigms such as stem cell quiescence or the establishment of immune-privileged sites, via site-specific production of characteristic ECM components and local secretion of a vast array of soluble factors. However, in pathological conditions such as cancer, these cues might be misguided, to support tumor growth and metastatic spread. For example, in mouse models, mesenchymal stromal cells (MSCs) show a particular tropism for inflammatory and tumor sites [1], where they potentially support 
cancer progression through secretion of immunomodulatory, pro-angiogenic and prometastatic factors [2]. If this applies in humans is still a matter of intense discussion [3].

Recent reports pointed to a role for MSCs in the hematopoietic stem cell niche, but besides that, these cells have also been investigated for their immunomodulatory and trophic properties for some time now. We will therefore first discuss the specific role of MSCs within this intricate signaling network, then elucidate on their immunomodulatory and trophic properties, and eventually present different therapeutic approaches, which are based on exploiting the intrinsic paracrine functions of MSCs. At the end of this review, we will furthermore introduce new approaches with the potential to enhance the therapeutic efficiency of these cells, and we will also discuss current limitations and future perspectives of these therapies.

\section{The hematopoietic stem cell niche}

HSCs reside at specific locations in the bone marrow, where the very complex control of their proliferation, differentiation and migration is regulated. A schematic representation of the cells and factors involved in the niche is shown in figure 1 . The idea of a so-called niche, where surrounding cells provide cues and instructive signals to control residing cells, was first proposed by Schofield [4]. Traditionally, the HSC niche was thought to consist of two compartments; an osteoblast and a vascular component. At the endosteal bone surface, HSCs co-localize with osteoblasts [5] and the number of long-term HSCs (LT-HSCs), which can contribute to hematopoiesis for a lifetime, was shown to correlate directly with the number of spindle-shaped N-cadherin ${ }^{+} \mathrm{CD} 45^{-}$ osteoblastic (SNO) cells [5], thus providing an environment in which HSCs remain quiescent. Within the vascular niche, HSCs localize adjacent to sinusoidal endothelial cells [6], supporting proliferation, differentiation and subsequent migration into the bloodstream [7-9]. However, recent research using high resolution microscopy demonstrated the very close proximity of vessels and osteoblasts, thus suggesting that HSCs located in one compartment are subjected to paracrine factors from the other [9, 10], and debate thus exists as to whether these two components form two physically separated compartments. As reviewed by Bianco et al. only 0.1-7.3\% of the endosteal surface of the human bone is actually covered by osteoblasts and they exist only for about 3 weeks, which would imply that the niche itself would be constantly migrating [11].

\section{A role for MSCs within the niche?}

Another cell type identified to be present in the HSC niche are CD $146^{+}$adventitial reticular cells, which were demonstrated to behave as CFU-Fs and are capable of osteogenic differentiation [11]. These cells were shown to share certain similarities 
with MSCs and to reside within a perivascular location in close proximity to HSCs. It was furthermore shown that MSCs and pericytes share a number of surface markers $[12,13]$. Supporting this idea, recently, Méndez-Ferrer et al. described the presence of nestin ${ }^{+}$cells with an exclusive perivascular distribution close to HSCs, which were characterized to be MSCs [14]. These cells showed high expression of HSC maintenance genes, appeared to regulate the maintenance of HSCs within the bone marrow and to control their migration towards the marrow. In addition, transcriptional analysis has identified the expression of several molecules specifically related to hematopoiesis

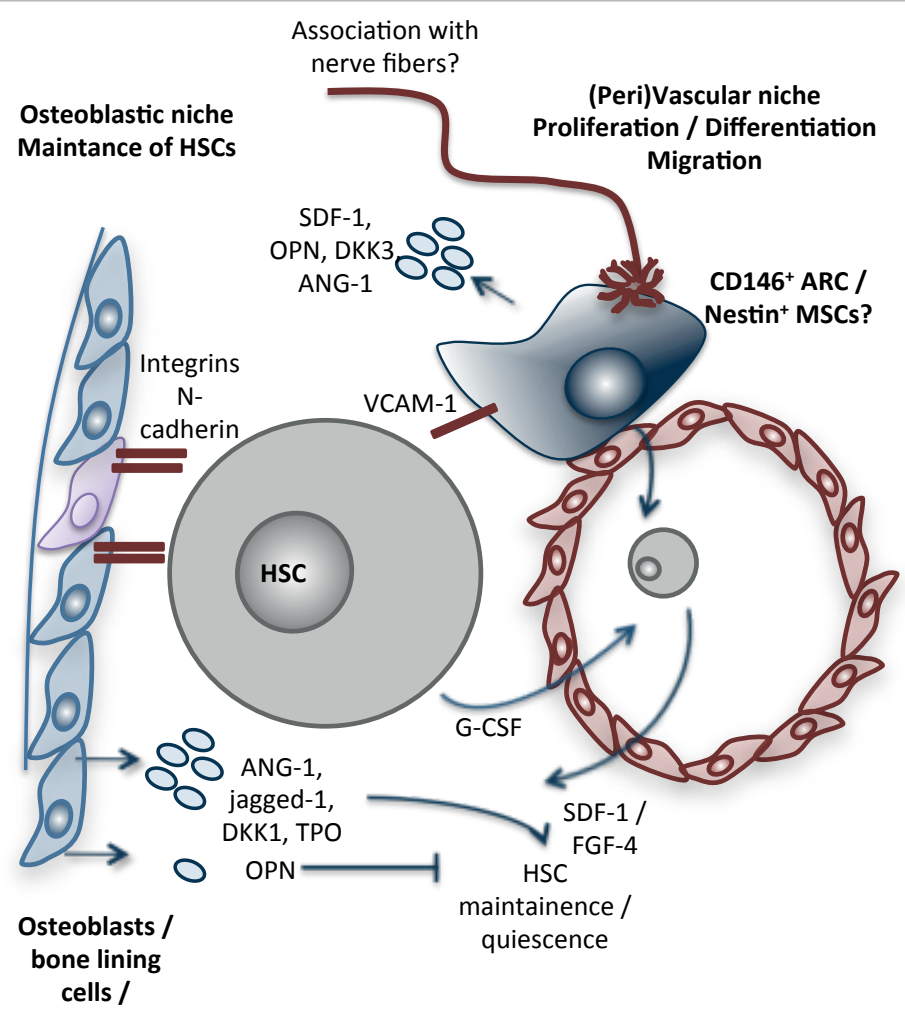

Figure 1. Schematic representation of the hematopietic stem cell niche. Hematopoietic stem cells reside in a niche in which their maintenance, proliferation, differentiation and migration is tightly regulated by various cell types. Traditionally, this niche was thought to be composed of an osteoblastic and vascular component, but recent data has led to a discussion as to whether these two are physically separated, and it thus likely that a HSC is in contact with both compartments. Cells in the osteoblastic component include osteoblasts, osteoclasts but also bone lining cells, whereas the vascular compartment is mainly composed of sinusoidal endothelial cells, but CD146 ${ }^{+}$adventitial reticular cells (ARCs) and/or MSCs also retain in this part of the niche. The HSC is retained in the niche by adhesion molecules such as integrins, N-cadherins and VCAM-1. Osteoblasts are thought to secrete angiopoietin-1 (ANG-1), jagged-1, dickkopf1 (DKK1) and thrombopoietin (TPO), which keep the cells in a quiescent state, but also osteopontin (OPN), which antagonizes the effect of ANG-1. ARCs/MSCs express, amongst other genes, stromal cell-derived factor-1 (SDF-1), OPN, DKK1 and ANG-1 and are thought to regulate the maintenance of HSCs and to control their migration. Migration into the bloodstream is induced by growth colony-stimulating factor (G-CSF), which is opposed by SDF-1 and fibroblast growth factor (FGF)-4. 
in MSCs, such as fibronectin-1 (FN1), osteopontin (OPN), angiopoietin-1 (ANG-1), thrombospondin (TSP)-1 and -2, vascular cell adhesion molecule-1 (VCAM-1), fibroblast growth factor-7 (FGF-7), transforming growth factor (TGF)- $\beta 2$, insulin-like growth factor (IGF) binding protein-4, bone morphogenetic protein (BMP) receptor type 1A, dickkopf-3 (DKK-3), secreted frizzled-related protein (Sfrp)-1 and -2, and CXCL12 [15]. Furthermore, HSCs also maintain their niche by directing the differentiation of MSCs towards osteoblasts through secreted BMP-2 and BMP-6 [16], and they increase proliferation of osteoblasts, via platelet-derived growth factor- $\beta$ (PDGF- $\beta$ ) and basic fibroblast growth factor (bFGF) [17]. In this way, HSCs contribute to the regeneration of their own niche after for example irradiation.

\section{Paracrine interactions within the niche}

Supportive paracrine interactions between HSCs and stromal cells were already demonstrated in 1989 by Dexter et al. who showed that stromal cells secrete an array of hematopoietic cytokines, including growth-colony stimulating factor (G-CSF), stem cell factor (c-kit ligand), granulocyte-macrophage-colony stimulating factor (GM-CSF) and interleukin-6 (IL-6) $[18,19]$. Osteoblasts within the endosteal niche are thought to maintain HSCs in an immature state via production of factors such as ANG-1 [20, 21], thrombopoietin (TPO) [22], and DKK-1 [23]. Their production of OPN may oppose quiescence via down regulation of ANG-1 [24]. Maintenance of HSCs is furthermore facilitated by cell adhesion molecules such as VCAM-1, integrins, N-cadherin and annexin II [25] [26, 27]. Furthermore, production of stromal cell derived factor-1 (SDF-1) supports homing of HSCs towards endosteum [10]. But G-CSF antagonizes SDF-1 expression in osteoblasts, to augment proliferation and mobilization of HSCs $[28,29]$, which may be augmented further by a release of proteolytic enzymes $[25,30]$. Application of G-CSF is therefore widely exploited clinically to mobilize stem cells into the peripheral blood.

\section{Immunomodulatory and trophic effects of therapeutic MSCs}

Clinical trials using stem cells are expanding quickly. A search on clinicaltrial.gov shows the versatility in applications and cells used, including, but not only, HSCs, endothelial progenitor cells, c-kit ${ }^{+}$cells, bone marrow mononuclear cells, whole bone marrow and MSCs. Human MSCs are a heterogenous pool of cells and can be isolated from different sources of the adult body, typically the bone marrow. Guidelines, as set by the international society for cellular therapy (ISCT) to identify these cells include plastic adherence, expression of surface markers CD73, CD90 and CD105, lack of CD11b, CD19, CD34, CD 45 and HLA-DR and the ability to differentiate in vitro into at least osteoblasts, adipocytes and chondrocytes [31]. Especially their non-immunogenicity and their ability to differentiate into various tissues make these cells an ideal source for cell 
Table 1. Trophic factors secreted by MSCs that (are suggested to) exert reparative and regenerative effects.

\begin{tabular}{|c|c|c|}
\hline Factor & Name and function & Refs \\
\hline SDF-1 & Stromal derived factor-1, regulates progenitor cell mobilization & 175,176 \\
\hline $\begin{array}{l}\text { G/M- } \\
\text { CSF }\end{array}$ & $\begin{array}{l}\text { Granulocyte/macrophage colony stimulating factors, mobilizes } \\
\text { progenitor cells, anti-apoptotic effects }\end{array}$ & 177,178 \\
\hline FGFs & $\begin{array}{l}\text { Fibroblast growth factors are expressed by MSCs (FGF-1/2/4/7/9), } \\
\text { induce angiogenesis (together with VEGF), FGF2 has anti-apoptotic } \\
\text { and -fibrotic effects, proliferative effects }\end{array}$ & $\begin{array}{l}35,122, \\
178-180\end{array}$ \\
\hline VEGFs & $\begin{array}{l}\text { Vascular endothelial growth factors, promote mobilization of pro- } \\
\text { genitor cells and induces angiogenesis, stimulates proliferation of } \\
\text { peritubular capillaries, anti-apoptotic effects }\end{array}$ & $\begin{array}{l}108,122 \\
178,179 \\
181\end{array}$ \\
\hline PDGF & Platelet derived growth factor, proliferative effects & 180 \\
\hline STC-1 & Stanniocalcin-1, anti-apoptotic effects & 173 \\
\hline ANGs & $\begin{array}{l}\text { Angiopoietins, ANG-1 induces angiogenesis, promotes survival of } \\
\text { myocytes in MI, increases survival of implanted MSCs, reduces in- } \\
\text { farct size and fibrosis }\end{array}$ & $\begin{array}{l}101,182 \\
183\end{array}$ \\
\hline EPO & Erythropoitin, induces angiogenesis, anti-apoptotic effects & 177 \\
\hline TPO & Thrombopoietin, supports maintenance and proliferation of HSCs & 184 \\
\hline SCF & Stem cell factor, supports maintenance and proliferation of HSCs & 184 \\
\hline TGF- $\beta s$ & $\begin{array}{l}\text { Transforming growth factor beta }(1,2 \text {, and } 3) \text {, stem cell differentia- } \\
\text { tion and protection, tubologenesis in kidney, anti-apoptotic effects }\end{array}$ & 122,178 \\
\hline IGFs & $\begin{array}{l}\text { Insulin like growth factors ( } 1 \text { and } 2 \text { ), mobilization of progenitors, } \\
\text { induces proliferation of renal tubular cells, anti-apoptotic effects }\end{array}$ & $\begin{array}{l}119,178, \\
185\end{array}$ \\
\hline HGF & $\begin{array}{l}\text { Hepatocyte growth factor, associated with mobilization of progeni- } \\
\text { tor cells, induction of angiogenesis, improves cell growth, anti-apo- } \\
\text { ptotic and -fibrotic effects }\end{array}$ & $\begin{array}{l}122,175 \\
178,180\end{array}$ \\
\hline Il-6 & Interleukin-6, angiogenic effects & 147 \\
\hline LIF & Leukemia inhibitory factor, mobilizes progenitor cells & 175 \\
\hline NGF & Nerve growth factor, neuroprotective effects & 186,187 \\
\hline GDNF & $\begin{array}{l}\text { Glial cell line-derived neurotrophic factor, reduces infarct size and } \\
\text { induces axonal growth, promotes survival and morphological dif- } \\
\text { ferentiation of dopaminergic neurons and motoneurons }\end{array}$ & 130,131 \\
\hline BDNF & $\begin{array}{l}\text { Brain-derived neurotrophic factor, reduces infarct size, promotes } \\
\text { survival and differentiation of neuronal tissue }\end{array}$ & 131,132 \\
\hline
\end{tabular}


therapies as well as tissue engineering applications. MSCs secrete immunomodulatory factors as well as reparative and regenerative factors. Several studies have demonstrated differentiation of MSCs into different target cells, whereas low engraftment percentages, the short window in which MSCs exert their effects and the fact that conditioned medium alone often exerts similar responses underlines the particular importance of immunomodulatory and trophic mediators [32].

\section{Trophic effects of MSCs}

Already in 1996, it was noticed that isolated MSCs are able to secrete a broad spectrum of cytokines and growth factors that affect neighboring cells (figure 2)[33]. Specific growth factor panels and concentrations were found to vary between differently committed cells, but not between donors, donor age and donor health. This trophic effect does not require differentiation of MSCs at target sites [34]. A selection of trophic factors implied in regenerative function is shown in table 1 . Work by Chen et al. showed that non-activated - mouse and human derived - mesenchymal progenitor cells differ in their secretion proteome from more mature stromal cells, such as fibroblasts [35]. A higher expression was found in MSCs for most investigated growth factors, such as VEGF-A, ANG-1, TPO, hepatocyte growth factor (HGF), leukemia inhibitory factor (LIF), IGF, IGF-binding proteins-1, -2, -3 -4, FGF-4, -6, -7, -9, and a number of other molecules such as leptin, fractalkine, neutrophil activating peptide-2 (NAP-2), macrophage inflammatory protein- $1 \beta$ (MIP- $1 \beta$ ), and macrophage inflammatory protein-3 $\alpha$ (MIP$3 \alpha$ ), whilst a small number of cytokines (IL-6, -7, -8, -10) and growth factors (G-CSF, M-CSF, GM-CSF, SDF-1, SCF) was expressed at similar levels in both cell types.

\section{Immunomodulatory effects of MSCs}

Apart from their high growth factor production, MSCs can modulate their microenvironment by locally suppressing immune responses via several direct and indirect mechanisms, which may potentially also lead to systemic shifts in immune activation, as depicted in figure 2. Firstly, MSCs produce factors that decrease proliferation of $\mathrm{CD}^{+}$and $\mathrm{CD}^{+} \mathrm{T}$ cells, B-cells, dendritic cells (DCs) and natural killer (NK) cells upon close contact [36-39]. MSCs can also polarize the differentiation and function of myeloid cells such as DCs [40]. MSC-derived factors may therefore alter the maturation of antigen-presenting cells [41], as well as the cytokine profile of various other cells. They may change the pro-inflammatory profile of $\mathrm{T}_{\text {helper1 }}$ (TH1) cells towards a TH2 cells anti-inflammatory profile and decrease the secretion of inflammatory proteins, such as tumor necrosis factor- $\alpha$ (TNF $\alpha$ ) and interferon- $\gamma$ (IFN $\gamma$ ) by DCs and T-cells, respectively [42]. These effects are mainly mediated by soluble factors, as summarized in table 2 , but are enhanced by cell-cell contact $[43,44]$. The factors identified to mediate these processes include short lived metabolites produced by enzymes such as: prostaglandin 


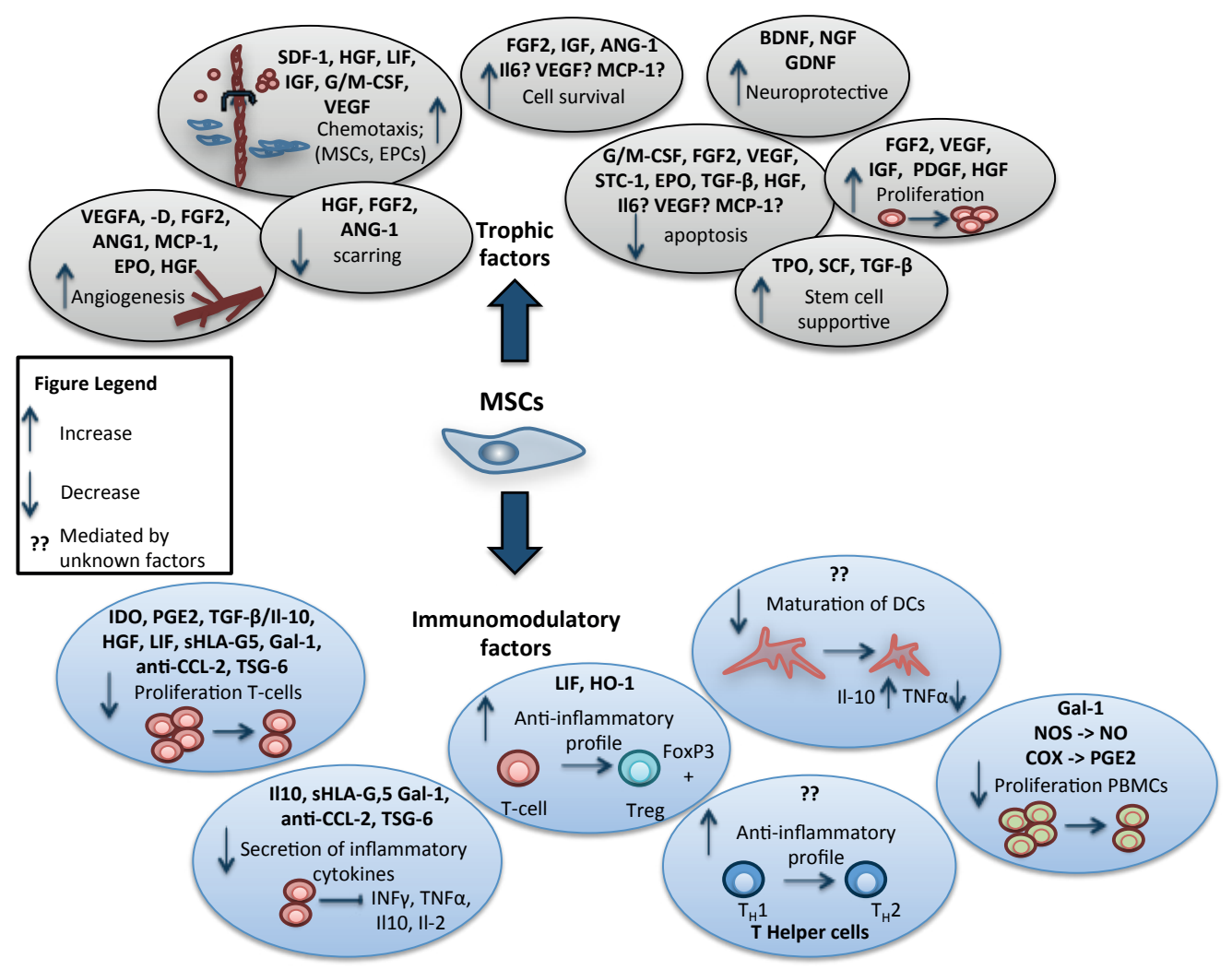

Figure 2. Immunomodulatory and trophic effects of MSCs. Factors secreted by MSCs can have either immunomodulatory, or regenerative/reparative (trophic) effects. Immunoregulatory factors are depicted on the bottom and exert anti-proliferative effects on T-cells, decrease secretion of antiinflammatory cytokines, alter the inflammatory profile of $\mathrm{T}_{\text {helper } 1}$ cells towards the more anti-inflammatory $\mathrm{T}_{\text {helper } 2}$ profile, and increase the amount of anti-inflammatory $\mathrm{T}_{\text {regulatory }}$ cells. The maturation of DCs is decreased, which is accompanied by a change in secretion profile. Trophic factors secreted by MSCs are depicted on the top and induce angiogenesis, increase mobilization of stem- and progenitor cells towards the injury, enhance cell survival and proliferation, support stem cells, whereas they decrease scarring (fibrosis) and apoptosis. In brain injuries, neural-specific growth factors can also exert neuroprotective effects.

E2 (PGE2), a product of cyclic oxide synthase (COX) [42]; kynurenine, a product of indoleamine 2,3- dioxygenase (IDO) [45]; biliverdin and carbon monoxide, the products of hemoxigenase-1 (HO-1); and nitric oxide, the product of nitric oxide synthase (NOS) [46]; but also cytokines such as IL-10 and TGF- $\beta$ [41-43], and a number of other factors such as HGF [44], LIF [47], and soluble human leukocyte-antigen-G5 (sHLA-G5) [48, 49] were identified as possible immunomodulatory mediators. More recently described molecules with immunoregulatory functions include CCL2 (MCP-1), galectin-1 (GAL1) and TNF $\alpha$-stimulated gene/protein 6 (TSG-6). MSCs were demonstrated to secrete high amounts of GAL-1, and by means of retroviral knockdown, GAL-1 was shown to mediate the anti-proliferative effects of MSCs on peripheral blood mononuclear cells 
Table 2. Factors secreted by MSCs that exert immunosuppressive and immunoregulatory effects.

\begin{tabular}{|c|c|c|}
\hline Factor & Name and function & Refs \\
\hline IDO & $\begin{array}{l}\text { Indoleamine 2,3- dioxygenase produces the active metabolite } \\
\text { kynurenine, which has anti-proliferative effects on T-cells }\end{array}$ & 45 \\
\hline $\mathrm{HO}-1$ & $\begin{array}{l}\text { Hemoxygenase- } 1 \text { produces the metabolites biliverdin and carbon } \\
\text { monoxide, which promote induction of regulatory T-cells }\end{array}$ & 188,189 \\
\hline NOS & $\begin{array}{l}\text { Nitric oxide synthase produces nitric oxide, which has anti-prolifer- } \\
\text { ative effects on PBMCs in a mouse model }\end{array}$ & 46 \\
\hline PGE2 & $\begin{array}{l}\text { Cyclic oxide synthase (COX) produces prostaglandin E2, which has } \\
\text { anti-proliferative effects on PBMCs }\end{array}$ & 42,55 \\
\hline $\begin{array}{l}\text { TGF-ß / } \\
\text { Il-10 }\end{array}$ & $\begin{array}{l}\text { Transforming growth factor- } ß \text { / interleukin-10, high concentrations } \\
\text { of these cytokines result in inhibition of INF } \gamma \text { and TNF } \alpha \text { secretion } \\
\text { and have anti-proliferative effects on T-cells }\end{array}$ & 41,43 \\
\hline $\mathrm{HGF}$ & Hepatocyte growth factor, has anti-proliferative effects on T-cells & 190 \\
\hline LIF & $\begin{array}{l}\text { Leukemia inhibitory factor, promotes induction of T-reg phenotype } \\
\text { (Foxp }{ }^{3+} \text { cells), and has anti-proliferative effects on T-cells }\end{array}$ & 47 \\
\hline sHLA-G5 & $\begin{array}{l}\text { Soluble human lecocyte antigen-G5, anti-proliferative effects on T- } \\
\text { cells and PBLs, inhibition of NK cell cytolysis of third party target } \\
\text { cells, inhibition of IFN } \gamma \text { secretion }\end{array}$ & 48,49 \\
\hline Gal-1 & $\begin{array}{l}\text { Galectin-1, anti-proliferative effects on PBMCs and CD4+ and CD8+ } \\
\text { T-cells, inhibition of INF } \gamma \text {, TNF } \alpha \text {, Il-2, Il-10 secretion }\end{array}$ & 50,191 \\
\hline TSG-6 & $\begin{array}{l}\text { TNF- } \alpha \text {-stimulated gene/protein } 6 \text {, decreases plasmin activity, neu- } \\
\text { trophil infiltration and levels of MMP-9, Il-6, Il-1 } \beta \text {, CXCL1/CICN-1 } \\
\text { and CCL2/MCP-1 }\end{array}$ & 51,192 \\
\hline $\begin{array}{l}\text { anti- } \\
\text { CCL2 }\end{array}$ & $\begin{array}{l}\text { Chemokine (C-C motif) ligand } 2 \text { (or MCP-1, monocyte chemotactic } \\
\text { protein-1) anti-proliferative effects on T-cells, inhibition of IFN } \gamma \text { se- } \\
\text { cretion, prevents migration of inflammatory cells }\end{array}$ & 53 \\
\hline
\end{tabular}

(PBMCs) and T-cells, but not on NK cells [50]. Furthermore, expression of TSG-6 was demonstrated to be highly upregulated after infusion of MSCs in mice with myocardial infarcts and siRNA against TSG-6 markedly reduced the beneficial effects of the infused MSCs on infarct size and heart function [51]. Similar anti-inflammatory effects of TSG6 were demonstrated in a mouse peritonitis model after stimulation with TNF $\alpha$ [52]. The CC chemokine ligand CCL2 mediates migration of inflammatory cells towards the spinal cord in autoimmune encephalomyelitis. The antagonistic form of this ligand, obtained via MSC-derived MMP-mediated cleavage, reduced secretion of inflammatory cytokines, suppressed proliferation of T-cells, and in vivo, MSC-secreted CCL2 was shown to suppress disease symptoms by preventing immune cells from infiltrating the spinal cord [53]. 


\section{Licensing and activation of MSCs}

As outlined above, MSCs produce factors that have so-called immunomodulatory or trophic effects on the cells in their direct proximity, and they can actively respond to the environment that they encounter, as depicted in figure 3. To exert their paracrine function in an optimal manner, MSCs need to be activated, or licensed, which can be achieved by various external stimuli. Pro-inflammatory cytokines, chemokines, blood activation products, toll like receptor (TLR) ligation, but also physical cues such as oxygen tension, surface ligand interactions and mechanical stimulation will change the secretion proteome and the amount of individual factors produced by MSCs, as well as their mobility and differentiation status.

Both INF $\gamma$-independent and -dependent pathways appear to be important for triggering the immunomodulatory functions of MSCs [54]. INF $\gamma$-independent priming leads to production of PGE2 via COX1 and -2, presumably due to engagement of soluble mediators, whereas stimulation of MSCs with INF $\gamma$ induces their expression of IDO, which suppresses T-cell activity through production of tryptophan metabolites and depletion of tryptophan from the local environment. Although MSCs can be activated by single pro-inflammatory mediators, combinations of INF $\gamma$ and either TNF $\alpha$, IL-1 $\alpha$, or IL-1 $\beta$ potentiate their immunomodulatory effects [46]. Furthermore, work by Nemeth et al. demonstrated that, upon intravenous infusion into septic mice, MSCs are activated by both TNF $\alpha$ and LPS. Furthermore, their immunomodulatory function required crosstalk with macrophages, which resulted in increased production of PGE2 by MSCs and IL-10 by macrophages [55]. This is only one example how activated MSCs may actively polarize adaptive and innate host resident immune cells, such as regulatory T-cells $\left(\mathrm{T}_{\text {regs }}\right.$ ), myeloid derived suppressor cells (MDSCs), tolerogenic immature dendritic cells (toll-DCs), or alternatively activated macrophages, to synergistically produce an antiinflammatory environment, as reviewed elsewhere [56]. However, MSCs are also subject to polarization themselves, which can occur in a TLR-dependent manner; resulting in generation of anti- or pro-inflammatory cells upon engagement of TLR3 and TLR4, respectively, which alters their migratory capacity and production of immunomodulatory cytokines [57]. Additionally, we and others have found that blood activation products, such as complement anaphylatoxins, clotting factors, and activated platelets may have the potential to license MSCs, resulting in altered chemotactic, immunomodulatory and ECM-degrading / infiltrating properties [58-60].

\section{Therapeutic applications of MSCs}

Infusion or injection of MSCs has been utilized in a wide-range of applications and here we provide an overview of the performed work and the current status per application. 


\section{Graft versus host disease}

The most advanced treatment protocol based on the immunomodulatory effects of hMSCs aims to treat graft-versus-host disease (GvHD). GvHD, currently treated with steroids, is caused by rejection of host tissue by transplanted bone marrow and can result in inflammations in the liver, skin and gastrointestinal tract. Rejection is mostly due to $\mathrm{CD}^{+}$and $\mathrm{CD} 8^{+} \mathrm{T}$-cells present in the transplant that produce excess amounts of cytokines, but activation of DCs, macrophages and NK cells also plays a role. The disease is accompanied by increased secretion TNF $\alpha$, INF $\gamma$, IL-1, Il-2 and Il-12 [61]. Based on positive effects with infused MSCs in GvHD in various animal models [62], several clinical trials were launched, with different outcomes. In 2008, we infused 55 patients with 1-5 doses of expanded bone marrow derived MSCs in a phase II clinical trial. 30 patients showed a complete response, 9 patients a partial response and 16 patients showed stable or progressive disease. Patients with complete response showed higher survival than patients with partial or no response [63]. We have also reported on a single-patient case of a 9-year old boy with treatment-resistant grade IV gastrointestinal GvHD, where intravenous infusions of ex vivo expanded MSCs resulted in complete recovery of the gut and liver [64]. In another clinical trial performed by Osiris Therapeutics Inc., 3-21 intravenous infusions of culture expanded allogeneic hMSCs resulted in complete remission in 7 out of 12 children after 1 month, and after 6 months, 95\% of these children were still alive [65]. However, a larger, more recent phase III clinical trial performed by the same company did not result in any effect of infused MSCs as compared to placebo treatment [66], which makes it difficult to draw any general conclusions, although on the positive side, adverse or side effects of infused MSCs were not reported in any of these trials. Data from animal models suggest that MSCs might act differently depending on their mode of activation [62,67], as supported by the fact that INF $\gamma$ pre-stimulated MSCs were more effective in combating GvHD than non-stimulated MSCs [68]. Further research is required to truly validate the effect of infusions of MSCs as an anti-GvHD therapy.

\section{Crohn's disease}

Also based on immunomodulatory mechanisms, MSCs may be useful in Crohn's disease, an inflammatory disease affecting the gastrointestinal tract. In a mouse colitis model, injections of adipose derived MSCs resulted in increased survival rate, reduced inflammation and increased weight, whereas injections of dead MSCs or human myoblasts did not have an effect [69]. In 2005, a clinical trial was performed, in which 35 patients with complex perianal fistulas received either fibrin glue or fibrin glue with adipose derived MSCs. In the control group only 16\% of the patients showed fistula healing, whereas in the group receiving MSCs, 71\% showed healing [70]. As with GvHD, the data are inconsistent and another study showed less promising results. In a phase I 


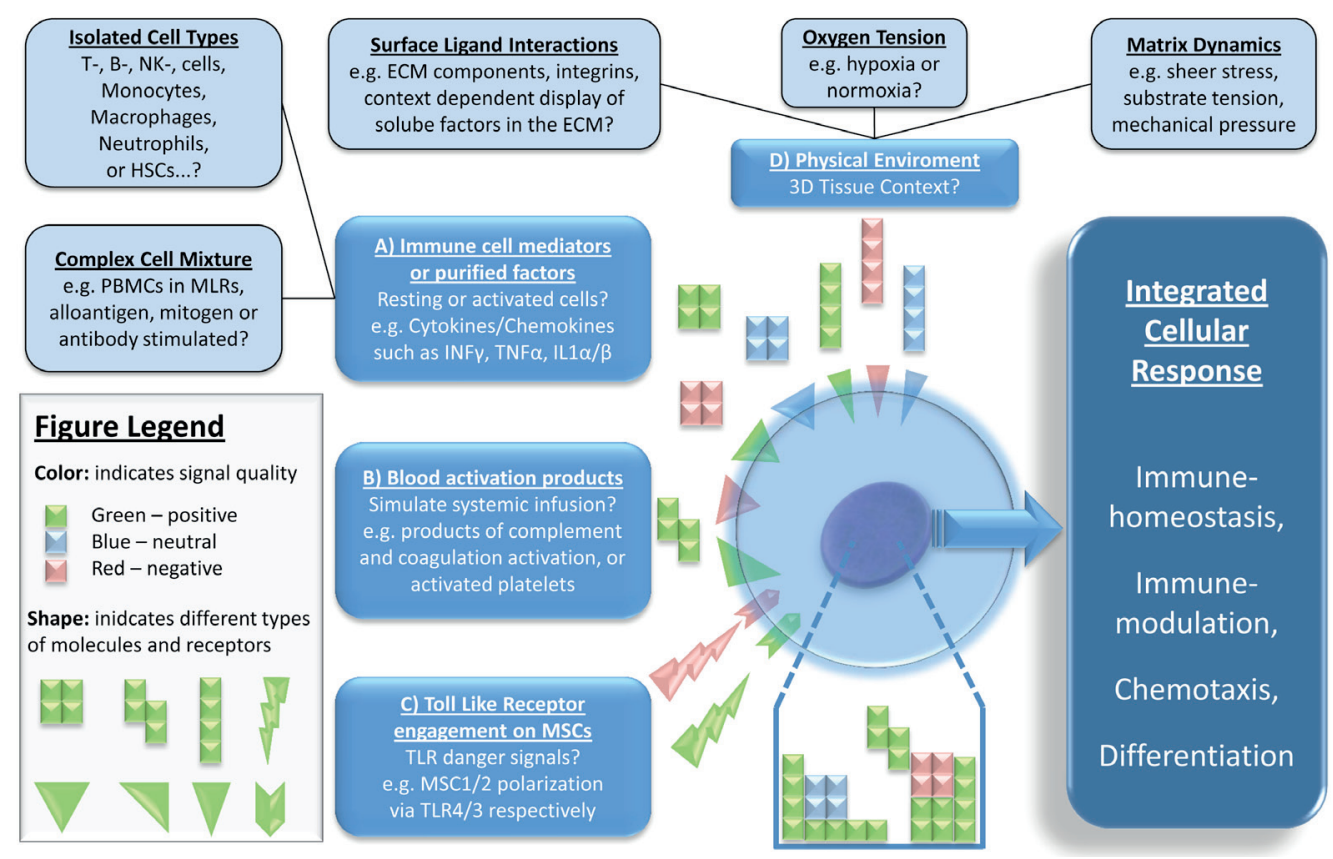

Figure 3. Licensing of MSCs by different stimuli. MSCs can be licensed by: (A) Immune cell mediators derived from either isolated cells types, such as T-, B-, NK-cells, monocytes, macrophages, neutrophils and hematopoietic stem cells (HSCs), or by factors derived from complex cell mixtures, which themselves can be activated in various ways (mitogen, alloantigen or antibodies), or by purified chemokines and cytokines, such e.g. INF $\gamma, \mathrm{TNF} \alpha, \mathrm{IL} 1 \alpha / \beta$; (B) Blood activation products, in the case of systemic infusion, such as activations products of complement and coagulation or activated platelets; (C) Toll like receptor (TLR) engagement, to polarize MSCs into the MSC1 or MSC2 phenotype, via signaling through TLR4 or TLR3, upon encounter of danger signals; and (D) Physical cues from their 3-dimensional environment, such as surface ligand interactions through e.g. integrins, ECM components, and context dependent display of soluble factors with the ECM, or changes in oxygen tension, and matrix dynamics, such as sheer stress, substrate tension, and mechanical force. These signals are taken up by receptors on the cells and integrated within the intracellular signaling network, to elicit an integrated cellular response, which results in different cellular properties, such as immune-homeostasis, immune-modulation, chemotaxis, and differentiation. The quality and quantity of signals and of their specific receptors can vary in a broad fashion, as indicated by different colors and shapes. The encounter of conflicting/contradictory signals (e.g. green vs. red) may impair cellular function, whereas the combination of activating signals (same color, e.g. green), may activate the cell to elicit a specific response, and others might elicit no response (blue).

clinical study including 9 patients, only 3 patients were responsive to infusions of MSC, whereas in 3 others the disease worsened [71]. Several other clinical trials are currently scheduled, for example by Osiris therapeutics, but disappointing preliminary results have reduced plans for late stage trials [66].

\section{Solid organ/graft transplantation}

Systemic administration of MSCs could potentially also prolong survival of various grafts, which is currently achieved with continuous treatment of immunosuppressive 
drugs. Again, immunomodulatory factors suppress the immune response by acting on T-cells, DC's and NK cells. In immunocompetent baboons infusions of allogeneic MSCs prior to graft placement slightly prolonged survival of a skin allograft [72] and the same was demonstrated with a heart allograft in rats [73]. On the other hand, another study showed that MSCs did not affect survival of a vascularized heart transplant in rodents [74] and a study in a mouse model demonstrated that MSCs only improved heart transplant survival in the absence of HSCs, which might explain failures in other studies [75]. Still, in combination with immunosuppressive drugs, administration of MSCs has demonstrated some promising results. A short course of low-dose mycophenolate mofetil (MMP) [76] or rapamycin [77] combined with administration of MSCs prior to transplantation resulted in long-term graft survival in rat heart transplant models. No studies in humans have been completed so far, but clinical trials have been approved to examine the effect of expanded MSCs on kidney transplants.

\section{Myocardial infarct}

MSCs secrete many growth factors that can have reparative and regenerative functions, of which most data comes from studies in myocardial infarcts, although immunomodulatory factors also contribute to the repair. Already in 2001, Orlic et al. showed that transplantation of Lin-c-kit ${ }^{+}$bone marrow cells resulted in the formation of new myocardium, consisting of infused cells [78]. Later, cardiac adipose tissue-derived progenitor cells were shown to engraft into the myocardium and to express both cardiac and endothelial markers, but in this case the secretion of pro-angiogenic growth factors suggested a trophic effect [79]. Debate thus exists on whether a therapeutic effect is due to trophic/immunomodulatory effects or due to direct differentiation into target cells. A trophic mechanism is supported by various studies that demonstrated a positive effect of injected MSCs, without showing evidence of engraftment or differentiation or that showed only very few engrafted cells $[80,81]$. Often, conditioned medium derived from MSCs alone has positive effects as well [82].

A study by Zisa et al. showed beneficial effects of conditioned medium on heart function after myocardial infarcts, which was attributed to either VEGF, IGF and monocyte chemotactic protein 1 (MCP1) [83]. Other known cardioprotective growth factors include FGFs, HGF and VEGF, which are produced by skeletal muscle cells, and whose overexpression was shown to benefit the myocardium [84-86]. Injection of MSCs resulted in elevated levels of both circulating HGF, LIF and granulocyte/macrophage colony-stimulating factor (G/M-CSF), as well as the HGF, IGF2 and VEGF levels in the myocardium. MSCs appear to exert beneficial effects by attracting progenitor cells and by triggering growth factor secretion by host cells [82]. Implantation of MSCs into mice activates muscle cells to secrete VEGF via activation of Il-1 $\beta$ [87] and MSC conditioned medium contains Il-6 and LIF factors, which activate host myocytes to produce elevated 
levels of HGF and VEGF [88]. In line with this, Cho et al. demonstrated that growth factor expression in injected endothelial progenitor cells (EPCs) returns to basal levels 3-7 days after injection, whereas expression of FGF-2, Ang-2, HGF, IGF-1, SDF-1 $\alpha$ and, to a lower extent, VEGF, ANG-1, PIGF and PDGF- $\beta$ in host cells was still increased after 2-14 days [89]. These trophic factors are thought to exert effects on scar formation, apoptosis, vascular repair, angiogenesis and the recruitment of stem cells and other regenerative factors $[90,91]$.

Regardless the underlying mechanisms, intracoronary administration of bone marrow derived cells for MI has been tested in several clinical trials, with various outcomes (reviewed in [92]). Meta-analysis of 13 clinical trials, with a total of 811 patients, concluded that stem cell therapy improves left ventricular ejection fraction (LVEF), reduces LV end-systolic volume and myocardial lesion area. No effect was found on post-infarction remodeling, which is considered a major predictor of late adverse outcomes [92]. Of these 13 trials, the REPAIR-AMI trial was with 204 patients the largest one. From this trial it was concluded that death, the necessity for revascularization or recurrence of infarction were reduced in patients administered with bone marrow cells after reperfused MI [93]. However, more recent trials show less encouraging results. In the HEBE trial, 200 patients were treated with either bone marrow-, peripheral bloodderived cells or standard therapy, but no effects of either cell type on LVEF was found [94]. The REGENT trial included 200 patients, with a control group, a group receiving bone marrow nuclear cells and a group receiving $\mathrm{CD} 34^{+} \mathrm{CXCR} 4^{+}$cells. Again, no effects on LVEF or volumes were found, although a trend in favor of cell therapy was observed [95]. In the FINCELL trial, 80 patients received either mononuclear cells or a placebo and LVEF was found to increase more in the cell therapy group compared to the placebo. It has to be noted though that the absolute LVEF values after 6 months did not differ between the two groups [96].

The non-uniformity in the results throughout these clinical trials is thought to be due to several aspects. Firstly, there seems to be a relation between the amount of the infused cells and the observed effects. Secondly, red blood cells and contamination of platelets in mononuclear cell fractions are suggested to affect functional behavior of the cell fraction [92], and thirdly, the site of injection plays a role; systemic infusion mainly results in uptake of cells by the lungs [97] whereas direct injection into the myocardium results in higher engraftment than a systemic approach [92]. Lastly, timing of the treatment is crucial. Activity of injected mononuclear cells was observed to be highest within the first 24 hours after a myocardial infarct, probably due to chemokines that are highly expressed shortly after the infarct [98]. In animal models, injection of MSCs almost always takes place directly after inducing the infarct, whereas in clinical trials, infusion often takes place within 6-12 months after the infarct, which might explain the more negative outcomes in clinical trials compared to studies in animals. 


\section{Wound healing}

Trophic factors secreted by MSCs are also implicated in the acceleration of wound healing. Interactions between MSCs and endothelial cells, but also their immunomodulatory properties seem to play a key role in accelerating wound healing and reducing scar formation [99]. Conditioned medium derived from MSCs was demonstrated to contain factors that promote recruitment of macrophages and endothelial cells into the wound [35]. Although the exact function of specific growth factors and cytokines was not revealed, a comparison between conditioned medium derived from MSCs and from fibroblasts (which does not affect wound healing) revealed clear distinctions between their secretomes, as outlined above. Conditioned medium promoted proliferation and cell survival of fibroblasts as well as production of collagen, elastin and fibronectin in vitro [100]. Although evidence exists for the differentiation of MSCs into keratinocytes and endothelial cells [101, 102], again, the low engraftment, the release of pro-angiogenic growth factors [101] and the fact that conditioned medium alone also has substantial effects on migration, proliferation and overall wound acceleration makes a trophic effect a more likely explanation [103]. In rat and mouse models, injection of MSCs around the wound [104, 105], but also systemic injection [106] improved wound healing and a preliminary clinical study including 10 patients, demonstrated that MSCs can be safely applied in chronic as well as acute wounds and that wound healing correlated with the amount of infused MSCs [107]. Another application includes cutaneous radiation syndrome, which occurs from overexposure to ionizing radiation. No controlled clinical trials have been performed so far, but Lataillade et al. have demonstrated possibilities of MSCs in several case studies [108].

\section{Kidney failure}

Kidney failure can occur as a result of damaging stimuli, such as sepsis-associated cytokines, toxins and ischemia. Due to these stimuli, renal tubular cells can become apoptotic or necrotic and there is a loss of tubular epithelial cells [109]. Damage and swelling of renal endothelial cells, which leads to an impaired microvasculature system [110] and an inflammatory reaction, also contribute to kidney failure. Trophic factors released by MSCs can exert effects on the vasculature system but also reduce the immune response. Although integration of injected MSCs into kidney compartments has been reported [111] and it is believed by some that differentiation of bone marrow MSCs into renal epithelial cells is possible [112-114], studies have also indicated an effect with little or no integration $[115,116]$ and intraperitoneal injection of MSC conditioned medium had reparative effects as well [117]. In addition, Tögel et al. reported that reparative effects of injected MSCs were visible as early as 24 hours after administration [118]. Paracrine and/or autocrine factors are thus likely explanations. Critical growth factors for this process include VEGF [115], IGF-1 [119] and TGF- $\beta$ [120], which might 
activate recently revealed local stem cells in the adult kidney $[121,122]$.

Several animal studies have demonstrated that injections of MSCs have beneficial effects in both acute and chronic kidney failure. Injected MSCs migrate towards the kidney [116] and significantly improve renal function and regeneration, restore capillary defects, whereas they decrease apoptosis, renal injury scores and mortality $[118,123]$ (for a detailed overview see [122]). Observed effects were attributed to a reduction in the expression of pro-inflammatory cytokines (Il-1, TNF $\alpha$, INF $\gamma$, and NO synthase) and an increase in anti-inflammatory cytokines (Il-10, bFGF, TGF $\alpha$ and Bcl-2) [118]. In contrast, infusion of MSCs did not affect renal injury in a sheep model, suggesting a species-dependent effect [124]. To the best of our knowledge, no clinical trials using MSCs to treat acute or chronic kidney failure have been completed so far, but one trial is currently ongoing and several others are scheduled.

\section{Neuroprotective effects}

In addition to immunoregulatory, pro-angiogenic, and anti-apoptotic factors, MSCs also secrete neurotrophic factors, which could potentially be used in neurological disorders, such as stroke, Amyotrophic Lateral Sclerosis (ALS), Multiple Sclerosis (MS), Alzheimer's disease, Huntington's disease and Parkinson's disease (PD). These diseases are mainly characterized by a loss of neural cells, but also by occurrence of inflammatory reactions. MSCs were shown to be able to differentiate into neuron-like cells $[125,126]$, but they also secrete neural growth factors, such as NGF, BDNF, and GDNF. Both stroke and PD are characterized by an inflammatory reaction [127], but also by a loss of (dopaminergic) neural cells $[128,129]$. Immunomodulatory factors secreted by MSCs thus act on the inflammatory response, whereas trophic factors may act to reduce infarct size, and to improve survival, functional recovery and regeneration of neural cells [130-134]. In addition, they can reduce apoptosis, improve vascularization and attract progenitor cells to the site of injury [135]. Improved function after injection of MSCs intravenously or into the cerebellum in various diseases has been demonstrated in several animal models [132,136-140], but the exact underlying mechanisms remain to be elucidated.

In a small pilot study with five stroke patients some improvements after injection of MSCs were demonstrated, but due to the small study number, no definitive conclusions could be made [141]. Similarly, a small, uncontrolled study with seven patients for treatment of Parkinson's disease showed encouraging results, but due to the lack of a control group and the small study number no conclusions could be drawn [142]. Another pilot study for the treatment of ALS including seven patients, showed a trend towards slowing down of muscular strength decline, but again no conclusions could be drawn. A somewhat larger study with 21 patients for the treatment of MS and ALS, 
reported fever as a small side effect of MSC injection, but no major adverse effects. They also showed slight increases in functional behavior [143]. Due to these encouraging results, several clinical trials are currently on the way or scheduled to test the use of MSCs in Parkinson's disease, stroke, ALS and multiple sclerosis.

\section{Functional improvement of MSCs by preconditioning}

To enhance survival, grafting and function of infused or implanted MSCs, cells can be pre-treated or preconditioned prior to implantation, or specific genes can be overexpressed. Implantation of MSCs into an oxygen- and nutrient-deprived environment, such as the myocardium, results in survival of very few cells [144]. Preconditioning of MSCs by culturing them in an hypoxic environment, which resembles the natural oxygen environment of the bone marrow (1-7\%) more closely than standard culture conditions (21\%) [145], improves their survival via HIF-1 $\alpha$ and Akt-dependent mechanisms. In addition, hypoxia stimulates the secretion of pro-angiogenic growth factors $[146,147]$ as well as expression of the chemokine receptors CX3CR1and CXCR4 and enhances engraftment of MSCs in vivo [148].

Another popular approach to achieve secretion of growth factors or overexpression of function-specific genes is insertion of these genes into the cell by (non-)viral methods. Using these methods, Akt [144] or phosphoinositide-3-kase class II alpha (PI3K-C2 $\alpha$ ) [149] overexpression was shown to improve survival of MSCs in the infarcted myocardium. Heat shock protein-20 (Hsp-20), which interacts with Akt, also improves survival of implanted MSCs, probably through induced secretion of VEGF, IGF-1 and FGF [150]. Another example is overexpression of tissue inhibitor of matrix metalloproteinase-3 (TIMP-3), which was shown to improve cardiac function [151]. Since bone marrow cells are also affected by, for example, cardiovascular risk factors such as diabetes mellitus or hypercholesterolemia, cells collected from patients often have diminished therapeutic potential. Mees et al. demonstrated that overexpression of endothelial nitric oxide synthase (eNOS) rescues reduced neovascularization and the proangiogenic potential of bone marrow mononuclear cells from diseased mice [152]. Overexpression of eNOS was associated with increased differentiation potential of these cells into endothelial-like cells, increased secretion of VEGF and enhanced NOdependent vasodilation.

Thirdly, MSC function can be improved by pre-treating the cells to alter their secretome, either with growth factors or small molecules. Treatment with TNF $\alpha$ or endotoxin for example increases VEGF, FGF2, HGF and IGF-1 [153]. TNF $\alpha$ treatment also increases the expression of a panel of inflammatory cytokines in adipose MSCs, amongst which Il-6, Il-8 and MCP-1 were demonstrated to enhance migration of monocytes [154], which suggests enhanced attractancy of these cells to the site of injury in vivo. 
Treatment with epidermal growth factor (EGF) before infusion in ischemic limbs [155] was demonstrated to improve functional outcome, most likely due to an increase in secreted pro-angiogenic growth factors such as VEGF [156]. Similarly, induction of MSCs into a cardiac phenotype using a cocktail of various growth factors prior to injection, resulted in improvement of functional cardiac behavior as compared to non-induced counterparts [157]. For applications in ischemic stroke, pre-treatment of MSCs with brain-extract resulted in enhanced secretion of BDNF, VEGF and HGF [158]. Recently it was also demonstrated that even the culture protocol can alter growth factor secretion; culturing of hMSCs in spheroids enhanced secretion of anti-inflammatory and antitumorigenic proteins as compared to conventional 2D culturing [159]. Pre-treatment with specific compounds thus can result in cells with a more specific secretome for a particular application or tissue.

\section{Current limitations and future perspectives}

The research and clinical trials described here apply MSCs in various therapeutic applications. Research is expanding quickly and in addition to the applications described, recent articles have also reported the use of MSCs for corneal repair [160, 161], pulmonary hypertension [162] diabetes [163,164] and ischemic wounds [165]. Although injection or infusion of (trophic) MSCs has rendered promising results, data is often conflicting and hampered by different culture methods, isolation protocols and amounts of infused MSCs and therefore, has to be interpreted with caution. Many clinical trials are scheduled for the coming years and it is of crucial importance that future trials are set-up in a controlled manner with proper control groups, although it might be difficult to obtain patient groups of sufficient size. In past studies many parameters fluctuated, which makes it difficult to compare results.

Firstly, application sites vary between different studies, which could account for varying outcomes. For example, direct infusion of MSCs into the heart instead of systemic infusion was suggested to improve myocardial infarcts [92, 97]. Application of cells in close proximity to the target tissue can potentially be further improved by preventing migration of cells away from the tissue, e.g. by implanting a hydrogel which encapsulates the cells. Secondly, it was shown that the window between myocardial infarct and MSC application is of significant importance [98], possibly explaining discrepancies between clinical trials and animal studies. In line with this finding, different phases of axonal sprouting after stroke are initiated [166] and depending on the mode of action of infused MSCs, application timing may be crucial. Thirdly, one of the major sources of variation lies in the cell type used. A wide-range of cell types is currently under investigation, which makes it difficult to compare individual trials and moreover, isolation and culture protocols are not standardized. In myocardial infarcts, 
not only MSCs, but also c-kit ${ }^{+}$cells and endothelial progenitor cells (EPCs), both derived from bone marrow, have been systemically infused or injected into the myocardium, with different success rates $[89,167]$. Similarly, injections of HSCs did not affect kidney failure, whereas MSCs did [112] and, also in kidney failure, identical doses of autologous MSCs were shown more effective than allogeneic cells [115]. The best cell type for specific applications thus remains to be determined. In line with this, it has been shown that the contents of the secretome differ widely between cell types [168] and it thus remains to be discovered whether it is the differentiation and grafting, trophic and/or immunomodulatory effects or a combination that accounts for the observed positive effect of infused MSC. Activation or licensing of the cells prior to infusion also plays an important role here. In animal studies, it was demonstrated that cells from healthy individuals improve myocardial infarcts, whereas MSCs from diseased counterparts have no effect. Autoimmune diseases, as well as underlying causes of myocardial infarct and kidney failure, may affect bone marrow residing stem cells, thus diminishing their therapeutic potential $[152,169,170]$. This clearly demonstrates the need to investigate differences between these cells as well as the mechanisms underlying effects of injected cells. A better understanding of these mechanisms can help improve cellular performance and pre-treatment of cells then can render their secretome more suitable for the intended application or, in contrast, induce differentiation prior to implantation.

For tissue engineering applications, the direct differentiation of MSCs is generally thought to be responsible for newly formed tissues, although in urinary tissue engineering, trophic effects of MSCs have been suggested to contribute to tissue formation. In this case, the use of a matrix led to induced secretion of Il- 4 and TGF- $\beta$, which enhanced bladder wall remodeling and reduced expression of pro-inflammatory cytokines [171]. For bone and cartilage applications, attempts to enhance differentiation prior to implantation have not led to huge improvements in new tissue formation. Since MSCs also secrete bone- and cartilage-specific growth factors, trophic factors might very well play a role in these applications. So far, pre-treatment of MSCs before implantation has been demonstrated beneficial for mainly two applications. As described, treatment with TNF $\alpha$ increases secretion of immunomodulatory factors whereas hypoxia treatment enhances secretion of angiogenic factors. Recently, it was demonstrated in our lab that treatment of hMSCs in vitro with the small molecule dibutyryl-cAMP (db-cAMP) results in more robust bone formation in vivo, which was accompanied by secretion of bone-specific growth factors such as IGF-1 and BMP-2 [172]. These trophic factors are biologically active and affect proliferation and differentiation of various cell types in vitro, and are thus also likely to play a role in in vivo bone [173]. Determination of the origin of the newly formed tissues, donor or host, should elucidate if and how these factors contribute to new bone formation. Besides db-cAMP, TNF $\alpha$ or hypoxic culture conditions, other compounds, growth factors or small molecules could increase 
specificity or enhance secretion of specific growth factors even further. In addition, properties of substrates used to deliver the cells could be modified in such a way that cells will secrete growth factors that are useful for the intended application, for example pro-angiogenic and anti-apoptotic factors for myocardial infarcts and osteoinductive, but also pro-angiogenic factors for bone tissue engineering. In our lab it was recently discovered that osteoinductive ceramics release calcium which induces expression of BMP-2 in hMSCs, possibly indicating a trophic mechanism behind osteoinductivity [174](unpublished data). High throughput screening may reveal novel compounds, but also optimal material properties like surface stiffnesses and topographies that induce differentiation and/or secretion of trophic factors for specific applications.

In conclusion, encouraging results in animal models as well as clinical trials strongly suggest an effect of the trophic factors secreted by MSCs in a wide range of applications. Application of MSCs in closer proximity to the target tissue as well as pre-treatment to alter their secretome for specific applications could potentially result in further enhancement of MSC performance. However, additional research is required to unravel underlying mechanisms and determine optimal factors for specific clinical applications.

\section{Acknowledgments}

The authors gratefully acknowledge the support of the TeRM Smart Mix Program of the Netherlands Ministry of Economic Affairs and the Netherlands Ministry of Education, Culture and Science. 


\section{References}

1. Spaeth E, Klopp A, Dembinski J, Andreeff M, et al. (2008) Gene Ther 15, 730-738

2. Karnoub AE, Dash AB, Vo AP, Sullivan A, et al. (2007) Nature 449, 557-563

3. Klopp AH, Gupta A, Spaeth E, Andreeff M, et al. (2011) Stem Cells 29, 11-19

4. Schofield R. (1978) Blood Cells 4, 7-25

5. Zhang J, Niu C, Ye L, Huang H, et al. (2003) Nature 425, 836-841

6. Kiel MJ, Yilmaz ÖH, Iwashita T, Yilmaz OH, et al. (2005) Cell 121, 1109-1121

7. Kopp H-G, Avecilla ST, Hooper AT, Rafii S. (2005) Physiology 20, 349-356

8. Heissig B, Hattori K, Dias S, Friedrich M, et al. (2002) Cell 109, 625-637

9. Lo Celso C, Fleming HE, Wu JW, Zhao CX, et al. (2008) Nature 457, 92-96

10. Xie Y, Yin T, Wiegraebe W, He XC, et al. (2009) Nature 457, 97-101

11. Bianco P, Sacchetti B, Riminucci M. (2011) Best Pract Res Clin Haematol 24, 37-47

12. da Silva Meirelles L, Caplan AI, Nardi NB. (2008) Stem Cells 26, 2287-2299

13. Crisan M, Yap S, Casteilla L, Chen C-W, et al. (2008) Cell Stem Cell 3, 301-313

14. Mendez-Ferrer S, Michurina TV, Ferraro F, Mazloom AR, et al. (2010) Nature 466, 829-834

15. Pedemonte E, Benvenuto F, Casazza S, Mancardi G, et al. (2007) BMC Genomics 8, 65

16. Jung Y, Song J, Shiozawa Y, Wang J, et al. (2008) Stem Cells 26, 2042-2051

17. Dominici M, Rasini V, Bussolari R, Chen X, et al. (2009) Blood 114, 2333-2343

18. Dexter TM. (1989) British medical bulletin 45, 337-349

19. Dexter TM, Heyworth CM, Spooncer E, Ponting IL. (1990) Philosophical transactions of the Royal Society of London Series B, Biological sciences 327, 85-98

20. Taichman R, Reilly M, Emerson S. (1996) Blood 87, 518-524

21. Arai F, Hirao A, Ohmura M, Sato H, et al. (2004) Cell 118, 149-161

22. Qian H, Buza-Vidas N, Hyland CD, Jensen CT, et al. (2007) Cell Stem Cell 1, 671-684

23. Fleming HE, Janzen V, Lo Celso C, Guo J, et al. (2008) Cell Stem Cell 2, 274-283

24. Stier S, Ko Y, Forkert R, Lutz C, et al. (2005) The Journal of Experimental Medicine 201, 17811791

25. Levesque J-P, Takamatsu Y, Nilsson SK, Haylock DN, et al. (2001) Blood 98, 1289-1297

26. Jung Y, Wang J, Song J, Shiozawa Y, et al. (2007) Blood 110, 82-90

27. Chan JY-H, Watt SM. (2001) Br J Haematol 112, 541-557

28. Semerad CL, Christopher MJ, Liu F, Short B, et al. (2005) Blood 106, 3020-3027

29. Katayama Y, Battista M, Kao W-M, Hidalgo A, et al. (2006) Cell 124, 407-421

30. McQuibban GA, Butler GS, Gong J-H, Bendall L, et al. (2001) Journal of Biological Chemistry 276, 43503-43508

31. Dominici M, Le Blanc K, Mueller I, Slaper-Cortenbach I, et al. (2006) Cytotherapy 8, 315-317

32. Crisostomo P, Markel TA, Wang Y, Meldrum D. (2008) Surgery 143, 577-581

33. Haynesworth SE, Baber MA, Caplan AI. (1996) J Cell Physiol 166, 585-592

34. Caplan AI. (2007) J Cell Physiol 213, 341-347

35. Chen L, Tredget EE, Wu PYG, Wu Y. (2008) PloS one 3, e1886 
36. Corcione A, Benvenuto F, Ferretti E, Giunti D, et al. (2006) Blood 107, 367-372

37. Podojil JR, Miller SD. (2009) Immunological reviews 229, 337-355

38. Krampera M, Cosmi L, Angeli R, Pasini A, et al. (2006) Stem Cells 24, 386-398

39. Krampera M, Glennie S, Dyson J, Scott D, et al. (2003) Blood 101, 3722-3729

40. Jiang X-X, Zhang Y, Liu B, Zhang S-X, et al. (2005) Blood 105, 4120-4126

41. Beyth S, Borovsky Z, Mevorach D, Liebergall M, et al. (2005) Blood 105, 2214-2219

42. Aggarwal S, Pittenger MF. (2005) Blood 105, 1815-1822

43. Nasef A, Chapel A, Mazurier C, Bouchet S, et al. (2007) Gene Expr 13, 217-226

44. Di Nicola M, Carlo-Stella C, Magni M, Milanesi M, et al. (2002) Blood 99, 3838-3843

45. Meisel R, Zibert A, Laryea M, Gobel U, et al. (2004) Blood 103, 4619-4621

46. Ren G, Zhang L, Zhao X, Xu G, et al. (2008) Cell Stem Cell 2, 141-150

47. Nasef A, Mazurier C, Bouchet S, François S, et al. (2008) Cellular Immunology 253, 16-22

48. Nasef A, Mathieu N, Chapel A, Frick J, et al. (2007) Transplantation 84, 231-237

49. Selmani Z, Naji A, Gaiffe E, Obert L, et al. (2009) Transplantation 87, S62-S66

50. Gieseke F, Böhringer J, Bussolari R, Dominici M, et al. (2010) Blood 116, 3770-3779

51. Lee RH, Pulin AA, Seo MJ, Kota DJ, et al. (2009) Cell Stem Cell 5, 54-63

52. Choi H, Lee RH, Bazhanov N, Oh JY, et al. (2011) Blood [Epub ahead of print],

53. Rafei M, Campeau PM, Aguilar-Mahecha A, Buchanan M, et al. (2009) The Journal of Immunology 182, 5994-6002

54. Singer NG, Caplan AI. (2011) Annu Rev Pathol 28,

55. Nemeth K, Leelahavanichkul A, Yuen PS, Mayer B, et al. (2009) Nat Med 15, 42-49

56. Uccelli A, Moretta L, Pistoia V. (2008) Nat Rev Immunol,

57. Waterman RS, Tomchuck SL, Henkle SL, Betancourt AM. (2010) PLoS One 5, e10088

58. Schraufstatter IU, Discipio RG, Zhao M, Khaldoyanidi SK. (2009) J Immunol 182, 3827-3836

59. Moll G, Jitschin R, von Bahr L, Rasmusson-Duprez I, et al. (2011) PLoS ONE 6, e21703

60. Agis H, Kandler B, Fischer MB, Watzek G, et al. (2009) J Orthop Res 27, 972-980

61. van den Brink MRM, Burakoff SJ. (2002) Nat Rev Immunol 2, 273-281

62. Yañez R, Lamana ML, García-Castro J, Colmenero I, et al. (2006) Stem Cells 24, 2582-2591

63. Le Blanc K, Frassoni F, Ball L, Locatelli F, et al. (2008) The Lancet 371, 1579-1586

64. Le Blanc K, Rasmusson I, Sundberg B, Götherström C, et al. (2004) Lancet 363, 1439-1441

65. Caplan AI. (2009) J Pathol 217, 318-324

66. Baker M. (2009) Nature News,

67. Sudres M, Norol F, Trenado A, Grégoire S, et al. (2006) Journal of immunology (Baltimore, Md : 1950) 176, 7761-7767

68. Polchert D, Sobinsky J, Douglas GW, Kidd M, et al. (2008) European Journal of Immunology 38, 1745-1755

69. González MA, Gonzalez-Rey E, Rico L, Büscher D, et al. (2009) Gastroenterology 136, 978-989

70. Garcia-Olmo D, Herreros D, Pascual I, Pascual JA, et al. (2009) Dis Colon Rectum 52, 79-86

71. Duijvestein M, Vos ACW, Roelofs H, Wildenberg ME, et al. (2010) Gut,

72. Bartholomew A, Sturgeon C, Siatskas M, Ferrer K, et al. (2002) Exp Hematol 30, 42-48 
73. Chabannes D, Hill M, Merieau E, Rossignol J, et al. (2007) Blood 110, 3691-3694

74. Inoue S, Popp FC, Koehl GE, Piso P, et al. (2006) Transplantation 81, 1589-1595

75. Casiraghi F, Azzollini N, Cassis P, Imberti B, et al. (2008) J Immunol 181, 3933-3946

76. Popp F, Eggenhofer E, Renner P, Slowik P, et al. (2008) Transplant Immunology 20, 55-60

77. Zhou H, Yi D, Yu S, Sun G, et al. (2006) Transplantation Proceedings 38, 3046-3051

78. Orlic D, Kajstura J, Chimenti S, Bodine DM, et al. (2003) Pediatr Transplant 7 Suppl 3, 86-88

79. Bayes-Genis A, Soler-Botija C, Farré J, Sepúlveda P, et al. (2010) J Mol Cell Cardiol 49, 771-780

80. Uemura R, Xu M, Ahmad N, Ashraf M. (2006) Circ Res 98, 1414-1421

81. Leiker M, Suzuki G, Iyer VS, Canty Jr. JM, et al. (2008) Cell Transplant 17, 911-922

82. Shabbir A, Zisa D, Suzuki G, Lee T. (2009) Am J Physiol Heart Circ Physiol 296, 1888-1897

83. Zisa D, Shabbir A, Suzuki G, Lee T. (2009) Biochem Biophys Res Commun 390, 834-838

84. Nakamura T, Matsumoto K, Mizuno S, Sawa Y, et al. (2005) American Journal of Physiology Heart and Circulatory Physiology 288, H2131-H2139

85. Suzuki G, Lee T-C, Fallavollita JA, Canty JM, Jr. (2005) Circ Res 96, 767-775

86. Testa U, Pannitteri G, Condorelli GL. (2008) Journal of Cardiovascular Medicine 9, 1190-1221

87. Tateno K, Minamino T, Toko H, Akazawa H, et al. (2006) Circ Res 98, 1194-1202

88. Shabbir A, Zisa D, Lin H, Mastri M, et al. (2010) Am J Physiol Heart Circ Physiol 299, 14281438

89. Cho H-J, Lee N, Lee JY, Choi YJ, et al. (2007) J Exp Med 204, 3257-3269

90. Dai Y, Xu M, Wang Y, Pasha Z, et al. (2007) J Mol Cell Cardiol 42, 1036-1044

91. Perl L, Weissler A, Mekori YA, Mor A. (2010) Isr Med Assoc J 12, 110-115

92. Menasche P. (2010) J Mol Cell Cardiol 50, 258-265

93. Schachinger V, Erbs S, Elsasser A, Haberbosch W, et al. (2006) European Heart Journal 27, 2775-2783

94. van der Laan A, Hirsch A, Nijveldt R, \{van Der Vleuten\} PA, et al. (2008) Netherlands heart journal : monthly journal of the Netherlands Society of Cardiology and the Netherlands Heart Foundation 16, 436-439

95. Tendera M, Wojakowski W, Ruzyłło W, Chojnowska L, et al. (2009) European heart journal 30, 1313-1321

96. Huikuri HV, Kervinen K, Niemela M, Ylitalo K, et al. (2008) European Heart Journal 29, 27232732

97. Barbash IM, Chouraqui P, Baron J, Feinberg MS, et al. (2003) Circulation 108, 863-868

98. Schachinger V, Aicher A, Dobert N, Rover R, et al. (2008) Circulation 118, 1425-1432

99. Sorrell JM, Caplan AI. (2010) Stem cell research \& therapy 1, 30

100. Jeon YK, Jang YH, Yoo DR, Kim SN, et al. (2010) Wound repair and regeneration : official publication of the Wound Healing Society [and] the European Tissue Repair Society,

101. Wu Y, Chen L, Scott PG, Tredget EE. (2007) Stem Cells 25, 2648-2659

102. Sasaki M, Abe R, Fujita Y, Ando S, et al. (2010) The Journal of Immunology,

103. Hocking AM, Gibran NS. (2010) Experimental Cell Research 316, 2213-2219

104. Li H, Fu X, Ouyang Y, Cai C, et al. (2006) Cell and Tissue Research 326, 725-736 
105. Javazon EH, Keswani SG, Badillo AT, Crombleholme TM, et al. (2007) Wound Repair and Regeneration 15, 350-359

106. McFarlin K, Gao X, Liu YB, Dulchavsky DS, et al. (2006) Wound Repair and Regeneration 14, 471-478

107. Falanga V, Iwamoto S, Chartier M, Yufit T, et al. (2007) Tissue Eng 13, 1299-1312

108. Lataillade J, Doucet C, Bey E, Carsin H, et al. (2007) Regen Med 2, 785-794.

109. Kelly K, Molitoris B. (2000) Semin Nephrol 20,

110. Leaf A. (1973) Circulation 48, 455-458

111. Poulsom R, Forbes SJ, Hodivala-Dilke K, Ryan E, et al. (2001) The Journal of Pathology 195, 229-235

112. Morigi M. (2004) Journal of the American Society of Nephrology 15, 1794-1804

113. Yokoo T. (2006) Journal of the American Society of Nephrology 17, 1026-1034

114. Herrera MB, Bussolati B, Bruno S, Fonsato V, et al. (2004) International journal of molecular medicine 14, 1035-1041

115. Tögel F, Cohen A, Zhang P, Yang Y, et al. (2009) Stem Cells and Development 18, 475-486

116. Ninichuk V, Gross O, Segerer S, Hoffmann R, et al. (2006) Kidney Int 70, 121-129

117. Bi B, Schmitt R, Israilova M, Nishio H, et al. (2007) Journal of the American Society of Nephrology 18, 2486-2496

118. Tögel F, Hu Z, Weiss K, Isaac J, et al. (2005) American Journal of Physiology - Renal Physiology 289, F31-F42

119. Imberti B, Morigi M, Tomasoni S, Rota C, et al. (2007) Journal of the American Society of Nephrology 18, 2921-2928

120. Kunter U, Rong S, Boor P, Eitner F, et al. (2007) Journal of the American Society of Nephrology 18, 1754-1764

121. Bussolati B, Tetta C, Camussi G. (2008) Am J Nephrol 28, 813-822

122. Asanuma H, Meldrum DR, Meldrum KK. (2010) J Urol 184, 26-33

123. Morigi M, Introna M, Imberti B, Corna D, et al. (2008) Stem Cells 26, 2075-2082

124. Behr L, Hekmati M, Lucchini A, Houcinet K, et al. (2009) Cell Prolif 42, 284-297

125. Woodbury D, Schwarz EJ, Prockop DJ, Black IB. (2000) Journal of Neuroscience Research 61, 364-370

126. Deng W, Obrocka M, Fischer I, Prockop DJ. (2001) Biochem Biophys Res Commun 282, 148152

127. Kriz J. (2006) Crit Rev Neurobiol 18, 145-157

128. Boka G, Anglade P, Wallach D, Javoy-Agid F, et al. (1994) Neurosci Lett 172, 151-154

129. Hunot S, Dugas N, Faucheux B, Hartmann A, et al. (1999) J Neurosci 19, 3440-3447

130. Lladó J, Haenggeli C, Maragakis NJ, Snyder EY, et al. (2004) Molecular and Cellular Neuroscience 27, 322-331

131. Kurozumi K, Nakamura K, Tamiya T, Kawano Y, et al. (2005) Mol Ther 11, 96-104

132. Nomura T, Honmou O, Harada K, Houkin K, et al. (2005) Neuroscience 136, 161-169 
133. Pan H-C, Cheng F-C, Chen C-J, Lai S-Z, et al. (2007) Journal of Clinical Neuroscience 14, 10891098

134. Mahmood A, Lu D, Chopp M. (2004) Journal of Neurotrauma 21, 33-39

135. Yang M, Wei X, Li J, Heine LA, et al. (2010) Cell Transplantation 19, 1073-1084

136. Chen J, Li Y, Wang L, Lu M, et al. (2001) J Neurol Sci 189, 49-57

137. Honma T, Honmou O, Iihoshi S, Harada K, et al. (2006) Experimental Neurology 199, 56-66

138. Omori Y, Honmou O, Harada K, Suzuki J, et al. (2008) Brain Research 1236, 30-38

139. Akiyama Y, Radtke C, Honmou O, Kocsis JD. (2002) Glia 39, 229-236

140. Inoue M, Honmou O, Oka S, Houkin K, et al. (2003) Glia 44, 111-118

141. Suarez-Monteagudo C, Hernandez-Ramirez P, Alvarez-Gonzalez L, Garcıa-Maeso I, et al. (2009) Restorative Neurology and Neuroscience 27, 151-161

142. Venkataramana NK, Kumar SKV, Balaraju S, Radhakrishnan RC, et al. (2010) Translational Research 155, 62-70

143. Karussis D, Karageorgiou C, Vaknin-Dembinsky A, Gowda-Kurkalli B, et al. (2010) Archives of Neurology 67, 1187-1194

144. Zhang M. (2001) Journal of Molecular and Cellular Cardiology 33, 907-921

145. Lennon DP, Edmison JM, Caplan AI. (2001) J Cell Physiol 187, 345-355

146. Hu X, Yu SP, Fraser JL, Lu Z, et al. (2008) J Thorac Cardiovasc Surg 135, 799-808

147. Hung S-C, Pochampally RR, Chen S-C, Hsu S-C, et al. (2007) Stem Cells 25, 2363-2370

148. Hung SC, Pochampally RR, Hsu SC, Sanchez C, et al. (2007) PLoS ONE 2, e416

149. Eun LY, Song B-W, Cha M-J, Song H, et al. (2010) Biochemical and Biophysical Research Communications 402, 272-279

150. Wang X, Zhao T, Huang W, Wang T, et al. (2009) Stem Cells 27, 3021-3031

151. Angoulvant D, Fazel S, Weisel RD, Lai TYY, et al. (2009) J Thorac Cardiovasc Surg 137, 471-480

152. Mees B, Récalde A, Loinard C, Tempel D, et al. (2011) The American journal of pathology $\mathbf{1 7 8}$, $55-60$

153. Crisostomo P, Wang Y, Markel T, Wang M, et al. (2008) Am J Physiol Cell Physiol 294, 675-682

154. Lee MJ, Kim J, Kim MY, Bae Y-S, et al. (2010) J Proteome Res 9, 1754-1762

155. Amin AH, Abd Elmageed ZY, Nair D, Partyka MI, et al. (2010) Lab Invest 90, 985-996

156. Tamama K, Kawasaki H, Wells A. (2010) Journal of Biomedicine and Biotechnology 2010, 1-11

157. Behfar A, Yamada S, Crespo-Diaz R, Nesbitt JJ, et al. (2010) J Am Coll Cardiol 56, 721-734

158. Choi YJ, Li WY, Moon GJ, Lee PH, et al. (2010) J Neurol Sci 298, 28-34

159. Bartosh TJ, Ylöstalo JH, Mohammadipoor A, Bazhanov N, et al. (2010) Proc Natl Acad Sci U S A 107, 1-6

160. Oh JY, Kim MK, Shin MS, Lee HJ, et al. (2008) Stem cells (Dayton, Ohio) 26, 1047-1055

161. Inoue Y, Iriyama A, Ueno S, Takahashi H, et al. (2007) Experimental Eye Research 85, 234-241

162. Sueblinvong V, Weiss DJ. (2009) Current Opinion in Pharmacology 9, 268-273

163. Urbán VS, Kiss J, Kovács J, Gócza E, et al. (2008) Stem cells 26, 244-253

164. Park K-S, Kim Y-S, Kim J-H, Choi B, et al. (2010) Transplantation 89, 509-517

165. Comerota AJ, Link A, Douville J, Burchardt ER. (2010) J Vasc Surg 52, 723-729 
166. Carmichael ST. (2006) Ann Neurol 59, 735-742

167. Balsam LB, Wagers AJ, Christensen JL, Kofidis T, et al. (2004) Nature 428, 668-673

168. Skalnikova H, Motlik J, Gadher SJ, Kovarova H. (2011) Proteomics 11, 691-708

169. Gremmels H, Fledderus JO, Van Balkom BWM, Verhaar MC. (2011) Antioxidants \& Redox Signaling 00,

170. Jie KE, Zaikova MA, Bergevoet MWT, Westerweel PE, et al. (2010) Nephrology Dialysis Transplantation 25, 1875-1882

171. Pokrywczynska M, Jundzi A, Bodnar M, Adamowicz J, et al. (2010) Eur Urol Suppl 9, 546

172. Siddappa R, Martens A, Doorn J, Leusink A, et al. (2008) Proc Natl Acad Sci U S A 105, 72817286

173. Block GJ, Ohkouchi S, Fung F, Frenkel J, et al. (2009) Stem Cells 27, 670-681

174. Yuan H, Fernandes H, Habibovic P, de Boer J, et al. (2010) Proc Natl Acad Sci U S A 107, 1361413619

175. Imai N, Kaur T, Rosenberg ME, Gupta S. (2009) Seminars in Dialysis 22, 629-635

176. Togel F, Isaac J, Hu Z, Weiss K, et al. (2005) Kidney Int 67, 1772-1784

177. Hou X, Wu X, Ma J, Lv X, et al. (2010) Molecular Biology Reports 37, 1467-1475

178. Rehman J, Traktuev D, Li J, Merfeld-Clauss S, et al. (2004) Circulation 109, 1292-1298

179. Spanholtz TA, Theodorou P, Holzbach T, Wutzler S, et al. (2010) Journal of Surgical Research,

180. Suga H, Eto H, Shigeura T, Inoue K, et al. (2009) Stem Cells 27, 238-249

181. Beckermann BM, Kallifatidis G, Groth A, Frommhold D, et al. (2008) Br J Cancer 99, 622-631

182. Sun L, Cui M, Wang Z, FengX, etal.(2007) Biochemical and Biophysical Research Communications 357, 779-784

183. Jiang S, Haider HK, Idris NM, Salim A, et al. (2006) Circulation Research 99, 776-784

184. Walenda T, Bokermann G, Ventura Ferreira MS, Piroth DM, et al. (2011) Experimental Hematology 39, 617-628

185. Togel F, Weiss K, Yang Y, Hu Z, et al. (2007) American Journal of Physiology - Renal Physiology 292, F1626-F1635

186. Li Y, Chen J, Chen XG, Wang L, et al. (2002) Neurology 59, 514-523

187. Munoz JR, Stoutenger BR, Robinson AP, Spees JL, et al. (2005) Proceedings of the National Academy of Sciences of the United States of America 102, 18171-18176

188. Mougiakakos D, Jitschin R, Johansson CC, Okita R, et al. Blood 117, 4826-4835

189. Zarjou A, Kim J, Traylor AM, Sanders PW, et al. Am J Physiol Renal Physiol 300, F254-262

190. Di Nicola M, Carlo-Stella C, Magni M, Milanesi M, et al. (2002) Blood 99, 3838 - 3843

191. Najar M, Raicevic G, Id Boufker H, Stamatopoulos B, et al. Exp Hematol 38, 922-932

192. Oh JY, Roddy GW, Choi H, Lee RH, et al. (2010) Proceedings of the National Academy of Sciences 107, 16875-16880 


\title{
CHAPTER 3.
}

\section{Forskolin enhances in vivo bone formation by human mesenchymal stromal cells}

\author{
Joyce Doorn \\ Ramakrishnaiah Siddappa \\ Clemens van Blitterswijk, \\ Jan de Boer
}

Department of Tissue Regeneration, MIRA Institute for Biomedical Technology and Technical Medicine, University of Twente, Enschede 7500 AE, The Netherlands.

Tissue Eng Part A. 2011 Sep 26

Science is always wrong.

It never solves a problem without creating ten more.

- George Bernard Shaw 


\begin{abstract}
Activation of the protein kinase A (PKA) pathway with dibutyryl-cAMP (db-cAMP) was recently shown to enhance osteogenic differentiation of human mesenchymal stromal cells (hMSCs) in vitro as well as bone formation in vivo. The major drawback of this compound is its inhibitory effect on proliferation of hMSCs. Therefore, we investigated if fine-tuning of the dose and timing of PKA activation could potentially enhance bone formation even further, with minimum effects on proliferation. To test this, we selected two different PKA activators, 8-bromo-cAMP and forskolin, and tested their effects on proliferation and osteogenic differentiation, in comparison with db-cAMP. We found that indeed ALP levels, bone specific target genes and secretion of insulin-like growth factor-1 were induced by all three compounds, although 8-brcAMP induced adipogenic differentiation in long-term cultures and was thus considered unsuitable for further in vivo testing. All three compounds inhibited proliferation of hMSCs in a dose-dependent manner, with forskolin inhibiting proliferation most. The effect of forskolin on in vivo bone formation was tested by pre-treating hMSCs prior to implantations and we observed increased amounts of bone using forskolin compared to db-cAMP. Our data shows forskolin as a novel agent that can be used to increase bone formation and also suggests a role for PKA in the delicate balance between adipogenic and osteogenic differentiation.
\end{abstract}




\section{Introduction}

Human mesenchymal stromal cells (hMSCs) offer a great deal of potential clinical use for tissue regeneration, due to their relatively easy isolation and expansion and their ability to differentiate into the chondrogenic, adipogenic and osteogenic lineage [1]. More recently these cells were also demonstrated to differentiate into neuron-like cells [2, 3], endothelial-like cells [4] and myocytes [5, 6]. In the traditional bone tissue engineering approach, hMSCs are isolated from a bone marrow biopsy of the patient, expanded in vitro, seeded on a calcium phosphate scaffold and implanted back into the patient to fill the defect. Studies in large animals [7-10] as well as in vivo experiments and clinical trials using human MSCs have demonstrated that this approach can be successful [11-14], thus providing proof of concept. However, patient numbers in these studies are limited and controls are often missing, which makes it difficult to draw conclusions with respect to the performance of the implanted constructs. In a study to repair jaw defects conducted by our own group, MSCs were seeded on hydroxyapatite scaffolds, cultured for seven days and implanted under the muco-periosteal flap [12]. In a group of six patients, de novo bone formation induced by implanted cells was observed in one patient, bone formation lining pre-existing bone was observed in two patients, whereas no bone formation was observed in the remaining patients. This study thus illustrates the need for improved bone formation. To enhance the amounts of newly formed bone, researchers aim to differentiate hMSCs prior to implantation by treating the cells with compounds that induce osteogenic differentiation. Pre-differentiation with dexamethasone resulted in increased bone formation by hMSCs [13-15], whereas other compounds such as vitamin D [16], trichostatin A [17] and lithium [18] induced osteogenic differentiation of hMSCs, but did not increase bone formation in vivo. The effect of dexamethasone on in vivo bone formation was shown to be donor dependent, as demonstrated by Mendes et al. who showed that dexamethasone increased ALP expression in a range of 14 donors, but not all 14 donors displayed enhanced bone formation [19]. So far, clinically relevant results are obtained upon co-implantation of the cells with osteoinductive growth factors such as BMP-2 [11]. We have recently demonstrated that treatment of hMSCs with dibutyryl-cAMP (db-cAMP) for 4 days in vitro enhances their bone forming capacity in vivo [20]. db-cAMP is an activator of the protein kinase A (PKA) pathway, which is normally activated by ligand binding to G-protein coupled receptors (GPCRs) (depicted in figure 1). Via dissociated G-proteins, adenylate cyclase is activated, which converts ATP into cAMP. In turn, cAMP activates PKA, which phosphorylates the cAMP responsive element binding (CREB) protein. CREB translocates into the nucleus where it activates transcription of target genes. The cAMP/ PKA pathway has been implicated in osteogenic differentiation of various cell lines. Treatment with GPCR ligands such as melatonin, prostaglandin E2 and PTH, increases osteogenic differentiation of MC3T3 cells, rat osteoblast-like osteosarcoma cells [21], 


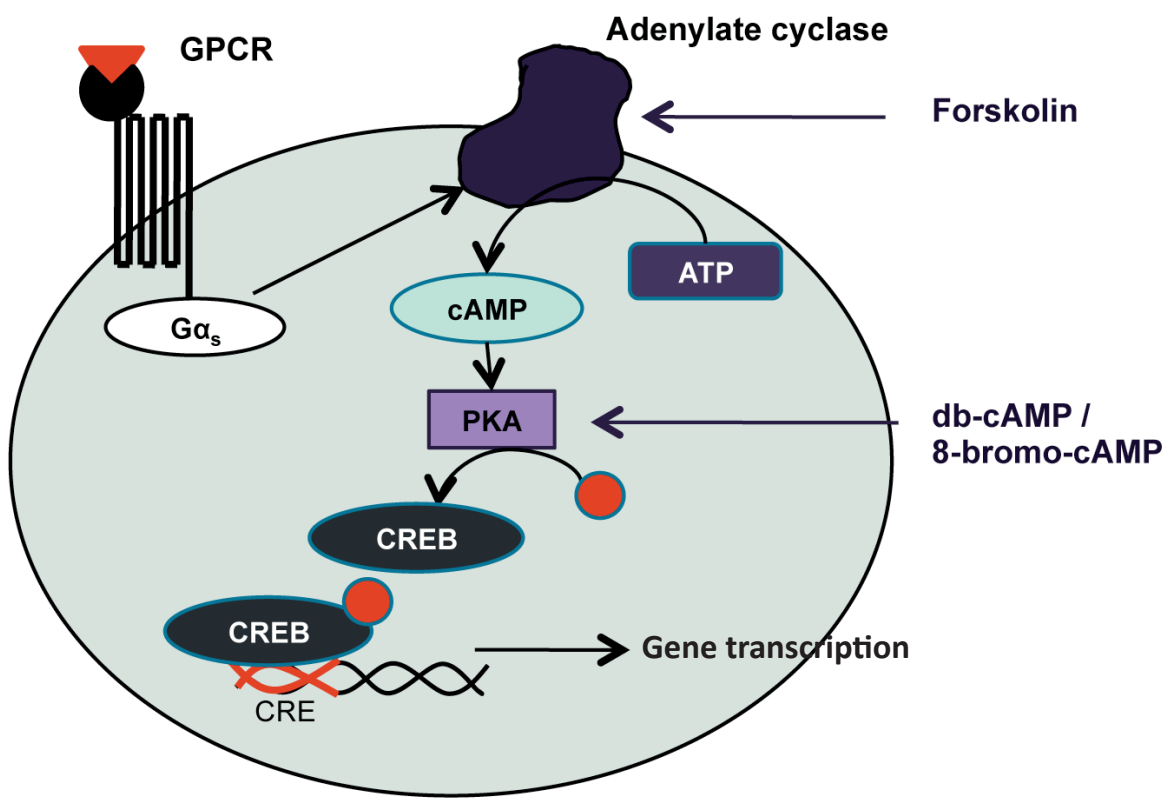

Figure 1. Schematic overview of the cAMP/PKA pathway. G-protein coupled receptor (GPCR) ligands bind to their receptors on the cell surface, which results in dissociation of the $\alpha$ subunit from its G-protein. The Gs $\alpha$-protein activates adenylate cyclase, which converts ATP into cAMP. cAMP binds to the regulatory subunits of PKA, inducing a conformational change that leads to activation of PKA. PKA in turn phosphorylates cAMP responsive element binding protein (CREB), which translocates into the nucleus where it binds to the cAMP responsive element (CRE) to induce transcription of target genes. db-cAMP and its analogue 8-br-cAMP directly activate PKA, whereas forskolin activates the more upstream adenylate cyclase.

calvaria osteoblast-like cells [22] and human osteoblasts [23] in vitro. Furthermore, using the rat osteosarcoma cell line UMR 106-01, PKA was shown to phosphorylate Runx2 via a PKA phosphorylation site [24] and direct activation of PKA with cAMP and forskolin in rat and human osteoblast-like cell lines lead to activation of the osteocalcin promoter [25]. We recently demonstrated that, besides the increase in bone formation, activation of PKA using db-cAMP resulted in increased ALP expression, mineralization and enhanced growth factor secretion in hMSCs [20]. However, a major drawback of dbcAMP is its strong inhibitory effect on proliferation of hMSCs. Therefore, we examined if osteogenic differentiation and the resulting bone formation can be enhanced even further by other PKA activators or by using lower concentrations. In addition to db-cAMP, we selected the cAMP analogue 8-bromo-cAMP (8-br-cAMP) and the adenylate cyclase activator forskolin as PKA activators and investigated their effects on proliferation, ALP expression, IGF-1 secretion and osteogenic gene expression of hMSCs. 


\section{Materials and methods}

\section{Isolation and culture of hMSCs}

Bone marrow aspirates were obtained from donors with written informed consent. Human mesenchymal stromal cells (hMSCs) were isolated and proliferated as described previously [26]. Briefly, aspirates were resuspended using $20 \mathrm{G}$ needles, plated at a density of $5 \times 10^{5}$ cells $/ \mathrm{cm}^{2}$ and cultured in hMSC proliferation medium, consisting of $\alpha$-minimal essential medium ( $\alpha$-MEM, Life Technologies), 10\% fetal bovine serum (FBS, Cambrex Bio sciences Verviers), $0.2 \mathrm{mM}$ ascorbic acid 2-phosphate (ASAP, Sigma Aldrich), $2 \mathrm{mM}$ L-glutamine (Invitrogen, Life Technologies), $100 \mathrm{U} / \mathrm{ml}$ penicillin (Life Technologies), $10 \mu \mathrm{g} / \mathrm{mL}$ streptomyocin (Life Technologies) and $1 \mathrm{ng} / \mathrm{mL}$ basic fibroblast growth factor (bFGF, Instruchemie, The Netherlands). Cells were grown at $37{ }^{\circ} \mathrm{C}$, in a humid atmosphere with $5 \% \mathrm{CO}_{2}$. Medium was refreshed twice a week and cells were used for further subculturing or cryopreservation upon reaching near confluence. hMSC basic medium was composed of proliferation medium without bFGF and osteogenic medium was composed of basic medium supplemented with $10^{-8} \mathrm{M}$ dexamethasone (Sigma).

\section{PKA activators}

Three different PKA activators were selected: db-cAMP (N6,2'-O-Dibutyryladenosine $3^{\prime}, 5^{\prime}$-cyclic monophosphate sodium salt, stock solution $20 \mathrm{mM}$ in water), 8-brcAMP, (8-Bromoadenosine $3^{\prime}, 5^{\prime}$-cyclic monophosphate sodium salt, stock solution $20 \mathrm{mM}$ in water) and forskolin (from Coleus forskohlii, stock solution $2 \mathrm{mM} ; 5 \mathrm{mg} /$ mL DMSO supplemented with basic medium) (all from Sigma). For db- and 8-brcAMP, concentrations of $0.1,0.5,0.75,1.0$ and $2.0 \mathrm{mM}$ were used and for forskolin concentrations of $0.01,0.05,0.075,0.10,0.15$ and $0.2 \mathrm{mM}$ were used.

\section{Proliferation}

hMSCs were seeded at 5000 cells $/ \mathrm{cm}^{2}$ in 24 -well plates in triplicate and cultured in basic medium supplemented with denoted concentrations of PKA activators. As a control, cells were cultured in basic medium. A 10\% v/v Alamar Blue (Biosource) solution was prepared in basic medium. After 4 and 7 days of culture the medium was removed and $1 \mathrm{~mL}$ of Alamar Blue solution was added to each well. For background measurements, Alamar Blue solution alone was used. After an incubation period of 4 hours, $200 \mu \mathrm{L}$ of the solution was transferred to a 96-wells plate and fluorescence intensity was measured using an LS50B luminescence spectrometer (Perkin-Elmer) with an excitation wavelength of $545 \mathrm{~nm}$ and an emission wavelength of $590 \mathrm{~nm}$. After measurements, cells were washed with PBS, fresh medium was added and cells were returned to culture. 


\section{ALP expression}

To determine ALP expression levels, hMSCs were seeded in triplicate at 5000 cells / $\mathrm{cm}^{2}$ in 6-well plates. Cells were kept overnight in proliferation medium to attach, after which the medium was replaced with either basic or osteogenic medium supplemented with denoted concentrations of PKA activators. As a negative control cells were cultured in basic medium, as a positive control in osteogenic medium. After 3 days, cells were trypsinized $(0.25 \%$ trypsin, Invitrogen life technologies) and $1 \mathrm{~mL}$ of blocking buffer (PBS with $5 \%$ bovine serum albumin (BSA, Sigma) and $0.1 \%$ sodium azide (Sigma)) was added and incubated for 30 minutes to prevent a-specific binding. After centrifugation and removal of the supernatant, cells were incubated with $50 \mu \mathrm{L}$ of primary antibody (anti-ALP, B4-78 (Developmental Studies Hybridoma Bank, University of Iowa, USA)), diluted 1:50 in wash buffer (PBS with 1\% BSA and 0.05\% sodium azide) for 1 hour. For each condition, part of the cells was used for the isotype control to determine a-specific binding. These cells were incubated with IgG-1 (BD bioscience, diluted 1:50 in wash buffer), a randomly binding antibody. Subsequently, cells were washed twice with 500 $\mu \mathrm{L}$ of wash buffer. Next, $100 \mu \mathrm{L}$ of secondary antibody (rat-anti-mouse IgG1-PE (BD bioscience), diluted 1:100 in wash buffer,) was added. After incubation for 30 minutes, cells were washed again 3 times. $10 \mu \mathrm{L}$ of Viaprobe (Pharmingen) was added for live/ dead staining, and ALP expression was determined using a FACS Calibur measuring 10,000 events (Becton Dickinson, Immunocytometer systems). FACS data was analysed using CellQuest software. Cells with the right size (forward scatter) and granularity (side scatter) were gated and debris and dead cells were excluded from analysis. The percentage of ALP positive cells was determined, with a minimum of 7500 gated events. Experiments were repeated with cells from at least three different donors.

\section{Gene expression analysis}

hMSCs were seeded in triplicate at 5000 cells $/ \mathrm{cm}^{2}$ in 6-well plates and kept overnight in proliferation medium to attach. Then the medium was replaced with basic medium containing various concentrations of PKA activators. As a control cells were cultured in basic medium or, as a control for BMP-2 target genes, basic medium supplemented with $100 \mathrm{ng} / \mathrm{mL}$ BMP-2. After 5 days, RNA was isolated using a Bioke RNA II nucleospin RNA isolation kit (Machery Nagel) and RNA concentrations were measured using an ND100 spectrophotometer (Nanodrop technologies, USA). cDNA was synthesized from 250 ng of RNA, using iScript (BioRad) according to the manufacturer's protocol. For semi-quantitative PCR, a master mix, containing distilled water, forward primer, reverse primer (Sigma Genosys), BSA, and SYBR green I mix (all from Invitrogen) was prepared and real-time qPCR was performed using a Light-Cycler (Roche). Light-Cycler data was analyzed using the fit points method of Light-Cycler software. The baseline was set at the lower log-linear part above baseline noise and the crossing temperature (Ct value) 
was determined. Ct values were normalized to the $18 \mathrm{~S}$ housekeeping gene and $\Delta \mathrm{Ct}$ (Ct control $-\mathrm{Ct}_{\text {sample }}$ ) was used to calculate the upregulation in gene expression [27]. Primer sequences are listed in table 1.

Table 1. Primer sequences

\begin{tabular}{lll}
\hline Gene & Forward primer & Reverse primer \\
\hline 18s & CGGCTACCACATCCAAGGAA & GCTGGAATTACCGCGGCT \\
Id1 & GCAAGACAGCGAGCGGTGG & GGCGCTGATCTCGCCGTTGAGGG \\
Id2 & CCTCCCGGTCTCGCCTTCC & GGTTCTGCCCGGGTCTCTGG \\
Osx & GAAGGGAGTGGTGGAGCCAAAC & ATTAGGGCAGTCGCAGGAGGAG \\
IGF-1 & CTTCAGTTCGTGTGTGGAGACAG & CGCCCTCCGACTGCTG \\
BMP-2 & Commercially obtained from SA Biosciences \\
\hline
\end{tabular}

\section{IGF-1 secretion}

hMSCs were seeded in triplicate at 5000 cells $/ \mathrm{cm}^{2}$ in 24 well plates and allowed to attach overnight in proliferation medium. Then the medium was removed and replaced with basic medium supplemented with various concentrations of PKA activators. As a negative control, cells were cultured in basic medium. After 5 days of culture the medium was removed and the concentration of IGF-1 in the medium was determined using ELISA (human IGF-1, Quantikine, R\&D systems), according to the manufacturer's protocol.

\section{In vivo bone formation}

2-3 $\mathrm{mm}$ biphasic calcium phosphate (BCP) particles were prepared and sintered at $1150{ }^{\circ} \mathrm{C}$ as described previously [28]. hMSCs were seeded at 200,000 cells/3 particles in proliferation medium. After 4 days the medium was changed to basic medium or basic medium supplemented with $1 \mathrm{mM}$ db-cAMP, $0.1 \mathrm{mM}$ forskolin or $0.15 \mathrm{mM}$ forskolin and cells were cultured for 4 more days. Twenty minutes before surgery, 6 nude male mice (Hsd-cpb:NMRI-nu, Harlan) were injected subcutaneously with $0.05-0.1 \mathrm{mg} / \mathrm{kg}$ Temgesic and subsequently anaesthetized with isoflurane. Particles were implanted in subcutaneous pockets, with 3 particles per pocket, four pockets per mouse and 6 samples per condition. Incisions were closed using vicryl 5-0 sutures and after 6 weeks the mice were sacrificed using $\mathrm{CO}_{2}$. Particles were explanted, fixed in $4 \%$ paraformaldehyde (Merck) dehydrated and embedded in methyl methacrylate (L.T.I. Bilthoven) for sectioning. Undecalcified sections were processed on a histological diamond saw (Leica). Sections were stained with methylene blue and basic fuchsin to visualize bone formation. Quantitative histomorphometry was performed by selecting three sections, with an intermediate section in between, after which a high resolution (5400 dpi) micrograph was made (Minolta Dimage Scan). Micrographs were pseudocolored (bone 
in red and scaffold in green) and image analysis was performed using the KS400 version 3.0 software (Carl Zeiss Vision, Oberkochen, Germany). Prior to measurements, the system was geometrically calibrated with an image of known dimensions. Bone was quantified as the percentage of bone area per scaffold area.

\section{Statistics}

All experiments were performed in triplicates. Data were analyzed in SPSS (PASW statistics) using one way Anova, followed by Tukey's multiple comparison test.

\section{Results}

\section{PKA activators inhibit proliferation}

Three different PKA activators (db-cAMP, 8-br-cAMP and forskolin) were investigated for their dose-dependent effects on hMSC proliferation. For db- and 8-br-cAMP, concentrations of $0.1,0.5,0.75,1.0$ and $2.0 \mathrm{mM}$ were used and for forskolin concentrations of $0.01,0.05,0.075,0.10,0.15$ and $0.2 \mathrm{mM}$. As a measure for cell number, metabolic activity was determined after 4 and 7 days and figure 2 depicts values relative to control (basic medium). In total, six donors were tested and for forskolin, which was dissolved
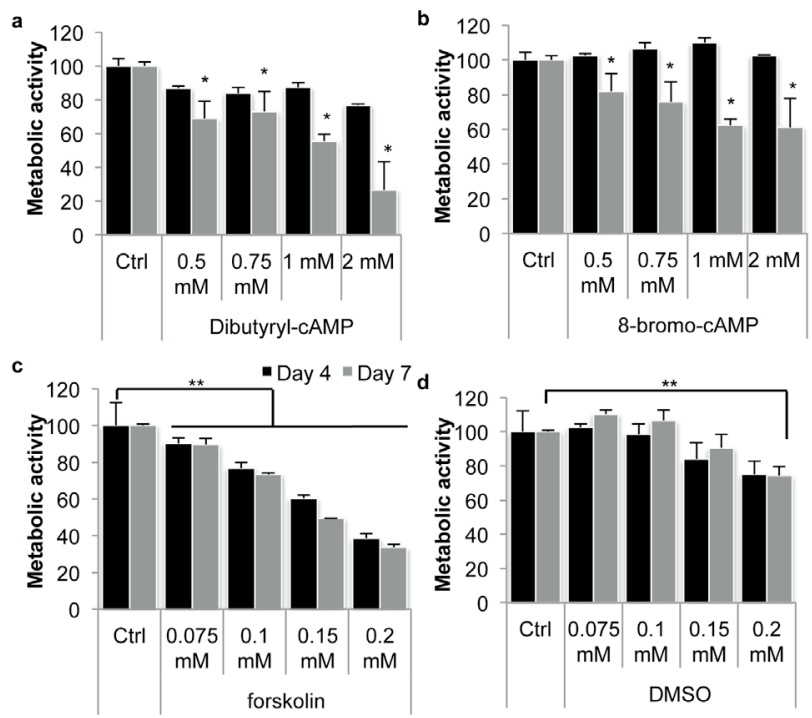

Figure 2. PKA activators inhibit proliferation of hMSCs in a dose-dependent manner. Cells were treated with db-cAMP or 8-br-cAMP in concentrations ranging from $0.5-2.0 \mathrm{mM}$ or with forskolin in concentrations ranging from $0.075-0.2 \mathrm{mM}$. A concentration of $0.5 \mathrm{mM}$ db-cAMP did not affect proliferation. Other concentrations significantly decreased proliferation after 7 days, but after 4 days only a slight decrease in cell number was observed (a). 8-br-cAMP had similar effects (b). Treatment with forskolin resulted in a significant decrease in cell number already after 4 days (c). This decrease in cell number by forskolin was partly due to the DMSO that was used as a solvent (d). Ctrl, basic medium; ${ }^{*}, \mathrm{p}<0.05 ;{ }^{* *}, \mathrm{p}<0,01$. 
in DMSO, the solvent alone was taken along as a control. After 4 days, proliferation was slightly decreased in two out of six donors using db-cAMP (figure 2a), whereas it did not affect proliferation of the other four. After 7 days, proliferation was inhibited in a concentration-dependent manner in every donor tested. 8-br-cAMP displayed similar effects (figure $2 \mathrm{~b}$ ); no change in proliferation after 4 days of treatment, and a concentration-dependent decrease in cell number after 7 days. For two donors, 8-brcAMP did not affect proliferation at all. Treatment with forskolin (figure 2c) resulted in a strong concentration-dependent decrease in proliferation already after 4 days, with an even larger decrease after 7 days, which was partly due to the DMSO (figure $2 \mathrm{~d}$ ). For all compounds the level of decrease was strongly donor-dependent, varying from $25 \%$ to $60 \%$ and from $10 \%$ to $55 \%$ using the highest concentrations of db-cAMP and forskolin respectively (for additional data on various donors see supplementary data S1). DMSO had similar donor-dependent effects, varying between $0 \%-5 \%$ in the lowest concentration to $10 \%-25 \%$ in the highest concentration.

\section{8-br-cAMP does not affect ALP expression but enhances expression of osteogenic marker genes}

Next, we investigated if osteogenic differentiation was dependent on the type of activator or the concentration, by measuring expression of the early osteogenic marker alkaline phosphatase (ALP). Concentrations used were the same as for proliferation experiments and each compound was tested on hMSCs from at least three donors. Representative results from one donor are depicted in figure 3 . For db-cAMP, 0.1 $\mathrm{mM}$ did not enhance ALP expression in any of the donors tested, consistent with cell morphology observations (data not shown). Concentrations of 0.5 to $2.0 \mathrm{mM} \mathrm{db}$-cAMP resulted in a 2- to 3-fold increase in ALP expression, comparable to dexamethasoneinduced ALP expression in that specific donor, without differences between these concentrations (figure 3a). In contrast, 8-br-cAMP did not significantly affect ALP expression in any of the donors tested (figure $3 \mathrm{~b}$ ). Using forskolin, treatment with 0.05-0.20 mM resulted in a dose-dependent increase in ALP expression, with $0.10 \mathrm{mM}$ resulting in highest expression levels (figure 3c). $0.01 \mathrm{mM}$ forskolin or DMSO alone did not affect ALP expression. We then selected concentrations of $1.0 \mathrm{mM} \mathrm{db}$ - and 8-brcAMP and $0.10 \mathrm{mM}$ forskolin to compare the three compounds (figure 3d). In hMSCs from every donor tested, db-cAMP induced highest ALP expression [for additional data on other donors, see supplementary data S2]. Since we previously observed synergistic effects between db-cAMP and dexamethasone on ALP expression levels, we also examined the combinatorial effects of 8-br-cAMP and forskolin with dexamethasone. As shown in figure $3 \mathrm{e}$, although 8-br-cAMP alone did not affect ALP levels, upon addition to dexamethasone, there was a small, but non-significant increase in ALP levels compared to dexamethasone alone. For forskolin, there was no significant increase in ALP levels upon addition of dexamethasone. Interestingly, in this donor, forskolin induced ALP 
levels to a significantly higher level than dexamethasone, indicating that forskolin might have potential for hMSCs that do not respond to dexamethasone.

Similar to the proliferation results described above, ALP expression levels were donor-dependent, but no correlation was found between the inhibitory effect on proliferation and the increase in ALP expression. Since $1 \mathrm{mM}$ db-cAMP was previously shown to increase gene expression of the BMP-2 target genes Id1 and Id2 [20], we also examined gene expression levels of these genes after treatment with the three compounds, in addition to the osteogenic genes BMP-2 and IGF-1. As shown in figure
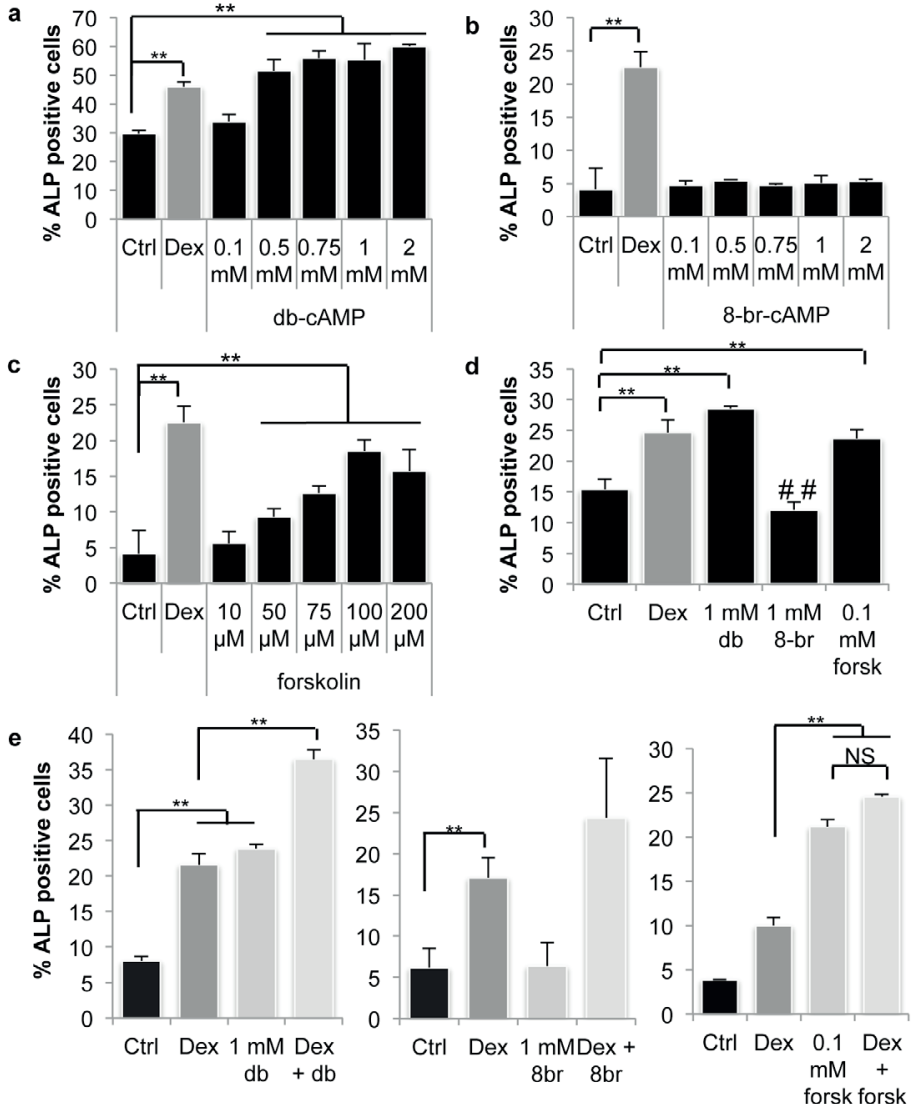

Figure 3. Both db-cAMP and forskolin enhance ALP expression of hMSCs. Cells were cultured in the presence of PKA activators for 3 days, after which ALP expression was measured. A concentration of $0.1 \mathrm{mM} \mathrm{db}$-cAMP did not enhance ALP expression, but concentrations ranging from $0.5-2.0$ $\mathrm{mM}$ increased ALP expression to the same extent as dexamethasone (a). In contrast, 8-br-cAMP did not affect ALP expression in any of the concentrations used (b). Forskolin enhanced ALP expression in a dose-dependent manner, with $0.1 \mathrm{mM}$ being the most optimum concentration (c). Of the three compounds that were tested, db-cAMP increased ALP expression most, although both basal and induced ALP expression were strongly donor dependent (d). In addition, when db-cAMP was combined with dexamethasone treatment a synergistic increase in ALP expression was observed, but not with 8-br-cAMP or forskolin (e). Ctrl, basic medium; Dex, dexamethasone; ${ }^{*} \mathrm{p}<0.05$; ${ }^{* *} \mathrm{p}<0,01, \# \# \mathrm{P}<0.01$ compared to ctrl. 
4, all three compounds increased expression of Id1, Id2, BMP-2 and IGF-1, generally in a dose-dependent manner. Treatment with the optimum concentration of db-cAMP $(1 \mathrm{mM})$ resulted in significantly higher expression of BMP-2 and IGF-1, compared to 8-brcAMP and forskolin. In contrast, expression of Id1 was higher in forskolin-treated cells, and no differences were found in Id2 expression between the optimal concentrations of these two compounds. 8-br-cAMP did not induce expression of Id1 or Id2. Since it has been described that both forskolin and 8-br-cAMP reduce expression of the osteogenic transcription factor osterix (Osx) in UMR-106-01 cells [29], the expression of this gene was also examined. In contrast to this study, figure $4 \mathrm{e}$ shows that all three compounds induce high expression of this gene and that 8-br-cAMP and forskolin induce significantly higher levels than db-cAMP.
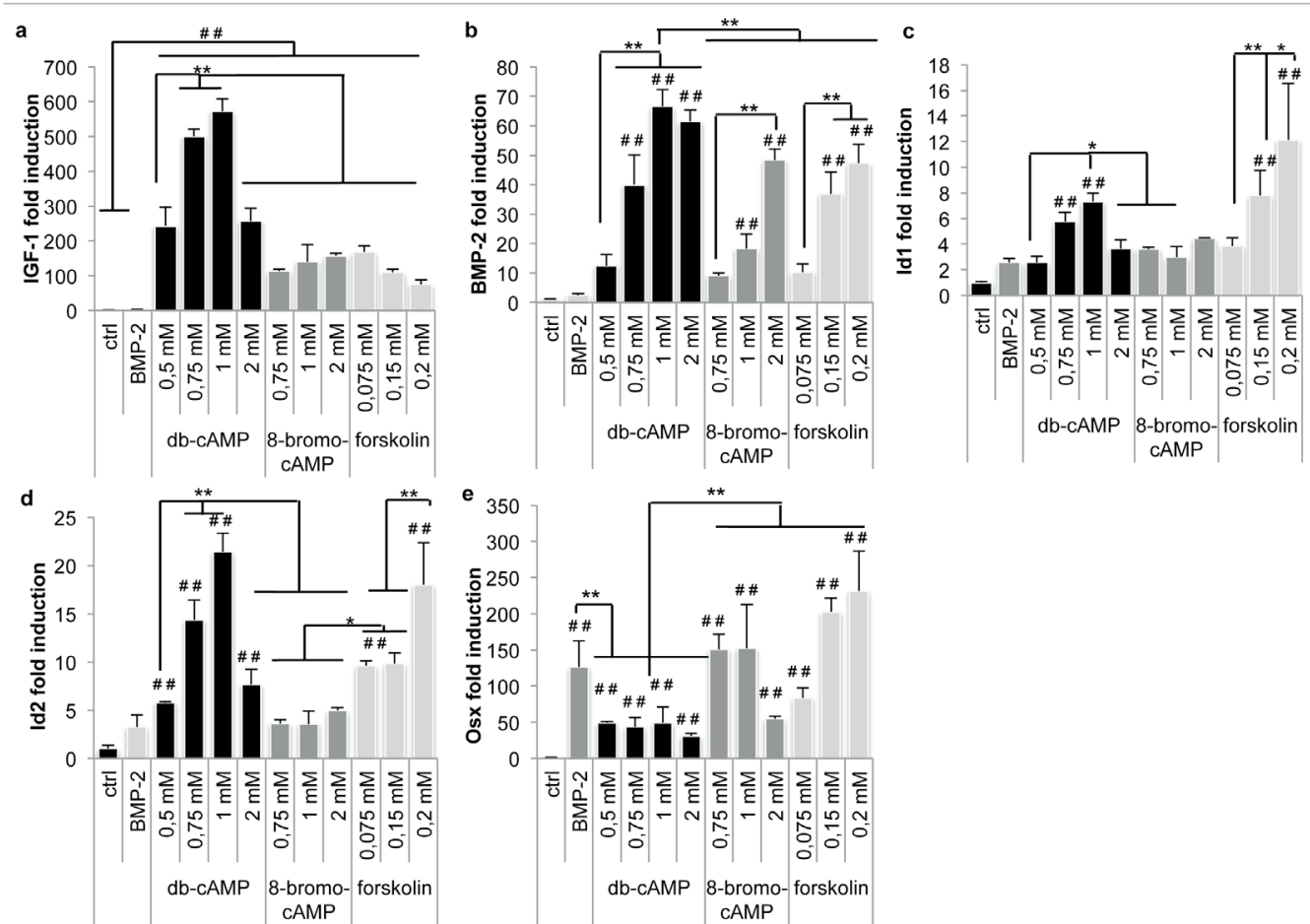

Figure 4. All three PKA activators increase expression of osteogenic genes in a dose-dependent manner. hMSCs were treated with db-cAMP, 8-br-cAMP or forskolin for 5 days, after which gene expression was determined. All three activators increased expression of IGF-1 (a), BMP-2 (b) and the BMP-2 target genes Id1 (c) and Id2 (d). db-cAMP increased IGF-1 and BMP-2 expression to a higher extent than 8-br-cAMP and forskolin. There were no differences in Id1 expression, but expression of Id2 was significantly higher in cells treated with db-cAMP and forskolin than 8-br-cAMP. Expression of the transcription factor osterix was highly induced by forskolin and by low concentrations of 8-br-cAMP whereas induced expression of this gene by db-cAMP was significantly lower. ${ }^{*} \mathrm{p}<0.05$; ${ }^{* *} \mathrm{p}<0,01, \# \# \mathrm{P}<0.01$ compared to control, Osx; osterix. 


\section{db-cAMP and forskolin induce IGF-1 secretion to a higher extent than 8-br-cAMP}

We previously demonstrated that PKA activation enhances secretion of bone-specific growth factors such as insulin-like growth factor-1 (IGF-1), interleukin-8 (Il-8) and interleukin-11 (Il-11) [20]. Since qPCR experiments showed higher IGF-1 expression after treatment with db-cAMP, we investigated if the secretion of IGF-1, one of the most abundant growth factors in bone, was dependent on the type of PKA activator and the concentration. Figure 5a shows that all three PKA activators increase IGF- 1 secretion, but db-cAMP and forskolin do so to significantly higher concentrations than 8-br-cAMP. No differences were found between different concentrations of these compounds. However, when IGF-1 concentrations were normalized to cell numbers, a clear concentrationdependent increase was observed, as shown in figure $5 \mathrm{~b}$. Of the concentrations tested here, $2.0 \mathrm{mM} \mathrm{db}$-cAMP and $0.2 \mathrm{mM}$ forskolin resulted in highest IGF-1 secretion per cell, however due to the severe inhibition of proliferation at these concentrations, the total amount of secreted IGF-1 was highest after treatment with 0.75-1.0 mM db-cAMP and $0.10 \mathrm{mM}$ forskolin. These optimum concentrations were then used to examine IGF-1 secretion in two more donors (supplementary data S3) and in these donors an increase in IGF-1 secretion, also by 8-br-cAMP, was found, although again, db-cAMP and forskolin have more profound effects.

\section{Pre-conditioning with forskolin enhances in vivo bone formation of hMSCs}

As described, differentiation of hMSCs in vitro does not necessarily result in enhanced bone formation in vivo. Since 8-br-cAMP-treatment resulted in adipogenic differentiation in long-term mineralization cultures (data not shown), only db-cAMP
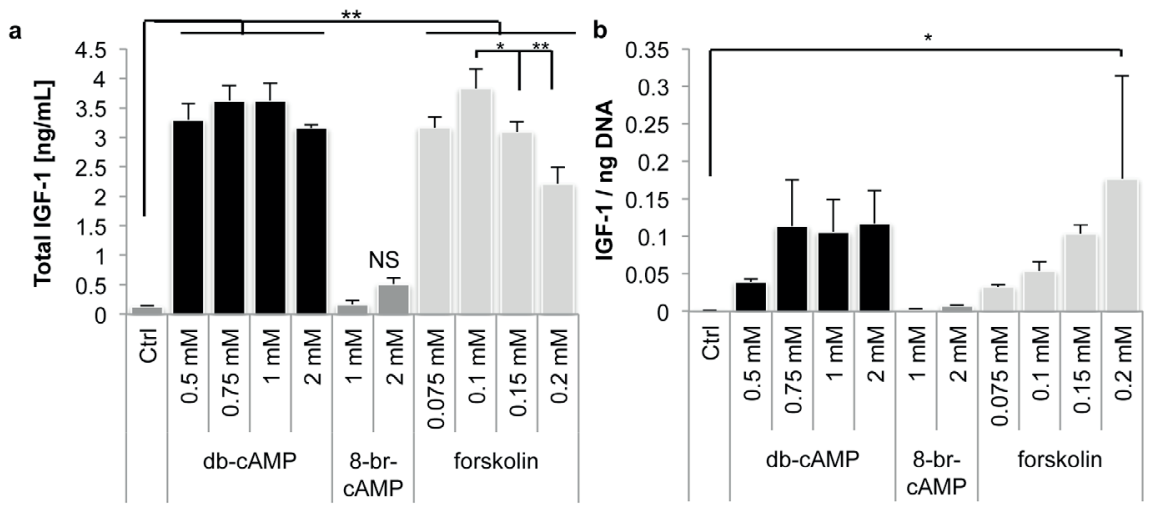

Figure 5. Both db-cAMP and forskolin enhance IGF-1 secretion. hMSCs were cultured in the presence of PKA activators for 5 days after which the concentration of IGF-1 in the medium was measured by ELISA. No significant differences in IGF-1 secretion between various concentrations of db-cAMP and forskolin were detected, whereas 8-br-cAMP treatment resulted in significant lower amounts of IGF-1 (a). Normalization of secreted IGF-1 to DNA content demonstrated a dose-dependent effect using forskolin, but no differences were observed between higher concentrations of db-cAMP (b). *, $\mathrm{p}<0.05$; $^{* *}, \mathrm{p}<0,01$ 

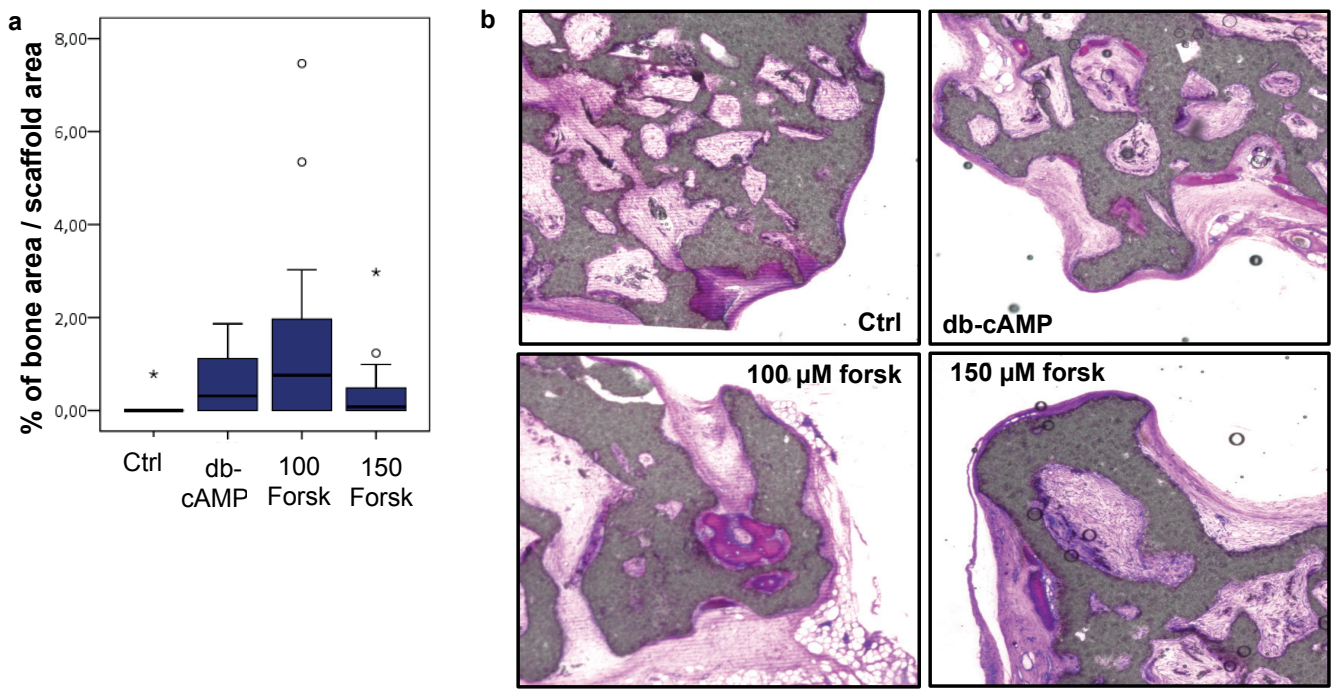

Figure 6. Forskolin enhances bone formation in vivo. hMSCs were cultured on BCP scaffolds for 4 days in proliferation medium followed by 3 days in basic medium in the presence of db-cAMP and forskolin. Then, samples were implanted for 6 weeks, after which the amounts of bone were analysed. Although not significant, treatment with $0.10 \mathrm{mM}$ forskolin resulted in higher amounts of bone than $1 \mathrm{mM} \mathrm{db}$-cAMP or $0.15 \mathrm{mM}$ forskolin (a). Histology shows that the newly formed bone in each condition was of mature appearance, with fibrous tissue filling the voids (b). Data in (a) is represented as percentage of bone per scaffold area. Open circles and asterisks represent outliers.

and forskolin were used to pre-treat hMSCs prior to implantation in an ectopic location in nude mice. Figure 6 shows the amount of bone per scaffold area (a) and histological sections (b) after 6 weeks of implantation. Pre-treatment with either $0.10 \mathrm{mM}$ or 0.15 $\mathrm{mM}$ forskolin or $1 \mathrm{mM}$ db-cAMP resulted in an increase in bone formation, compared to untreated hMSCs, thus confirming previous data. Although not significant, treatment with $0.10 \mathrm{mM}$ forskolin resulted in approximately twice the amount of bone compared with the higher concentration or with db-cAMP. The newly formed bone had a mature appearance.

\section{Discussion}

We previously demonstrated that activation of PKA with the small molecule dbcAMP significantly enhances bone formation of hMSCs in vivo, but the severe inhibition of cell proliferation by this compound lead us to investigate if osteogenic differentiation and bone formation as a result of PKA activation, can be improved further by reducing concentrations or using other PKA activators. In line with our previous findings, we here confirm increased bone formation upon pre-treatment of hMSCs with the PKA activator db-cAMP, and in addition, we show enhanced bone formation after treatment of hMSCs with forskolin, a more upstream activator of the PKA pathway. As demonstrated 
before with dexamethasone $[19,30]$, we found a donor-dependent effect with both compounds. Although ALP levels and expression of IGF-1, BMP-2 and BMP-2 target genes were consistently enhanced in the donors tested, basal levels as well as relative increases varied between different donors. The inhibitory effect on proliferation also varied between donors, but we did not find a link between the induced ALP expression or gene expression and the decrease in proliferation. A decrease in proliferation will ultimately result in lower numbers of implanted cells, and it has been demonstrated that implantation of larger cell numbers results in more bone formation, although maximums have been observed. For human periosteum derived cells, it was shown that implants seeded with less than $1.10^{6}$ cells did not form any bone, where implants with $1-5.10^{6}$ cells showed similar amounts of bone [31]. For hMSCs, a maximum of bone was observed at a cell number of $5.10^{5}$ cells per implant [32]. This suggests that above this threshold, the effect on proliferation becomes irrelevant and differentiation as well as release of bone-specific growth factors may be more important parameters. In our in vivo assay we initially seeded 200,000 cells/implant, well below this threshold. Although cell numbers were not quantified before implantation, a proliferation phase of four more days with three additional days of differentiation before implantation most certainly resulted in implantation of higher cell numbers. We found larger amounts of bone after pre-treatment of the cells with $0.10 \mathrm{mM}$ forskolin compared to $0.15 \mathrm{mM}$ forskolin, most likely due to the severe inhibition of proliferation after treatment with $0.15 \mathrm{mM}$ forskolin. In addition, $0.10 \mathrm{mM}$ forskolin also resulted in larger amounts of bone than using $1.0 \mathrm{mM}$ db-cAMP, although this was not reflected by in vitro data, which showed higher expression of IGF-1 and BMP-2 after treatment with db-cAMP. Expression of osterix however, was highly induced by forskolin, which demonstrates the need for a proper in vitro marker for in vivo bone formation. Possibly, the target of forskolin, adenylyl cyclase, being more upstream, eventually also results in activation of pathways other than via cAMP $[33,34]$, but this was not investigated here. Since we observed a concentration-dependent effect both in vitro but also in vivo, optimal concentrations may even be specific for each donor, depending on the compounds' effect on proliferation. The effect of forskolin could potentially be further enhanced, by using another solvent that would have less detrimental effects on proliferation. Ethanol would probably less interfere with proliferation and is also compatible, but was demonstrated to interfere with the activity of forskolin, whereas DMSO was shown to be least interfering and therefore also used in this study [35]. Forskolin has been tested before in clinical settings for the treatment of dilated cardiomyopathy $[36,37]$ and is known as a medicinal herb and its use thus has been shown safe. Translation to the clinic would thus be relatively easy compared to other PKA activators. Besides differentiation of hMSCs, cAMP/PKA activation is involved in a wide range of cellular processes and in vivo application of these compounds could potentially induce side effects. An overview of various biological applications for which these specific PKA activators have been 
used is given in table 2 .

The distinct effects of db-cAMP and 8-br-cAMP could possibly be explained by differences in downstream activation mechanisms. Recently we demonstrated that intermittent stimulation of PKA with db-cAMP results in a decrease in ALP expression, which suggests a dual role for PKA in the differentiation of hMSCs, depending on the duration of the signal [38]. Differences in the stability of db-cAMP and 8-br-cAMP could result in variations of downstream activation regimes and ultimately in alternative

Table 2. Effect of PKA activators in various biological systems.

\begin{tabular}{|c|c|c|}
\hline Model & Effect & Refs \\
\hline \multicolumn{3}{|l|}{ Forskolin } \\
\hline rabbit & Reduced intraocular pressure & 41 \\
\hline human/animal & Reduced intraocular pressure & 42 \\
\hline human & $\begin{array}{l}\text { Reduced diastolic pressure, improved left ventricular func- } \\
\text { tion, reduced arterial pressure in cardiomyopathy }\end{array}$ & 36,37 \\
\hline rabbit & $\begin{array}{l}\text { Acts as a vasodilator, lowers blood pressure, improves } \\
\text { blood flow to the brain }\end{array}$ & 43 \\
\hline hMSCs & Enhanced adipogenic differentiation & 44 \\
\hline 3T3-L1 & Enhanced adipogenic differentation via Epac and PKA & 39 \\
\hline hMSCs & Inhibited osteogenic differentiation & 45 \\
\hline MC3T3-E1 & Improved adhesion to PLGA & 46 \\
\hline UMR106-01 & Decreased gene expression of Osterix & 29 \\
\hline \multicolumn{3}{|l|}{ db-cAMP } \\
\hline hMSCs & Enhanced adipogenic differentiation & 45 \\
\hline hMSCs & Enhanced osteogenic differentation and bone formation & 20 \\
\hline rat & $\begin{array}{l}\text { In combination with rolipram, promoted myelination, ax- } \\
\text { onal growth and functional recovery in spinal cord injury }\end{array}$ & 47 \\
\hline rat & Improved cardiac graft survival & 48 \\
\hline PCC4uva & Induced neural differentiation & 49 \\
\hline \multicolumn{3}{|l|}{ 8-br-cAMP } \\
\hline MC3T3-E1 & Improved adhesion to PLGA & 46 \\
\hline rat & $\begin{array}{l}\text { In combination with an iron chelator (BPY-DCA), reduced } \\
\text { scar tissue formation, improved functional recovery in spi- } \\
\text { nal cord injury }\end{array}$ & 50 \\
\hline rat & Increased long term memory of trained rats & 51 \\
\hline UMR106-01 & Decreased gene expression of Osterix & 29 \\
\hline $\begin{array}{l}\text { Mice / Beta } \\
\text { cells }\end{array}$ & Increased glucose-induced insulin secretion & 52 \\
\hline
\end{tabular}


differentiation routes. For example, whereas for some time PKA was thought to be the sole mediator of cAMP signaling, it is now known that cAMP can also activate epac (exchange protein directly activated by cAMP), a factor demonstrated to be indispensible for adipogenic differentiation $[39,40]$. In conclusion, we introduce forskolin as a novel agent to induce osteogenic differentiation of hMSCs in vitro and to enhance bone formation in vivo and we suggest a role for the cAMP/PKA pathway, and possibly other downstream mediators, in controlling the balance between adipogenic and osteogenic differentiation.

\section{Acknowledgments}

We would like to thank Hugo Andre Alves and Anandkumar Nandakumar for their technical support and Dr. Auke Renard (Medisch Spectrum Twente, Enschede, The Netherlands) for kindly providing us with bone marrow aspirates. Furthermore, the authors gratefully acknowledge the support of the Smart Mix Program of the Netherlands Ministry of Economic Affairs and the Netherlands Ministry of Education, Culture and Science and STW for a VIDI grant to J.d.B. 


\section{References}

1. Pittenger MF, Mackay AM, Beck SC, Jaiswal RK, et al. (1999) Science 284, 143-147

2. Brazelton TR, Rossi FM, Keshet GI, Blau HM. (2000) Science 290, 1775-1779

3. Mezey E, Chandross KJ, Harta G, Maki RA, et al. (2000) Science 290, 1779-1782

4. $\quad$ Oswald J, Boxberger S, Jørgensen B, Feldmann S, et al. (2004) Stem cells 22, 377-384

5. Dezawa M, Ishikawa H, Itokazu Y, Yoshihara T, et al. (2005) Science 309, 314-317

6. Shake JG, Gruber PJ, Baumgartner WA, Senechal G, et al. (2002) Ann Thorac Surg 73, 19191925

7. Bruder SP, Kraus KH, Goldberg VM, Kadiyala S. (1998) J Bone Joint Surg Am 80, 985-996

8. Kon E, Muraglia A, Corsi A, Bianco P, et al. (2000) J Biomed Mater Res 49, 328-337

9. Petite H, Viateau V, Bensaïd W, Meunier A, et al. (2000) Nat Biotechnol 18, 959-963

10. Boyde A, Corsi A, Quarto R, Cancedda R, et al. (1999) Bone 24, 579-589

11. Jeon O, Rhie JW, Kwon I-K, Kim J-H, et al. (2008) Tissue Eng Part A 14, 1285-1294

12. Meijer GJ, de Bruijn JD, Koole R, Van Blitterswijk CA. (2007) PLoS Med 4, e9

13. Oliveira JM, Kotobuki N, Tadokoro M, Hirose M, et al. (2010) Bone 46, 1424-1435

14. Kang S-W, Lee J-S, Park MS, Park J-H, et al. (2008) J Microbiol Biotechnol 18, 975-982

15. Song I-H, Caplan AI, Dennis JE. (2009) J Orthop Res 27, 916-921

16. De Kok IJ, Hicok KC, Padilla RJ, Young RG, et al. (2006) J Oral Implantol 32, 103-109

17. De Boer J, Licht R, Bongers M, Van Der Klundert T, et al. (2006) Tissue Eng 12, 2927-2937

18. De Boer J, Wang HJ, Van Blitterswijk CA. (2004) Tissue Eng 10, 393-401

19. Mendes SC, Tibbe JM, Veenhof M, Both S, et al. (2004) J Mater Sci Mater Med 15, 1123-1128

20. Siddappa R, Martens A, Doorn J, Leusink A, et al. (2008) Proc Natl Acad Sci U S A 105, 72817286

21. Roth JA, Kim B-G, Lin W-L, Cho M-I. (1999) J Biol Chem 274, 22041-22047

22. Kaneki H, Takasugi I, Fujieda M, Kiriu M, et al. (1999) J Cell Biochem 73, 36-48

23. Swarthout JT, D’Alonzo RC, Selvamurugan N, Partridge NC. (2002) Gene 282, 1-17

24. Selvamurugan N, Pulumati MR, Tyson DR, Partridge NC. (2000) J Biol Chem 275, 5037-5042

25. Boguslawski G, Hale LV, Yu X-P, Miles RR, et al. (2000) J Biol Chem 275, 999-1006

26. de Bruijn JD, van den Brink I, Mendes S, Dekker R, et al. (1999) Adv Dent Res 13, 74-81

27. Livak KJ, Schmittgen TD. (2001) Methods 25, 402-408

28. Yuan H, \{van Den Doel $\}$ M, Li S, van Blitterswijk CA, et al. (2002) J Mater Sci Mater Med 13, 1271-1275

29. Hong SHH, Lu X, Nanes MS, Mitchell J. (2009) J Mol Endocrinol 43, 197-207

30. Siddappa R, Licht R, van Blitterswijk C, de Boer J. (2007) J Orthop Res 25, 1029-1041

31. Eyckmans J, Roberts SJ, Schrooten J, Luyten FP. (2009) J Cell Mol Med 14, 1845-1856

32. Stenderup K, Rosada C, Justesen J, Al-Soubky T, et al. (2004) Biogerontology 5, 107-118

33. Mills I, Moreno FJ, Fain JN. (1984) Endocrinology 115, 1066-1069

34. Tirapelli CR, Ambrosio SR, de Oliveira AM, Tostes RC. (2010) Fitoterapia 81, 690-702

35. Huang RDS, M.F. Zahler, W.L. (1982) J cyclic nucleotide Res 8, 385-394 
36. Kramer W, Thormann, J., Kindler, M., Schlepper, M. (1987) Arzneimittelforschung 3, 364-367

37. Schlepper M, Thormann, J., Mitrovic, V. (1989) Basic Res Cardiol 84, 197-212.

38. Siddappa R, Doorn J, Liu J, Langerwerf E, et al. (2010) J Tissue Eng Regen Med 4, 356-365

39. Petersen RK, Madsen L, Pedersen LM, Hallenborg P, et al. (2008) Mol Cell Biol 28, 3804-3816

40. Bos JL. (2006) Trends Biochem Sci 31, 680-686

41. Gupta S, Samanta MK, Raichur AM. (2010) AAPS Pharm Sci Tech 11, 322-335

42. Caprioli J, Sears M. (1983) The Lancet 321, 958-960

43. Wysham D, Brotherton A, Heistad D. (1986) Stroke 17, 1299-1303

44. Yang D-c, Tsay H-j, Lin S-y, Chiou S-h, et al. (2008) PLoS ONE 3, e1540

45. Zhao Y, Ding S. (2007) Proc Natl Acad Sci U S A 104, 9673-9678

46. Lo KWH, Ashe KM, Kan HM, Lee DA, et al. (2011) J Orthop Res 29, 602-608

47. Pearse DD, Pereira FC, Marcillo AE, Bates ML, et al. (2004) Nat Med 10, 610-616

48. Lee J-Y, Kim JH, Chae G, Lee B-K, et al. (2010) Exp Mol Med 42, 69-79

49. Sweeney TM, Frankfurter A, Little CD. (1990) Mol Cell Neurosci 1, 193-201

50. Klapka N, Hermanns S, Straten G, Masanneck C, et al. (2005) Eur J Neurosci 22, 3047-3058

51. Rossato JI, Bevilaqua LRM, Izquierdo In, Medina JH, et al. (2009) Science 325, 1017-1020

52. Fujimoto W, Miki T, Ogura T, Zhang M, et al. (2009) Diabetologia 52, 863-872 


\title{
CHAPTER 4.
}

\section{Timing rather than the concentration of cAMP correlates with osteogenic differentiation of human mesenchymal stromal cells}

\author{
Joyce Doorn*1 \\ Ramakrishnaiah Siddappa*1 \\ Jun Liư \\ Eli Langerwerf 2 \\ Roel Arends ${ }^{2}$ \\ Clemens van Blitterswijk ${ }^{1}$ \\ Jan de Boer ${ }^{1}$
}

${ }^{1}$ Department of Tissue Regeneration, MIRA Institute for Biomedical Technology and Technical Medicine, University of Twente, Enschede 7500 AE, The Netherlands.

${ }^{2}$ Department of Pharmacology, Schering-Plough Research Institute, Molenstraat 110 , P.O. Box 20, $5340 \mathrm{BH}$, Oss, The Netherlands.

*Both authors contributed equally.

J Tissue Eng Regen Med. 2010 Jul;4[5]:356-65.

The great tragedy of science: the slaying of a beautiful hypothesis by an ugly fact.

- Thomas Henry Huxley 


\begin{abstract}
Previously, we demonstrated that Protein Kinase A (PKA) activation using dibutyrylcAMP in human mesenchymal stem cells (hMSCs) induces in vitro osteogenesis and bone formation in vivo. To further investigate the physiological role of PKA in hMSC osteogenesis, we tested a selection of G-protein coupled receptor ligands which signal via intracellular cAMP production and PKA activation. Treatment of hMSCs with parathyroid hormone, parathyroid hormone-related peptide, melatonin, epinephrine, calcitonin or calcitonin gene related peptide did not result in accumulation of cAMP or induction of alkaline phosphatase (ALP) expression. The only ligand that did induce cAMP, prostaglandin E2, even inhibited ALP expression and mineralization, suggesting that physiological levels of cAMP may inhibit osteogenesis. Furthermore, intermittent exposure of hMSCs to dibutyryl-cAMP inhibited ALP expression whereas we did not observe an inhibitive effect at low dibutyryl-cAMP concentrations. Taken together, our results demonstrate that cAMP can either stimulate or inhibit osteogenesis in hMSCs, depending on the duration rather than the strength of the signal provided.
\end{abstract}




\section{Introduction}

Human mesenchymal stem cells (hMSCs) can differentiate into the adipogenic, chondrogenic, osteogenic and myogenic lineage and due to their extensive proliferation abilities they are a potential cell source for clinical use in regenerative medicine and tissue engineering $[1,2]$. Besides, hMSCs are increasingly accepted as a cell biological model to investigate molecular mechanisms governing signal transduction, differentiation, cell fate decision, senescence and plasticity, which brings basic research closer to the clinic [3-6]. hMSCs can be isolated from various sources including tibia, femur, lumbar spine, iliac crest, acetabulum and adipose tissue [7-9]. MSCs isolated from these sources are multipotent in vitro and form bone upon implantation in immune-deficient mice [1013]. We recently conducted a phase I clinical trial to treat patients with jaw defects [14]. Although we demonstrated that bone tissue was derived from in vitro cultured hMSCs, the newly formed bone did not fully bridge the implant. To improve the performance of hMSCs in vivo, we aim at pre-differentiating them into the osteogenic lineage in vitro $[15,16]$ and focus on molecular signals involved in bone formation. For example, we demonstrated that stimulation of the Wnt signaling pathway and inhibition of histone deacetylase activity using small molecules can be used as a tool to enhance proliferation and differentiation of hMSCs, respectively [17-19]. However, both approaches also have drawbacks. Wht signaling inhibits osteogenic differentiation, and inhibition of histone deacetylase negatively affects proliferation. More recently, we have demonstrated that Protein Kinase A (PKA) activation in hMSCs using N6, 2'-0-dibutyryl-cAMP (db-cAMP) induces osteogenic differentiation in vitro and bone formation in vivo, even though it negatively affects proliferation of hMSCs [20]. db-cAMP-induced bone formation is associated with a remarkable increase in the secretion of cytokines that are known for their bone-inducing activity such as BMP2, IGF-1 and IL-11. In addition, we were able to elicit the same response using forskolin and cholera toxin, small molecules which induce PKA activation. Naturally, pharmaceutical activation of a signal transduction cascade mimics only part of the complex regulatory circuits involved in the transmission of physiological signals. We hypothesized that activation of PKA in hMSCs through natural hormones may be even more effective and could potentially cause less side effects, i.e. growth inhibition, than the pharmaceutical compounds did. For instance, stimulation of PKA in osteoblasts can be mediated through hormones which bind to so-called G-protein coupled receptors (GPCRs). A proto-typical GPCR ligand is parathyroid hormone (PTH), which signals through its receptor PTHR1, and then activates both the PKA and PKC signaling pathways. The role of PTH has become evident from PTH-deficient mice which display diminished cartilage matrix mineralization, reduced numbers of metaphyseal osteoblasts and trabecular bone [21]. In addition, PTH-related peptide (PTHrP)deficient mice are not viable due to impaired bone formation [22]. PTH has gained a lot of attention due to its ability to stimulate bone formation in vivo when administered 
intermittently. In contrast, continuous administration results in bone resorption [23, 24]. PTH induces osteogenesis via transcription factors such as cyclic AMP response element binding protein (CREB) [25], AP-1 family members including c-jun, fosB, jun-B, fra-1 and fra-2 [26-28]. Activation of the PTH receptor in the MG-63 cell-line induces osteoblast differentiation by stimulation of collagen type I synthesis and ALP expression [29]. A recent report demonstrates that intermittent exposure of hMSCs to PTH suppresses adipogenic differentiation and increases ALP expression, although no effect on other osteogenic markers, such as Runx2 and osteocalcin, was observed [30]. Another GPCR ligand, melatonin, is known to induce osteogenesis in MC3T3-E1 and ROS 17/2.8 cells, evidenced by enhanced expression of osteogenic markers such as BSP, ALP, osteocalcin (BGLAP) and collagen type 1(COL1A1) [31]. hMSCs express the melatonin receptor and, in combination with dexamethasone, melatonin induces osteogenic differentiation through the MT2 receptor [32]. Recently, it was described that hMSCs secrete prostaglandin E2 (PGE2) which mediates BMP-2 expression via the EP4 receptor[33]. Furthermore, human osteoblast cell lines and hMSCs express receptors for calcitonin and calcitonin gene related peptide (CGRP) which regulate osteogenic differentiation and bone formation [34-38].

Previously we demonstrated increased bone formation of hMSCs after treatment with high non-physiological concentration of the PKA activator db-cAMP. Since this treatment is accompanied by side effects such as inhibition of proliferation, here we describe the response of hMSCs to more natural ways of PKA activation; stimulation with a series of GPCR ligands and intermittent stimulation with db-cAMP. We show how treatment with one of these ligands, PGE2, inhibits dexamethasone-induced ALP expression and mineralization and how intermittent treatment with the PKA activator db-cAMP inhibits, rather than activates the osteogenic program in hMSCs.

\section{Materials and methods}

\section{Isolation and culture of hMSCs}

Bone marrow aspirates $(5-20 \mathrm{ml})$ were obtained from donors with written informed consent. hMSCs were isolated and proliferated as described previously [13]. Briefly, aspirates were re-suspended using 20G needles, plated at a density of $5 \times 10^{5} \mathrm{cells} / \mathrm{cm}^{2}$ and cultured in hMSC proliferation medium containing $\alpha$-minimal essential medium ( $\alpha$-MEM, Life Technologies), 10\% fetal bovine serum (FBS, Cambrex), $0.2 \mathrm{mM}$ ascorbic acid (Asap, Life Technologies), 2 mM L-glutamine (Life Technologies), $100 \mathrm{U} / \mathrm{ml}$ penicillin (Life Technologies), $10 \mu \mathrm{g} / \mathrm{ml}$ streptomycin (Life Technologies) and $1 \mathrm{ng} /$ $\mathrm{ml}$ basic fibroblast growth factor (bFGF, Instruchemie, The Netherlands). Cells were grown at $37{ }^{\circ} \mathrm{C}$ in a humid atmosphere with $5 \% \mathrm{CO}_{2}$. Medium was refreshed twice a week and cells were used for further sub-culturing or cryopreservation upon reaching near 
confluence. hMSC basic medium was composed of hMSC proliferation medium without bFGF, and hMSC mineralization medium was composed of basic medium supplemented with $10^{-8} \mathrm{M}$ dexamethasone and $0.01 \mathrm{M} \beta$-glycerophosphate (Sigma).

\section{ALP analysis by flow cytometry}

hMSCs were seeded at 5000 cells $/ \mathrm{cm}^{2}$ and allowed to attach for 10 to 15 hours in proliferation medium before addition of any compounds. Each experiment was performed in triplicate with a negative control (cells grown in basic medium) and a positive control (cells grown in basic medium supplemented with $10^{-8} \mathrm{M}$ dexamethasone) and one or more experimental conditions. At the end of the culture period, cells were trypsinized and incubated for 30 minutes in block buffer (PBS with 5\% bovine serum albumin, BSA [Sigma] and $0.01 \% \mathrm{NaN}_{3}$ ), then incubated with primary antibody (anti-ALP, B478 [Developmental Studies Hybridoma Bank, University of Iowa, USA]) diluted in wash buffer (PBS with 1\% BSA and $0.05 \% \mathrm{NaN}_{3}$ ) for 1 hour or with isotype control antibodies. Cells were then washed three times with wash buffer and incubated with secondary antibody (rat anti mouse IgG PE, DAKO) diluted in wash buffer for 30 minutes. Cells were washed three times and resuspended in $250 \mu$ l wash buffer with $10 \mu$ l Viaprobe (Pharmingen) for live/dead cell staining. Only living cells were used for further analysis. With the isotypes set to zero, the amounts of ALP-positive cells were analyzed on a FACS Caliber using cell-quest software (Becton Dickinson Immunocytometry systems). ALP expression was then calculated relative to the respective negative control.

\section{Biochemical ALP analysis}

hMSCs were seeded at 1000 cells/well in 96-well plates and incubated in basic medium supplemented with PGE2 or both PGE2 and dexamethasone for 5 days. Each experiment was performed in triplicate with a negative control (cells grown in basic medium), a positive control (cells grown in basic medium supplemented with $10^{-8} \mathrm{M}$ dexamethasone) and experimental conditions. Samples were lysed with $0.2 \%$ Triton $\mathrm{X}-100$ in PBS and alkaline phosphatase activity was determined in $100 \mathrm{ml}$ aliquots of clarified cell lysate with $100 \mathrm{ml}$ of $20 \mathrm{mM}$ pNPP (p-Nitrophenyl phosphate, SigmaAldrich) as a substrate. The resulting absorbance at $450 \mathrm{~nm}$ was recorded after 30 min of incubation at $37{ }^{\circ} \mathrm{C}$, corrected for background signal and normalized to the total DNA content, as measured using a Cyquant proliferation assay according to the manufacturer's protocol.

\section{Mineralization and calcium deposition}

For mineralization, hMSCs were seeded in triplicate in mineralization medium at 5000 cells $/ \mathrm{cm}^{2}$ in T 25 culture flasks and cultured for 30 days with cells cultured in basic medium supplemented with $0.01 \mathrm{M} \beta$-glycerophosphate as negative control. The total 
calcium deposition was assayed using a calcium assay kit (587A, Sigma diagnostics) according to the manufacturer's protocol. Briefly, the culture medium was aspirated, washed twice with calcium- and magnesium-free PBS (Life Technologies) and incubated overnight with $0.5 \mathrm{M} \mathrm{HCl}$ on an orbital shaker at room temperature. The supernatant was collected for direct measurement or stored at $-200 \mathrm{C}$. The calcium content was measured at $620 \mathrm{~nm}$ (BioTek Instruments) and expressed as mg calcium/flask.

\section{Intracellular cAMP measurements}

hMSCs were seeded in triplicate at 5000 cells $/ \mathrm{cm}^{2}$ in basic or basic medium supplemented with $10^{-8} \mathrm{M}$ dexamethasone. After a 7 days culture period, hMSCs were washed with PBS and $50 \mu \mathrm{l}$ of $\alpha$-MEM was added, followed by $50 \mu \mathrm{l}$ of $\alpha$-MEM containing $0.02 \%$ BSA and $20 \mu \mathrm{M}$ Rolipram (Sigma), a phosphodiesterase-4 inhibitor. Cells were then incubated for 2 hours at $37{ }^{\circ} \mathrm{C}$ and lysed using $100 \mu \mathrm{l}$ of $1 \%$ triton X-100 in PBS on a shaking platform for 30 minutes. Intracellular cAMP was quantified using an Amersham cAMP Biotrack EIA kit. PTH (1-34) and PTHrP were purchased from Calbiochem. Cholera toxin, forskolin, melatonin, prostaglandin E2, calcitonin, calcitonin gene related peptide (CGRP), epinephrine and db-cAMP were purchased from Sigma.

\section{Statistics}

All experiments were performed in triplicate and ALP analysis and mineralization experiments were repeated with a minimum of two different donors. Intracellular cAMP measurements were performed on hMSCs from a single donor. ALP analysis and mineralization experiments using GPCR ligands were analyzed using one-way ANOVA followed by Dunnett's multiple comparison test, except for the biochemical ALP assay using PGE2 which was analyzed using one-way ANOVA followed by Tukey's multiple comparison test. All other assays were analyzed using Student's t-test. P-values below 0.05 were considered statistically significant.

\section{Results}

\section{The effect of PTH/PTHrP on osteogenesis}

Since activation of the PKA pathway with natural hormones may be more effective and cause less side effects than the pharmaceutical compounds did, we started by testing the effect of the most well-known GPCR-ligand, PTH. Exposure of hMSCs to $10^{-7} \mathrm{M} \mathrm{PTH/}$ PTHrP continuously for 2, 5 or 7 days did not result in induction of ALP expression while exposure to dexamethasone did (figure 1a). In view of the reported positive effect of intermittent exposure of hMSCs to PTH [30], we exposed hMSCs to PTH for 1 to 8 hours per day for a total period of 9 days. After 9 days ALP expression was measured. As depicted in figure $1 \mathrm{~b}$, none of the intermittent exposure schemes altered ALP 
expression. Next, we tested whether the differentiation stage of hMSCs influences their response to PTH. We first differentiated hMSCs into the osteogenic lineage with $10^{-8} \mathrm{M}$ dexamethasone for 4 days and subsequently incubated with $10^{-7} \mathrm{M}$ PTH in the presence or absence of dexamethasone. As shown in figure 1c, pre-differentiating hMSCs into the osteogenic lineage did not influence their response to PTH. In addition, neither PTH nor PTHrP initiated mineralization of hMSCs, nor did they affect dexamethasone-induced mineralization (figure 1d). We therefore conclude that under our culture conditions, hMSC osteogenesis is not affected by exposure to PTH or PTHrP. In contrast, both dbcAMP and PTH positively affected osteogenic differentiation of the human osteosarcoma cell line MG-63 (data not shown).

\section{Inhibition of osteogenesis by prostaglandin E2 is correlated with cAMP accumulation}

Considering the great number of GPCRs expressed in hMSCs and the fact that we did not observe an effect of PTH or PTHrP, we then continued to investigate a selection
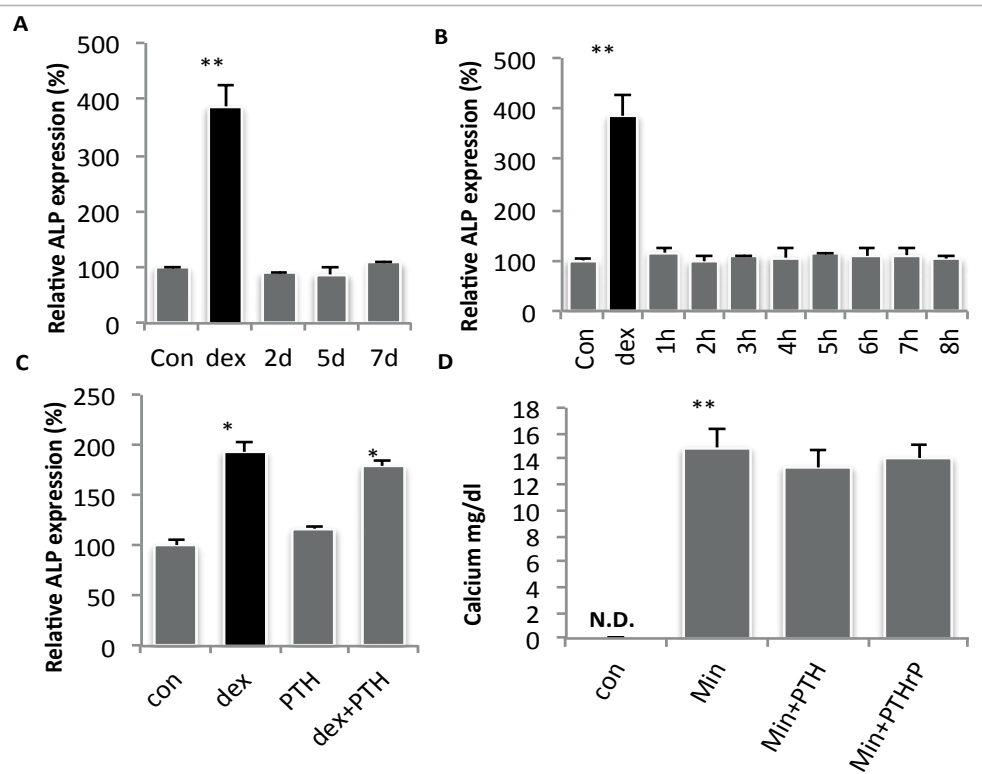

Figure 1. PTH (1-34) and PTHrP do not induce osteogenesis in hMSCs. A. hMSCs were cultured in basic medium (Con), basic medium supplemented with 10-8 dexamethasone (dex) or with $10^{-7} \mathrm{M}$ PTH (1-34) for 2, 5 and 7 days continuously. ALP expression was analyzed after 7 days. B. hMSCs were cultured in basic medium (Con) or basic medium supplemented with $10^{-8} \mathrm{M}$ dexamethasone (dex) for 9 days. hMSCs were treated with $10^{-7} \mathrm{M}$ PTH (1-34) in basic medium for 1 to 8 hours and kept in basic medium up to 24 hours. This cycle was repeated for 9 days and ALP expression was measured as described. C. hMSCs were pre-differentiated into the osteogenic lineage with $10^{-8} \mathrm{M}$ dexamethasone for 4 days. Cells were then treated with $10^{-7} \mathrm{M}$ PTH (1-34) for 4 more days with or without dexamethasone after which they were analyzed for ALP expression. D. hMSCs were cultured in basic medium (Con) or mineralization medium (min) with or without $10^{-7} \mathrm{M}$ PTH (1-34) or $10^{-7} \mathrm{M}$ PTHrP for 14 days and cultured until day 28. At the end of the culture period, calcium deposition was determined. The data were analyzed using one-way ANOVA followed by Dunnett's multiple comparison test and compared to cells grown in basic medium. ${ }^{*} \mathrm{P}<0.05$; ${ }^{* *} \mathrm{P}<0.01$, relative to Con. 
of other, commercially available GPCR ligands for their effect on hMSC osteogenesis. However, treating hMSCs with epinephrine, melatonin, calcitonin or CGRP did also not significantly affect ALP expression (figure 2a). PGE2 failed to induce ALP expression in hMSCs as well, however, when the cells were exposed to PGE2 in the presence of dexamethasone it significantly inhibited dexamethasone-induced ALP expression (figure $2 \mathrm{~b}$ ). We analyzed the ability of the above mentioned ligands to induce in vitro mineralization by treating the cells with the ligands continuously for 14 days. As shown in figure 2c, most of the compounds did not affect dexamethasone-induced in vitro mineralization except for PGE2, which significantly reduced calcium deposition. This suggests that PGE2-induced cAMP accumulation inhibits hMSC osteogenesis, which contradicts our previous observation that sustained treatment with $1 \mathrm{mM} \mathrm{db}$-cAMP stimulates osteogenesis [20]. Since the other ligands that we tested here, did not affect ALP expression, and both these ligands and PGE2 signal through intracellular cAMP as a second messenger, we further analyzed a putative relation between ligand-induced intracellular cAMP accumulation and osteogenesis. For this, we expanded hMSCs with or without dexamethasone for 7 days. As expected, treatment of hMSCs with increasing doses of the well known cAMP-inducers forskolin and cholera toxin resulted in a dosedependent accumulation of intracellular cAMP, as shown in figure $3 a$ and b. Interestingly,
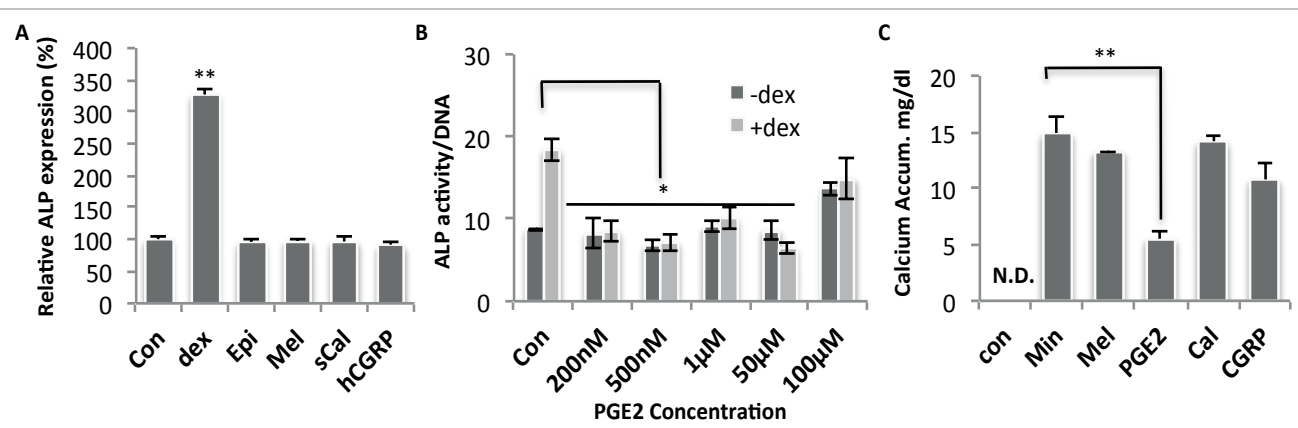

Figure 2. Prostaglandin E2 inhibits osteogenic differentiation of hMSCs. A. hMSCs were cultured in basic medium (Con), basic medium supplemented with $10^{-8} \mathrm{M}$ dexamethasone (dex) or basic medium supplemented with $10^{-5} \mathrm{M}$ epinephrine, $10^{-7} \mathrm{M}$ melatonin, $10^{-10} \mathrm{M}$ calcitonin or $10^{-8} \mathrm{M}$ calcitonin gene related peptide for 4 days and analyzed for ALP expression by flow cytometry. The data were analyzed using one-way ANOVA followed by Dunnett's multiple comparison test. ${ }^{* *} \mathrm{P}<0.01$, relative to Con. B. hMSCs were cultured in basic medium (con) or basic medium supplemented with PGE2 in concentrations ranging from $200 \mathrm{nM}$ to $100 \mu \mathrm{M}$ in the presence or absence of dexamethasone. After 4 days, cells were analyzed for ALP expression using a biochemical assay, which was then normalized to the total DNA content. The data were analyzed using one-way ANOVA followed by Tukey's multiple comparison test. ${ }^{*} \mathrm{P}<0.05$, relative to Dex C. hMSCs were cultured in basic medium (con), mineralization medium (min) or mineralization medium supplemented with $10^{-5} \mathrm{M}$ prostaglandin E2, $10^{-7} \mathrm{M}$ melatonin, $10^{-10} \mathrm{M}$ calcitonin or $10^{-8} \mathrm{M}$ calcitonin gene related peptide for 14 days and cultured up to 28 days in mineralization medium. The data were analyzed using one-way ANOVA followed by Dunnett's multiple comparison test.; ${ }^{* *} \mathrm{P}<0.01$, relative to Min. Dex; dexamethasone, Epi; epinephrine, Mel; melatonin, sCal; salmon calcitonin, hCGRP; human calcitonin gene related peptide, PGE2; prostaglandin E2. 
dexamethasone alone did not have an effect on cAMP levels, but forskolin and cholera toxin-mediated cAMP accumulation was synergistic with dexamethasone treatment, suggesting that dexamethasone modifies components of the PKA signaling pathway. We also treated hMSCs with various doses of PTH, PTHrP, melatonin, epinephrine, calcitonin, CGRP and PGE2 for two hours. Only PGE2 was able to induce intracellular cAMP production in a dose-dependent manner in dexamethasone-expanded cells, demonstrating that accumulation of intracellular cAMP in hMSCs is associated with inhibition of osteogenesis (figure 3c, only data from PGE2 shown).

\section{Intermittent cAMP accumulation is correlated to inhibition of osteogenesis}

In contrast with our findings here that PGE2 inhibits dexamethasone-induced ALP expression and mineralization, our previous work shows that prolonged exposure (several days) to a high concentration of db-cAMP enhances osteogenesis [20]. To explain the supposed contradiction with PGE2-mediated cAMP accumulation, we hypothesized that the difference can either be due to the concentration and/or duration of cAMP treatment. To investigate this, we treated hMSCs with a concentration range of db-cAMP for 3 days and analyzed ALP expression. As shown in figure 4a, db-cAMP induced ALP expression in a concentration-dependent manner and, as expected, db-cAMP treatment resulted in a synergistic ALP induction with dexamethasone. In addition, treatment of hMSCs with $1 \mathrm{mM}$ db-cAMP enhanced dexamethasone-induced mineralization (figure $4 \mathrm{~b}$ ). We did not observe a negative effect of db-cAMP on ALP, thus cAMP concentration does not explain the observed difference between PGE2 and db-cAMP treatment. Next, we exposed hMSCs intermittently to db-cAMP. Cells were treated with $1 \mathrm{mM} \mathrm{db}$-cAMP for 1 to 8 hours per day for a total period of 3 days and the effect on ALP expression was measured on day 4. As reported before, cells that were continuously exposed to $1 \mathrm{mM}$ db-cAMP for 3 days showed a significant increase in the percentage of ALP positive cells. In contrast, db-cAMP treatment for 1-8 hours a day for three days led to a significant decrease in ALP activity (figure 4c). These results suggest that a continuous raise in cAMP level is required to stimulate osteogenic differentiation of hMSCs, which cannot
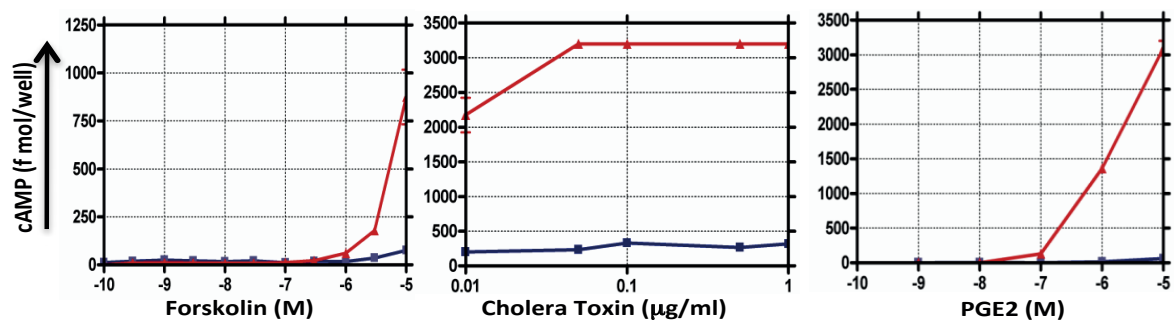

Figure 3. Prostaglandin E2 is the only ligand that induces intracellular cAMP levels. hMSCs were expanded in basic medium (control-expanded, blue lines) or basic medium supplemented with $10^{-8} \mathrm{M}$ dexamethasone (Dex-expanded, red lines) and treated with denoted concentrations of cAMP-inducing compounds and ligands for 2 hours, after which the amount of intracellular cAMP was measured. 


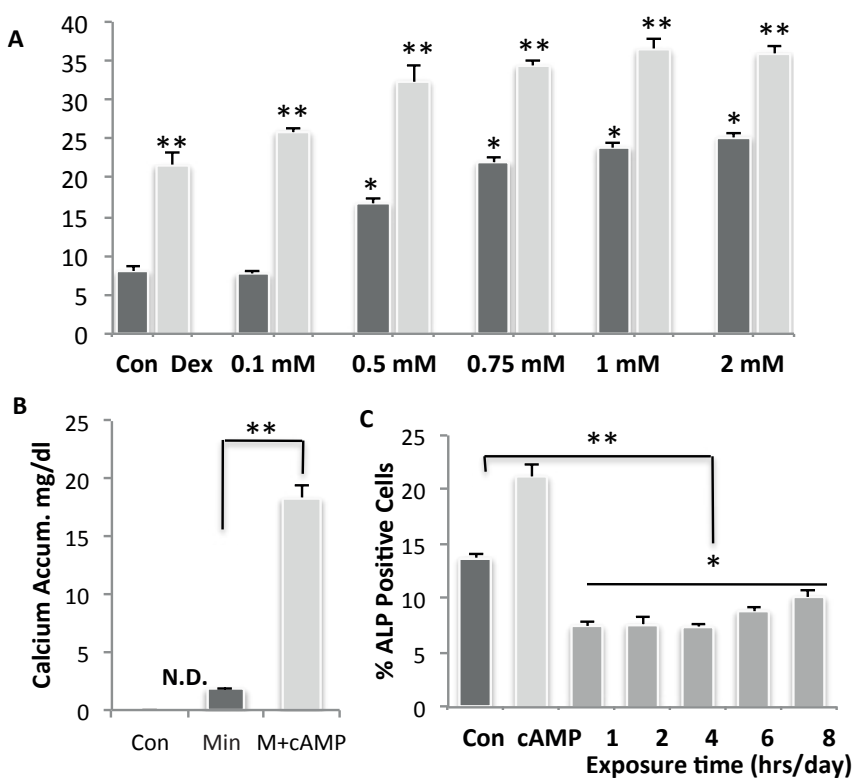

Figure 4. Osteogenic differentiation is enhanced by continuous exposure, but inhibited by intermittent exposure. A. hMSCs were cultured in basic medium (dark bars) or basic medium supplemented with dexamethasone (light bars) with various concentrations of db-cAMP ranging from 0.01-2.0 mM for four days. After four days, ALP expression was measured by flow cytometry. The data were analyzed using Student's t-test. Con; control, Dex; Dexamethasone. B. hMSCs were cultured in basic medium (Con), mineralization medium (Min) and mineralization medium supplemented with $1 \mathrm{mM}$ db-cAMP (M+cAMP) for 5 days and cultured in mineralization medium up to 28 days. Total calcium was measured as described. The data were analyzed using Student's t-test. N.D., not detectable. C. hMSCs were cultured in basic medium (Con), basic medium supplemented with $1 \mathrm{mM}$ db-cAMP (cAMP) or the cells were treated with $1 \mathrm{mM}$ db-cAMP for 1 to 8 hours per day. After 3 days, the cells were analyzed for ALP expression by flow cytometry. The data were analyzed using Student's t-test * $\mathrm{P}<0.05 ;{ }^{* *} \mathrm{P}<0.01$.

be achieved by treatment of hMSCs with GPCR ligands or intermittent exposure to dbcAMP.

\section{Discussion}

We show here that treatment of hMSCs with various GPCR ligands does not affect osteogenic differentiation of these cells, except for treatment with PGE2, which decreased dexamethasone-induced ALP expression and mineralization. This in contrast with previous findings that continuous activation of the PKA pathway with db-cAMP results in an increase in osteogenic differentiation. In addition to these findings we describe here that intermittent treatment with the same small molecule leads to a decrease in ALP expression.

PTH, probably the best-known GPCR ligand, is already clinically used as a drug for 
osteoporosis, but the treatment scheme is of vital importance for the desired positive effect. Whereas continuous treatment results in increased bone resorption, intermittent treatment leads to enhanced bone formation. We tried to mimic this effect in vitro, but with the cells we used, under the described conditions, neither intermittent nor continuous treatment with PTH had an effect on ALP expression or mineralization of hMSCs. Since PTH is thought to signal via the cAMP/PKA pathway, this seems to be in contrast with our previous findings that treatment with db-cAMP consistently increases osteogenic differentiation in vitro and bone formation in vivo [20]. A stimulatory effect of PTH on cAMP synthesis has been shown in numerous studies, but these are merely focused on osteoblastic cell lines such as ROS 17/2.8, OK cells [39], MC3T3-E1 cells [40] and UMR 106 osteosarcoma cells [41]. Rickard et al. recently showed that intermittent PTH treatment increased ALP expression of hMSCs cultured in adipogenic medium, however, intermittent treatment with forskolin did not affect ALP expression, suggesting that the effect of intermittent PTH treatment is not mediated by the cAMP/PKA pathway [30]. In line with this, we were not able to show an effect of PTH on intracellular cAMP levels in hMSCs in this study, and, as far as we know, such an effect has not been shown before. The effect of signaling molecules can vary between different cell types and species, and this raises the question whether PTH mediates an effect via hMSCs at all, although it is well possible that the in vivo niche, containing a cocktail of cytokines and growth factors, accounts for a totally different response of hMSCs to PTH compared to the in vitro situation. Similar effects have been described for instance for BMP, dexamethasone and other compounds, having diverged effects in different cell types and a different role in vivo $[42,43]$. Since PTH also activates $G_{q}$ and thus the PKC pathway, other pathways might also be involved in the stimulatory effect of PTH on bone formation in vivo. The increase in bone formation could, for example, result from an increase in the number of osteoblasts, either by the formation of new osteoblasts from bone lining cells [44] or an increase in proliferation of mature osteoblasts [45].

Of the ligands tested here, PGE2 is the only one that induces a rise in cAMP level. Melatonin has been shown to increase ALP expression of hMSCs in osteogenic medium, but not via the PKA pathway [32]. Other hormones, such as calcitonin and CGRP are expressed in various human osteoblastic cell lines and overexpression of these hormones resulted in increased trabecular mass [37] and prevented apoptosis of osteocytes and osteoblasts [36]. Little is known however about their effects on hMSCs. While stimulators of the PKA pathway such as forskolin, cholera toxin and db-cAMP have a positive effect on osteogenic differentiation, PGE2, the only ligand that affects cAMP levels, inhibits mineralization. This opposing effect could be explained by variations in concentration and/or stability of intracellular cAMP resulting from the different treatment compounds. So, we hypothesized that either the concentration and/or the treatment scheme are critical factors in cell fate decision. Treatment with forskolin, 
cholera toxin or PGE2 resulted in 1000, 3000 and $3000 \mathrm{fmol}$ intracellular cAMP/well respectively and treatment with low concentrations of db-cAMP or 8-bromo-cAMP did not have an effect on ALP expression [our own unpublished data], indicating that cAMP concentration does not explain the different effects of PGE2 and the other compounds. GPCR signaling is a tightly controlled process and once the required amount of signal is transduced, the cells have a feedback mechanism to internalize the receptors to stop surplus signaling [46]. In rat calvaria cells, it was shown that PGE2 increases cAMP levels, which quickly return to basal level within 40 minutes after treatment, whereas with forskolin, $70 \%$ of the maximum level is still present 60 minutes after treatment [47]. In the same study, it was shown that PGE2, but not forskolin, activates phosphodiesterases to degrade newly formed cAMP, and that the stimulatory effect of PGE2 on osteoblast differentiation is probably mediated by $\mathrm{Ca}^{2+} /$ Calmodulin [47]. In this study we showed that intermittent elevations in cAMP levels lead to a decrease in ALP expression. It is possible that PGE2 treatment results in intermittent cAMP elevations, thus negatively affecting osteogenesis, but the effect of PGE2 could also be mediated via another pathway.

In another study with rat calvarial cells, continuous treatment with high concentrations and intermittent treatment with either high or low dosages of forskolin inhibited formation of bone nodules, whereas continuous treatment with low dosages increased bone nodules [48]. For a positive effect on osteogenesis, a continuous rise in cAMP level is thus required, whereas intermittent elevations in cAMP level have an inhibitory effect. We thought of two possible explanations for this. Firstly, there could be a difference in degradation rate of cAMP-induced genes. Our microarray data has shown that a number of genes, both inhibiting and stimulating osteogenesis, are directly upregulated by db-cAMP treatment [20]. If certain inhibitory genes are more stable than stimulatory genes, it is likely that, when cAMP is removed and no more stimulatory genes are expressed, the inhibitory genes will negatively regulate bone formation. Secondly, research using fluorescently-labeled PKA has shown that intermittent elevations of cAMP levels are not sufficient to induce nuclear entry of PKA, whereas both intermittent and continuous elevations of cAMP levels, as induced by inhibition of phosphodiesterases, caused elevations in $\mathrm{Ca}^{2+}$ levels [49]. Although the precise effect of this second messenger in hMSCs remains elusive, it shows that intermittent and continuous treatment lead to quantitative differences downstream. Furthermore, it indicates that other, possibly inhibitory, pathways might be activated during GPCR signaling. Intermittent treatment of cells might thus be sufficient to activate inhibitory signaling, whereas continuous treatment results in a dominant, positive effect of PKA. We are currently investigating these hypotheses.

The observations we describe here indicate a dual role for cAMP/PKA in the delicate balance of cell fate decision. Continuous elevations in cAMP levels enhance osteogenic 
differentiation, whereas intermittent elevations inhibit osteogenesis in vitro. There seems to be an inverse relationship between osteogenesis and adipogenesis [50] and cAMP/PKA signaling might play a role in this decision. Recent findings in other studies point to an even more complicated role of cAMP/PKA signaling, involving an interaction with dexamethasone. PGE2 has recently been shown to inhibit osteogenic differentiation of hMSCs and to induce adipogenesis in combination with $10^{-7} \mathrm{M}$ dexamethasone [51]. In the same study, a positive effect on adipogenesis was observed after treatment with $0.5 \mathrm{mM} \mathrm{db}$-cAMP and $10^{-7} \mathrm{M}$ dexamethasone [51]. In addition, enhanced adipogenic differentiation of hMSCs after treatment with other PKA stimulators, such as forskolin, IBMX or Sp-cAMP [52] and $10^{-7} \mathrm{M}$ dexamethasone has been reported. These studies have in common that a concentration of $10^{-7} \mathrm{M}$ dexamethasone was used. Dexamethasone is commonly used in high concentrations in adipogenic medium, but it is also known to enhance osteogenic differentiation in low concentrations $\left(10^{-8} \mathrm{M}\right)$. To direct hMSCs more towards the osteogenic lineage, it would be very interesting to look in closer detail at the effect of various concentrations of dexamethasone and either intermittent or continuous activation of the cAMP/PKA pathway.

An interaction between dexamethasone and cAMP/PKA is further supported by the fact that dexamethasone itself does not have an effect on intracellular cAMP production, but it does have a synergistic effect on the induction of cAMP in combination with cholera toxin, PGE2 and forskolin. It seems as if dexamethasone sensitizes the cells for responsiveness to these compounds, a phenomena which was already described by Rodan et al. [53], who suggested that dexamethasone increases the number of receptors and the abundance of Gs in ROS 17/2.8 cells. It has been shown that when forskolin binds $\mathrm{Gs}_{\alpha}$, the activity of adenylate cyclase doubles, as compared to the effect of either forskolin or $\mathrm{Gs}_{\alpha}$ alone [54]. Since cholera toxin directly activates $\mathrm{Gs}_{\alpha^{\prime}}$, an increase in this stimulatory protein may cause a synergistic effect on cAMP production, in combination with either forskolin or cholera toxin. Synergism between dexamethasone and PGE2 as well as forskolin have also been described in the human osteoblast-derived SV-HFO cell line, where both compounds together induced an increase in aromatase expression, whereas PGE2 or forskolin alone did not have an effect $[55,56]$. The authors suggested that the upregulation of aromatase by PGE2 and dexamethasone was mediated via the cAMP/PKA pathway, but also via the PKC pathway. Another study showed an upregulation of IGF-1 mRNA expression by PGE2 and forskolin after pre-treating the cells with dexamethasone, whereas co-treatment with dexamethasone and either of the compounds had the same effect as treatment with PGE2 or forskolin alone [56, 57]. Treatment with dexamethasone increased the expression of $C / E B P \beta$ and C/EBP $\delta$, but treatment with PGE2 was required to form active DNA binding complexes and to upregulate IGF-1 expression. Dexamethasone does thus not seem to have a direct effect on the cAMP/PKA pathway, but increases the abundance of receptors, proteins 
and transcription factors which then still have to be activated by appropriate signaling molecules.

As shown before, we show here the positive effect of continuous treatment with $\mathrm{db}$-cAMP on osteogenic differentiation of hMSCs. One of the main advantages of the use of small molecules over the use of growth factors such as BMP-2 is that these growth factors have to be used in high non-physiological concentrations which makes their use very expensive. These high concentrations could potentially induce bone formation outside the defect area, which in some areas is no problem, but in case of spinal fusion for example can result in decreased mobility. In the case of db-cAMP, the cells are treated prior to in vivo implantation, which eliminates any chance of harm to the patient. Furthermore we conclude here that hMSCs are a very interesting and valuable biological model to study the effect of signaling molecules on cell fate decision. Differential responses to growth factor treatment in different species and cell lines have been shown before, and primary cells are therefore a better model to investigate. Once again, it becomes clear that cell fate decision is a very complex process, depending both on the treatment scheme (as shown by the contrast between continuous/intermittent cAMP treatment) and the concentration (as shown by the effect of high and low concentrations of dexamethasone). Also from a clinical point of view, it would be very interesting to get a better understanding of the cues driving cells towards osteogenic or adipogenic differentiation. Of course for bone tissue engineering applications, for which improved osteogenic differentiation in vitro is likely to result in more bone formation in vivo, but also for diseases such as osteoporosis and osteopenia, where bone density is reduced and fatty marrow tends to increase $[58,59]$. Reversing this process could be of help in the treatment of these diseases.

\section{Acknowledgments}

We thank Dr. L. Creemers and Dr. W. Dhert (University Medical Center Utrecht) and Dr. A. Renard (Medisch Spectrum Twente, Enschede, The Netherlands) for kindly providing us with bone marrow aspirates. The work was supported by grants from The Netherlands Ministry of Economic Affairs (SenterNovem; to R.S. and J.d.B.). 


\section{References}

1. Dezawa M, Ishikawa H, Itokazu Y, Yoshihara T, et al. (2005) Science 309, 314-317

2. Pittenger MF, Mackay AM, Beck SC, Jaiswal RK, et al. (1999) Science 284, 143-147

3. Kratchmarova I, Blagoev B, Haack-Sorensen M, Kassem M, et al. (2005) Science 308, 14721477

4. Boland GM, Perkins G, Hall DJ, Tuan RS. (2004) J Cell Biochem 93, 1210-1230

5. McBeath R, Pirone DM, Nelson CM, Bhadriraju K, et al. (2004) Dev Cell 6, 483-495

6. Simonsen JL, Rosada C, Serakinci N, Justesen J, et al. (2002) Nat Biotechnol 20, 592-596

7. Shi S, Gronthos, S., Chen, S., Reddi, A., Counter, C. M., Robey, P. G., \& Wang, C. Y. (2002) Nature biotechnology 20, 587-591

8. Cowan CM, Shi YY, Aalami 00, Chou YF, et al. (2004) Nature biotechnology 22, 560-567

9. D'Ippolito G, Schiller PC, Ricordi C, Roos BA, et al. (1999) J Bone Miner Res 14, 1115-1122

10. Jaiswal N, Haynesworth SE, Caplan AI, Bruder SP. (1997) Journal of cellular biochemistry 64, 295-312

11. de Bruijn JD, van den Brink I, Mendes S, Dekker R, et al. (1999) Adv Dent Res 13, 74-81

12. Haynesworth SE, Goshima, I., Goldberg, V.M., Caplan, A.I. (1992) Bone 13, 81-88

13. Both SK, Muijsenberg AJ, Blitterswijk CA, Boer JD, et al. (2006) Tissue Eng,

14. Meijer GJ, de Bruijn JD, Koole R, van Blitterswijk CA. (2007) PLoS Med 4, e9

15. Mendes SC, Tibbe JM, Veenhof M, Both S, et al. (2004) J Mater Sci Mater Med 15, 1123-1128

16. Mendes SC, Tibbe JM, Veenhof M, Bakker K, et al. (2002) Tissue Eng 8, 911-920

17. de Boer J, Siddappa R, Gaspar C, van Apeldoorn A, et al. (2004) Bone 34, 818-826

18. De Boer J, Licht R, Bongers M, Van Der Klundert T, et al. (2006) Tissue Engineering 12, 29272937

19. de Boer J, Wang HJ, van Blitterswijk C. (2004) Tissue Eng 10, 393-401

20. Siddappa R, Martens A, Doorn J, Leusink A, et al. (2008) Proceedings of the National Academy of Sciences 105, 7281-7286

21. Miao D, He B, Karaplis AC, Goltzman D. (2002) The Journal of clinical investigation 109, 11731182

22. Karaplis AC, Luz A, Glowacki J, Bronson RT, et al. (1994) Genes \& development 8, 277-289

23. Brommage R, Hotchkiss CE, Lees CJ, Stancill MW, et al. (1999) The Journal of clinical endocrinology and metabolism 84, 3757-3763

24. Schiller PC, D'Ippolito G, Roos BA, Howard GA. (1999) J Bone Miner Res 14, 1504-1512

25. Tyson DR, Swarthout JT, Jefcoat SC, Partridge NC. (2002) Endocrinology 143, 674-682

26. Clohisy JC, Scott DK, Brakenhoff KD, Quinn CO, et al. (1992) Molecular endocrinology (Baltimore, Md 6, 1834-1842

27. Koe RC, Clohisy JC, Tyson DR, Pulumati MR, et al. (1997) Calcified tissue international 61, 5258

28. McCauley LK, Koh-Paige AJ, Chen H, Chen C, et al. (2001) Endocrinology 142, 1975-1981 
29. Carpio L, Gladu J, Goltzman D, Rabbani SA. (2001) American journal of physiology 281, E489499

30. Rickard DJ, Wang FL, Rodriguez-Rojas AM, Wu Z, et al. (2006) Bone 39, 1361-1372

31. Nakade O, Koyama H, Ariji H, Yajima A, et al. (1999) Journal of pineal research 27, 106-110

32. Radio NM, Doctor JS, Witt-Enderby PA. (2006) Journal of pineal research 40, 332-342

33. Arikawa T, Omura K, Morita I. (2004) Journal of cellular physiology 200, 400-406

34. Burns DM, Stehno-Bittel L, Kawase T. (2004) American journal of physiology 287, C457-467

35. Villa I, Dal Fiume C, Maestroni A, Rubinacci A, et al. (2003) Am J Physiol Endocrinol Metab 284, E627-633

36. Plotkin LI, Weinstein RS, Parfitt AM, Roberson PK, et al. (1999) J Clin Invest 104, 1363-1374

37. Ballica R, Valentijn K, Khachatryan A, Guerder S, et al. (1999) J Bone Miner Res 14, 1067-1074

38. Drissi H, Hott M, Marie PJ, Lasmoles F. (1997) J Bone Miner Res 12, 1805-1814

39. Urena P, Iida-Klein A, Kong XF, Juppner H, et al. (1994) Endocrinology 134, 451-456

40. Lee DH, Park BJ, Lee M-S, Lee JW, et al. (2006) Tissue Engineering 12, 1577-1586

41. Verheijen MH, Defize, L.H. (1995) Endocrinology 136, 3331-3337

42. Diefenderfer DL, Osyczka AM, Reilly GC, Leboy PS. (2003) Connect Tissue Res 44 Suppl 1, 305 311

43. Siddappa R, Fernandes H, Liu J, van Blitterswijk C, et al. (2007) Current stem cell research \& therapy 2, 209-220

44. Dobnig H, Turner RT. (1995) Endocrinology 136, 3632-3638

45. Swarthout JT, Doggett TA, Lemker JL, Partridge NC. (2001) J Biol Chem 276, 7586-7592

46. Haasen D, Schnapp A, Valler MJ, Heilker R. (2006) Methods Enzymol 414, 121-139

47. Kaneki H, Takasugi, I., Fujieda, M., Kiriu, M., Mizuochi, S., Ide, H. (1999) Journal of cellular biochemistry 73, 36-48

48. Turksen K, Grigoriadis AE, Heersche JN, Aubin JE. (1990) Journal of cellular physiology 142, 61-69

49. Dyachok O, Sågetorp, J., Isakov, Y., Tengholm, A. (2006) Biochemical Society transactions 34, 498-501

50. Beresford JN, Bennett JH, Devlin C, Leboy PS, et al. (1992) Journal of cell science 102 ( Pt 2), 341-351

51. Zhao Y, Ding S. (2007) Proceedings of the National Academy of Sciences of the United States of America 104, 9673-9678

52. Yang DC, Tsay HJ, Lin SY, Chiou SH, et al. (2008) PLoS ONE 3, e1540

53. Rodan SB, Rodan, G.A. (1986) Endocrinology 118, 2510-2518

54. Mittag TW, Tormay, A. (1993) Experimental eye research 57, 13-19

55. Watanabe M, Ohno, S., Nakajin, S. (2005) European Journal of Endocrinology 152, 619-624

56. Watanabe M, Nodaa, M., Nakajin, S. (2007) Steroids 72, 686-692

57. McCarthy TL, Ji, C., Chen, Y., Kim, K., Centrella, M. (2000) Endocrinology 141, 127-137

58. Meunier P, Aaron, J., Edouard, C., Vignon, G. (1971) Clin Orthop Relat Res 80, 147-154

59. Minaire P, Edouard, C., Arlot, M., Meunier, P.J. (1984) Calcified tissue international 36, 338-340 


\title{
CHAPTER 5.
}

\section{PKA balances osteogenic and adipogenic differentiation of human mesenchymal stromal cells}

\author{
Joyce Doorn ${ }^{1}$ \\ Maarten Leusink' \\ Nathalie Groen ${ }^{1}$ \\ Jeroen van de Peppel $^{2}$ \\ Hans van Leeuwen ${ }^{2}$ \\ Clemens van Blitterswijk \\ Jan de Boer ${ }^{1}$ \\ ${ }^{1}$ Department of Tissue Regeneration, MIRA Institute for Biomedical Technology and \\ Technical Medicine, University of Twente, Enschede 7500 AE, The Netherlands. \\ ${ }^{2}$ Erasmus MC, Department of Internal Medicine, Dr. Molenwaterplein 50, 3015 GE, \\ Rotterdam, The Netherlands.
}

Two things are infinite: the universe and human stupidity; and I'm not sure about the the universe.

- Albert Einstein 


\begin{abstract}
Osteogenic differentiation of human mesenchymal stromal cells (hMSCs) may potentially be used in cell based bone tissue engineering applications to enhance the bone forming potential of these cells. Osteogenic and adipogenic differentiation are thought to be mutually exclusive and, although several signaling pathways and cues that induce osteogenic or adipogenic differentiation respectively have been identified, there is no general consensus on how to optimally differentiate hMSCs into the osteogenic lineage. Some pathways have also been reported to be involved in both adipogenic and osteogenic differentiation, as for example the protein kinase A (PKA) pathway. Here we show that activation of this pathway with dibutyryl-cAMP results in enhanced osteogenesis whereas another cAMP analogue induces adipogenesis in long-term mineralization cultures. Adipogenic differentiation, induced by 8-bromo-cAMP, was accompanied by stronger PKA activity and higher expression of cAMP-responsive genes. Furthermore, we show differences in PPAR $\gamma$ activation, either alone, or in combination with dexamethasone, thus demonstrating differential effects of the PKA pathway, most likely depending on its mode of activation.
\end{abstract}




\section{Introduction}

Human mesenchymal stromal cells (hMSCs) are a good source for bone tissue engineering applications. They are relatively easy to isolate, can be expanded in vitro and can be differentiated into osteoblasts, chondrocytes, adipocytes [1], but also into neuron-like cells [2,3], endothelial-like cells [4,5] and myocytes [6, 7]. Differentiation of hMSCs in vitro towards the osteogenic lineage can be induced with various stimuli and may also promote in vivo bone formation [8,9]. Osteogenic differentiation on the one hand and adipogenic on the other are thought to be mutually exclusive, as stimuli that induce osteogenic differentiation inhibit adipogenic differentiation $[10,11]$ and vice versa [12]. This observation is not only important for bone tissue engineering applications, but also for the maintenance of normal bone homeostasis, where the decline in osteoblasts and the associated increase in adipocytes with aging is thought to underlie the fattening of the bone marrow and is seen as the main cause of osteoporosis [13]. Similarly, it was found that chemotherapy, resulting in bone defects as a side effect, induces a shift in the bone marrow stem cell population towards a more adipogenic genotype with higher capacity to differentiate into adipocytes [14].

Both osteogenesis and adipogenesis are induced and regulated by a number of pathways and transcription factors. Whereas osteogenesis is regulated by runt-related transcription factor-2 (runx-2) and osterix (osx) [15], adipogenesis is controlled by peroxisome proliferator activated receptor- $\gamma$ (PPAR $\gamma$ ) [16]. Although there is suggested to be an inverse relation between adipogenic and osteogenic differentiation of hMSCs, various pathways, activated by external stimuli that induce differentiation seem to play dual roles. For example, there are indications that BMP signaling, one of the main inducers of osteogenic differentiation in hMSCs, is also involved in adipogenic differentiation, depending on the dose and type of receptor activated [17].

Several studies have demonstrated the involvement of the cAMP/protein kinase A (PKA) pathway in osteogenesis of different cell types. In MG-63 cells, it was demonstrated that high glucose levels inhibit osteogenic differentiation, via increased levels of intracellular cAMP and phosphorylated ERK 1/2 [18]. GPCR ligands such as melatonin, prostaglandin E2 (PGE2) and PTH were demonstrated to increase osteogenic differentiation of MC3T3 cells, rat osteoblast-like osteosarcoma cells [19], calvaria osteoblast-like cells [20] and human osteoblasts [21] in vitro and PKA was shown to activate Runx2 in the rat osteosarcoma cell line UMR 106-01 [22] as well as the osteocalcin promoter in human osteoblast-like cell lines via cAMP and forskolin [23]. In contrast, numerous studies have implicated this pathway in adipogenic differentiation. For example, Zhao et al. performed an siRNA screen on hMSCs and found that knockdown of GNAS, encoding the G protein $\alpha$-subunit (Gs $\alpha$ ), enhanced osteogenic differentiation. They demonstrated that treatment with forskolin inhibits osteogenic differentiation and 
treatment with dibutyryl-cAMP (db-cAMP), in combination with high concentrations of dexamethasone $\left(10^{-7} \mathrm{M}\right)$, enhanced adipogenic differentiation [24]. Similarly, Yang et al. demonstrated enhanced adipogenesis and adipogenic gene expression upon addition of PKA stimulators to MSCs in adipogenic induction medium [25]. In contrast, in our lab we have demonstrated that the same compound in the absence of dexamethasone can enhance osteogenic differentiation in vitro as well as improve the in vivo bone formation capacity of these cells [8]. In addition, we showed that intermittent exposure of hMSCs to db-cAMP decreased ALP expression, which points to a more complicated role for the cAMP/PKA pathway in the balance between osteogenic and adipogenic differentiation [26].

Here, we took two different cAMP analogues (db-cAMP and 8-bromo-cAMP (8-brcAMP)), investigated their effects on short- and long-term cultures of hMSCs and examined their downstream activation patterns to investigate the role of PKA in osteogenic versus adipogenic differentiation in more detail.

\section{Materials and methods}

\section{Isolation and culture of hMSCs}

Bone marrow aspirates were obtained from donors with written informed consent. Human mesenchymal stromal cells (hMSCs) were isolated and proliferated as described previously [27]. Briefly, aspirates were resuspended using 20G needles, plated at a density of $5 \times 10^{5}$ cells $/ \mathrm{cm}^{2}$ and cultured in hMSC proliferation medium, consisting of $\alpha$-minimal essential medium ( $\alpha$-MEM, Life Technologies), 10\% fetal bovine serum (FBS, Cambrex Bio sciences, Verviers), $0.2 \mathrm{mM}$ ascorbic acid 2-phosphate (ASAP, Sigma Aldrich), $2 \mathrm{mM}$ L-glutamine (Invitrogen, Life Technologies), $100 \mathrm{U} / \mathrm{ml}$ penicillin (Life Technologies), $10 \mu \mathrm{g} / \mathrm{mL}$ streptomyocin (Life Technologies) and $1 \mathrm{ng} / \mathrm{mL}$ basic fibroblast growth factor (bFGF, Instruchemie, The Netherlands). Cells were grown at 37 ${ }^{\circ} \mathrm{C}$, in a humid atmosphere with $5 \% \mathrm{CO}_{2}$. Medium was refreshed twice a week and cells were used for further subculturing or cryopreservation upon reaching near confluence. hMSC basic medium was composed of proliferation medium without bFGF, osteogenic medium was composed of basic medium supplemented with $10^{-8} \mathrm{M}$ dexamethasone (Sigma), and mineralization medium was composed of basic medium supplemented with $10^{-8} \mathrm{M}$ dexamethasone and $0.01 \mathrm{M} \beta$-glycerophosphate (BGP, Sigma Aldrich). Adipogenic medium was composed of DMEM (Life Technologies), 10\% FBS, $0.5 \mathrm{mM}$ isobutyl-methylxanthine (IBMX, Sigma), $1 \mu \mathrm{M}$ dexamethasone, $10 \mu \mathrm{M}$ insulin (Sigma) and $200 \mu \mathrm{M}$ indomethacin (Sigma). 


\section{Alkaline phosphatase (ALP) expression}

To assess ALP expression, hMSCs were seeded in triplicate at 5000 cells $/ \mathrm{cm}^{2}$ in 6-well plates. Cells were kept overnight in proliferation medium to attach, after which the medium was replaced with basic medium or basic medium supplemented with $1 \mathrm{mM}$ db-cAMP or 8-br-cAMP (both from Sigma, stock solutions $20 \mathrm{mM}$ in water). As a negative control cells were cultured in basic medium. After 5 days, cells were trypsinized (0.25\% Trypsin, Invitrogen life technologies) and $1 \mathrm{~mL}$ of blocking buffer (PBS with $5 \%$ bovine serum albumin (BSA, Sigma) and $0.1 \%$ sodium azide (Sigma)) was added and incubated for 30 minutes to prevent a-specific binding. After centrifugation and removal of the supernatant, cells were incubated with $50 \mu \mathrm{l}$ of primary antibody (anti-ALP, B4-78 (Developmental Studies Hybridoma Bank, University of Iowa, USA)), diluted 1:50 in wash buffer (PBS with 1\% BSA and 0.05\% sodium azide) for 1 hour. For each condition, part of the cells was used for the isotype control to determine a-specific binding. These cells were incubated with IgG-1 (BD bioscience, diluted 1:50 in wash buffer), a randomly binding antibody. Subsequently, cells were washed twice with 500 $\mu \mathrm{l}$ of wash buffer. Next, $100 \mu \mathrm{l}$ of secondary antibody (Rat-anti-mouse IgG1-PE (BD bioscience), diluted 1:100 in wash buffer) was added. After incubation for 30 minutes, cells were washed again 3 times. $10 \mu \mathrm{l}$ of Viaprobe (Pharmingen) was added for live/ dead staining, and ALP expression was determined using a FACS Calibur measuring 10,000 events (Becton Dickinson, Immunocytometer systems). FACS data was analysed using CellQuest software. Cells with the right size (forward scatter) and granularity (side scatter) were gated and debris and dead cells were excluded from analysis. The percentage of ALP positive cells was determined, with a minimum of 7500 gated events. Experiments were repeated with cells from five different donors.

\section{Gene expression analysis}

hMSCs were seeded in triplicate at 5000 cells $/ \mathrm{cm}^{2}$ in 6 -well plates and kept overnight in proliferation medium to attach. Then the medium was replaced with basic medium containing $1 \mathrm{mM}$ db-cAMP or 8-br-cAMP. Cells were lysed for RNA isolation after 3, 5 or 10 days. For dexamethasone experiments, either db-cAMP or 8-br-cAMP, in combination with various concentrations of dexamethasone $\left(10^{-8} \mathrm{M}, 10^{-7} \mathrm{M}\right.$ or $\left.10^{-6} \mathrm{M}\right)$, was added. As a control, cells were cultured in basic medium. After 5 days, RNA was isolated using a Bioke RNA II nucleospin RNA isolation kit (Machery Nagel) and RNA concentrations

Table 1. Primer sequences

\begin{tabular}{lll}
\hline Gene & Forward primer & Reverse primer \\
\hline $18 \mathrm{~s}$ & CGGCTACCACATCCAAGGAA & GCTGGAATTACCGCGGCT \\
runx2 & ATGGCGGGTAACGATGAAAAT & ACGGCGGGGAAGACTGTGC \\
PPAR $\gamma$ & GATGTCTCATAATGCCATCAGGTT & GGATTCAGCTGGTCGATATCACT \\
\hline
\end{tabular}


were measured using an ND100 spectrophotometer (Nanodrop technologies, USA). cDNA was synthesized from 250 ng of RNA, using iScript (BioRad) according to the manufacturer's protocol. For quantitative PCR, a master mix containing distilled water, forward primer, reverse primer (Sigma Genosys), BSA, and SYBR green I mix (all from Invitrogen) was prepared and real-time qPCR was performed using a Light-Cycler (Roche). Light-Cycler data was analyzed using the fit points method of Light-Cycler software. The baseline was set at the lower log-linear part above baseline noise and the crossing temperature (Ct value) was determined. Ct values were normalized to the $18 \mathrm{~S}$ housekeeping gene and $\Delta \mathrm{Ct}\left(\mathrm{Ct}_{\text {control }}-\mathrm{Ct}_{\text {sample }}\right)$ was used to calculate the upregulation in gene expression [28]. Primer sequences are listed in table 1.

\section{Mineralization / adipogenesis}

hMSCs were seeded at 5000 cells $/ \mathrm{cm}^{2}$ in 12 -well plates in triplicate and kept in proliferation medium overnight to attach to the surface. Then the medium was replaced with mineralization medium (low dexamethasone; $10^{-8} \mathrm{M}$ dexamethasone) or mineralization medium with a high concentration of dexamethasone $\left(10^{-6}\right.$ $\mathrm{M}$ ), with or without $1 \mathrm{mM}$ db-cAMP or 8-br-cAMP (only during the first 5 days). As controls, cells were cultured in basic medium supplemented with BGP or in adipogenic medium. After 5 days the medium was replaced with fresh medium, but without cAMP analogues. After 28 days, the medium was removed, and cells were washed with PBS twice. $0.5 \mathrm{~mL}$ of $0.5 \mathrm{~N}$ hydrochloric acid was added and incubated for at least 4 hours at room temperature on an orbital shaker. The supernatant was collected, and the amount of calcium was quantitatively determined, using a calcium assay kit (Sigma diagnostics, 587A) according to the manufacturer's protocol. The absorbance was measured using an ELx808 microplate reader (Biotek instruments). As a positive control for adipogenic cultures, $80 \%$ confluent cells were cultured in adipogenic medium. For adipogenic stainings, cells were fixed in formol $(3.7 \%$ formalin plus $1 \mathrm{~g} / 100 \mathrm{~mL} \mathrm{CaCl} 2 \cdot 2 \mathrm{H}_{2} \mathrm{O}$ (Sigma)), rinsed with water and incubated with $60 \%$ isopropanol for 5 minutes. Then cultures were incubated with freshly filtered Oil-Red-O solution (stock solution: $500 \mathrm{mg}$ Oil Red (Sigma), $99 \mathrm{~mL}$ isopropanol, $1 \mathrm{~mL}$ water; working solution: $42 \mathrm{~mL}$ stock $+28 \mathrm{~mL}$ water). For quantification, the stain was extracted by incubating with 4\% Igepal (Sigma) in isopropanol for 15 minutes on an orbital shaker at room temperature. $100 \mu \mathrm{L}$ of the solution was used to measure the absorbance at $520 \mathrm{~nm}$ using an ELx808 microplate reader (Biotek instruments).

\section{PKA activity}

hMSCs were seeded at 5000 cells $/ \mathrm{cm}^{2}$ in 6 -well plates in triplicate and kept in proliferation medium overnight to attach to the surface. The next day, either basic medium, or basic medium supplemented with $1 \mathrm{mM}$ db-cAMP or 8-br-cAMP was added 
and incubated for denoted time periods. Then, cells were lysed and PKA activity was assayed using the nonradioactive PepTag assay (Promega, Madison, WI), according to the manufacturer's protocol. Briefly, cells were pelleted and lysed in extraction buffer (20 mM Tris (Sigma), pH 7.5, 5.5 mM EDTA (Sigma), 1 mM PMSF (Roche) and $10 \mathrm{mg} / \mathrm{mL}$ aprotinin (Roche)). A reaction mixture containing lysate, the PKA specific peptide substrate Peptag A1 (Kemptide), water and peptide protection solution was prepared, which was incubated for 2 minutes at $30{ }^{\circ} \mathrm{C}$ and subsequently for 30 minutes at RT. The reaction was stopped by heat-treatment at $95{ }^{\circ} \mathrm{C}$ for 10 minutes, after which phosphorylated and unphosphorylated Peptag peptides were separated by gel electrophoresis. Bands were excised, solubilized in gel solubilization solution and the amount of peptide was quantified by measuring the fluorescence intensity of the solution with the excitation wavelength set at $540 \mathrm{~nm}$ and the emission wavelength set at $592 \mathrm{~nm}$ (Tecan). Liquefied agarose was used as a blank and data is expressed relative to the PKA activity in basic medium.

\section{Whole genome expression analysis}

hMSCs were seeded in 12-well plates at 5000 cells $/ \mathrm{cm}^{2}$ and allowed to attach for 1015 hours in proliferation medium. The next day, either basic medium or basic medium supplemented with $1 \mathrm{mM}$ db-cAMP or 8-br-cAMP was added. After 6 or 72 hours of treatment, cells were lysed directly from the plate and RNA was isolated as described above. Then, from 500 ng of RNA, cRNA was synthesized using the Illumina TotalPrep RNA amplification Kit, according to the manufacturer's protocol and RNA and cRNA quality were verified on a Bioanalyzer 2100 (Agilent). Microarrays were performed using Illumina HT-12 v3 expression Beadchips, according to the manufacturer's protocol. Briefly, $750 \mathrm{ng}$ of cRNA was hybridized on the array overnight after which the array was washed and blocked. Then, by addition of streptavidin Cy-3 a fluorescent signal was developed. Arrays were scanned on an Illumina iScan and raw intensity values were background corrected in Genomestudio (Illumina). Further data processing and statistical testing were performed using $\mathrm{R}$ and Bioconductor statistical software (http://www.bioconductor.org/). The probe-level raw intensity values were quantile normalized and transformed using variance stabilization (VSN). A linear modelling approach with empirical Bayesian methods, as implemented in Limma package [29], was applied for differential expression analysis of the resulting probe-level expression values. P-values were corrected for multiple testing using the Benjamini and Hochberg method [30] and differentially expressed genes were ranked on log2 fold change values.

\section{Statistics}

All experiments were performed in triplicates. Data were analyzed in SPSS (PASW statistics) using one-way Anova followed by Tukey's multiple comparison test $(\mathrm{P}<0.05)$. 


\section{Results}

\section{db-cAMP induces ALP expression to a higher extent than 8-br-cAMP}

To investigate the effect of both cAMP-analogues on osteogenic differentiation, we examined expression levels of the early osteogenic marker alkaline phosphatase (ALP), in hMSCs from 5 different donors after treatment with these compounds. As demonstrated before, db-cAMP increases the expression of this marker by approximately 2 - to 3 -fold, whereas 8-br-cAMP does induce ALP expression in some donors, but always to a lower extent than db-cAMP, as depicted in figure $1 \mathrm{a}$.

\section{8-br-cAMP induces adipogenic differentiation}

To investigate the effects of 8-br-cAMP on differentiation of hMSCs in more detail, a long-term culture assay was performed. hMSCs were cultured in mineralization medium supplemented with either of the two cAMP-analogues for 5 days, after which the cells were kept in mineralization medium for 3 more weeks. In contrast with previous findings, we did not find increased calcium deposition after treatment of hMSCs with $\mathrm{db}$-cAMP in the donor used. As demonstrated before using dexamethasone, hMSCs from different donors vary in their response to osteogenic stimuli [31], which is in line with our findings here. Surprisingly however, addition of 8-br-cAMP to mineralization medium resulted in the formation of lipid droplets (figure 1b), an observation that was
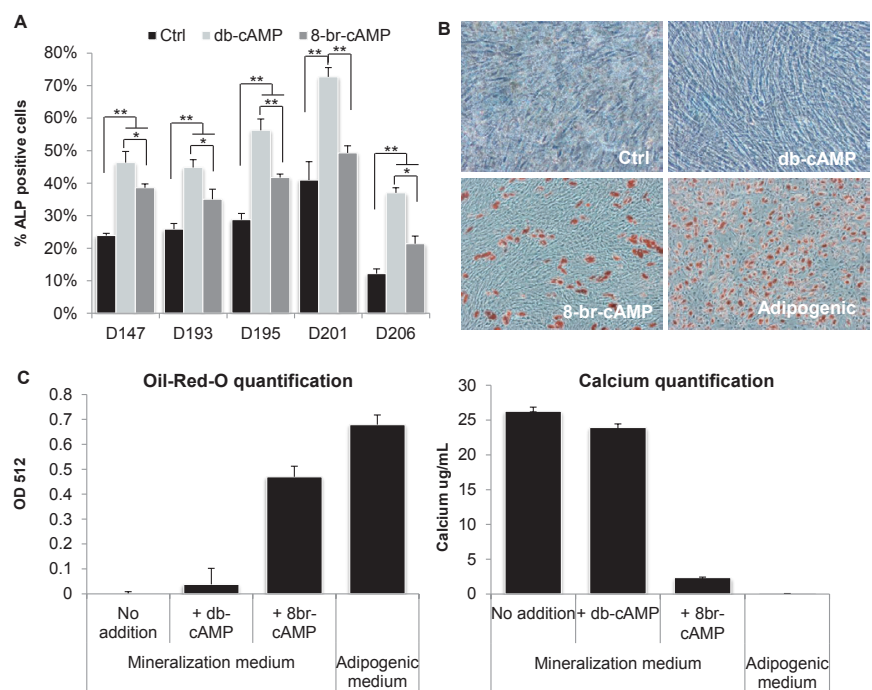

Figure 1. db-cAMP and 8-br-cAMP have distinct effects on differentiation of hMSCs. (a) As demonstrated before, db-cAMP induced ALP expression in hMSCs after 5 days of culture, whereas 8-brcAMP has no, or only slight effects. (b) When hMSCs were cultured in mineralization medium in the presence of db-cAMP, mineralization was not affected, whereas with 8-br-cAMP, the formation of lipid droplets was observed. (c) Quantification of the staining confirmed these observations. D147-D206; Donor numbers in laboratory databank, OD512; optical density at $512 \mathrm{~nm},{ }^{*} \mathrm{P}<0.05,{ }^{* *} \mathrm{P}<0.01$ 

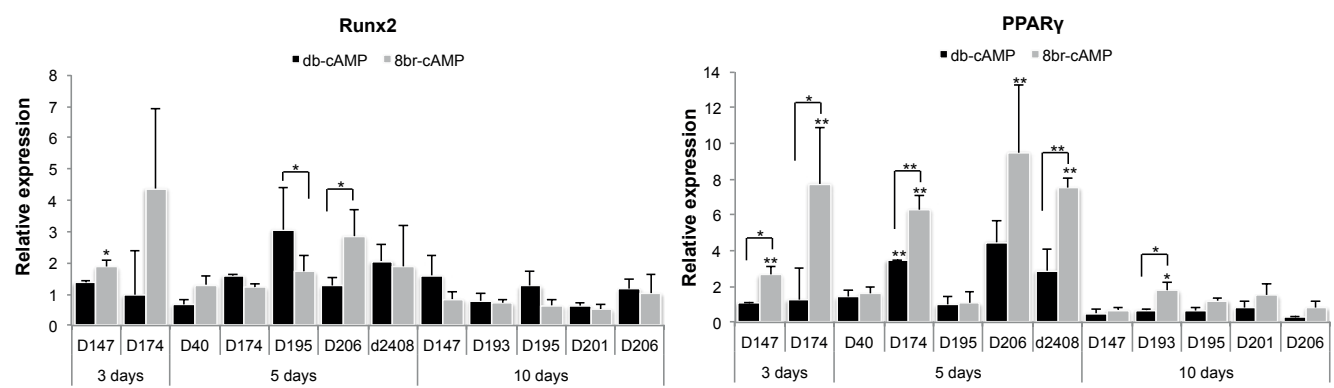

Figure 2. 8-br-cAMP induces expression of PPARy. Treatment of hMSCs with db-and 8-br-cAMP for 3, 5 and 10 days did not result in significant changes in runx2 expression. Expression of PPAR $\gamma$ however, showed a clear trend towards higher expression in 8-br-cAMP-treated cultures. Data is depicted as relative gene expression in either 8-br-cAMP- or db-cAMP-treated cells, relative to cells in basic medium. ${ }^{*} \mathrm{P}<0.05,{ }^{* *} \mathrm{P}<0.01$

confirmed using hMSCs from other donors (data not shown). Staining of lipids with Oilred-O and subsequent quantification showed that treatment with 8-br-cAMP resulted in almost $60 \%$ of the lipid amount in adipogenic control cultures (figure 1c), whereas db-cAMP did not induce any lipid formation. Although lipids and calcium nodules were observed in the same cultures, calcium deposition was severely inhibited by 8-br-cAMPtreatment.

\section{8-br-cAMP induces expression of PPAR}

We then examined the gene expression profile of the two transcription factors controlling osteogenic and adipogenic differentiation, runx 2 and PPAR $\gamma$ respectively, after treatment with both cAMP analogues. Figure 2 shows expression levels of these genes in hMSCs of several donors after 3, 5 and 10 days of treatment. Although for some donors runx2 expression was slightly higher after treatment with 8-br-cAMP, in general there was no difference between the two analogues. For PPAR $\gamma$ however, there was a clear trend towards higher expression in 8-br-cAMP-treated cells, especially during early timepoints, where PPAR $\gamma$ expression was induced by 8-br-cAMP treatment in 5 out of 7 donors. Since dexamethasone is known to have distinct effects on differentiation of hMSCs, depending on its concentration (high or low concentrations induce adipogenic or osteogenic differentiation respectively), we combined 8-br-cAMP treatment with various concentrations of dexamethasone in mineralization medium. As shown in figure $3 \mathrm{a}$, the amounts of lipid droplets gradually increased with increasing concentrations of dexamethasone, with $10^{-6} \mathrm{M}$ resulting in the highest amounts of lipid droplets. In contrast, no lipids were present in the absence of cAMP and hardly any lipids were present in cultures with both db-cAMP and $10^{-6} \mathrm{M}$ dexamethasone. In addition, gene expression profiling of runx2 and PPAR $\gamma$ also demonstrated that, whereas in the absence of dexamethasone neither cAMP analogue affected expression of these genes 
A
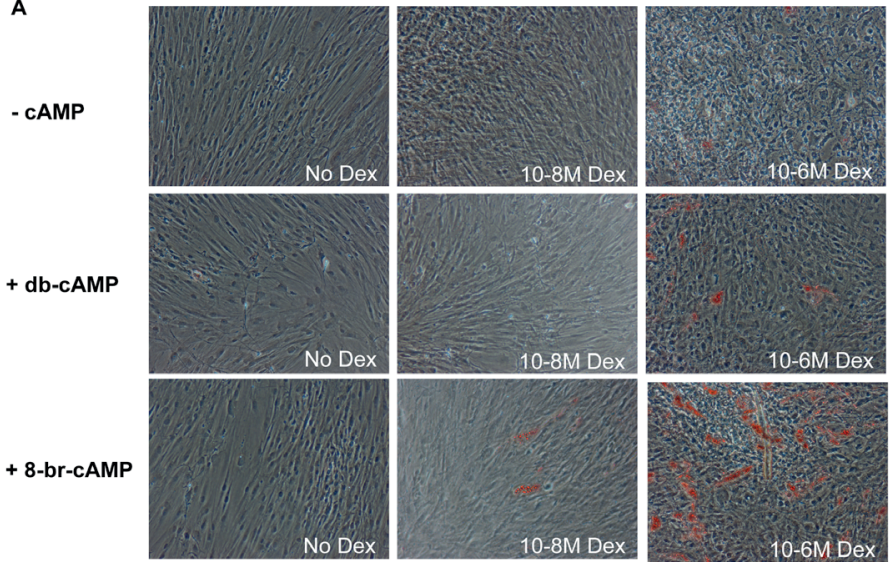

B
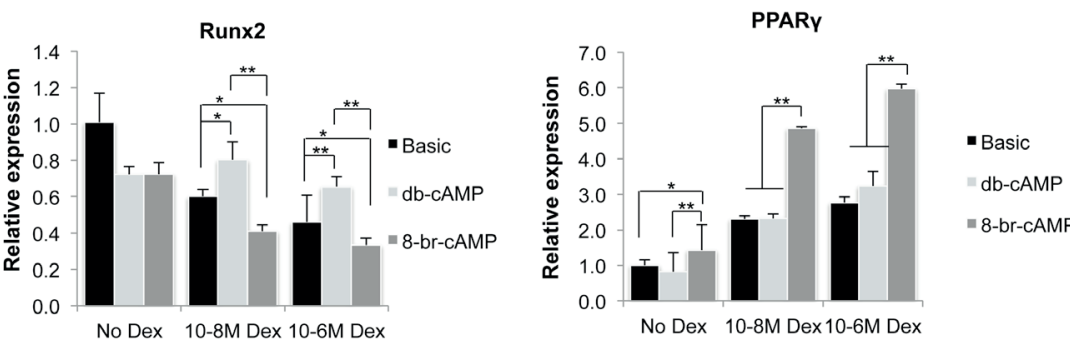

Figure 3. 8-br-cAMP induces adipogenesis synergistically with dexamethasone. (a) Treatment of hMSCs with db-cAMP and 8-br-cAMP in mineralization medium with increasing amounts of dexamethasone demonstrated that, in long-term cultures, the amount of lipid droplets in 8-br-cAMP cultures increases with higher amounts of dexamethasone. (b) In addition, after 5 days of culture, 8-br-cAMP reduced runx2 expression with increasing amounts of dexamethasone, whereas runx2 expression was increased with db-cAMP, compared to basic medium. In contrast, PPAR $\gamma$ expression was significantly increased by treatment with 8-br-cAMP with synergistic effects of dexamethasone. Data is depicted as gene expression in treated cells, relative to cells in basic medium. ${ }^{*} \mathrm{P}<0.05,{ }^{* *} \mathrm{P}<0.01$

(see figure $3 \mathrm{~b}$ ), in the presence of dexamethasone, 8-br-cAMP significantly increased expression of PPAR $\gamma$ compared to db-cAMP. Expression of runx2 was decreased with higher concentrations of dexamethasone, and even further by 8-br-cAMP, but not by db-cAMP.

\section{8-br-cAMP is more potent in activating PKA and cAMP-responsive genes}

To elucidate if both analogues differentially activate downstream targets, we examined PKA activity after 2, 8, 24 and 48 hours of stimulation. Figure 4 a demonstrates that, although there was no difference in activity after 2 hours, after 8, 24 and 48 hours PKA activity was higher after stimulation with 8-br-cAMP, which was significant after 8 and 48 hours. To explore this further, hMSCs were cultured in basic medium or basic medium supplemented with either 8-br-cAMP or db-cAMP for 6 hours, after which we performed whole genome expression profiling. Using the lists of cAMP-responsive 
genes as described by Zhang et al. [32], we examined the expression of cAMP-responsive genes in both db-cAMP- and 8-br-cAMP-treated hMSCs. Figure 4b demonstrates the fold change in expression in either 8-br-cAMP- or db-cAMP-treated cells, relative to cells in basic medium. Of 154 analyzed genes, the expression of 21 genes was increased by treatment with 8-br-cAMP, whereas the expression of 2 genes was decreased. On the other hand, treatment with db-cAMP resulted in increased expression of 13 genes and decreased expression of 9 genes. Interestingly, of the 37 genes with altered expression, 26 showed higher expression in 8-br-cAMP-treated hMSCs, whereas only 11 genes were higher expressed after treatment with db-cAMP. This suggests that 8-br-cAMP more strongly induces transcription of downstream PKA / CREB target genes.

\section{8-br-cAMP induces adipogenic gene expression}

To provide more insight in the different mechanisms of db-cAMP and 8-br-cAMP, we analyzed the global gene expression profile of hMSCs treated with both compounds for either 6 or 72 hours. Figure 5 shows the relative gene expression in 8-br-cAMP cultures,
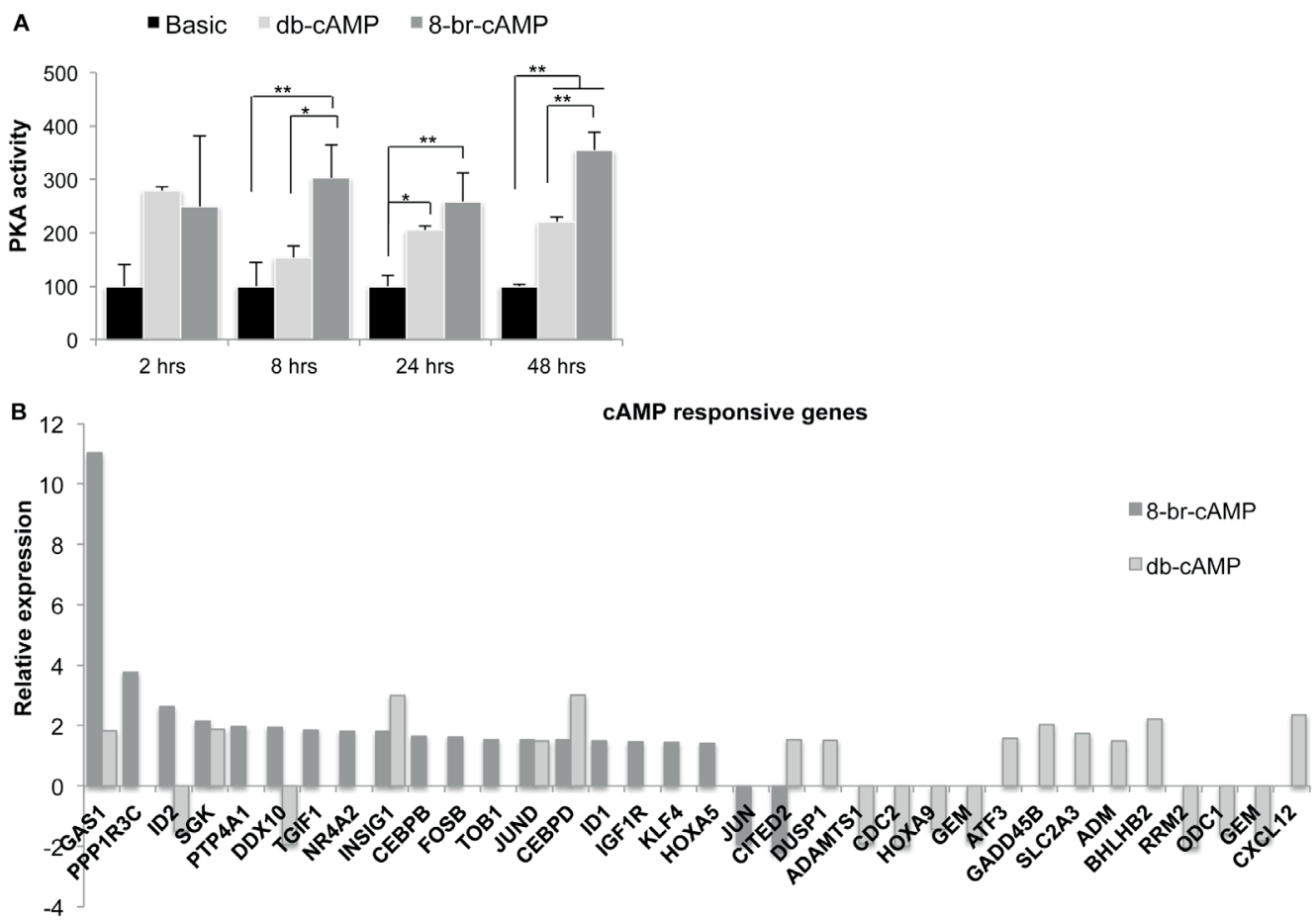

Figure 4. db-cAMP and 8-br-cAMP have distinct activation mechanisms. (a) PKA activity assay after 2, 8, 24 and 48 hours of treatment with both cAMP analogues showed that 8-br-cAMP is a more potent stimulator of PKA. Data is depicted as PKA activity relative to basic medium. (b) Gene expression analysis of cAMP-responsive genes, after 6 hours of treatment with either 8-br-cAMP or db-cAMP showed a trend towards higher expression of cAMP-responsive genes after treatment with 8-br-cAMP. Data is depicted as gene expression in either 8-br-cAMP- or db-cAMP-treated cells relative to cells in basic medium. ${ }^{*} \mathrm{P}<0.05,{ }^{* *} \mathrm{P}<0.01$ 
compared to db-cAMP cultures. In line with our long-term culture experiments, the expression of several adipogenic genes was higher in cells treated with 8-br-cAMP compared to db-cAMP after 6 hours and expression of these genes increased even further after 72 hours. After 6 hours of treatment, expression of several osteogenic genes was also increased in 8-br-cAMP cultures, but after 72 hours, expression of most of these genes had declined and was instead increased in db-cAMP cultures. Functions of these genes are listed in table 2. Also of interest was the large number of Wnt-related genes with differential expression. After 6 hours, positive regulators of Wnt were mainly decreased in 8-br-cAMP cultures, whereas after 72 hours the expression of both stimulators and inhibitors of the Wnt-pathway was higher in 8-br-cAMP cultures, as

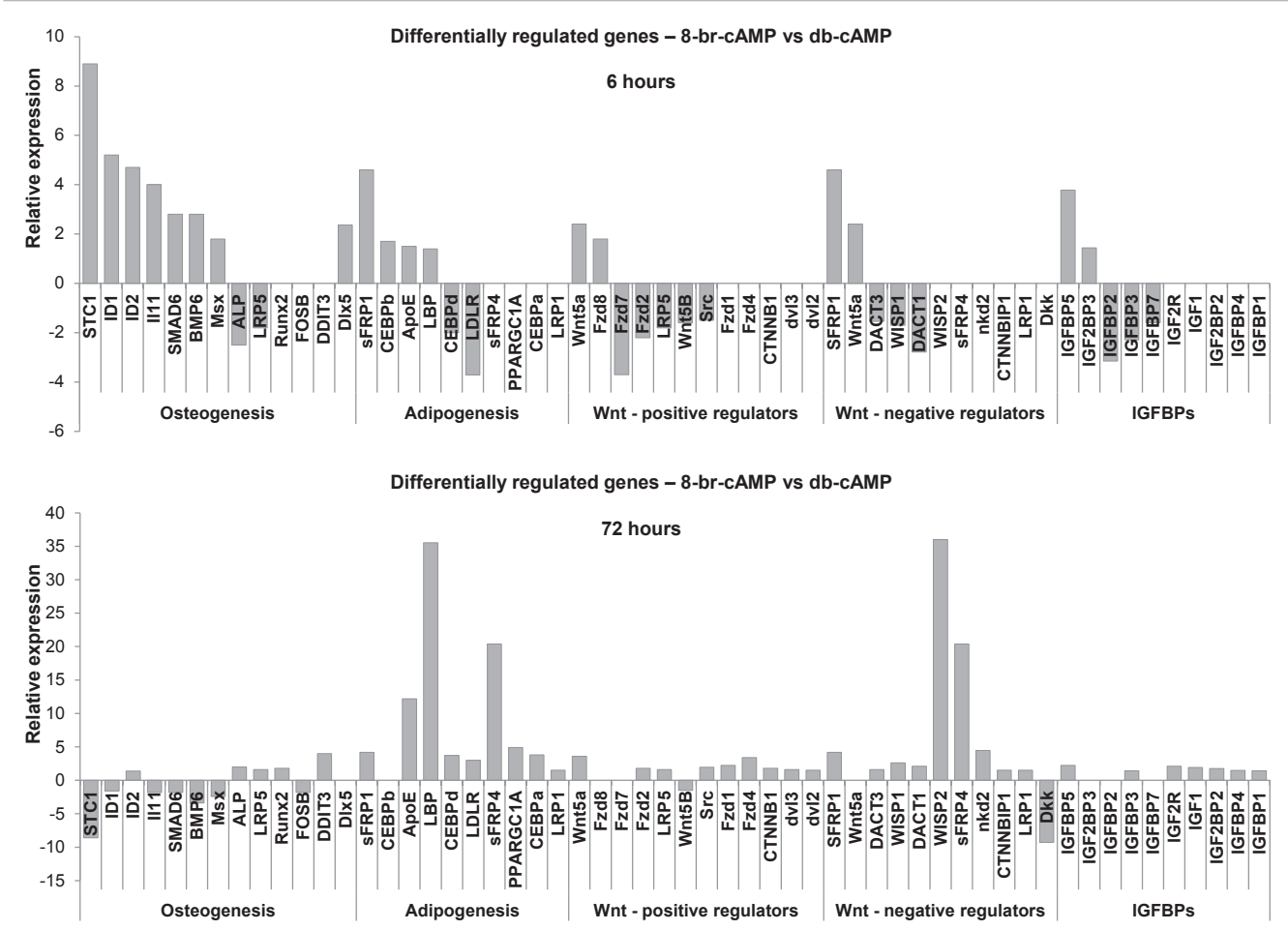

Figure 5. 8-br-cAMP induces adipogenic gene expression. Whole genome expression analysis after 6 and 72 hours of treatment with 8-br-cAMP and db-cAMP. After 6 hours, expression of several adipogenic genes was increased in 8-br-cAMP-treated cultures, and this number increased further after 72 hours. In addition, expression of several osteogenic genes was increased after 6 hours, but, after 72 hours this profile had changed, and these genes were mostly decreased in 8-br-cAMP. Also of interest was the high number of Wnt-regulated genes. After 6 hours, a few negative regulators were increased in 8-br-cAMP cultures, whereas most positive regulators were decreased. However, after 72 hours, 8-br-cAMP had increased expression of a large number of positive Wnt regulators, as well as negative regulators, suggesting active Wnt signaling in 8-br-cAMP-treated cultures. In addition, expression of IGF binding proteins was differentially regulated. After 6 hours, expression of IGFBP5 and IGF2BP3 was increased by treatment with 8-br-cAMP, whereas expression of IGFBP2, -3 and -7 was decreased. After 72 hours however, expression of all IGFBPs was increased by treatment with 8-br-cAMP. Data is depicted as gene expression in 8-br-cAMP cultures relative to db-cAMP cultures. 
Table 2. Name and function of differentially expressed genes as identified by whole genome expression analysis.

\begin{tabular}{|c|c|c|}
\hline Gene & Name and function & Refs \\
\hline \multicolumn{3}{|c|}{ Adipogenesis } \\
\hline LDLR & Low density lipoprotein receptor, ApoE receptor & 47 \\
\hline sFRP1 & $\begin{array}{l}\text { Secreted frizzled-1, Wnt antagonist, induces maturation of adipocytes, inhibits } \\
\text { osteoblast differentiation, stimulates adipocyte differentiation }\end{array}$ & 48,49 \\
\hline sFRP4 & $\begin{array}{l}\text { Secreted frizzled-4, Wht antagonist, inhibits osteoblast proliferation, specific } \\
\text { overexpression results in decreased bone mass, sFRP4 mRNA was gradually } \\
\text { increased during adipogenic differentiation in hMSCs }\end{array}$ & 50,51 \\
\hline CEBPß & $\begin{array}{l}\text { CCAAT-enhancer binding protein } ß \text {, expressed during early stages of adipogen- } \\
\text { esis, induces expression of CEBP } \alpha \text { and PPAR } \gamma\end{array}$ & 52 \\
\hline ApoE & $\begin{array}{l}\text { Apoelipoprotein E, lipid transport / scavenger, secretion of ApoE can be in- } \\
\text { duced by dexamethasone or adipogenic medium }\end{array}$ & 47 \\
\hline LBP & $\begin{array}{l}\text { lipopolysaccharide binding protein, circulating levels are associated with obe- } \\
\text { sity }\end{array}$ & 53 \\
\hline СЕВРӘ & $\begin{array}{l}\text { CCAAT-enhancer binding protein } \partial \text {, expressed during early stages of adipogen- } \\
\text { esis, induces expression of CEBP } \alpha \text { and PPAR } \gamma\end{array}$ & 52 \\
\hline $\begin{array}{l}\text { PPARG } \\
\text { C1A }\end{array}$ & $\begin{array}{l}\text { PPARg coactivater } 1 \mathrm{a} \text {, enhances lipogenesis, activates the fatty acid synthase } \\
\text { (FAS) promoter }\end{array}$ & 54 \\
\hline $\operatorname{CEBP} \alpha$ & $\begin{array}{l}\text { CCAAT-enhancer binding protein } \alpha \text {, expression was increased during terminal } \\
\text { stage of adipogenic differentiation }\end{array}$ & 52 \\
\hline LRP1 & $\begin{array}{l}\text { Low density lipoprotein receptor-related protein-1, regulator of adipogenic dif- } \\
\text { ferentiation and PPAR } \gamma \text { expression }\end{array}$ & 55 \\
\hline \multicolumn{3}{|c|}{ Osteogenesis } \\
\hline STC1 & Stanniocalcin-1, enhances maturation of osteoblasts & 56 \\
\hline ID1 & Inhibitor of differentiation-1, BMP target gene, promotes bone formation & 57,58 \\
\hline ID2 & Inhibitor of differentiation-2, BMP target gene (mouse) & 59 \\
\hline Il11 & Interleukin-11, involved in both osteoblast and osteoclast signaling & 60 \\
\hline SMAD6 & Mothers against decapentaplegic-6, inhibitory smad & 61 \\
\hline BMP6 & Bone-morphogenetic protein- 6 , induces osteogenic differentiation of hMSCs & 62 \\
\hline Msx & Msh homeobox 1, regulates frontal bone development & 15 \\
\hline ALP & $\begin{array}{l}\text { Alkaline phosphatase, early osteogenic marker, enzyme mediating mineraliza- } \\
\text { tion }\end{array}$ & 63 \\
\hline LRP5 & Low density lipoprotein receptor-related protein, enhances bone formation & 64 \\
\hline Runx2 & Runt-related transcription factor-2, master transcription factor of osteogenesis & 15 \\
\hline DDIT3 & DNA damage inducible transcript 3 , induces osteoblast differentiation & 65 \\
\hline FosB & $\begin{array}{l}\text { FBJ murine osteosarcoma viral oncogene homolog B, osteogenic transcription } \\
\text { factor, increases number of osteoblasts, inhibits adipogenic differentiation }\end{array}$ & 15 \\
\hline
\end{tabular}


Table 2-continued. Name and function of differentially expressed genes as identified by whole genome expression analysis.

Dlx5 Distal-less homeobox 5, stimulates osteoblast differentiation

15,66

Wnt signaling

sFRP1 see above

sFRP4 see above

Dkk Dickkopf1, Wnt inhibitor, expressed during early stages and decreased rapidly 48, during late stages of adipogenesis in hMSCs, reported to promote osteogenic 51, differentiation, overexpression reported to induce adipogenic differentiation $\quad 67$

FZD1 Frizzled-1, expression was reduced during adipogenic differentiation of hMSCs

FZD2 Frizzled-2, Wnt receptor

FZD4 Frizzled-4, Wnt receptor

FZD7 Frizzled-7, expression was reduced during adipogenic differentiation of hMSCs

FZD8 Frizzled-8, Wnt receptor

CTNNB1 B-catenin, Wnt stimulator

CTNN B-catenin interacting protein 1, Wnt inhibitor

BIP1

Wnt5a Wingless-type MMTV integration site family, member 5a, inactivates PPAR $\gamma$ 48 , function/adipogenesis, induces osteogenesis in ST2 cells, associated with obe68 , sity in mice, induces mineralization and osteopontin expression in hMSCs

Wnt5b Wingless-type MMTV integration site family, member 5b, induces PPAR $\gamma$ and 70 AP2 in mouse 3T3-L1 preadipocytes

LRP1 see above

LRP5 see above

Src Tyrosine kinase, binds Dishevelled2, Wnt stimulation

Nkd2 Naked2, Wnt inhibitor

Dvl2 Dishevelled 2, Wnt inhibitor

Dvl3 Dishevelled 3, Wnt inhibitor, after an initial increase, gene expression decreases during adipogenic differentiation of 3T3-L1 cells

DACT1 DAPPER/FROD0 protein 1, Wnt inhibitor, expression was decreased after early induction of adipogenesis in human preadipocytes, required for adipogenesis in 3T3-L1 preadipocytes

DACT3 DAPPER/FRODO protein 3, Wnt inhibitor

WISP1 WNT1-inducible-signaling pathway protein 1, enhances effects of BMP-2 to induce osteogenic differentiation/bone formation of hMSCs

WISP2 WNT1-inducible-signaling pathway protein 2, in hMSCs expressed during the initial stage of adipogenic differentiation, followed by a gradual decrease 
well as two Wnt target genes, WISP1 and WISP2. We and others have demonstrated that activation of Wht signaling in hMSCs inhibits osteogenic differentiation [33-36], and the high number of Wnt-regulated genes in 8-br-cAMP possibly negatively correlates with osteogenic differentiation. IGF signaling and in particular the IGF binding proteins (IGFBPs), were also differentially expressed between the two types of cultures. As depicted in figure 5, after 6 hours, expression of IGF2BP3 and IGFBP5 was higher in 8-br-cAMP cultures, whereas expression of IGFBP2, -3 and-7 was lower. After 72 hours, expression of all IGFBPs was higher in 8-br-cAMP cultures. Generally, disruptions in IGF signaling result in reduced adipogenic differentiation, and most IGFBPs were shown to be present at moderate to high levels in fat tissue and to inhibit IGF or insulin induced adipogenesis [37].

\section{Discussion}

We have previously demonstrated enhanced osteogenic differentiation and in vivo bone formation of hMSCs, after treatment with db-cAMP and forskolin, both activators of the PKA pathway [8]. Here, we show that, in contrast, the cAMP-analogue 8-br-cAMP does induce ALP expression, but to a much lower extent than db-cAMP and, in the longterm induces adipogenesis in osteogenic culture medium. This effect was even stronger in combination with higher concentrations of dexamethasone, whereas db-cAMP had no effect on lipid formation, even in combination with dexamethasone. These data suggest that the cAMP/PKA pathway is involved in maintaining the balance between osteogenic and adipogenic differentiation of hMSCs, based on the strength or the duration of the signal, and possibly influenced by the dexamethasone signal.

As described in the introduction, cAMP/PKA signaling has been involved in both osteogenic and adipogenic differentiation, but no general consensus exists on the specific role of this pathway in hMSC cell fate. The studies by Zhao et al. [24] and Yang et al. [25] have in common that both used a relatively high concentration of dexamethasone $\left(10^{-7} \mathrm{M}\right)$, which may explain the contradictory results obtained in our study, where a lower concentration of dexamethasone was used (no or $10^{-8} \mathrm{M}$ dex). Here, we show that treatment with 8-br-cAMP in combination with higher concentrations of dexamethasone results in higher expression of PPAR $\gamma$ and several other studies already described that dexamethasone may sensitize receptors or promote responsiveness of cells to other stimuli. In 1986, Rodan and Rodan suggested that dexamethasone increases the abundance of receptors and Gs in ROS 12/2.8 cells [38] and Ma et al. demonstrated that dexamethasone increases expression of $\beta 2$-adrenergic receptors in calvarial osteoblasts, thereby increasing their responsiveness to adrenergic stimulation [39]. Watanabe et al. showed that both PGE2 and forskolin induce expression of aromatase synergistically with dexamethasone, but not alone [40,41]. In line with 
these data, we have also demonstrated synergistic effects between the cAMP-inducers forskolin and cholera toxin and dexamethasone in our own lab. Dexamethasone also induced intracellular cAMP levels when combined with PGE2, whereas PGE2 alone did not affect cAMP levels [26].

Besides the interplay with dexamethasone, the various downstream signaling pathways that are activated by cAMP may have distinct effects. Although it was traditionally believed that cAMP exerts its effects through PKA, around a decade ago it was recognized that cAMP also activates Epac. Two Epac variants (1 and 2), also called guanine-nucleotide exchange factor (GEF) 1 and 2, have been identified, and they activate the small GTPases Rap1 and Rap2 (reviewed in [42]). It has been suggested that at low concentrations, cAMP activates PKA, whereas at higher concentrations, additional effects are exerted via Epac [42]. Specific PKA- and Epac-activating cAMP analogues have been designed, but the cAMP analogues used here activate both PKA and Epac. Our microarray data shows that treatment with 8-br-cAMP results in higher expression of cAMP-responsive genes and in addition, 8-br-cAMP activates PKA more strongly than $\mathrm{db}$-cAMP. This suggests a mechanism where 8-br-cAMP is either more stable or more potent than db-cAMP and exerts additional effects via Epac, thus resulting in adipogenic differentiation, or a mechanism where low PKA activity (db-cAMP) results in osteogenic differentiation and strong PKA activity (8-br-cAMP) leads to adipogenic differentiation.

The distinct roles of PKA and Epac in adipogenic and/or osteogenic differentiation are now topic of investigation and it was demonstrated that, whereas knockdown of Epac resulted in a significant inhibition, blockage of PKA did not affect adipogenesis of 3T3-L1 preadipocytes $[43,44]$, thus suggesting a model in which cAMP activates Epac to stimulate adipogenesis. On the other hand, it was nicely demonstrated by Petersen et al. that adipogenic differentiation of 3T3-L1 cells requires activation of both PKA and Epac [45]. Using Epac or PKA-specific activators, they demonstrated that Epac nor PKAselective stimulation is sufficient to induce adipogenic differentiation. Furthermore, they showed that PKA inhibits Rho kinase signaling and that knockdown of Rho kinase signaling results in enhanced adipogenic differentiation. Thus, activation of PKA is not required for adipogenic differentiation, as long as Rho kinase is inhibited. The involvement of RhoA and Rho-associated protein kinase (ROCK) was also demonstrated before by McBeath et al., who showed that ROCK activity was associated with cell shape and accordingly, with lineage commitment [46]. Overexpression of RhoA resulted in osteogenic differentiation, whereas expression of dominant negative RhoA lead to the formation of adipocytes in the absence of any inducing factors.

To conclude, we demonstrate here that two analogues, activating the same pathway can have differential effects on long-term differentiation of hMSCs and gene expression levels, thus pointing to a role for the PKA pathway in the balance between osteogenic and 
adipogenic differentiation. In addition, information on the underlying biology between osteo- and adipogenic differentiation may be valuable for the treatment of osteoporosis, where this balance is disturbed.

\section{Acknowledgments:}

We would like to thank prof. André Uitterlinden for the use of the Illumina equipment. Furthermore, the authors gratefully acknowledge the support of the Smart Mix Program of the Netherlands Ministry of Economic Affairs and the Netherlands Ministry of Education, Culture and Science. 


\section{References}

1. Pittenger MF, Mackay AM, Beck SC, Jaiswal RK, et al. (1999) Science 284, 143-147

2. Brazelton TR, Rossi FM, Keshet GI, Blau HM. (2000) Science 290, 1775-1779

3. Mezey E, Chandross KJ, Harta G, Maki RA, et al. (2000) Science 290, 1779-1782

4. $\quad$ Oswald J, Boxberger S, Jørgensen B, Feldmann S, et al. (2004) Stem cells 22, 377-384

5. Rouwkema J, Westerweel PE, de Boer J, Verhaar MC, et al. (2009) Tissue Eng Part A 15, 20152027

6. Dezawa M, Ishikawa H, Itokazu Y, Yoshihara T, et al. (2005) Science 309, 314-317

7. Shake JG, Gruber PJ, Baumgartner WA, Senechal G, et al. (2002) Ann Thorac Surg 73, 19191925

8. Siddappa R, Martens A, Doorn J, Leusink A, et al. (2008) Proc Natl Acad Sci U S A 105, 72817286

9. Oliveira JM, Kotobuki N, Tadokoro M, Hirose M, et al. (2010) Bone 46, 1424-1435

10. Gimble J, Morgan, C, Kelly, K, Wu, X, Dandapani, V, Wang, CS, Rosen, V. (1995) J Cell Biochem 85, 393-402.

11. Kha HT, Basseri B, Shouhed D, Richardson J, et al. (2004) J Bone Miner Res 19, 830-840

12. Dorheim M, Sullivan, M, Dandapani, V, Wu, X, Hudson, J, Segarini, PR, Rosen, DM, Aulthouse, AL, Gimble, JM. (1993) J Cell Physiol 154, 317-328

13. Duque G. (2008) Curr Opin Rheumatol 20, 429-434

14. Georgiou KR, Scherer MA, Fan C-M, Cool JC, et al. (2011) J Cell Physiol, n/a-n/a

15. Komori T. (2006) J Cell Biochem 99, 1233-1239

16. Gimble JM, Zvonic S, Floyd ZE, Kassem M, et al. (2006) J Cell Biochem 98, 251-266

17. Muruganandan S, Roman AA, Sinal CJ. (2008) Cell Mol Life Sci 66, 236-253

18. Wang W, Zhang X, Zheng J, Yang J. (2010) Mol Cell Biochem 338, 115-122

19. Roth JA, Kim B-G, Lin W-L, Cho M-I. Melatonin Promotes Osteoblast Differentiation and Bone Formation. 1999. p. 22041-22047.

20. Kaneki H, Takasugi I, Fujieda M, Kiriu M, et al. (1999) J Cell Biochem 73, 36-48

21. Swarthout JT, D’Alonzo RC, Selvamurugan N, Partridge NC. (2002) Gene 282, 1-17

22. Selvamurugan N, Pulumati MR, Tyson DR, Partridge NC. Parathyroid Hormone Regulation of the Rat Collagenase-3 Promoter by Protein Kinase A-dependent Transactivation of Core Binding Factor alpha 1. 2000. p. 5037-5042.

23. Boguslawski G, Hale LV, Yu X-P, Miles RR, et al. Activation of Osteocalcin Transcription Involves Interaction of Protein Kinase A- and Protein Kinase C-dependent Pathways. 2000. p. 999-1006.

24. Zhao Y, Ding S. (2007) Proc Natl Acad Sci U S A 104, 9673-9678

25. Yang D-c, Tsay H-j, Lin S-y, Chiou S-h, et al. (2008) PLoS ONE 3, e1540

26. Siddappa R, Doorn J, Liu J, Langerwerf E, et al. (2010) J Tissue Eng Regen Med 4, 356-365

27. de Bruijn JD, van den Brink I, Mendes S, Dekker R, et al. Bone induction by implants coated with cultured osteogenic bone marrow cells. 1999. p. 74-81. 
28. Livak KJ, Schmittgen TD. (2001) Methods 25, 402-408

29. Wettenhall JM, Smyth GK. (2004) Bioinformatics 20, 3705-3706

30. Benjamini Y, Hochberg, Y. (1995) J Roy Stat Soc B 57, 289-300

31. Siddappa R, Licht R, van Blitterswijk C, de Boer J. (2007) J Orthop Res 25, 1029-1041

32. Zhang X, Odom DT, Koo S-H, Conkright MD, et al. (2005) Proc Natl Acad Sci U S A 102, 44594464

33. De Boer J, Siddappa R, Gaspar C, Van Apeldoorn A, et al. (2004) Bone 34, 818 - 826

34. Boland GM, Perkins G, Hall DJ, Tuan RS. (2004) J Cell Biochem 93, 1210-1230

35. Cho HH, Kim YJ, Kim SJ, Kim JH, et al. (2006) Tissue Eng 12, 111-121

36. De Boer J, Wang HJ, Van Blitterswijk CA. (2004) Tissue Eng 10, 393-401

37. Baxter RC, Twigg SM. (2009) Trends in Endocrinology \& Metabolism 20, 499-505

38. Rodan SB, Rodan GA. (1986) Endocrinology 118, 2510-2518

39. Ma Y, Nyman JS, Tao H, Moss HH, et al. (2011) Endocrinology 152, 1412-1422

40. Watanabe M, Ohno S, Nakajin S. (2005) Eur J Endocrinol 152, 619-624

41. Watanabe M, Noda M, Nakajin S. (2007) Steroids 72, 686-692

42. Bos JL. (2006) Trends Biochem Sci 31, 680-686

43. Ji Z, Mei FC, Cheng X. (2010) Front Biosci (Elite Ed) 2, 392-398

44. Martini C, Plaza M, Vila M. (2009) Mol Cell Endocrinol 298, 42-47

45. Petersen RK, Madsen L, Pedersen LM, Hallenborg P, et al. (2008) Mol Cell Biol 28, 3804-3816

46. Mcbeath R, Pirone DM, Nelson CM, Bhadriraju K, et al. (2004) Dev Cell 6, 483-495

47. Zeitouni S, Ford BS, Harris SM, Whitney MJ, et al. (2008) BMC Biotechnol 8, 75

48. Laudes M. (2011) J Mol Endocrinol 46, R65-R72

49. Taipaleenmäki H, Abdallah B, AlDahmash A, Säämänen A, et al. (2011) Exp Cell Res 317, 745756

50. Nakanishi R, Akiyama H, Kimura H, Otsuki B, et al. (2008) J Bone Miner Res 23, 271-277

51. Park JR, Jung JW, Lee YS, Kang KS. (2008) Cell Prolif 41, 859-874

52. Lane MD, Tang Q-Q, Jiang M-S. (1999) Biochem Biophys Res Commun 266, 677-683

53. Sun L, Yu Z, Ye X, Zou S, et al. (2010) Diabetes Care 33, 1925-1932

54. Summermatter S, Baum O, Santos G, Hoppeler H, et al. (2010) J Biol Chem 285, 32793-32800

55. Masson O, Chavey C, Dray Cd, Meulle A, et al. (2009) PLoS ONE 4, e7422

56. Yoshiko Y, Maeda N, Aubin JE. (2003) Endocrinology 144, 4134-4143

57. Katagiri T, Imada M, Yanai T, Suda T, et al. (2002) Genes Cells 7, 949-960

58. Maeda Y, Tsuji K, Nifuji A, Noda M. (2004) Reactions 93, 337-344

59. Nakahiro T, Kurooka H, Mori K, Sano K, et al. (2010) Biochem Biophys Res Commun 399, 416421

60. Sims NA, Jenkins BJ, Nakamura A, Quinn JMW, et al. (2005) J Bone Miner Res 20, 1093-1102

61. Chen D, Zhao M, Mundy GR. (2004) Growth Factors 22, 233-241

62. Friedman MS, Long MW, Hankenson KD. (2006) J Cell Biochem 98, 538-554

63. Hoemann CD, El-Gabalawy H, McKee MD. (2009) Pathol Biol (Paris) 57, 318-323

64. Yadav VK, Ducy P. (2010) Ann N Y Acad Sci 1192, 103-109 
65. Pereira RC, Delany AM, Canalis E. (2004) Endocrinology 145, 1952-1960

66. Li H, Marijanovic I, Kronenberg MS, Erceg I, et al. (2008) Dev Biol 316, 458-470

67. Liu N, Shi S, Deng M, Tang L, et al. (2011) J Bone Miner Res, n/a-n/a

68. Bilkovski R, Schulte DM, Oberhauser F, Gomolka M, et al. (2010) J Biol Chem 285, 6170-6178

69. Takada I, Mihara M, Suzawa M, Ohtake F, et al. (2007) Nat Cell Biol 9, 1273-1285

70. van Tienen FHJ, Laeremans H, van der Kallen CJH, Smeets HJM. (2009) Biochem Biophys Res Commun 387, 207-211

71. Lagathu C, Christodoulides C, Virtue S, Cawthorn WP, et al. (2009) Diabetes 58, 609-619

72. Ono M, Inkson CA, Kilts TM, Young MF. (2011) J Bone Miner Res 26, 193-208

73. Schutze N, Noth U, Schneidereit J, Hendrich C, et al. (2005) Cell Commun Signal 3, 5 


\section{CHAPTER 6.}

\section{Pro-osteogenic trophic effects by protein kinase $A$ activation in human mesenchymal stromal cells}

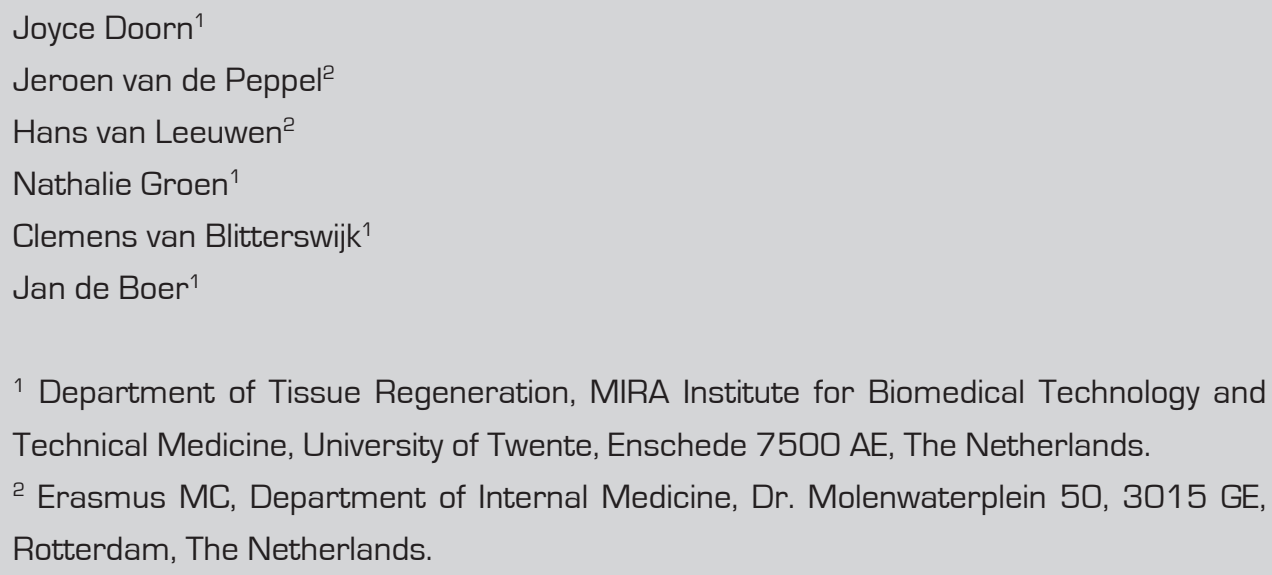

Biomaterials. 2011 Sep;32[26]:6089-98.

A pessimist sees the difficulty in every opportunity; an optimist sees the opportunity in every difficulty.

- Winston Churchill 


\section{Abstract}

Human mesenchymal stromal cells (hMSCs) are able to differentiate into a wide variety of cell types, which makes them an interesting source for tissue engineering applications. On the other hand, these cells also secrete a broad panel of growth factors and cytokines that can exert trophic effects on surrounding tissues. In bone tissue engineering applications, the general assumption is that direct differentiation of hMSCs into osteoblasts accounts for newly observed bone formation in vivo. However, the secretion of bone-specific growth factors, but also pro-angiogenic factors, could also contribute to this process. We recently demonstrated that secretion of bone specific growth factors can be enhanced by treatment of hMSCs with the small molecule dbcAMP (cAMP) and here we investigate the biological activity of these secreted factors. We demonstrate that conditioned medium contains a variety of secreted growth factors, with differences between medium from basic-treated and cAMP-treated hMSCs. We show that conditioned medium from cAMP-treated hMSCs increases proliferation of various cell types and also induces osteogenic differentiation, whereas it has differential effects on migration. Microarray analysis on hMSCs exposed to conditioned medium confirmed upregulation of pathways involved in proliferation as well as osteogenic differentiation. Our data suggests that trophic factors secreted by hMSCs can be tuned for specific applications and that a good balance between differentiation on the one hand and secretion of bone trophic factors on the other, could potentially enhance bone formation for bone tissue engineering applications. 


\section{Introduction}

Human mesenchymal stromal cells (hMSCs) are a promising tool in the field of bone tissue engineering, due to their easy isolation, in vitro expansion capacity and differentiation potential. hMSCs were first discovered by Friedenstein et al. in 1968 [1] and exhibit the capacity to differentiate into the adipogenic, chondrogenic and osteogenic lineage [2]. Subsequently, it became evident that hMSCs can differentiate into neuron-like cells [3], endothelial-like cells [4] and myocytes [5]. Besides their ability to differentiate into various lineages, Haynesworth et al. discovered as early as 1996 that hMSCs secrete a broad spectrum of biologically active factors [6] with immunoregulatory $[2,7]$, tissue-supportive and instructive functions for surrounding cell types [8]. These so-called trophic factors are currently employed in clinical trials as a tool to fight autoimmune diseases such as Crohn's and graft-versus-host disease (GVHD), where co-infusion of MSCs with the bone marrow of the donor can prevent an auto-immune response [9]. Immunoregulatory effects include a decrease in proliferation and action of various immune cells, but trophic factors also suppress the secretion of inflammatory proteins [10]. Similarly, in myocardial infarcts, systemic infusion of MSCs or MSC-conditioned medium alone showed beneficial effects on the heart as well [11], although engraftment and differentiation of cells in the infarct zone of the myocardium has been demonstrated as well [12]. In this case, secreted pro-angiogenic factors, such as vascular endothelial growth factor (VEGF), improve the microvasculature, but antiapoptotic and anti-scarring factors may also play a role [13].

In bone tissue engineering, it is generally believed that not the trophic factors, but the direct differentiation of MSCs into osteoblasts accounts for observed effects on bone formation. Studies in larger animals have demonstrated that the traditional bone tissue engineering approach, where MSCs are isolated, seeded onto a scaffold and implanted back into the patient, can be successful [14]. However, studies using human MSCs have resulted in limited amounts of newly formed bone [15-17]. Thus, in order to improve the therapeutic efficacy, researchers aim to differentiate hMSCs prior to implantation by treating the cells with compounds that induce osteogenic differentiation. It was shown that pre-differentiation with dexamethasone can increase bone formation by hMSCs [17], whereas other compounds such as trichostatin A [18] and lithium [19], which did induce osteogenic differentiation, did not affect bone formation in vivo. Thus, so far, better results are obtained by co-implantation of the cells with osteoinductive growth factors such as bone morphogenetic protein-2 (BMP-2) [14]. In our group we recently demonstrated that treatment of hMSCs with the small compound dibutyrylcAMP (cAMP) for 4 days in vitro, resulted in more robust bone formation in vivo [20]. Originally this increase in bone formation was thought to be due to the direct differentiation of these cells into the osteogenic lineage, as treated cells demonstrated 
enhanced ALP expression and mineralization. However, microarray analysis revealed that cAMP treatment also increased the secretion of a number of bone specific growth factors that led us to the hypothesis of a trophic effect of these cAMP-treated cells. In the present study, we investigated if these secreted factors are biologically active, by examining proliferation and differentiation of various cell types after culture in conditioned medium derived from cAMP-treated cells.

\section{Materials and methods}

\section{Cell culture}

Bone marrow aspirates $(5-20 \mathrm{ml})$ were obtained from donors with written informed consent. Briefly, aspirates were resuspended using 20G needles, plated at a density of $5 \times 10^{5}$ cells $/ \mathrm{cm}^{2}$ and cultured in proliferation medium containing $\alpha$-minimal essential medium ( $\alpha$-MEM, Life Technologies), 10\% fetal bovine serum (FBS, Cambrex), $0.2 \mathrm{mM}$ ascorbic acid (Asap, Life Technologies), $2 \mathrm{mM}$ L-glutamine (Life Technologies), 100 $\mathrm{U} / \mathrm{mL}$ penicillin (Life Technologies), $10 \mu \mathrm{g} / \mathrm{ml}$ streptomycin (Life Technologies) and $1 \mathrm{ng} / \mathrm{mL}$ basic fibroblast growth factor (bFGF, Instruchemie, The Netherlands). The osteosarcoma cell line MG-63 and the breast cancer cell line MCF-7 were expanded in basic medium, consisting of proliferation medium without bFGF. The mouse myoblast cell line C2C12 was expanded in C2C12 proliferation medium, consisting of DMEM (Life Technologies), 10\% FBS, $100 \mathrm{U} / \mathrm{mL}$ penicillin and $10 \mu \mathrm{g} / \mathrm{mL}$ streptomycin. HUVECs were commercially obtained from Lonza and cultured in Endothelial Growth Medium-2 (EGM-2) with the addition of the microvascular bulletkit (MV, all from Clonetics, Lonza), containing hEGF, hydrocortisone, Gentamicin, 5\% FBS, VEGF, hFGF-B, R3-IGF-1 and Ascorbic Acid. Cells were grown at $37{ }^{\circ} \mathrm{C}$ in a humid atmosphere with $5 \% \mathrm{CO}_{2}$. Medium was refreshed twice a week and cells were used for experiments, further sub-culturing or cryopreservation upon reaching near confluence.

\section{Growth factor secretion}

hMSCs were seeded in triplicate in 24-well plates at 5000 cells $/ \mathrm{cm}^{2}$ in proliferation medium and allowed to attach overnight. The next day, medium was changed to either basic medium, or basic medium supplemented with cAMP. After 5 days, the medium was collected and the concentrations of Interleukin-8 (Il-8), Il-11, Insulin-like-growth factor-1 (IGF-1) and BMP-2 in the medium were determined by ELISA (quantikine, R\&D systems), according to the manufacturer's protocol.

\section{Conditioned medium preparation}

hMSCs were seeded in T75 culture flasks in proliferation medium and grown until near confluence. Then, either basic medium (basic-treated; BT) or basic medium 
supplemented with $1 \mathrm{mM}$ dibutyryl-cAMP (Sigma) (cAMP-treated; CT) was added. After 3 days the medium (and cAMP) was removed, cells were washed twice with PBS and fresh basic medium without FBS was added. After two days the conditioned medium (CM) was collected and centrifuged for 5 minutes at $900 \mathrm{~g}$ to remove cell debris, and directly applied to target cells. For experiments with HUVECs, conditioned medium was prepared by mixing conditioned medium with EGM-2 in a 1:1 ratio. As a control, nonconditioned medium (non-treated; NT), consisting of medium without FBS that had not been in contact with any cells, was used.

\section{Proliferation assays}

Cells were seeded in triplicate in 24-well plates at 2000 cells $/ \mathrm{cm}^{2}$ and allowed to attach for 10 to 15 hours in denoted expansion medium. The next day, conditioned medium was added and after 5 days an Alamar Blue assay (Biosource) was performed. A $10 \% \mathrm{v} / \mathrm{v}$ solution of Alamar Blue in medium was prepared and $1 \mathrm{~mL}$ of solution was added to each well. After 4 hours, the fluorescence intensity of the solution in each well was determined by measuring $200 \mu \mathrm{L}$ of solution at an excitation wavelength of 545 $\mathrm{nm}$ and an emission wavelength of $590 \mathrm{~nm}$ (Victor, Perkin Elmer). To examine the role of IGF-1 signaling, CT-CM was supplemented with $20 \mu \mathrm{g} / \mathrm{mL}$ anti-IGF-1 (AF-291-NA) or $10 \mu \mathrm{g} / \mathrm{mL}$ anti-IGFR (receptor blocker, MAB391) (all from R\&D systems) and Alamar Blue was performed as described. As controls, cells were cultured in NT-CM, NT-CM supplemented with $10 \mathrm{ng} / \mathrm{mL}$ IGF-1, NT-CM supplemented with both IGF-1 and an IGF-1 inhibitor or BT-CM.

\section{Scratch wound healing assay}

hMSCs, C2C12s, MG-63s and HUVECs were seeded in triplicate in 6-well plates at 10,000 cells $/ \mathrm{cm}^{2}$ and allowed to attach for 10 to 15 hours in denoted culture medium. When the cells reached confluence, a wound was created, by scratching the surface with a pipet tip and the medium was changed to conditioned medium. After 12 hours, pictures were taken to examine migration of cells into the wound.

\section{Transwell migration assay}

hMSCs, C2C12s, MG-63s and HUVECs were expanded as described and serum starved overnight. The next day, a migration assay was performed using the Thincert system (BioGreiner). $500 \mu \mathrm{L}$ of either NT-CM, BT-CM or CT-CM was pipetted in the well of a 24-well plate (lower chamber) (for HUVECs, a 1:1 mixture of CM and EGM-2) and 200,000 cells were seeded per insert (upper chamber). After 20 hours, inserts were removed, washed with PBS and placed in a fresh well containing $500 \mu \mathrm{L}$ of trypsin. After 10 minutes of incubation, $1 \mathrm{~mL}$ of medium was added and $200 \mu \mathrm{L}$ of cell suspension was used to count the number of migrated cells in a Coulter counter (Becton Dicks). Data is 
depicted as percentage of migrated cells.

\section{Glucose / lactate measurements}

hMSCs were seeded in 12-well plates in proliferation medium and kept until near confluence. Then, either basic medium or basic medium supplemented with 1 mM dibutyryl-cAMP (Sigma) was added. After three days, the medium was collected for glucose/lactate measurements. Cells were washed twice with PBS and fresh medium without FBS was added. After two more days the medium was collected for measurements. Collected medium was analyzed for glucose and lactate concentrations using a VITROS DT60 II chemistry system (Ortho-Clinical Diagnostics, Tilburg, The Netherlands).

\section{ALP activity}

C2C12 cells were seeded in triplicate in 12 -well plates at 5000 cells $/ \mathrm{cm}^{2}$ and allowed to attach for 10-15 hours in C2C12 expansion medium. The next day, the medium was changed to conditioned medium and after 4 days an Alamar Blue assay was performed. Then the cells were lysed with CDP star lysis buffer and the lysate was used for a CDPstar assay (Roche). Briefly, $30 \mu \mathrm{L}$ of CDP star substrate was incubated with $10 \mu \mathrm{L}$ of cell lysate for 30 minutes after which luminescence was measured (Victor, Perkin Elmer). ALP expression was normalized to cell numbers, and data is depicted as percentage relative to NT-CM.

\section{ALP analysis by flow cytometry}

hMSCs were seeded in triplicate in 6-well plates at 5000 cells $/ \mathrm{cm}^{2}$ and allowed to attach for 10-15 hours in proliferation medium. The next day, the medium was changed to conditioned medium. After 4 days, cells were trypsinized, incubated for 30 minutes in block buffer (PBS with 5\% bovine serum albumin, BSA [Sigma] and 0.01\% $\mathrm{NaN}_{3}$ ), and subsequently incubated with primary antibody (anti-ALP, B4-78 [Developmental Studies Hybridoma Bank, University of Iowa, USA]) diluted in wash buffer (PBS with $1 \% \mathrm{BSA}$ and $0.05 \% \mathrm{NaN}_{3}$ ) for 1 hour or with isotype control antibodies. Cells were then washed three times with wash buffer and incubated with secondary antibody (rat anti mouse IgG PE, DAKO) diluted in wash buffer for 30 minutes. Again, cells were washed three times and resuspended in $250 \mu \mathrm{l}$ wash buffer with $10 \mu \mathrm{l}$ Viaprobe (Pharmingen) for live/dead cell staining. Only living cells were used for further analysis. With the isotypes set to zero, the amounts of ALP-positive cells were analyzed on a FACS Caliber using cell-quest software (Becton Dickinson Immunocytometry systems).

\section{Gene expression analysis}

hMSCs were seeded in triplicate in 6 -well plates at 5000 cells $/ \mathrm{cm}^{2}$ and allowed 
to attach for 10-15 hours in proliferation medium. For PCR on the osteogenic panel; conditioned medium was added the next day and cells were lysed after 6 and 72 hours. For PCR on BMP-2 target genes; medium was replaced with either basic medium, basic medium + $100 \mathrm{ng} / \mathrm{mL}$ BMP-2 (R\&D systems) or basic medium + 1 mM cAMP. The latter two were cultured in the presence or absence of recombinant human BMPRIA/ALK3 (BMPR-IA, 315BR/CF R\&D systems), which actively binds BMPs and thus prevents binding to the type I receptor. After 5 days, cells were lysed. RNA was isolated using a Bioke RNA II nucleospin RNA isolation kit (Machery Nagel) and RNA concentrations were measured using an ND100 spectrophotometer (Nanodrop technologies, USA). cDNA was synthesized from 100 ng of RNA, using iScript (BioRad) according to the manufacturer's protocol. For quantitative PCR, a master mix, containing distilled water, forward primer, reverse primer (Sigma Genosys), BSA, and SYBR green I mix (all from Invitrogen) was prepared. Real-time qPCR was performed in a Light-Cycler (Roche). Light-Cycler data was analyzed using the fit points method of Light-Cycler software. The baseline was set at the lower log-linear part above baseline noise and the crossing temperature (Ct value) was determined. Ct values were normalized to the $18 \mathrm{~S}$ housekeeping gene and $\Delta \mathrm{Ct}\left(\mathrm{Ct}_{\text {control }}-\mathrm{Ct}_{\text {sample }}\right)$ was used to calculate the upregulation in gene expression. Primer sequences are listed in table 1.

Table 1. Primer sequences

\begin{tabular}{lll}
\hline Gene & Forward primer & Reverse primer \\
\hline 18s & CGGCTACCACATCCAAGGAA & GCTGGAATTACCGCGGCT \\
Id1 & GCAAGACAGCGAGCGGTGG & GGCGCTGATCTCGCCGTTGAGGG \\
Id2 & CCTCCCGGTCTCGCCTTCC & GGTTCTGCCCGGGTCTCTGG \\
OC & GGCAGCGAGGTAGTGAAGAG & GATGTGGTCAGCCAACTCGT \\
ON & ACTGGCTCAAGAACGTCCTG & GAGAGAATCCGGTACTGTGG \\
OP & CCAAGTAAGTCCAACGAAAG & GGTGATGTCCTCGTCTGTA \\
BSP & TGCCTTGAGCCTGCCTGCTTCC & CAAAATTAAAGCAGTCTTCATTTTG \\
runx2 & ATGGCGGGTAACGATGAAAAT & ACGGCGGGGAAGACTGTGC \\
ALP & GACCCTTGACCCCCACAAT & GCTCGTACTGCATGTCCCCT \\
IGF-I & CTTCAGTTCGTGTGTGGAGACAG & CGCCCTCCGACTGCTG \\
Col-I & AGGGCCAAGACGAAGACATC & AGATCACGTCATCGCACAACA \\
BMP-2 & Commercially obtained from SA Biosciences \\
\hline
\end{tabular}

\section{Microarray analyis}

hMSCs were seeded in 12-well plates at 5000 cells $/ \mathrm{cm}^{2}$ and allowed to attach for 10-15 hours in proliferation medium. The next day, conditioned medium was added 
and cells were kept in culture for 6 or 72 hours after which they were lysed directly from the plate. RNA was isolated as described above. Then, from 500 ng of RNA, cRNA was synthesized using the Illumina TotalPrep RNA amplification Kit (Ambion/Life Technologies), according to the manufacturer's protocol. Both RNA and cRNA quality were verified on a Bioanalyzer 2100 (Agilent). Microarrays were performed using Illumina HT-12 v3 expression Beadchips, according to the manufacturer's protocol. Briefly, 750 ng of cRNA was hybridized on the array overnight after which the array was washed and blocked. Then, by addition of streptavidin Cy-3 a fluorescent signal was developed. Arrays were scanned on an Illumina iScan reader and raw intensity values were background corrected in GenomeStudio (Illumina). Further data processing and statistical testing were performed with R and Bioconductor statistical software (http:// www.bioconductor.org/), using package lumi. Raw intensity values were transformed using variance stabilization and a quantile normalization was performed. A linear modelling approach with empirical Bayesian methods, as implemented in Limma package [21], was applied for differential expression analysis of the resulting probelevel expression values. A gene list, containing only those genes with an absolute 1.5fold change between different treatments, was uploaded to Ingenuity Pathway Analysis (IPA) software and used for core analysis. Pathways or networks with a p-value of 0.05 were considered statistically significant.

\section{Statistics}

All experiments were performed in triplicates. Data were analyzed in SPSS (PASW statistics) using one-way Anova followed by Tukey's multiple comparison test $(\mathrm{P}<0.05)$.

\section{Results}

\section{Effect of cAMP on growth factor secretion}

hMSCs have been shown to increase gene expression of bone-specific growth factors in response to treatment with cAMP. To investigate the actual production and secretion into the medium, hMSCs were seeded at $5000 \mathrm{cells} / \mathrm{cm}^{2}$ and cultured for 5 days in the presence or absence of cAMP, after which ELISAs on Il-8, Il-11, IGF-1 and BMP-2 were performed. As shown in figure 1, the concentration of all growth factors examined was increased upon treatment with cAMP. More specifically; treatment with cAMP resulted in concentrations of 250, 100 and $50 \mathrm{pg} / \mathrm{mL}$ of Il-8, Il-11 and BMP-2 respectively, and induced concentrations of IGF-1 as high as $6 \mathrm{ng} / \mathrm{mL}$. However, these concentrations decline upon removal of the stimuli. Thus, to determine the most effective preparation method for conditioned medium, IGF-1 was used as a representative growth factor. MSCs were incubated with cAMP for 2 or 3 days and subsequently kept in basic medium until denoted measurement points, after which the concentration of IGF-1 was determined. 

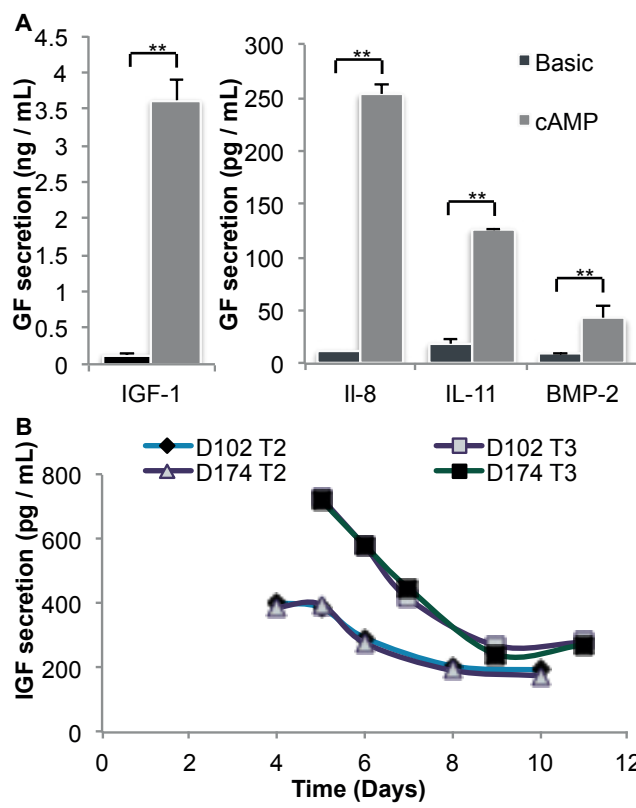

Figure 1. cAMP enhances secretion of bone specific growth factors by hMSCs. (a) hMSCs were cultured in basic medium or basic medium supplemented with $1 \mathrm{mM}$ cAMP for 5 days, after which the medium was collected for ELISA. cAMP treatment significantly enhanced secretion of bone-specific growth factors such as IGF-1, Il-8, Il-11 and BMP-2. (b) hMSCs from 2 different donors (102 and 174) were treated with cAMP for either 2 (T2) or 3 days (T3), after which medium was replaced with fresh medium. Concentrations of IGF-1 in conditioned medium were determined after denoted time periods. IGF-1 concentrations were found to be highest after 3 days of cAMP treatment and 2 more days of incubation with fresh medium. GF; growth factor, IGF-1; Insulin-like growth factor-1, Il-8; Interleukin-8, Il-11; Interleukin-11; BMP-2, bone morphogenetic protein- $2 ;^{* *}=\mathrm{p}<0.01$.

As shown in figure 1b, the concentration of IGF-1 in the medium declined with time, and 3 days of treatment and 2 additional days of incubation with fresh medium resulted in the highest concentration of IGF-1.

\section{Effect of conditioned medium on proliferation}

To investigate if the secreted growth factors are biologically active and can influence the behavior of surrounding cells, conditioned medium from hMSCs was added to various cell types after which proliferation was examined. hMSCs, C2C12s, MG-63s and HUVECs were cultured for 5 days in NT-CM, BT-CM and CT-CM, all prepared without FBS. Figure 2 shows the increase in proliferation in BT-CM as compared to NT-CM in all cell types, demonstrating the basal activity level of secreted growth factors by MSCs without treatment. Culturing cells in CT-CM resulted in an even higher cell number suggesting an increase in mitogenic growth factors in CT-CM. Only on hMSCs, CT-CM did not have an additive effect over BT-CM, indicating a differential response of different cell types to the secreted growth factors. CM was also prepared using $2 \%, 5 \%$ and $10 \%$ FBS, resulting in less profound effects of secreted growth factors. Possibly, the high concentrations of growth factors present in FBS eliminate the effect of the secreted growth factors or FBS contains proteins that neutralize the effect of the secreted growth factors. As shown in figure 1, IGF-1 is one of the proteins present in high concentrations in CT-CM and since IGF-1 has been demonstrated to have mitogenic effects on various cell lines, we investigated if IGF was responsible for the observed effects on proliferation by using the IGF-responsive cell line MCF-7. Figure $2 \mathrm{~b}$ shows that CT-CM increases MCF-7 proliferation to the same extent as $10 \mathrm{ng} / \mathrm{mL}$ rhIGF-1, 

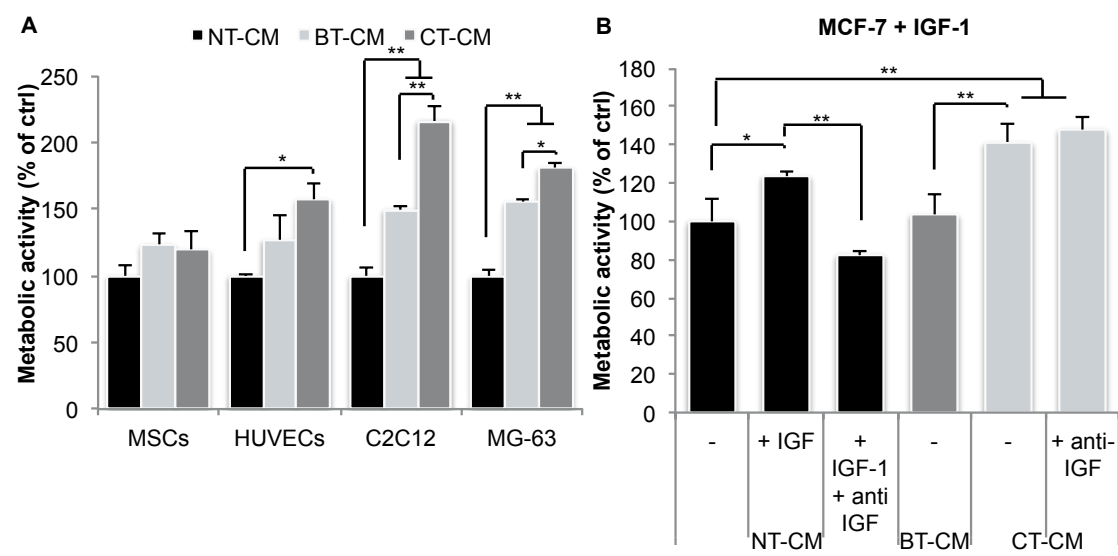

Figure 2. CT-CM enhances proliferation of various cell types but not via IGF-1. Conditioned medium was prepared as described and added to hMSCs, MG-63, HUVECs or C2C12s. After 5 more days of culture an Alamar Blue assay was performed to assess proliferation (figure a). BT-CM increased proliferation of all cell types, and in MG-63s, HUVECs and C2C12s, CT-CM increased proliferation even further. (b) To investigate if this effect on proliferation was mediated via IGF-1, conditioned medium was prepared as described before and added to the IGF-1 responsive cell line MCF-7. $10 \mathrm{ng} / \mathrm{mL}$ IGF1 induced the same increase in proliferation as CT-CM, whereas BT-CM did not have an effect. IGF1-induced proliferation was blocked by an IGF-1 neutralizing antibody as well as an IGF-1 receptor neutralizing antibody (data not shown). In contrast, CT-CM-induced proliferation was not affected by either of these antibodies, indicating that CT-CM-induced proliferation is not mediated via IGF-1. Proliferation was measured as metabolic activity and is shown as percentage of control. IGF-1; insulinlike growth factor-1, anti-IGF; IGF-1 neutralizing antibody. ${ }^{*}=\mathrm{p}<0.05,{ }^{* *}=\mathrm{p}<0.01$.

whereas BT-CM does not have an effect. However, whereas neutralization of IGF-1 using an IGF-1-binding antibody or a receptor-neutralizing antibody (data not shown) reduced IGF-1-induced proliferation, the antibody had no effect on CT-CM-induced proliferation, indicating other active signaling pathways.

Previously, we found that cAMP itself, both in high and low concentrations, has a detrimental effect on proliferation of hMSCs and it is thus unlikely that the increase in proliferation is due to trace elements of cAMP in the conditioned medium. However, the increase in cell number when preparing BT-CM, as compared to the relatively lower cell numbers during preparation of CT-CM, could result in exhaustion of the medium, thus explaining the differences between BT-CM and CT-CM. Therefore, glucose and lactate concentrations in the medium were measured both directly after treatment and in the CM. Figure 3a shows that there are no differences between glucose levels in medium from cells cultured in basic medium or cells cultured in the presence of cAMP. Lactate levels however, were significantly lower when cells were cultured in the presence of cAMP, confirming higher cell numbers in basic medium (figure $3 \mathrm{~b}$ ). No differences in glucose levels were found between different conditioned mediums, or between fresh (NT-CM) and conditioned medium, indicating sufficient, and similar levels of nutrients 

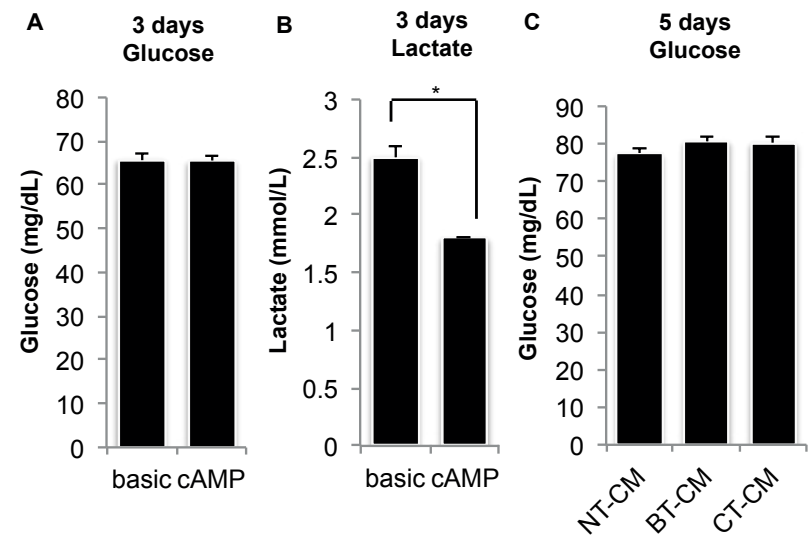

Figure 3. Nutrient availability in hMSC-conditioned medium. hMSCs were cultured with and without cAMP and medium was collected after 3 days. Then, medium without FBS was added and after two more days of incubation medium was collected again. As a measure for nutrient availability and waste production respectively, glucose and lactate concentrations were measured. After 3 days, no differences in glucose levels were found between medium from basic and cAMP-treated hMSCs (a), whereas lactate concentrations were significantly higher in medium from hMSCs in basic medium (b), demonstrating the inhibitory effect on proliferation of cAMP. After 5 days, glucose concentrations did not differ between different types of conditioned medium and lactate levels were below detection limits (c). $3 \mathrm{~d}$; 3 days, $5 \mathrm{~d} ; 5$ days. ${ }^{*}=\mathrm{p}<0.05$.

in all types of medium (figure 3c). Lactate levels in conditioned medium were all below detection limits.

\section{Effect of conditioned medium on migration}

IGF-1, which we found in high concentrations in CT-CM, has been implicated in migration of MSCs and osteoblasts $[22,23]$. To examine the effect of CT-CM on migration of various cell types, a scratch wound healing assay was performed. C2C12s, MG-63s, HUVECs and MSCs were cultured until near confluence, scratched and kept in culture in CM. Figure 4 shows pictures directly after scratching (left) and after 12 hours of culture in CM (right). Wound healing was more advanced in both types of CM and cell migration was more profound in these CMs, as compared to NT-CM after 12 hours. In order to obtain more quantitative data, a Boyden-chamber assay was used, where fresh cells were inserted in the upper chamber and conditioned medium was placed in the lower chamber. As demonstrated in figure 5, migration of C2C12s and HUVECs did not differ between BT-CM and CT-CM, although for HUVECs there was a non-significant increase in CT-CM. For MSCs and MG-63s however, migration was decreased in CT-CM as compared to BT-CM, although migration was still higher than in NT-CM. 


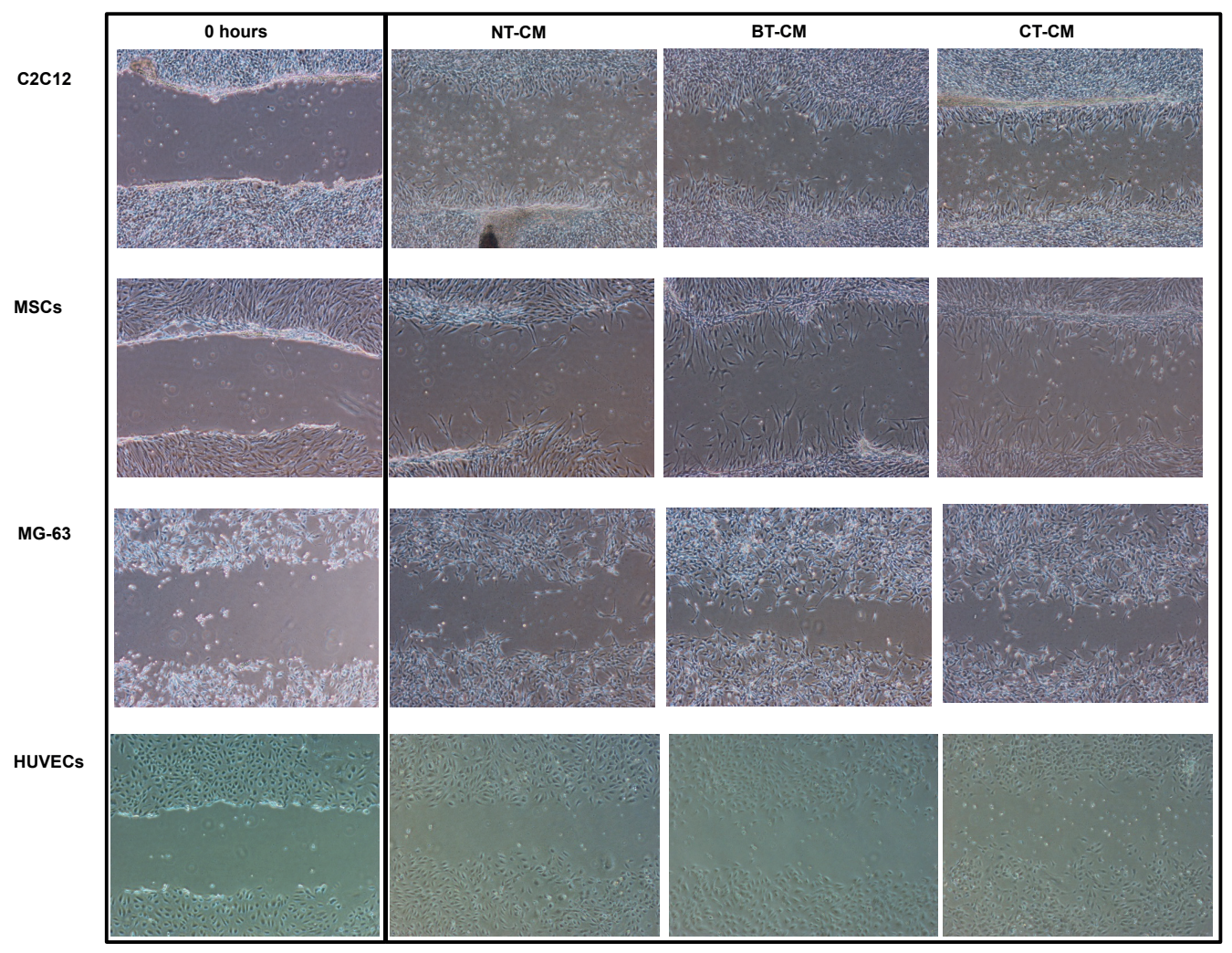

Figure 4. Conditioned medium increases migration. Conditioned medium was prepared as described, after which a scratch wound healing assay on hMSCs, MG-63s, HUVECs and C2C12s in CM was performed. Pictures on the left show the wound directly after scratching, pictures on the right show the same wound after 12 hours. Both BT-CM and CT-CM increased migration of cells into the wound compared to NT-CM, but no differences were found between the two types of CM.

\section{Effect of conditioned medium on differentiation}

To investigate if growth factor secretion induced by cAMP-treatment influences osteogenic differentiation, we cultured both C2C12s and hMSCs in CM and assessed ALP expression. Figure 6a shows that in C2C12s, both BT-CM and CT-CM elevated ALP expression compared to NT-CM, and CT-CM treatment resulted in highest ALP levels. In contrast, ALP expression of hMSCs was not affected by BT-CM or by CT-CM (figure 6b). qPCR on a panel of osteogenic genes however, showed that CT-CM does affect differentiation of hMSCs. After 6 hours of culture, osteopontin (OP), osteonectin (ON), osteocalcin (OC), Runx2 and BMP-2 expression were significantly higher in CT-CM, as shown in figure 6c. After 72 hours, expression of bone sialoprotein (BSP) was still increased, whereas expression of all other genes had returned to basal levels, suggesting fast degradation of secreted proteins in CT-CM. 

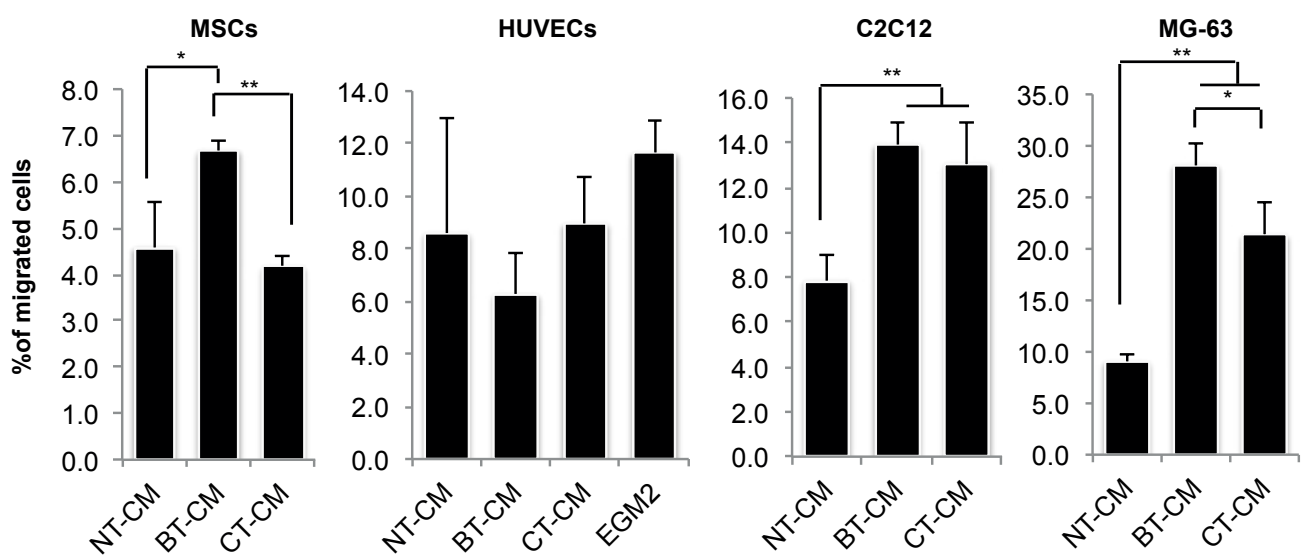

Figure 5. Conditioned medium differentially affects cell migration. Conditioned medium was prepared as described, after which migration of hMSCs, MG-63s, HUVECs and C2C12s towards CM was investigated using a transwell assay. Migration of MSCs and MG-63s was decreased in CT-CM compared to BT-CM, although migration was still higher than in NT-CM. Migration of C2C12s and HUVECs was not changed between BT-CM and CT-CM, although for HUVECs there was a non-significant increase in CT-CM. ${ }^{*}=\mathrm{p}<0.05,{ }^{* *}=\mathrm{p}<0.01$.

\section{Paracrine signaling via the BMP pathway}

We have previously demonstrated that cAMP induces the expression of BMP-2 and BMP-2 target genes, such as inhibitors of differentiation (Id) 1 and 2 and that expression of Id2 is sensitive to an inhibitor of translation, suggesting that this gene is indirectly activated [20]. To examine if Id1 and Id 2 are activated through secreted BMPs as well, hMSCs were treated with cAMP in the presence or absence of a BMP inhibitor (BMPRIA). Figure 7a shows that both BMP-2 and cAMP induce Id 2 gene expression, but cAMP is much more potent and activates Id 2 almost 50 -fold. In hMSCs treated with both BMP2 and BMPR-IA, Id2 gene expression was reduced to basal level, and in hMSCs treated with both CAMP and BMPR-IA, Id2 gene expression was reduced to almost 25-fold (2fold decrease). Similarly, a non-significant 2-fold decrease in Id1 expression was found in the presence of BMPR-IA. Id1 contains a cAMP responsive element (CRE) [24] and Id2 was implicated in cAMP/PKA signaling as well [25] and this data demonstrates that both Id 1 and Id 2 are in part directly activated by cAMP and partly indirectly via paracrine BMPs. In addition, figure $7 \mathrm{~b}$ shows that CT-CM induced a significant increase in Id2 gene expression in MSCs after 6 hours of culture, which was reduced to basal levels after 72 hours, whereas Id1 expression was increased after both 6 and 72 hours. The discrepancy after 72 hours might be due to other growth factors in the CM that can activate Id genes. 

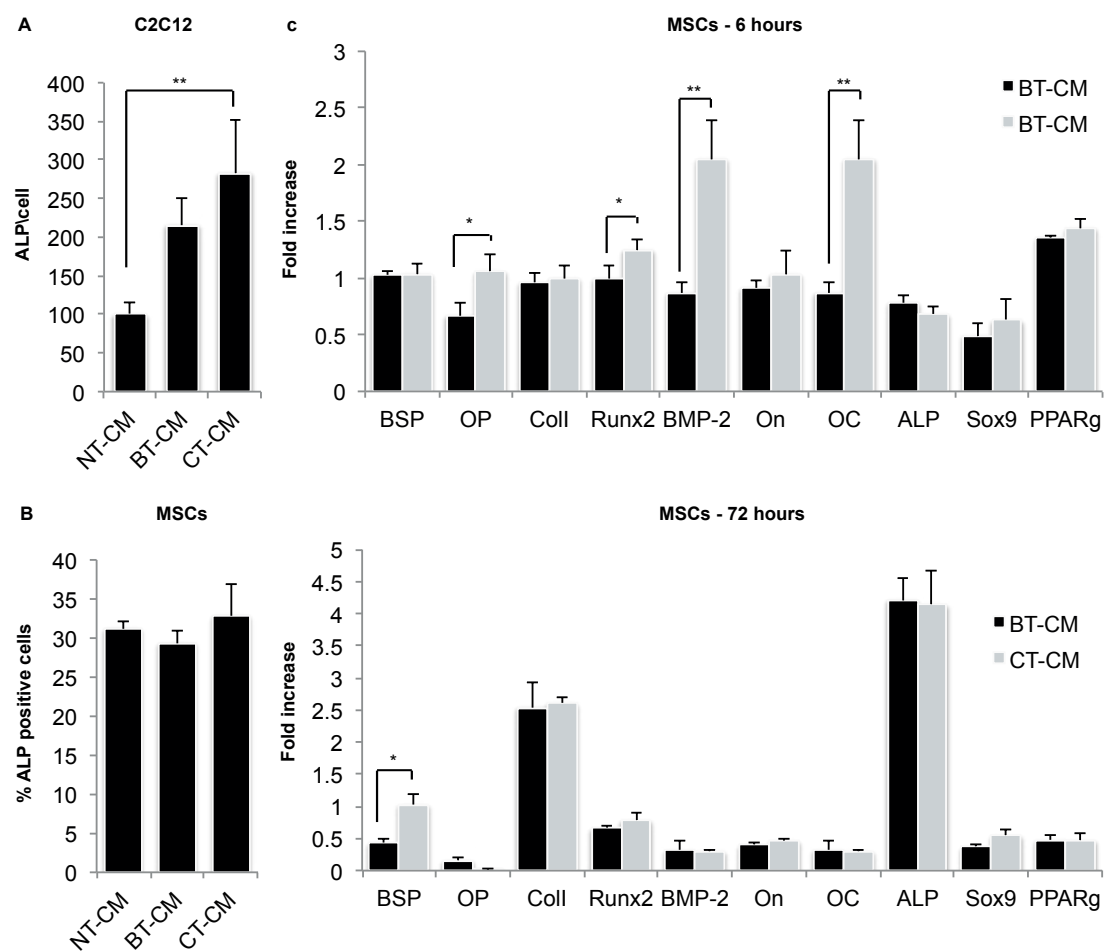

Figure 6. CT-CM induces differentiation of C2C12s and hMSCs. Conditioned medium was prepared as described, after which hMSCs and C2C12s were cultured in this medium. After 4 days, cells were lysed and ALP expression levels were determined by FACS (for hMSCs) or CDP-star (for C2C12s). For CDP-star, ALP levels were normalized to cell number and data is depicted as percentage of control (NT-CM). (a) In C2C12s, both BT-CM and CT-CM induced ALP expression, but culture in CT-CM resulted in higher ALP levels than BT-CM. (b) ALP expression of hMSCs was not affected by either type of CM. (c) hMSCs were cultured in CM for 6 and 72 hours after which qPCR on a panel of osteogenic genes was performed. After 6 hours of culture, an increase in expression of BSP, OP, ON, Runx2, BMP-2 and OC was found. After 72 hours, expression of most genes returned to basal levels, except for BSP which was upregulated 2-fold in CT-CM. BSP; bone sialoprotein, Col I; collagen type I, OP; osteopontin, OC; osteocalcin, ON; osteonectin, BMP-2; bone morphogenetic protein-2, Runx2; runt-related transcription factor $2 .^{*}=\mathrm{p}<0.05,{ }^{* *}=\mathrm{p}<0.01$.

\section{Microarray analysis}

Previously, we identified a number of bone-specific growth factors secreted by cAMPtreated-MSCs, amongst which BMP-2, IGF-1, Il-11 and Il-8, but also BMP-6, BMP-8, growth differentiation factor-1 and -10, [20]. To investigate the downstream signaling pathways that are activated by these secreted growth factors, a microarray was performed on hMSCs that were cultured in BT-CM or CT-CM for 6 and 72 hours. The obtained data was analyzed for changes in canonical pathways using IPA, as well as for up- or downregulation of single genes. IPA demonstrated that various pathways involved in proliferation and cell survival were upregulated in CT-CM, amongst which 


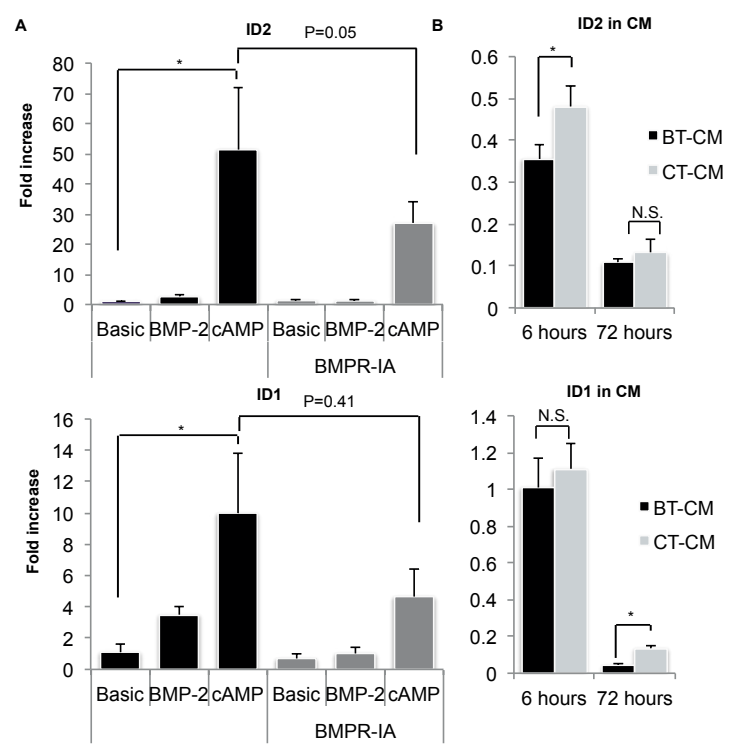

Figure 7. CT-induced Id1 and Id2 expression is partly mediated via the BMP-pathway. hMSCs were cultured in the presence or absence of cAMP, BMP2 and/or BMPR-IA. (a) After 5 days of culture, gene expression of the BMP target genes Id1 and Id2 were increased by both cAMP- and BMP-2 treatment. BMP-induced expression of these genes was inhibited by BMPR-IA, and blockage of this receptor also resulted in a 2 -fold decrease of cAMP-induced Id1 and Id2 expression. (b) Treatment of hMSCs with CT-CM for 6 hours resulted in a slight increase in Id2 expression, but no differences were found after 72 hours. Id1 expression was increased in CT-CM after both 6 and 72 hours. BMPR-IA; anti-BMP receptor-IA. ${ }^{*}=\mathrm{p}<0.05$.

interleukin signaling $(\mathrm{p}=0,0002)$, IGF-signaling $(\mathrm{p}=0,0014)$ and ERK5-signaling $(p=0,0125)$. In line with these findings, the top five single genes upregulated in CT-CM, contained four genes involved in cell metabolism. Phosphoserine aminotransferase 1 (PSAT1), which was demonstrated to be involved in cell growth and survival [26], was increased 14-fold in MSCs in CT-CM. Furthermore, asparagine synthetase (ASNS) and tribbles homolog 3 (TRIB3) were increased 9-fold by CT-CM. These genes have been described to be involved in the stress-induced activating transcription factor 4 (ATF4) pathway, which can be activated upon amino acid starvation, with ASNS a target gene of ATF4 and TRIB3 a negative regulator of this pathway [27]. ATF4 gene expression itself was changed approximately 3 -fold, suggesting induction of stress or a lack of amino acids for hMSCs in CT-CM, perhaps due to extensive proliferation. As mentioned above, cAMP has a negative effect on proliferation of hMSCs, and due to lower cell numbers during the preparation of CT-CM, it is unlikely that the ATF4 pathway is activated due to a lack of nutrients in CT-CM as compared to BT-CM. It has been demonstrated that IGF-1 increases cellular and nuclear levels of ATF 4 upon stress-induction, thereby preventing apoptosis [28]. Canonical pathway analysis also showed increased signaling of other pathways involved in osteogenesis; oncostatin $M$ signaling $(p=0,001)$, wnt $/ \beta$ signaling $(\mathrm{p}=0,047)$ and vitamin $\mathrm{D} / \mathrm{XRX}$ activation $(\mathrm{p}=0,015)$.

\section{Discussion}

Bone tissue engineering is based on the concept that implanted cells differentiate, deposit a matrix and thus form new bone. Pre-differentiation of implanted cells may increase bone formation due to a more osteogenic phenotype of the implanted cells. 
Here, we hypothesize that not only the direct differentiation, but also increased growth factor secretion of pre-differentiated cells contributes to the increase in bone formation by triggering surrounding cells (host cells) to participate in the bone formation process. Untreated MSCs have been demonstrated to secrete VEGF, which enhances new blood vessel formation, hepatocyte growth factor (HGF), transforming growth factor- $\beta$ (TGF- $\beta$ ), prostaglandin-E2 (PGE2) and Il-10 [29] which are involved in immunosuppression, as well as stromal derived factor- $1 \alpha$ (SDF-1 $\alpha$ ), IGF-1, and fibroblast growth factor-2 (FGF2) which are involved in migration, recruitment of regenerative factors and the reduction of apoptosis and scar formation [30]. For various applications, it has been demonstrated that pre-treatment of MSCs can make their growth factor secretion more suitable and more specific for the given application. For GVHD for example, pre-conditioning of MSCs with TNF $\alpha$ results in immune activation and thus leads to enhanced secretion of antiinflammatory growth factors and cytokines [31]. On the other hand, for applications where enhanced vasculature is required, such as myocardial infarcts and kidney failure, hypoxia pre-treatment increases the amount of secreted angiogenic cytokines, such as VEGF, angiopoietin-like-1 and Il-6 [32], but also pro-survival genes, such as Bcl-2 and Bcl-xL [33]. In vivo, the effect of hypoxia pre-conditioning was also demonstrated, as hypoxia hMSCs were shown to improve blood flow and vessel formation in an ischemic hind limb model [34] and to increase angiogenesis in a rat model with myocardial infarct [33].

Here we used the small molecule cAMP to train hMSCs to secrete specific growth factors for bone tissue engineering applications. Two of the most important growth factors in bone, BMP-2 and IGF-1, were indeed secreted in high concentrations by cAMP-treated-MSCs, as well as other bone-specific factors. Furthermore, proliferation and differentiation of different cell types; endothelial cells, osteoblast-like cells, and progenitor cells were increased by CT-CM. We suggest that secreted factors in vivo trigger migration of endothelial cells, thus improving the vasculature, but also enhance proliferation of both osteoblasts and endothelial cells. We found that paracrine signaling occurs via the BMP pathway, suggesting that BMPs might trigger differentiation of surrounding host cells. We also found IGF-1 in high concentrations in medium from CT-MSCs. IGF-1 has been described as a chemoattractant $[22,23]$, but we did not observe increased migration in CT-CM. IGF-1 is also known as a mitogen [35], but we were not able to confirm that the observed effects on proliferation were due to IGF1. Microarray analysis demonstrated upregulation of various other pathways involved in proliferation, possibly underlying the observed effects on proliferation. Microarray analysis also pointed to increased ATF4 signaling, possibly preventing apoptosis and resulting in increased cell survival upon implantation in vivo. On the other hand, several studies have implicated ATF4 as a regulator of osteogenesis. It has been described to control transcriptional regulation of more mature osteoblasts, although not exclusively, 
to control posttranscriptional regulation of collagen type I and to regulate expression of osteocalcin and BSP, which indeed we found upregulated in MSCs in CT-CM [36]. ATF4-deficient mice display significantly lower bone mass, due to a lack of terminal differentiation of osteoblasts as well as defects in osteoblast function [36]. Both insulin and IGF-1 induce expression of ATF4, as well as the ATF4 target genes ASNS and Psat1 in $\mathrm{C} 2 \mathrm{C} 12 \mathrm{~s}$ [37], but also BMP-2 induces endoplasmic reticulum stress and, as a result, expression of ATF4 [38]. Furthermore, ATF4 increases the expression of collagen receptor discoidin domain receptor tyrosine kinase (DDR2), which in turn stimulates runx2 expression [39] and indeed a 2-fold increase in DDR2 expression in CT-CM was found here. Also of interest, TRIB3, increased 9-fold in CT-CM, has been implicated as a negative regulator of adipogenic differentiation [40] and as a positive regulator of BMP signaling by prompting smad ubiquitin regulatory factor 1 (Smurf1) for degradation [41].

The concept of growth factor secretion to enhance bone formation is not novel. MSCs engineered to overexpress genes such as BMPs improve bone formation. Secreted BMP-2 also acts in paracrine manners on target tissues in vitro [42] and bone formation in vivo using BMP-7 expressing cells, was composed of a mixture of host and donor cells [43], suggesting the release of active, paracrine osteoinductive factors. In addition, release of BMP-2 from scaffolds induces bone formation by host cells, although implanted cells participate in new bone formation as well [17]. Newly formed vasculature is of key importance in bone tissue engineering, stretching the importance of VEGF signaling. Although overexpression of VEGF alone does not improve bone formation, it does have synergistic effects with BMP-induced bone formation [44]. Conditioned medium of VEGF-overexpressing MSCs improved tube formation by endothelial cells, whereas MSCs infected with lentiviral siRNA against VEGF reduced blood vessel formation upon implantation in tumors, as compared to non-infected counterparts [45]. In addition, human MSCs secrete relatively low amounts of VEGF, as compared to porcine MSCs [46], which was reflected in the effect of their conditioned medium on cardiac repair. Overexpression of VEGF however, resulted in similar effects by human MSCs as porcine MSCs. Overall these experiments suggest that the enhanced vasculature induced by these cells is indeed mediated via trophic signaling. Indicating a trophic effect of MSCs in bone tissue engineering as well, is the recently published data by He et al., who demonstrated that higher hydroxyapatite content in scaffolds correlated to increased secretion of both osteopontin and VEGF, which was accompanied by increased bone formation and blood vessel density [47]. Although the species origin of the newly formed bone and vessels was not determined, these results suggest that these secreted growth factors have trophic effects in vivo. Enhanced secretion of bone-specific growth factors is likely to increase the contribution of host cells. Stenderup et al. showed that bone formation by MSCs ectopically implanted on HA/TCP scaffolds was solely from human origin [48], 
but there are also cases where implanted MSCs in mice or rat could not be traced back after a few weeks (unpublished data, personal communication with Henk-Jan Prins), suggesting that the cells migrate from the implantation site or die and that new bone formation is not due to implanted cells.

Regardless of safety issues associated with viral introduction of specific genes into MSCs, this approach has been shown to be successful and to improve bone tissue engineering in animal models. This approach, however, results in the enhanced secretion of one specific growth factor; thus leading to either enhanced bone formation, or an improved vasculature. Overexpression of multiple growth factors has even more robust effects on bone formation [44]. Priming hMSCs using cAMP, as we show here, results in the enhanced secretion of a panel of bone-specific growth factors, but also angiogenic growth factors, although naturally the concentrations obtained here are much lower than would be achieved by viral overexpressing. As demonstrated, this panel of growth factors improves proliferation and also affects differentiation. It is likely that these effects could be further optimized. Therefore, for future applications, we suggest that high-throughput-screens (HTS) on small molecules, instead of using conventional ALP as a read-out, should be aimed at the secretion of bone-specific and angiogenic growth factors. The same could be applied to the design of new scaffold and/ or surface topographies. Similarly, to improve the use of trophic MSCs in therapeutic applications, HTS using libraries of small molecules can be used to identify compounds that for example, induce secretion of immunomodulatory factors for treatment of graftversus-host-disease.

\section{Conclusions}

We demonstrate here that treatment of hMSCs with the small molecule db-cAMP, which has been shown to enhance bone formation of hMSCs in vivo, results in secretion of growth factors involved in bone formation. These secreted factors are biologically active, as demonstrated by conditioned medium derived from cAMP-treated MSCs, which improves proliferation and osteogenic differentiation of different cell types. This data suggests that not only the direct differentiation of hMSCs, but also their trophic effect contributes to new bone formation in bone tissue engineering applications.

\section{Acknowledgments}

We would like to thank dr. Auke Renard from the Medisch Spectrum Twente for kindly providing us with bone marrow aspirates, prof. Joop van Zoelen from Radboud University Nijmegen for providing the MCF-7 cell line and prof. André Uitterlinden at Erasmus MC for the use of the Illumina equipment. Furthermore, the authors gratefully 
acknowledge the support of the TeRM Smart Mix Program of the Netherlands Ministry of Economic Affairs and the Netherlands Ministry of Education, Culture and Science and STW for a VIDI grant to J.d.B. 


\section{References}

1. Friedenstein AJ, Petrakova KV, Kurolesova AI, Frolova GP. (1968) Transplantation 6, 230-247

2. Pittenger MF, Mackay AM, Beck SC, Jaiswal RK, et al. (1999) Science 284, 143-147

3. Brazelton TR, Rossi FM, Keshet GI, Blau HM. (2000) Science 290, 1775-1779

4. Oswald J, Boxberger S, Jørgensen B, Feldmann S, et al. (2004) Stem cells 22, 377-384

5. Dezawa M, Ishikawa H, Itokazu Y, Yoshihara T, et al. (2005) Science 309, 314-317

6. Haynesworth SE, Baber MA, Caplan AI. (1996) J Cell Physiol 166, 585-592

7. Beyth S, Borovsky Z, Mevorach D, Liebergall M, et al. (2005) Blood 105, 2214-2219

8. Majumdar MK, Thiede MA, Mosca JD, Moorman M, et al. (1998) J Cell Physiol 176, 57-66

9. Caplan AI. (2007) J Cell Physiol 213, 341-347

10. Nauta AJ, Fibbe WE. (2007) Blood 110, 3499-3506

11. Shabbir A, Zisa D, Suzuki G, Lee T. (2009) Am J Physiol Heart Circ Physiol 296, 1888-1897

12. Quevedo HC, Hatzistergos KE, Oskouei BN, Feigenbaum GS, et al. (2009) Proc Natl Acad Sci U $S$ A 106, 14022-14027

13. Perl L, Weissler A, Mekori YA, Mor A. (2010) Isr Med Assoc J 12, 110-115

14. Cancedda R, Giannoni P, Mastrogiacomo M. (2007) Biomaterials 28, 4240-4250

15. Meijer GJ, de Bruijn JD, Koole R, Van Blitterswijk CA. (2007) PLoS Med 4, e9

16. Jeon O, Rhie JW, Kwon I-K, Kim J-H, et al. (2008) Tissue Eng Part A 14, 1285-1294

17. Kang S-W, Lee J-S, Park MS, Park J-H, et al. (2008) J Microbiol Biotechnol 18, 975-982

18. De Boer J, Licht R, Bongers M, Van Der Klundert T, et al. (2006) Tissue Eng 12, 2927-2937

19. De Boer J, Wang HJ, Van Blitterswijk CA. (2004) Tissue Eng 10, 393-401

20. Siddappa R, Martens A, Doorn J, Leusink A, et al. (2008) Proc Natl Acad Sci U S A 105, 72817286

21. Wettenhall JM, Smyth GK. (2004) Bioinformatics 20, 3705-3706

22. Nakasaki M, Yoshioka K, Miyamoto Y, Sasaki T, et al. (2008) Bone 43, 869-879

23. Ponte AL, Marais E, Gallay N, Langonné A, et al. (2007) Stem Cells 25, 1737-1745

24. Katagiri T, Imada M, Yanai T, Suda T, et al. (2002) Genes Cells 7, 949-960

25. Kurabayashi M, Dutta S, Jeyaseelan R, Kedes L. (1995) Mol Cell Biol 15, 6386-6397

26. Vié N, Copois V, Bascoul-Mollevi C, Denis V, et al. (2008) Mol Cancer 7, 14

27. Jousse Cl, Deval C, Maurin A-C, Parry L, et al. (2007) J Biol Chem 282, 15851-15861

28. Novosyadlyy R, Kurshan N, Lann D, Vijayakumar A, et al. (2008) Cell Death Differ 15, 13041317

29. Salem HK, Thiemermann C. (2010) Stem Cells 28, 585-596

30. Asanuma H, Meldrum DR, Meldrum KK. (2010) J Urol 184, 26-33

31. Lee MJ, Kim J, Kim MY, Bae Y-S, et al. (2010) J Proteome Res 9, 1754-1762

32. Hung S-C, Pochampally RR, Chen S-C, Hsu S-C, et al. (2007) Stem Cells 25, 2363-2370

33. Hu X, Yu SP, Fraser JL, Lu Z, et al. (2008) J Thorac Cardiovasc Surg 135, 799-808

34. Leroux L, Descamps B, Tojais NF, Seguy B, et al. (2010) Mol Ther 18, 1545-1552

35. Kappel CC, Velez-Yanguas MC, Hirschfeld S, Helman LJ. (1994) Cancer Res 54, 2803-2807 
36. Yang X, Matsuda K, Bialek P, Jacquot S, et al. (2004) Cell 117, 387-398

37. Adams CM. (2007) J Biol Chem 282, 16744-16753

38. Saito A, Ochiai K, Kondo S, Tsumagari K, et al. (2011) J Biol Chem 286, 4809-4818

39. Lin K-L, Chou C-H, Hsieh S-C, Hwa S-Y, et al. (2010) J Bone Miner Res 25, 2489-2503

40. Takahashi Y, Ohoka N, Hayashi H, Sato R. (2008) J Lipid Res 49, 880-892

41. Chan MC, Nguyen PH, Davis BN, Ohoka N, et al. (2007) Mol Cell Biol 27, 5776-5789

42. Gersbach CA, Guldberg RE, García AJ. (2007) J Cell Biochem 100, 1324-1336

43. Krebsbach PH, Gu K, Franceschi RT, Rutherford RB. (2000) Hum Gene Ther 11, 1201-1210

44. Peng H, Wright V, Usas A, Gearhart B, et al. (2002) J Clin Invest 110, 751-759

45. Beckermann BM, Kallifatidis G, Groth A, Frommhold D, et al. (2008) Br J Cancer 99, 622-631

46. Zisa D, Shabbir A, Suzuki G, Lee T. (2009) Biochem Biophys Res Commun 390, 834-838

47. He J, Genetos DC, Leach JK. (2010) Tissue Eng Part A 16, 127-137

48. Stenderup K, Rosada C, Justesen J, Al-Soubky T, et al. (2004) Biogerontology 5, 107-118 


\section{CHAPTER 7.}

\section{Insulin-like growth factor-1 enhances proliferation and differentiation of human mesenchymal stromal cells}

Joyce Doorn ${ }^{1}$

Scott Roberts ${ }^{2,3}$

Janneke Hilderink ${ }^{1}$

Aart van Apeldoorn ${ }^{1}$

Clemens van Blitterswijk ${ }^{1}$

Jan Schrooten ${ }^{3,4}$

Jan de Boer ${ }^{1}$

1 Department of Tissue Regeneration, MIRA Institute for Biomedical Technology and Technical Medicine, University of Twente, Enschede 7500 AE, The Netherlands.

${ }^{2}$ Laboratory for Skeletal Development and Joint Disorders, Katholieke Universiteit Leuven, O\&N 1, Herestraat 49, bus 813, 3000 Leuven, Belgium.

${ }^{3}$ Prometheus, Division of Skeletal Tissue Engineering, Katholieke Universiteit Leuven, O\&N 1, Herestraat 49, bus 813, 3000 Leuven, Belgium.

${ }^{4}$ Department of Metallurgy and Materials Engineering, Katholieke Universiteit Leuven, Kasteelpark Arenberg 44, bus 2450, 3001 Heverlee, Belgium.

Fortune favors the prepared mind.

- Louis Pasteur 


\begin{abstract}
Human mesenchymal stromal cells (hMSCs) offer great potential for bone tissue engineering applications, but their in vivo performance remains limited. Pre-conditioning of these cells with small molecules to improve their differentiation prior to implantation or incorporation of growth factors are possible solutions. Insulin-like growth factor-1 (IGF1 ) is one of the most abundant growth factors in bone, involved in growth, development and metabolism, but its effects on hMSCs is still subject of debate. Herein, we examined the effects of IGF-1 on proliferation and differentiation of hMSCs in vitro and we found that serum abolished the effects of IGF-1. Only in the absence of serum, IGF-1 increased proliferation, ALP expression and osteogenic gene expression of hMSCs. Furthermore, we examined synergistic effects of BMP-2 and IGF-1 and, although IGF-1 enhanced BMP-2induced mineralization, IGF-1 only slightly affected in vivo bone formation.
\end{abstract}




\section{Introduction}

Cell-based bone tissue engineering aims to construct substitutes for large bone defects. Human mesenchymal stromal cells (hMSCs) are one of the most interesting cell sources for this application, due to their easy isolation, their presence in the adult body and their capacity to proliferate and differentiate. However, so far the in vivo performance of these cells is limited and to improve their performance, efforts are made to differentiate the cells prior to implantation, or to add molecules or growth factors that induce bone formation.

Insulin-like-growth-factor-I (IGF-I or somatomedin C) is one of the most abundant growth factors in the bone matrix, involved in growth, development and metabolism. It is produced locally as well as systemically by the liver and its biological actions are regulated by the acid-labile subunit (ALS) and six binding proteins (IGFBPs), which can either enhance or inhibit its actions by preventing access to the IGF-I receptor (IGFR-I) [1]. Systemic production of IGF-1 by the liver is regulated by growth hormone (GH) and this system is thus referred to as the GH/IGF-1 axis [2,3]. Locally, IGF-1 is produced by a variety of cell types, which is regulated not only by GH but also by numerous other factors.

Several mouse models have demonstrated a key role of IGF-1 in bone formation $[4,5]$. Complete disruption of IGF signaling, by deletion of the IGFR-I results in a reduction of cancellous bone volume, connectivity and trabecular number and increases trabecular spacing [6]. Interestingly, these mice display a dramatic decrease in mineralization, indicating an essential role for IGF-1 in the development of mature mineralized tissue [6]. IGF-1 null mice have reduced cortical bone size and femur length, although an increase in trabecular bone density and connectivity were also observed [7]. Impaired osteoclastogenesis may explain the latter findings, in line with in vitro studies showing that IGF-1 promotes osteoclastogenesis [7, 8]. Local overexpression of IGF-1 in osteoblasts resulted in increased bone mineral density and trabecular bone volume [9] and, since no increase in osteoblast number was observed, the effects of IGF-1 were suggested to be mediated via enhanced osteoblast function.

Due to its positive effects on osteoblasts, its presence at fracture sites and its involvement in the synthesis of bone matrix [10], IGF-1 has gained interest as a therapeutic factor in fracture healing; either alone or in combination with other growth factors. In vitro IGF-1 was shown to enhance proliferation of C2C12 cells, osteoblasts [11], osteoblast-like cells [12] and periodontal ligament fibroblasts [13]. It also induces alkaline phosphatase (ALP) activity, osteocalcin, matrix calcium content, and nodule formation in osteoblasts [14] and has been proven as a chemotactic factor for these cells [15]. Furthermore, in fetal rat calvariae, IGF-1 was shown to enhance osteocalcin 
secretion and incorporation of proline into collagen type I [16] and to decrease collagen degradation [17].

In hMSCs, similar effects of IGF-1 on migration were shown $[18,19]$, but the effects of IGF-1 on proliferation and differentiation are less clear. Some studies show that IGF-1 does not affect hMSCs at all $[20,21]$, whereas on the other hand, MSCs transduced with an IGF-1 adenovirus displayed increased runx2 and collagen type I expression, but not ALP [22]. Also, incorporation of IGF-1 in scaffolds enhanced proliferation and differentiation of attached hMSCs and periodontal ligament fibroblasts [23, 24]. In contrast, it has been reported that IGF-1 stimulates chondrogenic differentiation of hMSCs in the presence of TGF- $\beta$ [25], which was also demonstrated by adenoviral overexpression of IGF-1 and bone morphogenetic protein-2 (BMP-2) in adipose-derived MSCs [26]. In our own lab, we have shown that treatment of hMSCs with the small molecule db-cAMP enhances in vivo bone formation, which is accompanied by increased secretion of bone specific growth factors, such as BMP-2, but also IGF-1 [27]. Conditioned medium from these treated cells increased proliferation of various cell types, thus indicating a trophic effect [28], but it is unknown if secreted IGF-1 can affect the implanted hMSCs.

In this study we examined the effects of IGF-1 on proliferation and differentiation of hMSCs, both in the presence and absence of serum, which may contain proteins that neutralize IGF-1 function. In addition, with an adenoviral transduction system, we investigated if IGF-1 has effects on in vivo bone forming capacity of hMSCs, either alone or in combination with BMP-2.

\section{Materials and methods}

\section{Cell culture}

Bone marrow aspirates (5-20 ml) were obtained from donors with written informed consent. hMSCs were isolated and proliferated as described previously [29]. Briefly, aspirates were re-suspended using 20G needles, plated at a density of $5 \times 10^{5}$ cells $/ \mathrm{cm}^{2}$ and cultured in hMSC proliferation medium containing $\alpha$-minimal essential medium ( $\alpha$-MEM, Life Technologies), 10\% fetal bovine serum (FBS, Cambrex), $0.2 \mathrm{mM}$ ascorbic acid (Asap, Life Technologies), 2 mM L-glutamine (Life Technologies), $100 \mathrm{U} / \mathrm{ml}$ penicillin (Life Technologies), $10 \mu \mathrm{g} / \mathrm{ml}$ streptomycin (Life Technologies) and $1 \mathrm{ng} /$ $\mathrm{ml}$ basic fibroblast growth factor (bFGF, Instruchemie, The Netherlands). Cells were grown at $37{ }^{\circ} \mathrm{C}$ in a humid atmosphere with $5 \% \mathrm{CO}_{2}$. Medium was refreshed twice a week and cells were used for further sub-culturing or cryopreservation upon reaching near confluence. For osteogenic experiments, hMSCs were cultured in basic medium, composed of hMSC proliferation medium without bFGF. The osteosarcoma cell line MG63 was expanded and cultured in basic medium as described above. Recombinant human 
insulin-like growth factor-I (rhIGF-1) was obtained from R\&D systems and used in concentrations between 10 and $150 \mathrm{ng} / \mathrm{mL}$. Recombinant human bone morphogenetic protein-2 (rhBMP-2) was obtained from Biodoor Biotechnology co., Ltd (Hangzhou, China) and used at a concentration of $100 \mathrm{ng} / \mathrm{mL}$, unless stated otherwise.

\section{Proliferation}

hMSCs or MG-63 cells were seeded in triplicate in 24-well plates at 2000 cells $/ \mathrm{cm}^{2}$ and allowed to attach for 10 to 15 hours in proliferation medium or basic medium respectively. Then, the medium was changed to basic medium with or without FBS with various concentrations of rhIGF-1. After 5 days an Alamar Blue assay (BioSource) was performed. A $10 \% \mathrm{v} / \mathrm{v}$ solution of Alamar Blue in medium was prepared and 1 $\mathrm{mL}$ of solution was added to each well. After 4 hours, the fluorescence intensity of the solution in each well was determined by measuring $200 \mu \mathrm{L}$ of solution at an excitation wavelength of $545 \mathrm{~nm}$ and an emission wavelength of $590 \mathrm{~nm}$ (Victor, Perkin Elmer).

\section{ALP expression}

hMSCs were seeded in triplicate in 6-well plates at 5000 cells $/ \mathrm{cm}^{2}$ and allowed to attach for 10 to 15 hours in proliferation medium. Each experiment was performed in triplicate with a negative control (cells grown in basic medium) and one or more experimental conditions (with or without FBS, various concentrations of IGF-1). After 4 days, cells were trypsinized and incubated for 30 minutes in block buffer (PBS with 5\% bovine serum albumin, BSA [Sigma] and $0.01 \% \mathrm{NaN}_{3}$ ) and then incubated with primary antibody (anti-ALP, B4-78 [Developmental Studies Hybridoma Bank, University of Iowa, USA]) diluted in wash buffer (PBS with 1\% BSA and $0.05 \% \mathrm{NaN}_{3}$ ) for 1 hour or with isotype control antibodies. Cells were then washed three times with wash buffer and incubated with secondary antibody (rat anti mouse IgG PE, DAKO) diluted in wash buffer for 30 minutes. Cells were washed three times and resuspended in 250 $\mu \mathrm{l}$ wash buffer with $10 \mu \mathrm{l}$ Viaprobe (Pharmingen) for live/dead cell staining. Only living cells were used for further analysis. With the isotypes set to zero, the amount of ALP-positive cells were analyzed on a FACS Caliber using cell-quest software (Becton Dickinson Immunocytometry systems). ALP expression was then calculated relative to the respective negative control.

\section{ALP activity}

MG-63 cells were seeded in triplicate in 12-well plates at 5000 cells $/ \mathrm{cm}^{2}$ and allowed to attach for 10-15 hours. The next day, medium was changed to medium with or without FBS, with various concentrations of IGF-1. As a negative control, cells were cultured in basic medium. After 4 days of culture an Alamar Blue assay was performed. Then, cells were lysed with CDP star lysis buffer and the lysate was used for a CDP star 
assay (Roche). Briefly, $30 \mu \mathrm{L}$ of CDP star substrate was incubated with $10 \mu \mathrm{L}$ of cell lysate for 30 minutes after which luminescence was measured (Victor, Perkin Elmer). ALP expression was normalized to metabolic activity, and data is depicted as percentage relative to control.

\section{Calcium deposition}

Cells were seeded in triplicate in 6-well plates at 5000 cells $/ \mathrm{cm}^{2}$ and allowed to attach for 10 to 15 hours in proliferation medium. Then, either mineralization medium alone (composed of basic medium supplemented with $10^{-8} \mathrm{M}$ dex and $0.01 \mathrm{M}$ $\beta$-glycerophosphate (Sigma)) or mineralization medium supplemented with $75 \mathrm{ng} / \mathrm{mL}$ BMP-2, $100 \mathrm{ng} / \mathrm{mL}$ IGF-1 or a combination of both was added and cells were kept in culture for 14-21 days. Then, culture medium was aspirated, cells were washed twice with calcium- and magnesium-free PBS (Life Technologies) and incubated overnight with $0.5 \mathrm{M} \mathrm{HCl}$ on an orbital shaker at room temperature. Then the supernatant was collected and the amount of calcium was determined using a calcium assay kit (Quantichrom calcium assay kit, Gentaur), by measuring the absorbance at $620 \mathrm{~nm}$ (Tecan). Data is depicted as dg calcium per $\mathrm{mL} \mathrm{HCl}$.

\section{Gene expression analysis}

Cells were seeded in triplicate in 6-well plates at 10,000 cells $/ \mathrm{cm}^{2}$ in proliferation medium. The next day, medium was replaced with basic medium with or without serum, and $100 \mathrm{ng} / \mathrm{mL} \mathrm{IGF-1} \mathrm{was} \mathrm{added} \mathrm{to} \mathrm{denoted} \mathrm{conditions.} \mathrm{RNA} \mathrm{was} \mathrm{isolated} \mathrm{after} 24 \mathrm{hrs}$, 48 hrs, 72 hrs, 5 days and 10 days, using a Bioke RNA II nucleospin RNA isolation kit (Machery Nagel). For gene overexpression experiments, cells were kept in culture for 2 or 5 days after medium change and RNA was isolated. RNA concentrations were measured using an ND100 spectrophotometer (Nanodrop technologies, USA) and cDNA was synthesized from $100 \mathrm{ng}$ of RNA, using iScript (BioRad) according to the manufacturer's protocol. For quantitative PCR, a master mix, containing distilled water,

Table 1. Primer sequences

\begin{tabular}{lll}
\hline Gene & Forward primer & Reverse primer \\
\hline 18s & CGGCTACCACATCCAAGGAA & GCTGGAATTACCGCGGCT \\
IGF-I & CTTCAGTTCGTGTGTGGAGACA & CGCCCTCCGACTGCTG \\
Collagen type I & AGGGCCAAGACGAAGACATC & AGATCACGTCATCGCACAACA \\
Runx2 & ATGGCGGGTAACGATGAAAAT & ACGGCGGGGAAGACTGTGC \\
ALP & GACCCTTGACCCCCACAAT & GCTCGTACTGCATGTCCCCT \\
Osteocalcin & GGCAGCGAGGTAGTGAAGAG & GATGTGGTCAGCCAACTCGT \\
Osteonectin & ACTGGCTCAAGAACGTCCTG & GAGAGAATCCGGTACTGTGG \\
S100A4 & AGCTTCTTGGGGAAAAGGAC & CCCCAACCACATCAAGAGG \\
\hline
\end{tabular}


forward primer, reverse primer (Sigma Genosys), BSA, and SYBR green I mix (all from Invitrogen) was prepared. Real-time qPCR was performed in a Light-Cycler (Roche). Light-Cycler data were analyzed using the fit points method of Light-Cycler software [30]. The baseline was set at the lower log-linear part above baseline noise and the crossing temperature (Ct value) was determined. Ct values were normalized to the $18 \mathrm{~S}$ housekeeping gene and $\Delta \mathrm{Ct}\left(\mathrm{Ct}_{\text {control }}-\mathrm{Ct}_{\text {sample }}\right)$ was used to calculate the relative increase in gene expression. Primer sequences are listed in table 1.

\section{Confocal Raman microspectroscopy}

UV grade $\mathrm{CaF}_{2}$ slides for Raman (Crystran LTD, UK) were sterilized using $70 \%$ ethanol and subsequently coated with proteins by incubation with FBS for 30 minutes. Then, hMSCs were seeded in triplicate at 5000 cells $/ \mathrm{cm}^{2}$ and allowed to attach overnight in proliferation medium. The next day, medium was replaced with mineralization medium, with and without IGF-1 (100 ng/mL) and BMP-2 (100 ng/mL). After 28 days of culture, cells were fixed using $10 \%$ formalin and Raman spectra were acquired. A krypton ion laser (Innova 90-K, Coherent Inc.) emitting at $647.1 \mathrm{~nm}$ was used as an excitation source. A 63x/1.0NA water-dipping objective (Zeiss W-plan Apochromat, Carl Zeiss MicroImaging) was used to focus the laser light over the sample and the Raman scattered photons were collected and dispersed on an air-cooled electron-multiplying chargecoupled device (EMCCD: Newton DU-970N, Andor Technology). An excitation power of $35 \mathrm{~mW}$ on the sample was used. Raman spectra were acquired from 15 randomly chosen cells in each culture condition.

\section{Scanning electron microscopy}

Cells were seeded in triplicate in 6-well plates at 5000 cells $/ \mathrm{cm}^{2}$ in proliferation medium. The next day, medium was replaced with basic medium with or without 100 ng/mL IGF-1 and/or $100 \mathrm{ng} / \mathrm{mL}$ BMP-2. After 10 and 17 days of culture, cells were fixed using 10\% formalin. Samples were dehydrated through a graded series of ethanol (70-100\%), critical point dried using $\mathrm{CO}_{2}$ (CPD 030, Balzers) and sputtered with gold (Cressington). SEM images were obtained using a scanning electron microscope (XL30 ESEM, Philips) at an accelerating voltage of 5 or $10 \mathrm{kV}$.

\section{Adenoviral transductions}

Adenoviruses containing an expression vector for IGF-1 (adIGF-1), BMP-2 (adBMP-2) or green fluorescent protein (adGFP, control) were purchased from Biofocus (Leiden, The Netherlands). For adenoviral transductions, hMSCs were seeded at 15,000 cells $/ \mathrm{cm}^{2}$ and allowed to attach overnight. The next day, cells were transduced in basic medium using a previously optimized (data not shown) multiplicity of infection (MOI) of 1000 for adIGF-1 and adGFP and an MOI of 250 for adBMP-2 for 24 hours, after which the 
medium was replaced with fresh medium. Transduced cells were then used for further in vitro experiments or, in case of the in vivo experiments, trypsinized, and seeded onto ceramic scaffolds for implantation.

\section{Secretion of IGF-1 and BMP-2}

hMSCs were seeded and transduced as described above. After the medium change, every 3 days medium was collected and replaced with fresh medium for a total period of 15 (control for in vitro experiments) or 30 (control for in vivo experiment) days. The concentrations of IGF-1 and/or BMP-2 in the medium were determined using ELISA (human IGF-1/BMP-2, Quantikine, R\&D systems), according to the manufacturer's protocol.

\section{In vivo bone formation}

1-2 mm biphasic calcium phosphate (BCP) particles were prepared and sintered at $1150{ }^{\circ} \mathrm{C}$ as described previously [31]. hMSCs were seeded and transduced as described above. The next day, cells were trypsinized and seeded onto BCP scaffolds with 200,000 cells/4 particles in basic medium and allowed to attach overnight. 20 minutes before surgery, nude female mice (Hsd-cpb:NMRI-nu, Harlan) were injected intraperitoneally with avertin. Particles were implanted in subcutaneous pockets, with 4 particles per pocket, 4 pockets per mouse and 10 samples per condition. Incisions were closed using surgical staples and after 6 weeks the mice were sacrificed by cervical dislocation. Particles were explanted, fixed in 4\% paraformaldehyde (Merck), dehydrated and embedded in methyl methacrylate (L.T.I. Bilthoven) for sectioning. Undecalcified sections were processed on a histological diamond saw (Leica) and sections were stained with methylene blue and basic fuchsin to visualize bone formation. Quantitative histomorphometry was performed by pseudocoloring (bone in green, scaffolds in red) scanned images of high-resolution (7200 dpi) micrographs (Pathscan Enabler IV), after which the percentage of bone per scaffold area was determined using the pixel count option in Photoshop CS5 (Adobe).

\section{Masson's Trichrome staining}

hMSC/BCP constructs were firstly fixed in $4 \%$ formaldehyde at $4{ }^{\circ} \mathrm{C}$ overnight before being decalcified in EDTA/PBS (pH 7.5) for 4 weeks. The decalcified implants were subsequently paraffin embedded and sectioned at $6 \mu \mathrm{m}$. For Masson's Trichrome analysis, the sections were deparaffinized in Histoclear ${ }^{\mathrm{TM}}$ (Laborimpex, Brussels, Belgium), then methanol and rinsed with distilled water. The slides were then immersed in Weigerts iron hematoxylin solution for 10 minutes before rinsing in warm running tap water for 10 minutes. The sections were subsequently stained with ponceau-acid fuchsin solution ( $0.5 \%$ ponceau BS, $0.5 \%$ acid fuchsin in $10 \%$ acetic acid) for 15 minutes, washed in 
distilled water and differentiated in 5\% phosphomolybdic acid 5\% phosphotungstic acid solution for 15 minutes. The sections were then transferred directly to Masson's green solution (Klinipath, Olen, Belgium) for 10 minutes before differentiation for 5 minutes in $1 \%$ acetic acid. The sections were then rinsed in distilled water, dehydrated through graded alcohol before being cleared in Histoclear for 2 minutes and mounted in Pertex.

\section{Statistics}

Data were analyzed in SPSS (PASW statistics) using one-way Anova followed by Tukey's multiple comparison test $(\mathrm{P}<0.05)$.

\section{Results}

\section{IGF-1 increases proliferation of hMSCs and MG-63 cells in the absence of serum}

To investigate the effect of IGF-1 on proliferation of hMSCs, cells were cultured in the presence of $10-150 \mathrm{ng} / \mathrm{mL}$ rhIGF-1 for 4 days, after which metabolic activity, as a measure for cell number, was determined. Since IGF-1 was previously shown to enhance proliferation of human osteoblasts in serum-free medium and the MG-63 cell line is frequently used as a model system for these cells, we used this cell line as a control.
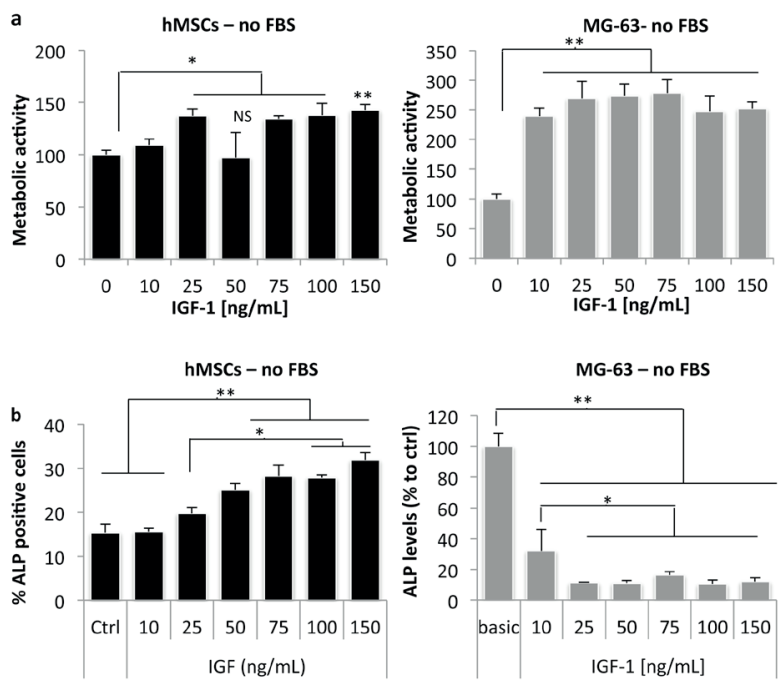

Figure 1. IGF-1 increases proliferation and differentiation of hMSCs and MG63 cells, but only in the absence of FBS. hMSCs and MG63 cells were cultured in the presence of various concentrations rhIGF-1 and proliferation and ALP activity were assessed after 4 days. When FBS was supplemented to the medium, IGF-1 did not affect proliferation (data not shown), but in the absence of FBS, IGF-1 significantly increased cell number (a). In hMSCs, IGF-1 also significantly increased ALP expression of hMSCs, whereas, in contract, in MG-63 cells, IGF decreased ALP levels. Alamar blue data is represented relative to ctrl. ${ }^{*} \mathrm{P}<0.05$ compared to $\mathrm{ctrl},{ }^{* *} \mathrm{P}<0.01$ compared to ctrl. CDP-star data is represented relative to ctrl. ${ }^{*} \mathrm{P}<0.05$ compared to ctrl, ${ }^{* *} \mathrm{P}<0.01$ compared to ctrl. 
None of the used IGF-1 concentrations affected proliferation of MG-63 cells or hMSCs (supplementary figure 1) in culture medium containing FBS. In contrast, when FBS was removed from the medium, a clear dose-dependent increase in proliferation was observed for both cell types, although MG-63 cells showed a stronger response (50\% increase in cell number) than hMSCs (20\% increase in cell number) (figure 1a).

\section{IGF-1 enhances differentiation of hMSCs in the absence of serum but decreases ALP expression of MG-63 cells}

Then, to investigate if IGF-1 also has a positive effect on osteogenic differentiation of these cells, hMSCs and MG-63 cells were cultured in the presence of rhIGF-1 with concentrations ranging from $10-150 \mathrm{ng} / \mathrm{mL}$ and ALP levels were determined. Again, in the presence of FBS there was no effect of IGF-1 (supplementary figure 2), but in the absence of FBS, a dose-dependent increase in ALP expression was observed (figure 1b).
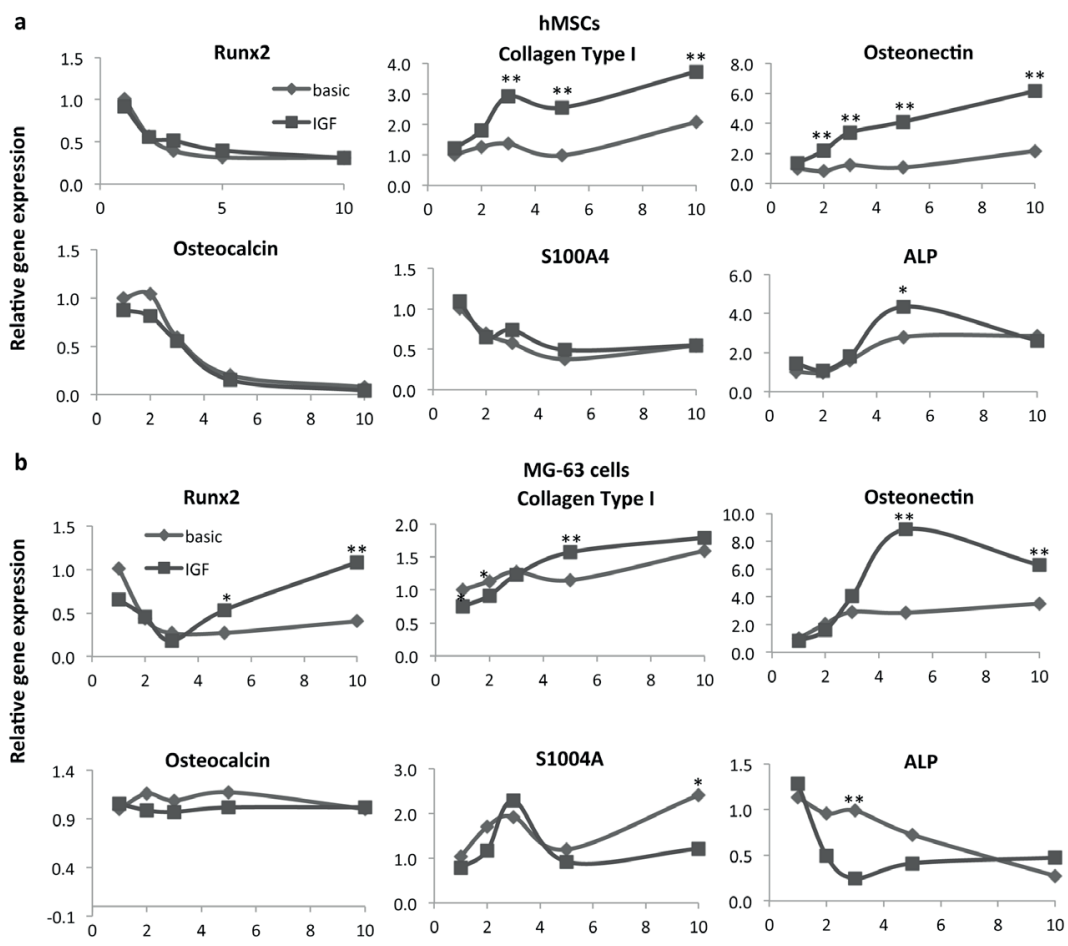

Figure 2. IGF-1 induces expression of osteogenic genes in hMSCs and MG-63. hMSCs and MG-63 cells were cultured in the presence of $100 \mathrm{ng} / \mathrm{mL}$ rhIGF, but in the absence of FBS for 1-10 days, after which gene expression levels were analyzed by qPCR. IGF-1 significantly increased gene expression of Collagen type I, osteonectin and ALP and non-significantly increased runx2 expression in hMSCs. No effect was found on osteocalcin and S100A4 (a). In MG-63 cells, IGF-1 significantly increased gene expression of Runx2, collagen type I and osteonectin, did not affect osteocalcin levels and, at day 10, decreased S1004A levels. In line with biochemical assays, ALP levels were decreased at early timepoints, but increased at later timepoints. Data is represented relative to ctrl. ${ }^{*} \mathrm{P}<0.05$ compared to ctrl, $* * \mathrm{P}<0.01$ compared to ctrl. 
In line with this, treatment of hMSCs with $100 \mathrm{ng} / \mathrm{mL}$ rhIGF-1 for a period of 1-10 days, resulted in an increase in the expression of bone marker genes such as osteonectin, collagen type I, ALP. Runx2 expression was increased, but this was not significant and osteocalcin and S1004A were not affected, as demonstrated by qPCR (figure 2a). Again, IGF-1 had no effect when FBS was supplemented to the medium. In contrast, ALP expression of MG-63 cells was significantly decreased with all concentrations of IGF-1, both in FBS-supplemented and FBS-free medium, although in the latter the effect was clearly stronger (supplementary figure 2 and figure 1b). qPCR on MG-63 cells, using a concentration of $100 \mathrm{ng} / \mathrm{mL}$ rhIGF-1, confirmed the effect on ALP gene expression, although at day 10, ALP expression was slightly higher in IGF-1 treated cells. Expression of other osteogenic markers, such as runx2, collagen type I and osteonectin, was also increased by IGF-1 at later timepoints (day 5-10), whereas there was no change in expression of osteocalcin (figure 2b), and S1004A expression was decreased. These data show that IGF-1 increases osteogenic differentiation of both MG-63 cells and hMSCs.

\section{IGF-1 enhances BMP-2-induced mineralization of hMSCs}

In mouse knock-out models, IGF-1 was suggested to correlate with matrix formation and therefore we examined the effect of IGF-1 on mineralization of hMSCs. Previously, BMP-2 has been demonstrated to increase mineralization of hMSCs, which was confirmed here for concentrations of 75 and $100 \mathrm{ng} / \mathrm{mL}$ (figure 3a), and therefore we also examined synergistic effects between these two growth factors. hMSCs were cultured in mineralization medium supplemented with $75 \mathrm{ng} / \mathrm{mL}$ BMP-2, $100 \mathrm{ng} / \mathrm{mL}$ IGF-1 or both. After 14 days, neither BMP- 2 nor IGF-1 increased calcium deposition, but, compared to control, combined treatment resulted in significant higher amounts of calcium (figure 3b). After 21 days a slight increase in calcium deposition was observed using BMP-2 or IGF-1 alone, but this was not significant. In contrast, addition of both factors resulted in a synergistic increase in calcium deposition, suggesting an interaction between these two factors. To investigate the mechanism behind the effects of IGF-1, mineralized samples were examined using Raman spectroscopy and scanning electron microscopy (SEM). Figure 3c shows Raman spectra after 28 days of culture. The calcium phosphate peak $\left(961 \mathrm{~cm}^{-1}\right)$ observed in cells cultured with BMP- 2 and BMP2/IGF-1 was higher compared to control, but no differences were observed between BMP-2 and BMP-2/IGF-1. Similarly, SEM images showed large amounts of mineralized nodules in both BMP-2 and BMP-2/IGF-1 groups, but we did not find differences in size or frequency of the nodules (figure $3 \mathrm{~d}$ ).

\section{AdIGF-1 increases runx2 and osteonectin expression in vitro}

To investigate the effects of secreted IGF-1 on in vitro differentiation of hMSCs, cells were adenovirally transduced with IGF-1 and after 5 days of culture, gene expression 

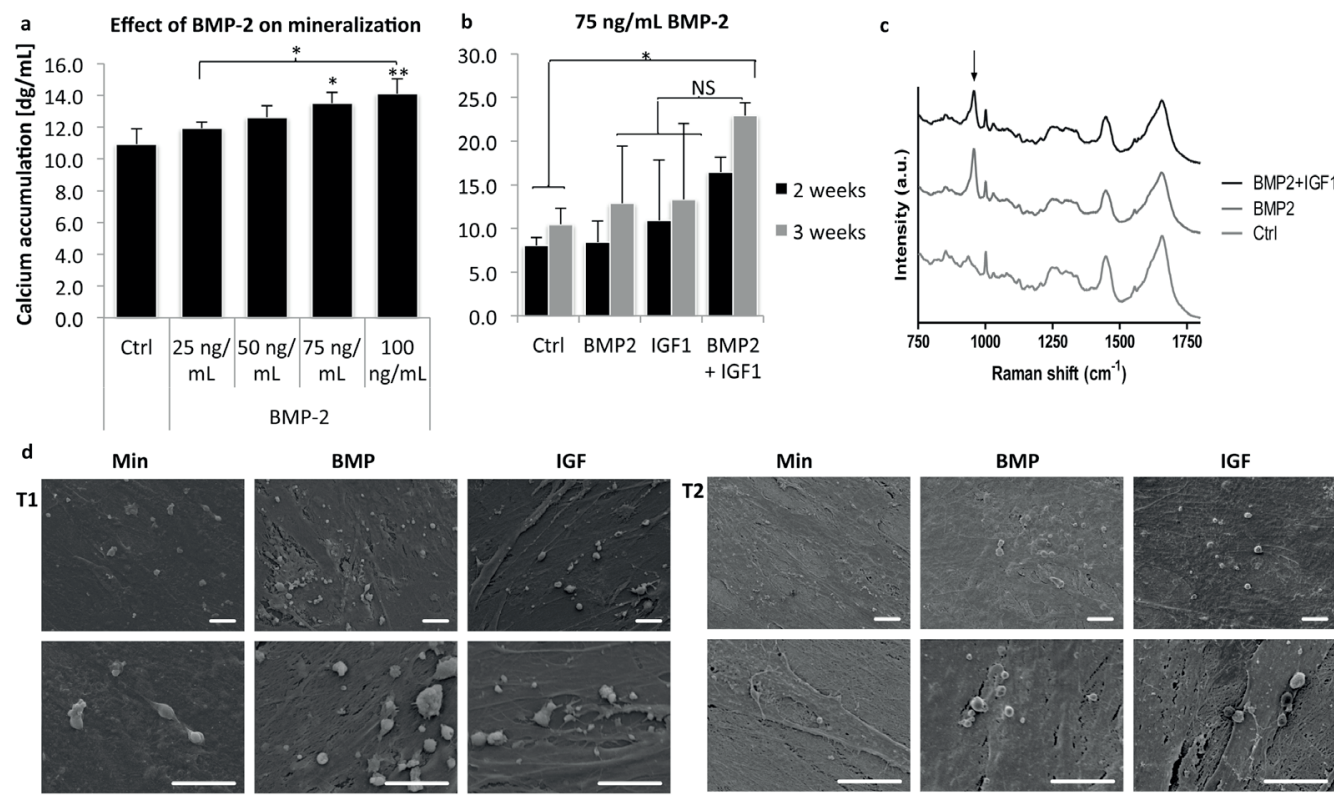

Figure 3. IGF-1 synergistically acts with BMP-2 to induce mineralization in hMSCs. hMSCs were cultured in mineralization medium in the presence of various concentrations of BMP-2. 75 and 100 ng/mL BMP-2 significantly increased calcium deposition, whereas concentrations below had no effect (a). Then, hMSCs were cultured in mineralization medium in the presence of $75 \mathrm{ng} / \mathrm{mL} \mathrm{BMP-2}$ and/or $100 \mathrm{ng} / \mathrm{mL}$ IGF-1. After 2 and 3 weeks, calcium deposition was determined. After 2 weeks, there was no effect of either BMP-2 or IGF-1, and after 3 weeks both BMP- 2 and IGF-1 alone had a small but nonsignificant effect on calcium deposition, whereas the combination of BMP-2 and IGF-1 significantly increased the amount of calcium deposited both after 2 and 3 weeks (b). Raman spectra of hMSCs cultured for 28 days in mineralization medium, with or without BMP-2 or BMP-2/IGF-1 showed no differences in proteins or nodule size (c). In addition, electron micrographs showed no differences in mineralized ECM produced by hMSCs in A) control, B) BMP-2, and C) BMP-2 + IGF-1 after 10 and 17 days of culture. Arrow in (c) indicates the Raman band around $961 \mathrm{~cm}^{-1}$, reflecting the presence of $v 1$ vibration of phosphates. Spectra are offset for clarity. T1 = 10 days, $\mathrm{T} 2=17$ days; scale bar $=10 \mu \mathrm{m}$. *

levels of runx2, collagen type I and osteonectin were examined. As depicted in figure 4a, transduction with IGF-1 resulted in high expression levels of IGF-1 already after 2 days. Compared to control, GFP transduced cells, IGF-1 also increased osteonectin and runx2 expression, but collagen type I levels were not affected. The amount of secreted IGF-1 after adenoviral transduction was determined every 3 days for a total period of 15 days, and at the time of qPCR ( 2 and 5 days), cells secreted approximately 6 or $20 \mathrm{ng} / \mathrm{mL}$ IGF1 respectively (figure $4 \mathrm{~b}$ ).

Then, to investigate the effects of IGF-1 and synergistic effects of IGF-1 and BMP-2 on in vivo bone formation, hMSCs were adenovirally transduced with IGF-1 or BMP2, or both (IGF-1/BMP-2). As a control, cells were transduced with GFP. As a control, cells from the same transduction batch were kept in culture in vitro and the cumulative 

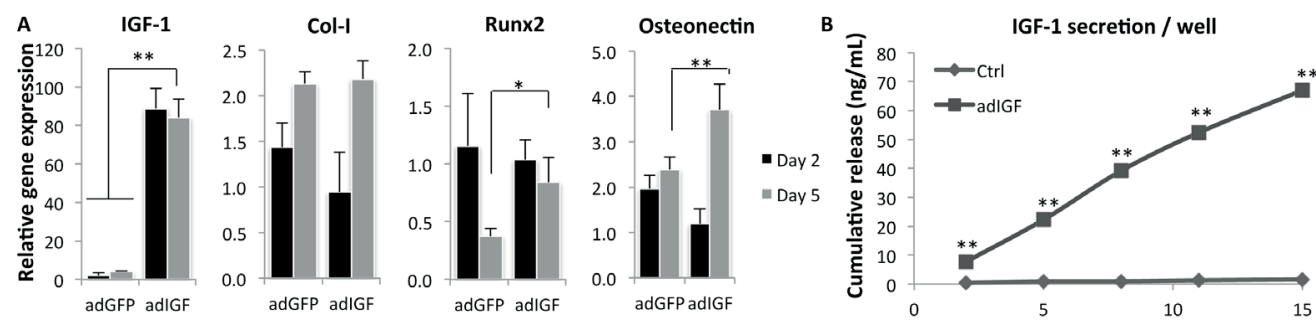

Figure 4. Adenoviral transduction with IGF-1 increases expression of runx2 and osteonectin. hMSCs were transduced with adIGF-1 and after 5 days of culture, Runx2 and collagen type I gene expression levels were determined. Overexpression of IGF-1 resulted in high expression of IGF-1, and, compared to the control (adGFP), significantly increased osteonectin levels, and runx2 levels after 5 days, but collagen type I expression was not affected (a). Every 3 days, levels of secreted IGF-1 were determined by ELISA, and showed that after 5 days, $14 \mathrm{ng} / \mathrm{mL} \mathrm{IGF-1}$ was secreted and that cells kept releasing IGF-1 until at least day 15 (b). ${ }^{*} \mathrm{P}<0.05$ compared to ctrl; ${ }^{* *} \mathrm{P}<0.01$ compared to ctrl.

release profile was determined by collecting medium every 3 days for a total period of 30 days. As depicted in figure 5a, the release of IGF-1 was significantly lower in cotransduced cells but, surprisingly, the secretion of BMP-2 was significantly increased in cells transduced with both BMP-2 and IGF-1, compared to cells transduced with BMP-2 alone. Therefore, to investigate the interplay between adIGF-1 and adBMP-2 transductions in more detail, hMSCs were co-transduced with IGF-1 (MOI 1000) and a range of BMP-2 (MOI 31.25 - 250). Figure $5 \mathrm{~b}$ shows the cumulative release of IGF-1 and BMP-2 from single-transduced and co-transduced cells. As expected, transduction with IGF-1 alone, resulted in higher secretion of IGF-1 compared to co-transduced cells, and this decreases with increasing concentrations of BMP-2. Secretion of BMP-2 also increased with increasing MOI, but surprisingly, in samples with a low MOI of adBMP-2, BMP-2 secretion was higher after co-transduction with both IGF-1 and BMP-2, whereas secretion levels were similar upon co-transduction of adIGF-1 and high concentrations of adBMP-2. To determine if overexpression of IGF-1 induces secretion of BMP-2 via a feedback mechanism, BMP-2 secretion by adIGF-1 transduced cells was examined, but these levels were comparable to control (GFP).

In line with these findings, after 6 weeks of implantation, bone formation in the IGF-1/BMP-2 group was higher than in the BMP-2 group (39\% and $48 \%$ respectively). In contrast, no bone was formed in the GFP group, whereas some scaffolds in the IGF group displayed a low percentage of bone $(0.6 \%)$ (figure $5 \mathrm{c}$ ). The in vitro release profile suggests that the increased amounts of bone may be related to enhanced BMP-2 secretion. On the other hand, histological observations showed that bone in the BMP2/IGF-1 group displayed a lower level of mineralization, indicating a less mature state, compared to BMP-2 or IGF-1 groups. In both BMP-2 and BMP-2/IGF-1 groups, bone marrow was formed inside the scaffold pores, but the marrow was more densely packed and more granular in the BMP-2/IGF-1 group (arrows, figure 6). The less mature state 
A
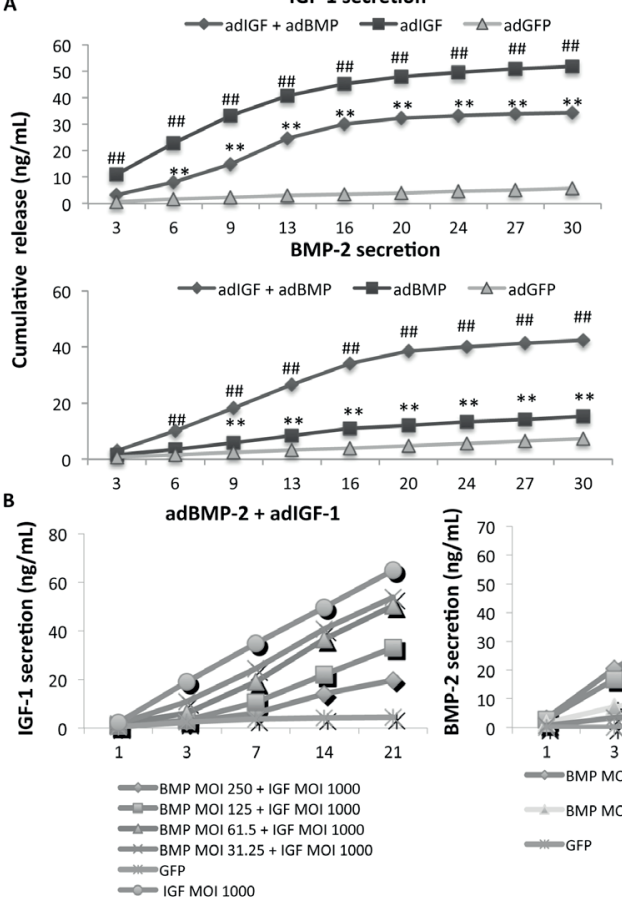

$c$

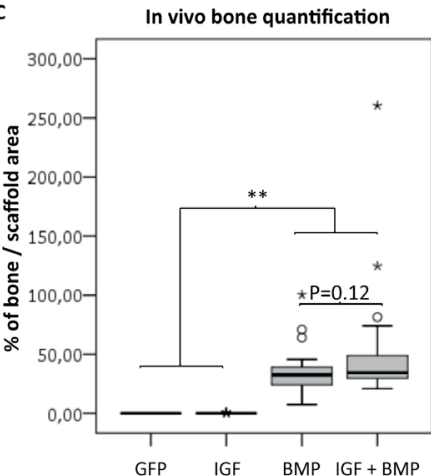

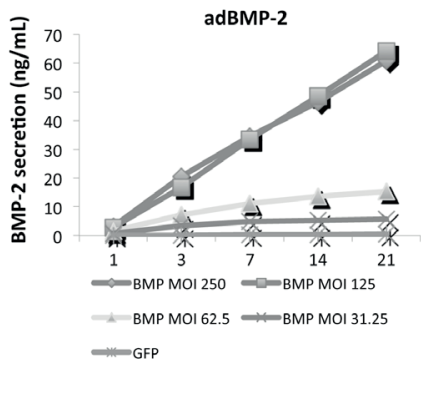

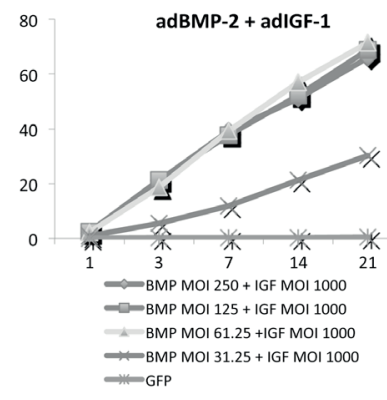

Figure 5. Co-transduction of IGF-1 and BMP-2 facilitates BMP-2 secretion and results in increased amounts of bone formation in vivo. hMSCs were transduced with IGF-1, BMP-2 or both and implanted in vivo. (a) The concentration of secreted IGF-1 was reduced upon co-transduction of IGF-1 and BMP-2, whereas the secretion of BMP-2 was increased upon co-transduction (a). To investigate this in more detail, hMSCs were transduced with 1000 MOI adIGF-1, 31.2-250 MOI adBMP-2 or both. The next day medium was changed for basic medium and after 3, 7, 14 and 21 days, medium was collected and the amount of secreted IGF-1 and/or BMP-2 was determined. Indeed, secretion of IGF-1 was reduced with increasing concentrations of co-transduced BMP-2, and transduction of BMP2 alone resulted in increased secretion of BMP-2 with increasing MOI, with a maximum of an MOI of 125. However, co-transductions of adIGF-1 (MOI 1000) and various concentrations of BMP-2 resulted in an increase in BMP-2 secretion, compared to transduction with BMP-2 alone (b). Cells transduced with BMP-2, IGF-1 or both were implanted in nude mice and after 6 weeks, small amounts of bone were observed in the IGF-1 group $(0.60 \%$ of bone / scaffold area), whereas no bone was found in the control (adGFP transduced). Transduction with BMP-2 resulted in high amounts of bone (39\% bone / scaffold area), which was increased even further by co-transduction of BMP-2 and IGF-1 (48\% bone / scaffold area) (c). * $\mathrm{P}<0.05$ compared to ctrl; ${ }^{* *} \mathrm{P}<0.01$ compared to $\mathrm{ctrl} ; \# \# \mathrm{P}<0.01$ compared to IGF1+BMP-2; asterisks and circles in (c) represent outliers.

of the bone in the BMP-2/IGF-1 group was confirmed by Masson's Trichrome staining (figure 7), which showed that only the BMP-2 group contained areas of mature bone (red).

\section{Discussion}

Numerous studies have investigated the effects of IGF-1 on MSCs from different sources and, whereas some studies show increased proliferation and differentiation of 


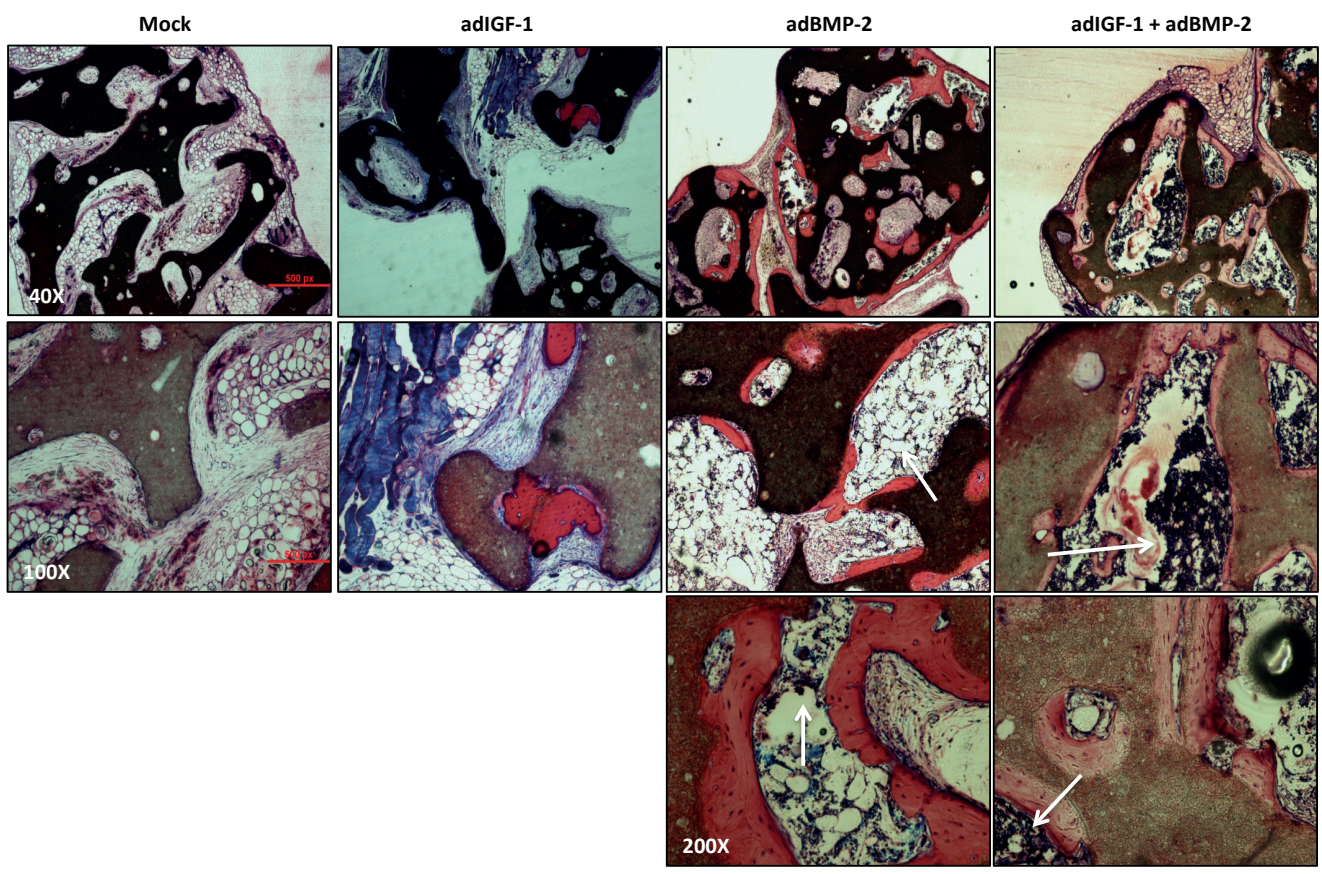

Figure 6. Histological overview of in vivo bone formation. No bone was formed in the GFP group whereas in the IGF group small amounts of mature bone were observed in some implants. Large amounts of mature bone were formed in the BMP-2 group, whereas in the BMP-2/IGF-1 group, large amounts of osteoid were formed. In addition, in both the BMP-2 and the BMP-2/IGF-1 group, large amounts of bone marrow (arrows) occupied spaces between the scaffolds, but this was denser and more granular in the BMP-2/IGF-1 group. Magnifications; top 40X, middle 100X, bottom 200X.

hMSCs in response to IGF-1, others fail to show an effect. Culture protocols vary greatly between these studies, which makes it difficult to compare them. Walsh et al. reported that a concentration of $10 \mathrm{ng} / \mathrm{mL}$ IGF-1 had no effect on proliferation or ALP expression of CFU-Fs [20] whereas a study by Koch et al. showed increased expression of runx 2 and collagen type I after adenoviral transductions, with the levels of secreted IGF-1 around $120 \mathrm{ng} / \mathrm{mL} 10$ days post-transduction [22]. These data suggest that low concentrations of IGF-1 do not affect proliferation or differentiation of hMSCs, which was also demonstrated by our ALP experiments, which show a clear dose-dependent effect. In addition, we show here that with a concentration of $100 \mathrm{ng} / \mathrm{mL}$ rhIGF-1, expression of osteonectin and runx2 increase 3-5 fold, whereas adenoviral overexpression (resulting in $20 \mathrm{ng} / \mathrm{mL}$ secreted IGF-1 5 days post-transduction) only slightly increased runx2 and osteonectin expression and did not affect collagen type I. Other studies using scaffoldrelease systems that result in a high concentration of IGF-1 (80-100 ng/mL) indeed also show positive effects on proliferation and osteogenic differentiation [23, 24].

The presence of serum in the medium also plays a key role when investigating the effects of IGF-1. In the absence of serum, we found an increase in both proliferation 


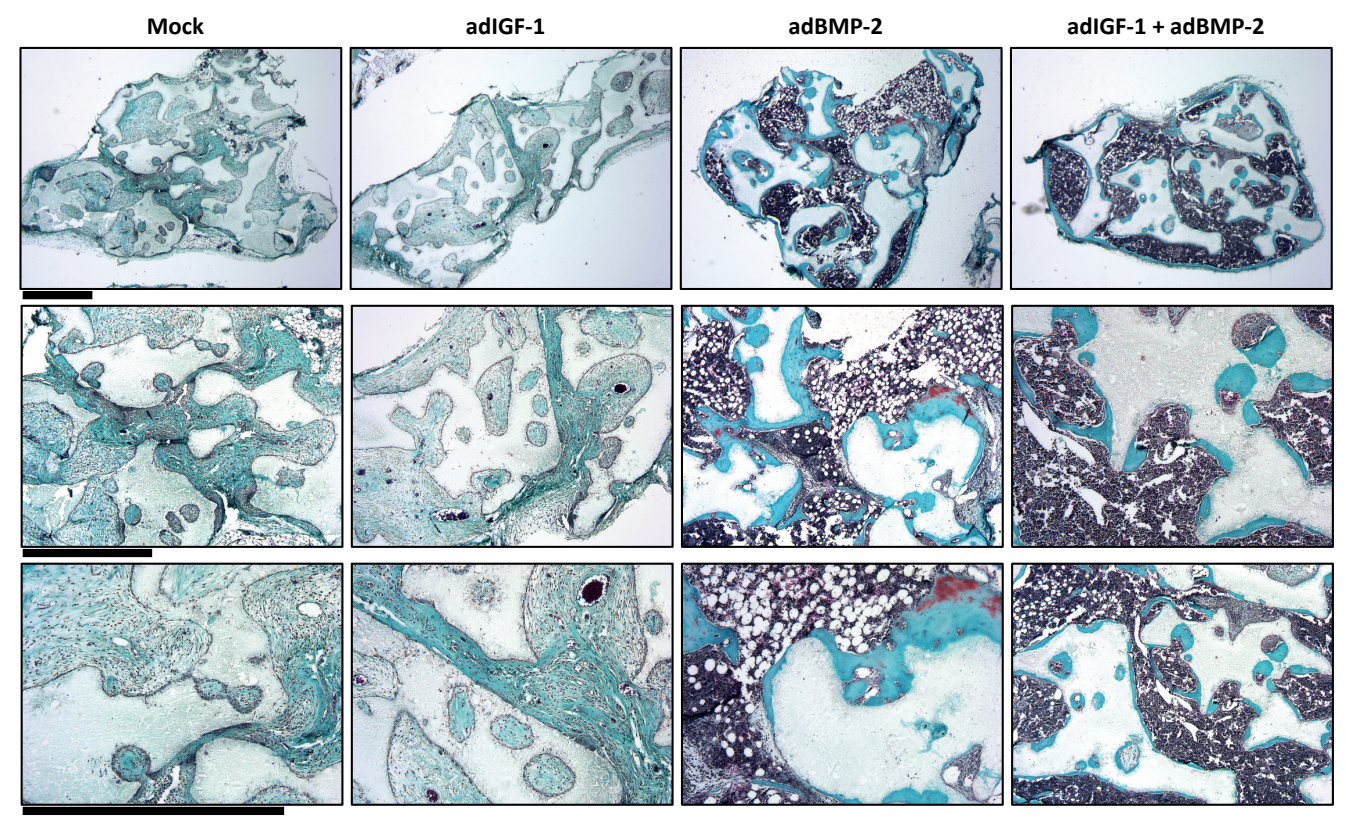

Figure 7. Mature bone was observed in the BMP-2 group, but not in the BMP-2/IGF-1 group. Mason's Trichrome staining of decalcified in vivo samples showed parts of mature bone formation (red) in the BMP-2 group. This was surrounded by immature bone (green), which was also formed in the BMP-2/IGF-1 group. Scale bar $=1 \mathrm{~mm}$.

and differentiation of hMSCs, whereas in the presence of serum IGF-1 had no effect. Most likely, serum contains proteins that neutralize IGF-1 function, such as IGF binding proteins (IGFBPs) and the acid-labile subunit (ALS), which were shown to inhibit IGF-1 function in mouse models. Overexpression of ALS [34], IGFBP1 [35], -2 [36], -3 [37] or -5 [38] resulted in deficiencies in the skeleton, such as reduced body weight, growth retardation, diminished mineralization, decreased cortical thickness and reduced cortical bone volume. Although total IGF-1 serum levels were not affected in these models, the amounts of extracellular fluid IGF-1 available to bind to tissue receptors were decreased, thus suggesting that these proteins inhibit IGF-1 activities.

The potential of IGF-1 to improve fracture healing has been demonstrated in in vivo models, but studies are not consistent. Both local and systemic delivery of rhIGF-1 were reported to enhance bone formation in a distraction osteogenesis mouse model [39], but systemic administration in a rat femoral defect had no effect [40]. Also, systemic delivery increased IGF-1 serum levels, which could potentially result in negative side effects. Therefore, local application using controlled release systems offers a better alternative, especially for tissue engineering applications, but also in this case reports are not consistent. Meinel et al. showed enhanced bone formation by IGF-1-releasing scaffolds [41], whereas a study by Laffargue et al. shows a slight increase at best [42]. So far, better results are obtained using dual release systems. Implants releasing both IGF- 
1 and TGF- $\beta$ resulted in more advanced bone remodeling in fracture models in rats and sheep $[43,44]$ and the combination of IGF-1 and platelet-derived growth factor (PDGF) also improved bone regeneration $[45,46]$. BMP-2 is the main player in stimulating fracture repair, and therefore we investigated the combined treatment/secretion of IGF1 and BMP-2 [47]. We demonstrate that IGF-1 potentiates BMP-2-induced mineralization in vitro, whereas IGF-1 alone does not affect mineralization, thus showing a synergistic effect. This is in line with a mouse model, which demonstrates that IGF-1 is involved in mineralization [6]. Unexpectedly, using a range of BMP-2 concentrations, mineralization of hMSCs was increased by 75-100 ng/mL BMP-2, but in a second study using both BMP2 and IGF-1, a concentration of $75 \mathrm{ng} / \mathrm{mL}$ BMP-2 did not significantly affect calcium deposition, although synergistic effects between BMP-2 and IGF-1 were still observed. We speculate that this is a donor-dependent effect.

In addition to these in vitro data, we found higher amounts of newly formed bone by cells co-transduced with both IGF-1 and BMP-2, compared to BMP-2 alone. Surprisingly, the amount of BMP-2 secreted by co-transduced cells was higher than by cells transduced with BMP-2 alone. Additional experiments using a range of adBMP-2 MOI's also demonstrated that, when using low MOI, the secretion of BMP-2 increases upon co-transduction, suggesting that adIGF-1 facilitates adBMP-2 transduction, BMP2 gene expression or BMP2 protein secretion. This is interesting, since secreted IGF-1 is reduced upon co-transduction with adBMP-2, and also negatively correlates with increasing MOI's of adBMP-2. Further experiments are required to investigate this in more detail. Overexpression of IGF-1 alone resulted in small amounts of new bone in vivo, but did not lead to clinically relevant amounts of bone. Due to the increase in BMP-2 secretion after co-transduction it is difficult to draw conclusions regarding the effect of IGF-1 on BMP-2-induced bone formation. We have previously demonstrated that scaffold incorporation of 1-40 $\mu$ g rhBMP-2 does not result in morphological differences of newly formed bone, although more bone marrow was found with increasing concentrations of BMP-2 [48]. Therefore, the increased BMP-2 secretion probably accounts for the increase in bone and bone marrow, however, it is unlikely that the osteoid appearance of the bone is due to higher concentrations of BMP-2, which suggests that IGF-1 has a negative effect on the maturation of bone.

In conclusion, we demonstrate that IGF-1 enhances proliferation and osteogenic differentiation of both hMSCs and MG-63 in vitro, but its effects are highly dependent on the used concentration and the presence of serum. However, IGF-1 had small effects on bone formation of hMSCs in vivo, and possibly negatively affects maturation of BMP2-induced bone. 


\section{Acknowledgments}

The authors gratefully acknowledge the support of the TeRM Smart Mix Program

of the Netherlands Ministry of Economic Affairs and the Netherlands Ministry of Education, Culture and Science. 


\section{References}

1. Kawai M, Rosen CJ. (2008) Pediatric Nephrology 24, 1277-1285

2. Daughaday WH. (2000) Pediatric Nephrology 14, 537-540

3. Le Roith D, Bondy C, Yakar S, Liu J-L, et al. (2001) Endocrine Reviews 22, 53-74

4. $\quad$ He J, Rosen CJ, Adams DJ, Kream BE. (2006) Bone 38, 826-835

5. Mohan S, Baylink DJ. (2005) J Endocrinol 185, 415-420

6. Zhang M. (2002) J Biol Chem 277, 44005-44012

7. Wang Y, Nishida S, Elalieh HZ, Long RK, et al. (2006) J Bone Miner Res 21, 1350-1358

8. Bikle D, Majumdar S, Laib A, Powell-Braxton L, et al. (2001) Journal of Bone and Mineral Research 16, 2320-2329

9. Zhao G, Monier-faugere MC, Langub MC, Geng Z, et al. (2000) Endocrinology 141, 2674-2682

10. Salgado AJ, Coutinho OP, Reis RL. (2004) Macromol Biosci 4743,

11. Wildemann B, Burkhardt N, Luebberstedt M, Vordemvenne T, et al. (2007) J Orthop Surg Res 2,27

12. Zhang W, Lee JC, Kumar S, Gowen M. (1999) Journal of bone and mineral research : the official journal of the American Society for Bone and Mineral Research 14, 528-535

13. Sant'Ana ACP, Marques MM, Barroso TEC, Passanezi E, et al. (2007) Journal of periodontology 78, 2007-2017

14. Li S-H, Guo D-Z, Li B, Yin H-B, et al. (2009) Vet J 179, 430-436

15. Nakasaki M, Yoshioka K, Miyamoto Y, Sasaki T, et al. (2008) Bone 43, 869-879

16. Canalis E, Lian JB. (1988) Bone 9, 243-246

17. McCarthy TL, Centrella M, Canalis E. (1989) Endocrinology 124, 301-309

18. Fiedler J, Brill C, Blum WF, Brenner RE. (2006) Biochemical and biophysical research communications $\mathbf{3 4 5}, 1177-1183$

19. Ponte AL, Marais E, Gallay N, Langonné A, et al. (2007) Stem Cells 25, 1737-1745

20. Walsh S. (2003) Bone 33, 80-89

21. Thomas T, Gori F, Spelsberg TC, Khosla S, et al. (1999) Endocrinology 140, 5036-5044

22. Koch H, Jadlowiec JA, Campbell PG. (2005) Stem Cells Dev 14, 621-631

23. Jeong W-K, Park S-W, Im G-I. (2008) J Biomed Mater Res A 86A, 1137-1144

24. Chen F-M, Chen R, Wang X-J, Sun H-H, et al. (2009) Biomaterials 30, 5215-5224

25. Uebersax L, Merkle HP, Meinel L. (2008) Journal of Controlled Release 127, 12-21

26. An C, Cheng Y, Yuan Q, Li J. (2010) Annals of biomedical engineering 38, 1647-1654

27. Siddappa R, Martens A, Doorn J, Leusink A, et al. (2008) Proc Natl Acad Sci U S A 105, 72817286

28. Doorn J, van de Peppel J, van Leeuwen JPTM, Groen N, et al. (2011) Biomaterials 32, 60896098

29. Both SK, van der Muijsenberg AJC, van Blitterswijk CA, de Boer J, et al. (2007) Tissue Eng 13, 3-9

30. Livak KJ, Schmittgen TD. (2001) Methods 25, 402-408 
31. Yuan H, van den Doel M, Li S, van Blitterswijk CA, et al. (2002) Journal of Materials Science: Materials in Medicine 13, 1271-1275

32. Silha JV, Gui Y, Modric T, Suwanichkul A, et al. (2001) Endocrinology 142, 4305-4313

33. Ben Lagha N, Seurin D, Le Bouc Y, Binoux M, et al. (2006) Endocrinology 147, 4730-4737

34. Eckstein F, Pavicic T, Nedbal S, Schmidt C, et al. (2002) Anatomy and Embryology 206, 139148

35. Silha JV, Mishra S, Rosen CJ, Beamer WG, et al. (2003) Journal of Bone and Mineral Research 18, 1834-1841

36. Salih DAM, Mohan S, Kasukawa Y, Tripathi G, et al. (2005) Endocrinology 146, 931-940

37. Fowlkes JL, Thrailkill KM, Liu L, Wahl EC, et al. (2006) Journal of Bone and Mineral Research 21, 1359-1366

38. Kirkeby OJ, Ekeland A. (1990) Acta Orthop Scand 61, 335-338

39. Meinel L. (2003) Bone 33, 660-672

40. Laffargue P, Fialdes P, Frayssinet P, Rtaimate M, et al. (2000) Journal of biomedical materials research 49, 415-421

41. Schmidmaier G, Wildemann B, Bail H, Lucke M, et al. (2001) Bone 28, 341-350

42. Bernstein A, Mayr HO, Hube R. (2010) Journal of Biomedical Materials Research Part B: Applied Biomaterials 92B, 215-225

43. Giannobile WV, Finkelman RD, Lynch SE. (1994) Journal of periodontology 65, 1158-1168

44. Lynch SE, Trippel SB, Finkelman RD, Hernandez RA, et al. (1994) Wound repair and regeneration : official publication of the Wound Healing Society [and] the European Tissue Repair Society 2, 182-190

45. Yu YY, Lieu S, Lu C, Colnot Cl. (2010) Bone 47, 65-73

46. Yuan H, Bruijn JDd, Zhang X, Blitterswijk CAv, et al. (2001) Journal of Materials Science: Materials in Medicine 12, 761-766 


\title{
CHAPTER 8.
}

\section{Hypoxia mimicing small molecules as a tool to train human mesenchymal stromal cells for revascularization strategies}

\author{
Joyce Doorn*1 \\ Hugo Fernandes*1 \\ Jeroen van de Peppel ${ }^{2}$ \\ Hans van Leeuwen? \\ Margreet de Vries ${ }^{3}$ \\ Zeen Aref $^{3}$ \\ Paul Quax ${ }^{3}$ \\ Clemens van Blitterswijk ${ }^{1}$ \\ Jan de Boer ${ }^{1}$
}

1 Department of Tissue Regeneration, MIRA Institute for Biomedical Technology and Technical Medicine, University of Twente, Enschede 7500 AE, The Netherlands.

${ }^{2}$ Erasmus MC, Department of Internal Medicine, Dr. Molenwaterplein 50, 3015 GE, Rotterdam, The Netherlands.

${ }^{3}$ Einthoven Laboratory for Experimental Vascular Medicine, Department of Surgery, Leiden University Medical Centre, PO box 9600, 2300 RC, Leiden, The Netherlands.

*These authors contributed equally

All models are wrong, but some are useful.

- George E. P. Box 


\section{Abstract}

Human mesenchymal stromal cells (hMSCs) secrete a panel of immunomodulatory and trophic factors that can be altered by culture protocols. Culture of hMSCs under hypoxic conditions has been shown to enhance secretion of angiogenic growth factors, but this is expensive, labor intensive and mostly restricted to in vitro use. In contrast, hypoxia can be mimicked by small molecules that are relatively cheap and easy to handle. The response to hypoxia is mediated via the hypoxia-inducible factor-1 (HIF-1) that binds to hypoxia responsive elements (HRE) in the promoter of several HIF target genes. Here we employed a high throughput assay on a cell line containing an HRE-GFP reporter to identify novel small molecules that activate this pathway. The effects of several of these small molecules were cell type/species dependent, but we identified phenanthroline (PHE) as the primary hit and show that this compound induces high expression of HIF-1 target genes in hMSCs. Furthermore, we demonstrate that conditioned medium derived from cells treated with hypoxia, desferoxamine (DFO, a known hypoxia mimic) or PHE has similar effects on proliferation and differentiation of primary cells. Interestingly, only PHE induced high expression and secretion of interleukin-8, suggesting that the mechanism of PHE-induced hypoxia is distinct from DFO and hypoxia and might involve the activation of other, additional pathways. In addition, we were able to demonstrate that in vivo angiogenesis in a matrigel plug assay is stimulated by addition of DFO or PHE, pointing to an enhanced activity of the angiogenic HIF-regulated genes in the presence of DFO or PHE. 


\section{Introduction}

Human mesenchymal stromal cells (hMSCs) secrete a broad panel of growth factors and cytokines that have trophic (i.e. anti-apoptotic, pro-angiogenic) and anti-inflammatory properties [1]. Several clinical trials have been completed or are currently on the way investigating the use of hMSCs for the treatment of, amongst others, autoimmune diseases [2-5], myocardial infarcts (reviewed in [6]), solid organ/ graft transplantations [7, 8] and ischemic wounds [9]. Debate exists on the mechanisms underlying the effects of infused MSCs. Although differentiation of MSCs into cells of the target tissue has been shown [10-12], low engraftment percentages, the short window in which effects are observed and the fact that conditioned medium alone also has effects, support a trophic effect [13-16].

Several studies have demonstrated that culture of hMSCs under hypoxic conditions, which closely resemble oxygen concentrations in natural bone marrow (1-7\%) [17], results in enhanced secretion of pro-angiogenic growth factors - of which most importantly vascular endothelial growth factor (VEGF) - but also improves survival, engraftment and differentiation of implanted cells [18-22]. Cellular responses to hypoxia are mainly regulated by hypoxia-inducible factors (HIFs) - heterodimers consisting of an $\alpha$ and $\beta$ subunit $[23,24]$. The HIF- $1 \alpha$ isoform is ubiquitously expressed in all cell types and, upon hydroxylation by prolyl hydroxylase domain proteins (PHDs), it is rapidly degraded by the proteasome [25]. PHD's inactivation leads to accumulation and stabilization of HIF- $1 \alpha$, which then translocates into the nucleus where it binds to the hypoxia responsive elements (HREs) and initiates transcriptional activation of HIF-target genes [23, 24]. Subsets of genes containing an HRE have been identified, including angiogenic, endothelial and metabolism-related genes.

Culture under hypoxia is expensive, labor-intensive and, most importantly, restricted to an in vitro scenario. Alternatively, small molecules can be used that activate the same subset of genes via the HIF- $1 \alpha$ pathway, but are cheap and easy to use. In addition, controlled release of these molecules in an in vivo set-up is possible in a spatially and temporally controlled manner.

In the past, our lab has shown that by using a small molecule we can modulate the secretome of hMSCs and control their differentiation into the osteogenic lineage [26]. Nevertheless, the effects observed with hMSCs could not be extrapolated to different cell types or species, clearly demonstrating that the biological function attributed to some molecules in one species or cell type are not valid in a different cellular context. For example, we have shown that the same molecule that induced osteogenesis in hMSCs (dibutyryl-cAMP) led to a distinct phenotype in MSCs from another species, i.e. adipogenic differentiation in rat MSCs [27]. Based on this observation and on the fact 
that previous screens for activators of the HIF pathway have been performed mostly with cancer cells lines $[21,28,29]$, we decided to develop a new screening strategy based on a more clinically relevant cell type. We generated a cell line using human immortalized mesenchymal stromal cells containing an HRE-GFP reporter and used high-throughput screening (HTS) to identify novel compounds that activate the HIF-1 pathway. We show here that one of the newly identified compounds is a pan-activator of this pathway and can be used to modulate the secretome of MSCs in vitro and/or prior to their in vivo delivery, but also to induce a hypoxia mimicking condition in vivo in order to stimulate angiogenesis.

\section{Materials and methods}

\section{Cell culture}

Bone marrow aspirates $(5-15 \mathrm{~mL})$ were obtained from patients with written informed consent and isolated as previously described [30]. Human mesenchymal stromal cells (hMSCs) were expanded in proliferation medium consisting of alpha minimal essential medium ( $\alpha$-MEM; Gibco, Carlsbad, CA), 10\% fetal bovine serum (Lonza, Verviers, Belgium), $0.2 \mathrm{mM}$ ascorbic acid (Sigma Aldrich, St. Louis, M0), $2 \mathrm{mM}$ L-Glutamine (Gibco), $100 \mathrm{U} / \mathrm{mL}$ of penicillin and $100 \mu \mathrm{g} / \mathrm{mL}$ of streptomycin (Invitrogen, Carlsbad, $\mathrm{CA}$ ) and $1 \mathrm{ng} / \mathrm{mL}$ of basic fibroblast growth factor (bFGF, Instruchemie, Delfzijl, The Netherlands). Basic medium consisting of proliferation medium without bFGF was used during the experiments. Human umbilical vein endothelial cells (HUVECs) were commercially obtained from Lonza and cultured in Endothelial Growth Medium-2 (EGM-2) with addition of the microvascular bullet kit (MV, all from Clonetics, Lonza), containing hEGF, hydrocortisone, gentamicin, 5\% FBS, VEGF, hFGF-B, R3-IGF-1 and ascorbic acid. Cells were kept at $37^{\circ} \mathrm{C}$ and $5 \% \mathrm{CO}_{2}$. Medium was refreshed three times per week and cells were trypsinised when a confluency of $70-80 \%$ was reached.

\section{Generation of HRE-GFP cell line}

The pHRE-luc plasmid was kindly provided by Dr. Kiyoshi Nose (Showa University, Japan) [31]. To create the plasmid pcDNA3/HRE-GFP, the CMV promoter from pCDNA3 (Promega) was excised and replaced by the HRE promoter from the plasmid pHRE-luc (pcDNA3/HRE). Subsequently, a GFP fragment was cloned into pcDNA3/HRE (pcDNA3/ HRE-GFP). Restriction digestion and sequence analysis were performed to confirm the identity of the plasmid. Telomerase-immortalized bone marrow-derived mesenchymal stromal cells (iMSCs) were kindly provided by Prof. Ola Myklebost (University of Oslo, Norway) and expanded in proliferation medium. To generate a reporter cell line, iMSCs were seeded at 10,000 cells $/ \mathrm{cm}^{2}$ in a 6 -well plate with serum-free medium (Opti-MEM $₫$; Invitrogen) and transfected with $2 \mu \mathrm{g}$ of pcDNA3/HRE-GFP and $4 \mu \mathrm{L}$ of Fugene®6 
transfection reagent for $8 \mathrm{~h}$. The next day, transfection medium was replaced by basic medium containing $200 \mu \mathrm{g} / \mathrm{mL}$ of G418 and selection was done for two weeks. After clonal expansion a clone was selected (iMSCs HRE-GFP).

\section{LOPAC screen}

A library of 1280 pharmacologically active compounds (LOPAC; Sigma Aldrich) was screened for activators of the HRE-GFP reporter system in iMSCs. The compounds were aliquoted in 96-well plates in the presence of DMSO, with each compound present at one given concentration. Sub-stocks at different concentrations can be prepared. In our case, we used a concentration of $4.5 \mu \mathrm{M}$ in a final volume of $200 \mu \mathrm{L}$ of basic medium containing $0.25 \%(\mathrm{v} / \mathrm{v})$ DMSO. The first and last columns of each plate were used for controls (four negative and four positive controls per column). The order of the controls in each column was inverted, and the amount of DMSO was equal to sample wells $(0.25 \%$ (v/v)). To perform the screen, 4000 HRE-GFP iMSCs were seeded in black 96-well plates (BD Biosciences) and allowed to attach overnight. Then, the 1280 test compounds and controls (basic medium and $100 \mu \mathrm{M}$ desferoxamine as negative and positive control respectively) were added. After one day of incubation with the test compounds, an Alamar Blue assay was performed to assess cell numbers/metabolic activity [32] and GFP intensity was measured as readout for the HRE activity. Briefly, medium containing $10 \%(\mathrm{v} / \mathrm{v}$ ) Alamar Blue solution (Biosource, Camarillo, CA) was added and incubated at $37^{\circ} \mathrm{C}$ for $4 \mathrm{~h}$. Then, fluorescence was measured at $590 \mathrm{~nm}$ on a Victor plate reader (Perkin Elmer, Wellesley, MA). Upon removal of the Alamar Blue solution, cells were washed with phosphate buffered saline (PBS; Life Technologies) and GFP intensity was measured at $520 \mathrm{~nm}$ on a Victor plate reader.

\section{Hit validation}

Obtained hits were further tested. Briefly, four different concentrations of each hit were tested for their capacity to induce HRE activity. In addition, twelve compounds previously identified in an HRE screen using a cancer cell line [28] were tested along with our hits. These experiments were performed as described above for the primary screen. Based on the HRE-GFP activity (high signal and low cytotoxicity) we selected a concentration for subsequent experiments with primary human mesenchymal stromal cells (hMSCs).

\section{Conditioned medium preparation}

To prepare conditioned medium (CM), hMSCs were cultured until near confluency in proliferation medium. Then, medium was changed to basic medium (basic-CM), basic medium supplemented with $150 \mu \mathrm{M}$ DFO (DFO-CM) or $200 \mu \mathrm{M}$ PHE (PHE-CM) or cells were added to a hypoxia chamber $\left(2 \% \mathrm{O}_{2}\right)$. After 2 days of culture, medium was removed 
and cells were washed with PBS twice, after which serum-free basic medium was added and cells were kept in culture for 2 more days. Then, CM was collected and centrifuged at $900 \mathrm{~g}$ for 5 minutes to remove cell debris. CM was directly applied to target cells. As a control, serum free medium that had not been in contact with any cells was used (nonCM). For HUVECs, a 7:3 mixture of CM and EGM-2 was used.

\section{Gene expression analysis}

hMSCs were seeded in triplicate in 6-well plates at 5000 cells $/ \mathrm{cm}^{2}$ and allowed to attach for 10-15 hours in proliferation medium. Upon reaching near confluency, cells were treated as described above. After 2 days of treatment and 2 subsequent days of incubation with fresh medium, cells were lysed immediately with TRIzol. RNA was isolated using a Bioke RNA II nucleospin RNA isolation kit (Machery Nagel) and RNA concentrations were measured using an ND100 spectrophotometer (Nanodrop technologies, USA). cDNA was synthesized from 100 ng of RNA, using iScript (BioRad) according to the manufacturer's protocol. For qualitative PCR, a master mix, containing distilled water, forward primer, reverse primer (Sigma Genosys), BSA, and SYBR green I mix (all from Invitrogen) was prepared. Real-time qPCR was performed in a Light-Cycler (Roche). Light-Cycler data was analyzed using the fit points method of Light-Cycler software. The baseline was set at the lower log-linear part above baseline noise and the crossing temperature (Ct value) was determined. Ct values were normalized to the $18 \mathrm{~S}$ housekeeping gene and $\Delta \mathrm{Ct}\left(\mathrm{Ct}_{\text {control }}-\mathrm{Ct}_{\text {sample }}\right)$ was used to calculate the upregulation in gene expression [33]. Primer sequences are listed in table 1.

Table 1. Primer sequences

\begin{tabular}{lll}
\hline Gene & Forward primer & Reverse primer \\
\hline 18s & CGGCTACCACATCCAAGGAA & GCTGGAATTACCGCGGCT \\
CD31 & TCTATGACCTCGCCCTCCACAAA & GAACGGTGTCTTCAGGTTGGTATTTCA \\
vWF & TGCTGACACCAGAAAAGTGC & AGTCCCCAATGGACTCACAG \\
KDR & ACTTTGGAAGACAGAACCAAATTATCTC & TGGGCACCATTCCACCA \\
eNOS & GATGCTCCCAACTTGACCAT & TGTCCTGCACGTAGGTCTTG \\
Tie1 & GACTGACCCAGCTTTTGCTC & GTCCCTGTGGATGAACTGCT \\
VEGF & Commercially obtained from SA Biosciences \\
\hline
\end{tabular}

\section{Protein expression analysis}

hMSCs were seeded at 5000 cells $/ \mathrm{cm}^{2}$ in T25 flasks. Upon reaching near-confluence, medium was changed for basic medium, basic medium with $150 \mu \mathrm{M}$ DFO or $200 \mu \mathrm{M}$ PHE or cells were added to a hypoxia chamber $\left(2 \% \mathrm{O}_{2}\right)$. After 2 days, cells were lysed with 250 $\mu \mathrm{L}$ RIPA buffer with addition of protease/phosphatase inhibitors (Roche). Total protein concentrations were determined using a BCA kit (Pierce) and $10 \mu \mathrm{g}$ of total protein was 
used to determine concentrations of VEGF, IL-8, basic fibroblast growth factor (bFGF), growth-colony stimulating factor (G-CSF) and epidermal growth factor (EGF) using a Luminex assay (Invitrogen) according to the manufacturer's protocol. Briefly, cells and standards were incubated with fluorescent beads, followed by incubation with a biotinylated detection antibody. After incubation with streptavidin-R-Phycoerythrin and washing, both the fluorescence of the coupled beads and the R-phycoerythrin were measured using a Luminex® FlexMapTM.

\section{Whole genome expression analysis}

hMSCs were seeded in T25 flasks at 5000 cells $/ \mathrm{cm}^{2}$ and allowed to attach overnight in proliferation medium. The next day, medium was added with the following conditions; basic medium, basic medium supplemented with $150 \mu \mathrm{M}$ DFO or basic medium supplemented with $200 \mu \mathrm{M}$ PHE. After 48 hours, RNA was isolated as described above. From 500 ng of RNA, cRNA was synthesized using the Illumina TotalPrep RNA amplification Kit (Ambion), according to the manufacturer's protocol and the quality of RNA and cRNA was verified on a Bioanalyzer 2100 (Agilent). Microarrays were performed using Illumina HT-12 v4 expression Beadchips, according to the manufacturer's protocol. Briefly, 750 ng of cRNA was hybridized on the array overnight after which the array was washed and blocked. Then, by addition of streptavidin Cy-3 a fluorescent signal was developed. Arrays were scanned on an Illumina iScan reader and raw intensity values were background corrected in GenomeStudio (Illumina). Further data processing and statistical testing were performed with R and Bioconductor statistical software (http:// www.bioconductor.org/), using package lumi. Raw intensity values were transformed using variance stabilization and a quantile normalization was performed. A linear modelling approach with empirical Bayesian methods, as implemented in Limma package [34], was applied for differential expression analysis of the resulting probelevel expression values. A gene list, containing only those genes with an absolute 1.5fold change between different treatments, was uploaded to Ingenuity Pathway Analysis (IPA) software and used for core analysis. Pathways or networks with a p-value of 0.05 were considered statistically significant.

\section{Proliferation}

hMSCs and HUVECs were seeded in triplicate in 6-well plates at 3000 cells $/ \mathrm{cm}^{2}$ and allowed to attach overnight in denoted culture medium. Then, cells were washed and conditioned medium was added. After 3 days, proliferation of hMSCs was determined by measuring the metabolic activity using a $10 \%(\mathrm{v} / \mathrm{v}$ ) Alamar Blue (Invitrogen) and for HUVECs, nuclei were stained with DAPI (Sigma Aldrich) and counted. 


\section{Scratch wound healing assay}

hMSCs and HUVECs were seeded in triplicate in 6-well plates at 10,000 cells $/ \mathrm{cm}^{2}$ and allowed to attach for 10 to 15 hours in denoted culture medium. When the cells reached near confluency, a wound was created by scratching the surface with a pipet tip, and the medium was changed to different types of conditioned medium. After 12 and 20 hours pictures were taken to examine migration of cells into the wound.

\section{Sprouting assay}

6-well plates were coated with $1 \mathrm{~mL}$ of a 1:1 mixture of ice-cold Matrigel (Biosciences) and endothelial basic medium (EBM, Lonza). Plates were kept at $37{ }^{\circ} \mathrm{C}$ for at least 30 minutes to allow solidification of the Matrigel. Then, HUVECs in passage 2-3 were trypsinized, resuspended in EGM-2 (Lonza) and seeded onto the Matrigel at 500,000 cells/well in a volume of $600 \mu \mathrm{L}$. Conditioned medium was prepared as described and $1.4 \mathrm{~mL}$ of denoted conditioned medium $+0.6 \mathrm{~mL}$ of EGM- 2 was added to each well. After 24 hours cells were lysed using TRIzol for RNA isolation as described above.

\section{In vivo murine matrigel plug assay}

In vivo angiogenesis analysis was performd using a matrigel plug assay in male C57/ BL6 mice (age 8 weeks)(Charles River). Growth factor reduced matrigel $(0.5 \mathrm{ml}$ ) (BD Biosciences) was injected into the subcutaneous space on the dorsal side of mice on both the left and right flank. Matrigel was mixed at $4{ }^{\circ} \mathrm{C}$ with PBS, DFO (150 $\left.\mu \mathrm{M}\right)$ or PHE $(200 \mu \mathrm{M})$ ( $n=7$ mice per group). Mice were sacrificed 7 days post-implantation. Matrigel plugs were excised and processed for histological analysis. Paraffin sections (5 $\mu \mathrm{m}$ ) were stained with Hematoxylin, Phloxine and Saffron (HPS) or anti-CD31 (PECAM,

A
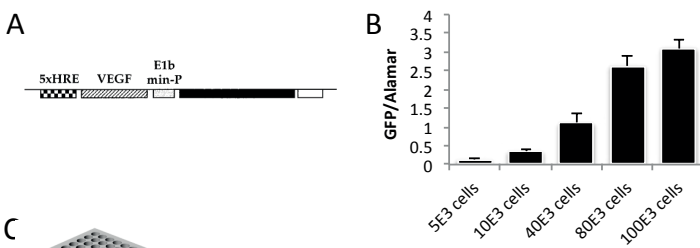

C

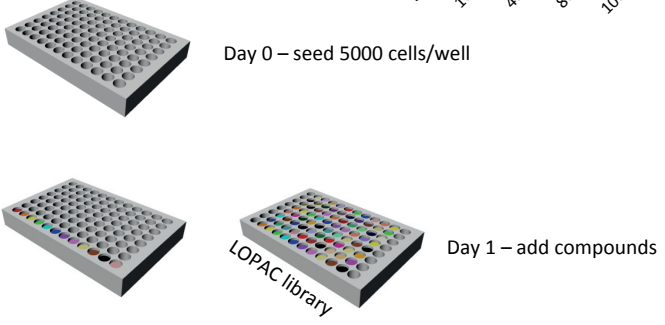

Day 2 - Alamar Blue and GFP
Figure 1 - Generation of the HRE-reporter cell line. a, schematic representation of the reporter construct used (modified from (31)). b, GFP/Alamar represents HRE activity at different cell concentrations. c, schematic representation of the HTS assay developed. Legend: $5 \times \mathrm{xHRE}=5$ copies of the $35 \mathrm{bp}$ fragment derived from the VEGF HRE; VEGF = $385 \mathrm{bp}$ of the 5' flanking region of the VEGF gene; $\mathrm{E} 1 \mathrm{~b}$ min-P $=32 \mathrm{bp}$ of the adenovirus E1b minimal promoter. 
Abcam, Cambridge, UK). Vascular ingrowth was scored in a double blinded fashion and quantified using the following method: every individual section was scored for the degree of ingrowth, using five different categories of ingrowth $(1=$ minimal ingrowth at the border of the plug, 5 =capillary ingrowth throughout the total plug), and the mean ingrowth score per group was defined (6 sections per plug, 7 mice per group). The endothelial nature of the infiltrating cells was confirmed by the CD31 staining.

\section{Statistics}

Data was analyzed using one-way ANOVA followed by Tukey's multiple comparison's test $(\mathrm{P}<0,05)$. For the analysis of the ingrowth in the matrigel plug statistical analysis was performed using ANOVA and unpaired t-test.

\section{Results}

\section{Identification of small molecules capable of inducing HRE activity in immortalized human mesenchymal stromal cells}

The firststepin identifying compounds capable of inducing HREactivity was togenerate a reporter cell line in which the GFP gene is driven by a hypoxia responsive element (reporter construct pCDNA3/HRE-GFP) (figure 1a). The uniqueness of our assay lies in the cellular background; human mesenchymal stromal cells, a clinically relevant cell type for regenerative medicine as well as for cancer-related diseases [35]. Upon transfection of immortalized MSCs and selection with G418 we selected 21 clones for further analysis. Using a known hypoxia mimic, desferoxamine (DFO), we selected the clone with the highest HRE-GFP activity after $24 \mathrm{~h}$ exposure to DFO (supplementary figure 1). To further confirm the capacity of the selected clone to respond to hypoxia we reduced the
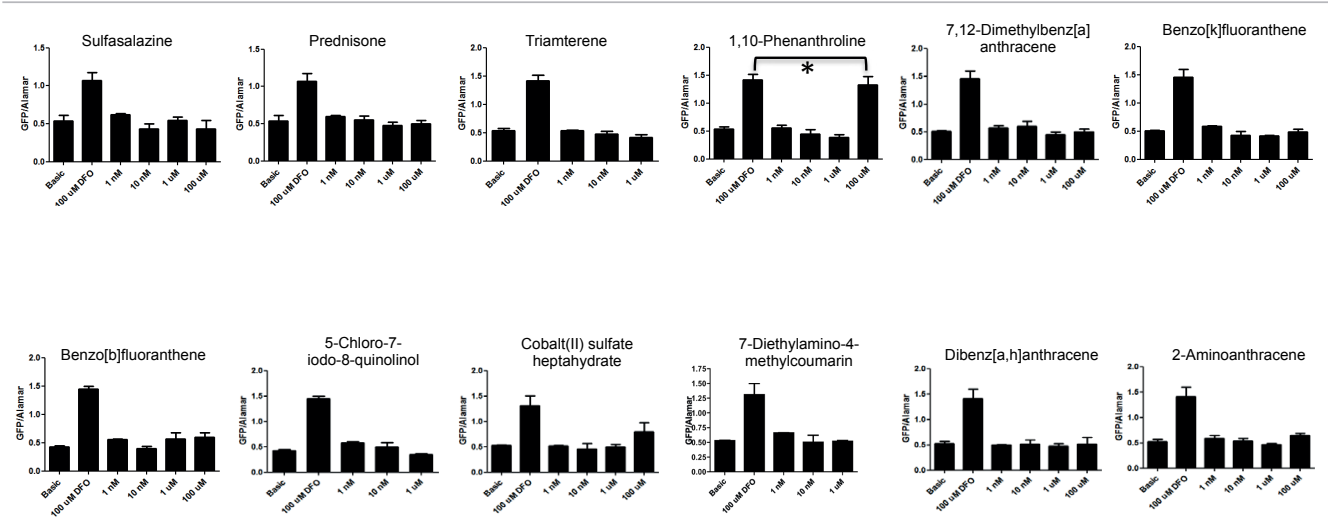

Figure 2 - Hypoxia mimics identified using a cancer cell line. Twelve previously identified hypoxia mimics tested on our human HRE-GFP reporter cell line. Note that only one compound induces HRE activity. An asterisk $\left({ }^{*}\right)$ denotes no statistical significant difference (One-way Anova and Tukey's test, $\mathrm{P}<0.05$ ). 
A

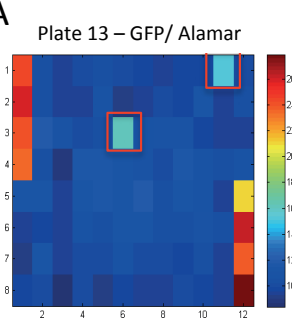

Plate 13 - Alamar blue

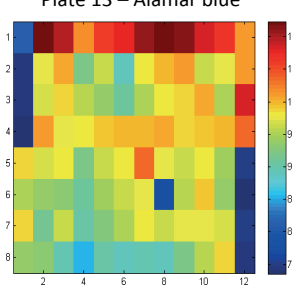

Plate $14-$ GFP/ Alamar

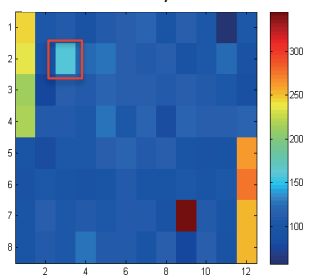

Plate 14 - Alamar blue

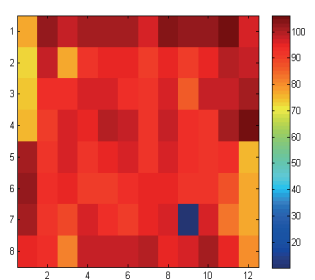

B

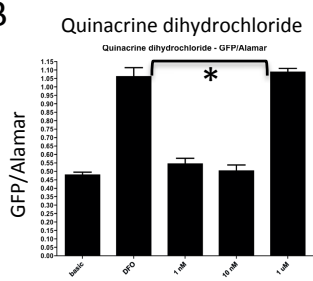

1,10-Phenanthroline monohydrate
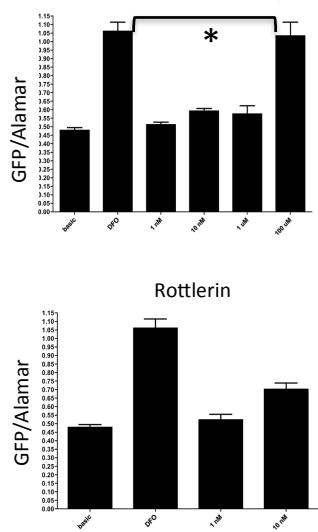

Figure 3 - HTS assay on human HRE-GFP reporter cell line. a, HRE-GFP cells were seeded in sixteen 96-well plates (4000 cells/well) in basic medium. One day later the LOPAC library was added to the wells and two days later we measured GFP and Alamar Blue as readout for HRE activity and metabolic activity, respectively. Here are represented the wells with hits (top: GFP/Alamar and bottom Alamar Blue alone). b, effect of different concentrations of the three identified hits in HRE activity. An asterisk $\left({ }^{*}\right)$ denotes no statistical significant difference. (One-way Anova and Tukey's test, $\mathrm{P}<0.05$ )

concentration of oxygen $\left(\mathrm{O}_{2}\right)$ by increasing the number of cells per well and analyzed HRE-GFP activity [36]. As expected, this increase in cell density led to a dose-dependent increase in HRE-GFP activity (figure 1b).

To the best of our knowledge, this is the first HRE assay performed in hMSCs and as such, we decided to test compounds previously described as HRE activators in a cancer cell line (ME-180 cells from human cervical cancer cells) [28] in our model. Twelve compounds were tested at four different concentrations $(1 \mathrm{nM}, 10 \mathrm{nM}, 1 \mu \mathrm{M}$ and 100 $\mu \mathrm{M})$, with DFO as a positive control, and HRE activity was measured after $24 \mathrm{~h}$. Our results showed that exposure of HRE-GFP iMSCs to $100 \mu \mathrm{M}$ DFO results in a 2.8-fold increase in HRE activity and a 38\% reduction in metabolic activity relative to control (figure 2 and supplementary figure 2). For the twelve compounds tested, concentrations that reduced metabolic activity more than 50\% compared to $100 \mu \mathrm{M}$ DFO were excluded (supplementary figure 2). To our surprise, of these twelve compounds only 1,10-phenanthroline was able to induce HRE-GFP activity to the same level as $100 \mu \mathrm{M}$ DFO (figure 2). These results highlight the importance of the cellular background on the regulation of HIF signaling. 
In order to find new small molecules capable of activating the HRE we screened the LOPAC library using our HRE-GFP iMSC cell line (overview of the assay in figure 1c). Again, the well-known hypoxia mimic DFO was used as a positive control. Our results showed that DFO significantly decreased cell viability after $24 \mathrm{~h}$ exposure $24 \%$ reduction in viability: $\mathrm{Bas}=100 \pm 5$ vs. $\mathrm{DFO}=76 \pm 3 \%$; supplementary figure $3 \mathrm{a}$ ). In addition, HRE activity was significantly increased relative to the control when DFO was added (2.5-fold increase in HRE activity: Bas $=100 \pm 11$ vs. DFO = $249 \pm 33 \%$; supplementary figure $3 \mathrm{~b}$ ). Given the fact that only one concentration per molecule was tested - thus reducing our chances to find hits, we decided to use relaxed criteria to define a hit as any molecule that did not inhibit cell viability more than $24 \%$ (DFO reference value) and that showed an increase in HRE activity higher than 1.5-fold relative to the control. Based on these criteria we identified three hits: 1,10-phenanthroline monohydrate (PHE), quinacrine dihydrochloride (both in plate 13) and rottlerin (plate 14) (figure $3 a)$. Interestingly, one of the hits (1,10-phenanthroline monohydrate) is from the same family as the compound previously identified as an HRE activator in the cancer cell line (1,10-phenanthroline).

\section{Confirmation of HRE-GFP activators in HRE-GFP iMSCs}

Selected hits were further tested using the same concentration range described above. As in the screening assay, $100 \mu \mathrm{M}$ DFO was used as a positive control and, metabolic activity was again partially inhibited compared with the control (supplementary figure 4). Of the four different concentrations tested per compound, the ones that reduced metabolic activity more than $50 \%$ compared to $100 \mu \mathrm{M}$ DFO were excluded from further analysis (supplementary figure 4). Moreover, only $1 \mu \mathrm{M}$ quinacrine dihydrochloride and $100 \mu \mathrm{M}$ PHE were able to induce HRE activity to a similar level as $100 \mu \mathrm{M}$ DFO (figure $3 \mathrm{~b}$ ), but since quinacrine dihydrochloride did not affect VEGF gene expression, this compound was excluded from further analysis (supplementary figure 5).

\section{Phenanthroline induces expression and secretion of angiogenic growth factors}

To identify differences between the known hypoxia mimic DFO and PHE, we performed a whole genome expression analysis of hMSCs treated for two days and compared this with cells grown under standard hypoxia conditions $\left(2 \% \mathrm{O}_{2}\right)$. Heatmaps in figure 4 show the expression levels of previously identified HRE-containing genes [37], grouped by function. Both DFO and PHE increased expression of genes involved in metabolism, cell growth and survival as well as endothelial genes, but PHE markedly induced higher expression. Expression of various known hypoxia-responsive genes was increased by hypoxia culture, but expression of these genes was markedly higher after treatment with DFO or PHE. Interestingly, interleukin-8 (Il-8) was highly induced by PHE (top gene), whereas DFO and hypoxia did not affect this gene at all. 

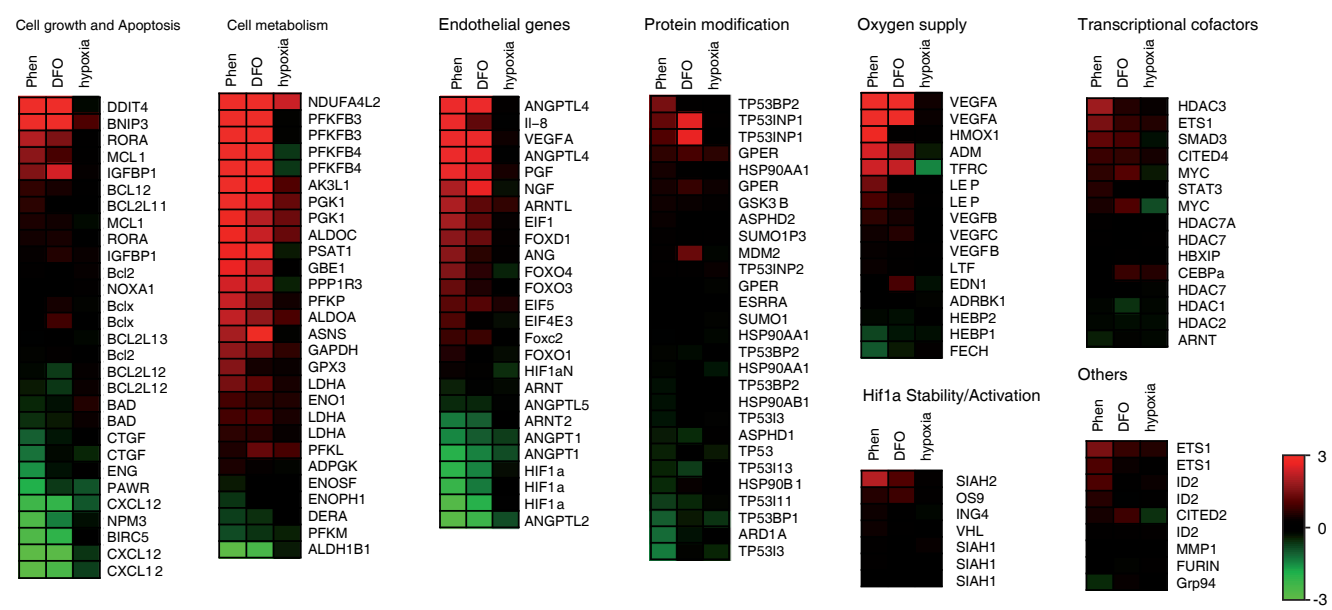

Figure 4 - Phenanthroline induces strong expression of HRE-containing genes, compared to DFO and hypoxia culture. Primary hMSCs were cultured in the presence of $150 \mu \mathrm{M} \mathrm{DFO}, 200 \mu \mathrm{M}$ PHE or in an hypoxia chamber $\left(2 \% \mathrm{O}_{2}\right)$. After 2 days, whole genome expression analysis was performed and the expression of known HRE-containing genes was examined. Of the three culture methods, most genes were strongest induced using PHE. Heatmaps show the relative expression of denoted genes compared to cells in basic medium, with all genes statistically significant regulated compared to cells in basic medium $(\mathrm{P}<0.05)$.

We then examined the secretion of angiogenic factors at a protein level, including IL-8 and VEGF and, as shown in figure 5, PHE indeed increased the secretion of IL- 8 to 300-500 pg/mL, whereas in DFO and hypoxia-treated cells IL-8 levels were comparable to basic (15-25 pg/mL). In contrast, although VEGF secretion was induced by all three treatments, it was higher in DFO-treated cells $(140 \mathrm{pg} / \mathrm{mL})$ than in PHE-treated cells (65 pg/mL), even though microarray data showed higher expression of VEGF after treatment with PHE. In contrast, secretion of growth-colony stimulating factor (G-CSF) and basic fibroblast growth factor (bFGF) was lower in the PHE-treatment group compared to DFO and hypoxia. To investigate if these secreted growth factors exert trophic effects, conditioned medium (CM) was prepared from DFO-, PHE- or hypoxiatreated hMSCs, which was then used to culture fresh HUVECs and MSCs. After 2 days of treatment and 2 more days of incubation with fresh medium, VEGF was still highly expressed in PHE-treated cells, whereas expression levels in DFO- or hypoxia-treated cells were comparable to non-treated cells (supplementary figure 5). However, PHE-CM did not increase proliferation of HUVECs or MSCs, compared to basic- or hypoxia-CM (figure 6a), although in MSCs, PHE-CM was the only medium to significantly increase proliferation compared to non-CM. To investigate the effect of secreted factors on sprouting of HUVECs, cells were seeded on Matrigel in different types of conditioned medium (CM). As shown in figure 6b, whereas expression of endothelial genes was slightly decreased in basic-CM, DFO-CM and PHE-CM increased expression of these genes and demonstrated similar effects as hypoxia-CM. Similarly, a scratch wound 

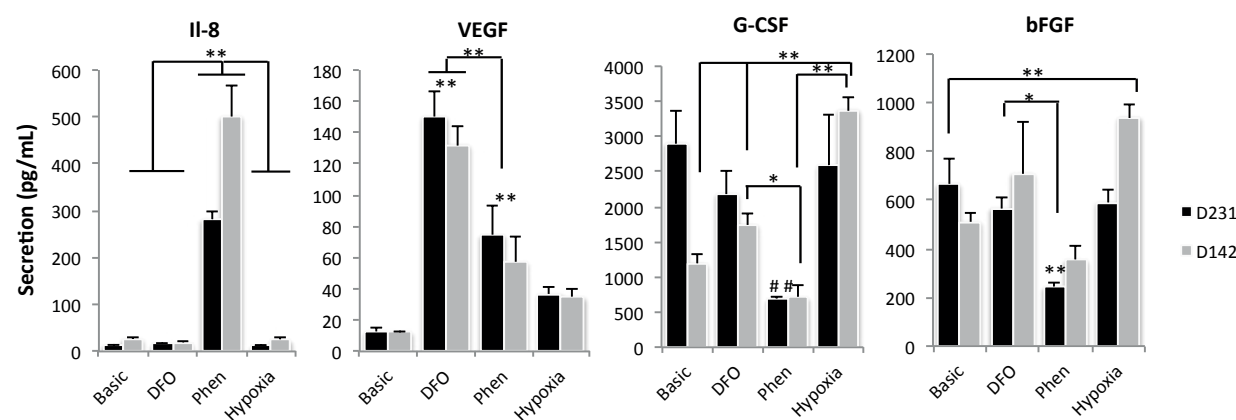

Figure 5 - Phenanthroline induces secretion of IL-8, but DFO induces higher secretion of VEGF. Primary hMSCs were cultured in the presence of $150 \mu \mathrm{M}$ DFO, $200 \mu \mathrm{M}$ PHE or in a hypoxia chamber $\left(2 \% \mathrm{O}_{2}\right)$ for 2 days, after which cells were lysed. Protein concentrations of IL-8, VEGF, bFGF and G-CSF were determined in cell lysates and as shown, only phenanthroline induced secretion of high levels of Il-8, which were not affected by DFO or hypoxia culture. In contrast, VEGF secretion was increased by all three culture methods, but highest by DFO. D231 and D142; donor number as specified in the laboratory database, $\left({ }^{*}\right)$ denotes $\mathrm{P}<0.05,\left({ }^{* *}\right)$ denotes $\mathrm{P}<0.01$, (\#\#) denotes $\mathrm{P}<0.01$ compared to basic, DFO and hypoxia (one-way Anova and Tukey's test).

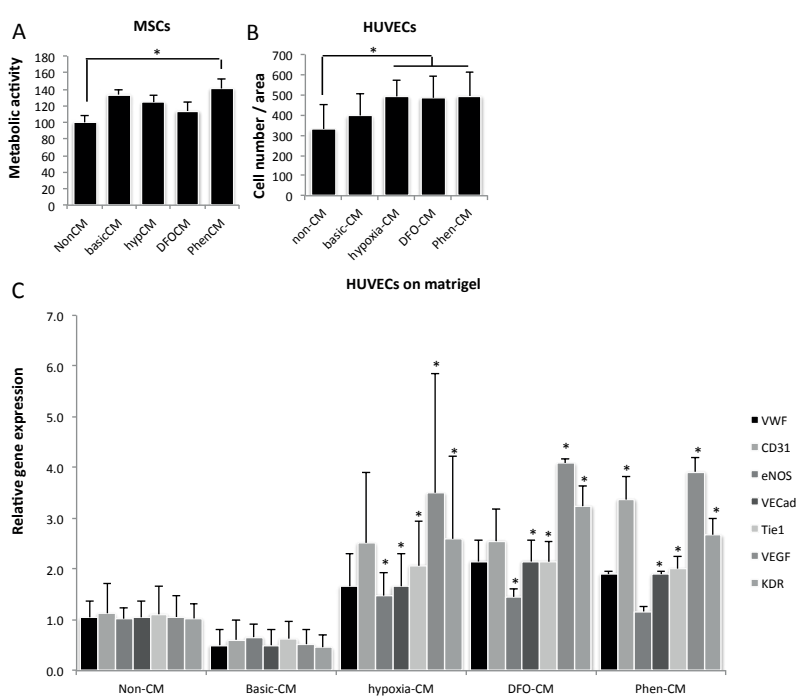

Figure 6 - Conditioned medium enhances proliferation and sprouting. Conditioned medium was prepared by culturing cells in the presence of $150 \mu \mathrm{M}$ DFO, $200 \mu \mathrm{M}$ PHE or in a hypoxia chamber $(2 \%$ $\mathrm{O}_{2}$ ), after which the medium was changed and cells were kept in culture for 2 more days. As a control non-treated cells were incubated with medium. Conditioned medium was used to culture HUVECs and MSCs and proliferation was determined by counting the cell number or measuring metabolic activity, respectively. a, proliferation of MSCs was significantly increased by PHE-CM, but not by other types of $\mathrm{CM}$, although there was no significant difference between PHE-CM and other CM. $\left({ }^{*}\right)$ denotes $\mathrm{P}<0.05$, (One-way Anova and Tukey's test). b, in contrast, proliferation of HUVECs was significantly increased by DFO-, PHE- and hypoxia-CM. c, gene expression analysis of sprouted HUVECs on matrigel showed that expression of endothelial genes was increased by DFO-CM, PHE-CM and hypoxia-CM, compared to basic- and non-CM. VWF; von Willebrand factor, eNOS; endothelial nitric oxide synthase, VECad; VE cadherin, VEGF; vascular endothelial growth factor, Tie1; tyrosine kinase receptor, KDR; kinase insert domain receptor, $\left({ }^{*}\right)$ denotes $\mathrm{P}<0.05$ compared to basic-CM (One-way Anova and Tukey's test). 


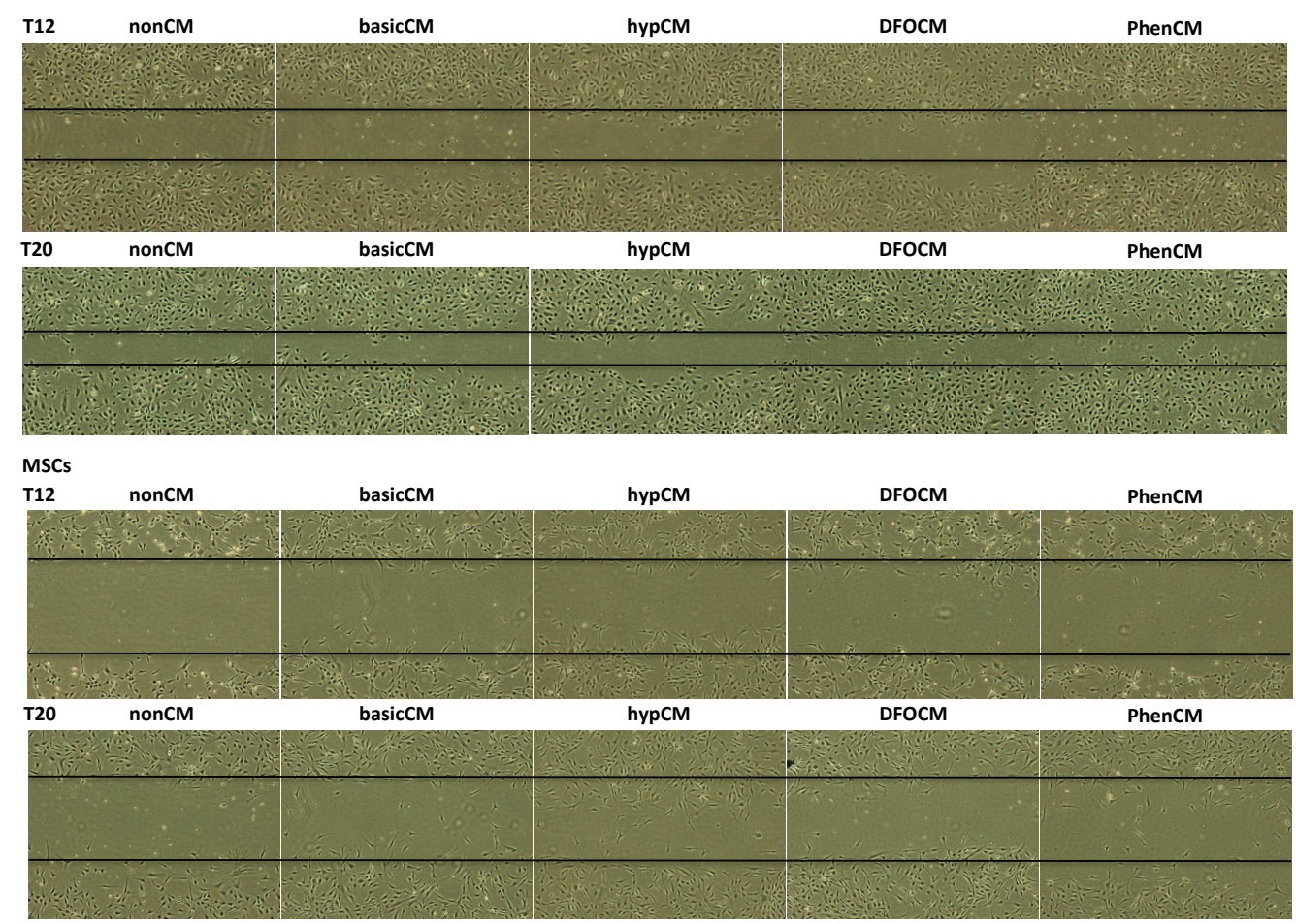

Figure 7. Cell migration is enhanced by conditioned medium. Conditioned medium was prepared by culturing cells in the presence of $150 \mu \mathrm{M}$ DFO, $200 \mu \mathrm{M}$ PHE or in a hypoxia chamber $\left(2 \% \mathrm{O}_{2}\right)$, after which the medium was changed and cells were kept in culture for 2 more days. As a control nontreated cells were incubated with medium. Conditioned medium was then used to culture HUVECs and MSCs for a scratch wound healing assay. Migration of cells was increased in conditioned medium, but no differences between these types of conditioned medium were observed, although migration of HUVECs in PHE-CM seemed to be slightly enhanced.

healing assay demonstrated that migration of both HUVECs and MSCs was increased by CM, but no differences were observed between these groups, although for HUVECs, migration seemed slightly increased in DFO- and PHE-CM (figure 7).

\section{Phenanthroline enhances in vivo blood vessel formation}

Ultimately, we tested the efficacy of DFO and PHE as factors that can stimulate the hypoxia driven angiogenic response in vivo by incorporating DFO (150 $\mu \mathrm{M})$ or PHE $(200 \mu \mathrm{M})$ in matrigel plugs that are injected subsutaneously in mice. After 7 days a significantly increased capillary ingrowth could be observed in the DFO-treated as well as the PHE-treated mice (figure 8). The ingrowth in DFO and PHE did not differ significantly, however it should be noted that in the PHE treated group two mice showed excessive capillary ingrowth that resulted in the presence of capillary structures throughout the total plug (figure 8c). 

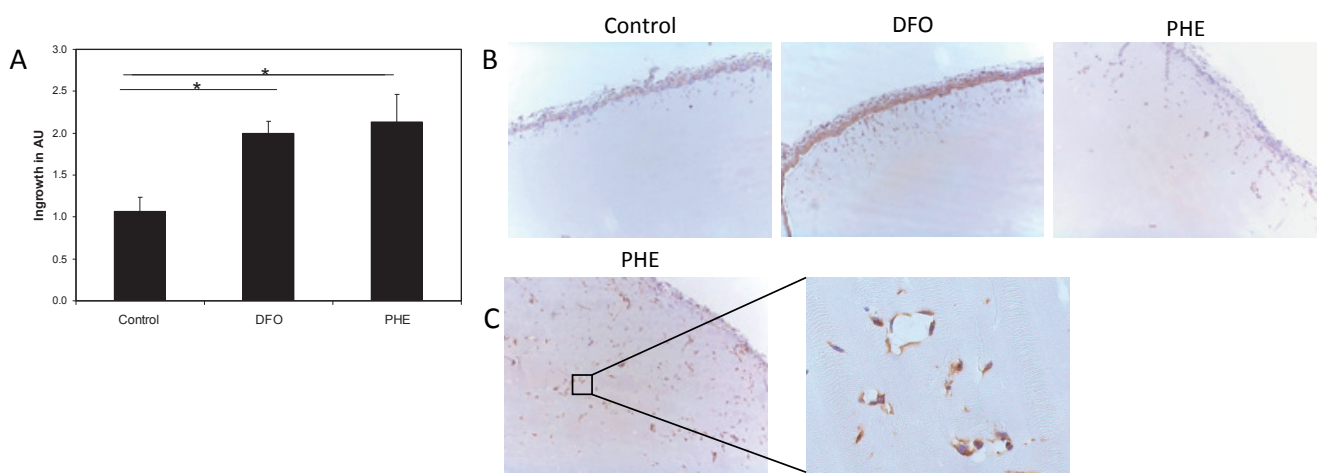

Figure 8. In vivo capillary ingrowth in matrigel containing DFO or PHE. Matrigel plugs $(0.5 \mathrm{~mL})$ containing either PBS , DFO $(150 \mu \mathrm{M})$ or PHE $(200 \mu \mathrm{M})$ were injected subcutaneously and analyzed for capillary ingrowth after 7 days. The ingrowth was scored in a categorical way and expressed as mean \pm SEM per group $(n=7)$ in arbitrary units $(A U)$ (panel A). The endothelial nature of the ingrowing cell structures was confirmed by CD31 staining (panel B). In two plugs in the PHE treated group extraordinary ingrowth of capillary-like structures throughout the total plug could be observed, demonstrated a clear lumen surrounded by CD31 positive cells.

\section{Discussion}

Since conditioned medium derived from MSCs has similar therapeutic effects as the cells itself, the secreted trophic and immunomodulatory factors are suggested to account for these effects [18-22, 38]. Pre-conditioning or "training" of MSCs prior to in vivo delivery can alter their differentiation status and secretome, which might increase their therapeutic value. Hypoxia pre-conditioning has gained special interest, since this increases the secretion of pro-angiogenic and pro-survival factors, but also improves engraftment of infused MSCs. This could thus improve therapeutic efficiency of these cells in defects where neo-angiogenesis is required, but is relatively expensive and labor-intensive. On the other hand, treatment of MSCs with growth factors, such as epidermal growth factor or sonic hedgehog, has similar effects [39-41], but relies on the use of recombinant proteins, which are expensive and pose challenges to incorporate into drug delivery systems while maintaining their bioactive potential. An alternative would be the use of small molecules during the ex vivo expansion of MSCs in order to "train" these cells and modulate their secretome or even the in vivo co-delivery of the molecules with the cells.

Here we show that treatment of MSCs with such a small molecule, PHE, results in enhanced secretion of VEGF, compared to hypoxia treatment and in addition, enhances vessel formation in vivo and results in high protein levels of IL-8, which is involved in proliferation, survival, sprouting and angiogenesis [42]. The stronger effects of chemical hypoxia might be the result of the severity of the hypoxia stimulus, which in turn results in a more sustained response. Our data suggest that PHE offers a cheap and 
easy alternative for hypoxia cultures and in addition, PHE could be applied directly in an in vivo setup. Indeed, the effects of PHE-conditioned medium on proliferation and sprouting of HUVECs were comparable to those of hypoxia-conditioned medium, even though cell numbers were significantly decreased after treatment with PHE. Dissolving the compound in water, opposed to the DMSO used here, would reduce its inhibitory effects on proliferation and possibly improve therapeutic value further. Compared with DFO, PHE treatment had similar effects in vitro, but the stronger activation of HIF target genes by PHE suggests this compound is more potent, which was reflected in the matrigel plug assay, where PHE increased formation of vessel structures, compared to DFO.

Whole genome analysis showed that, although DFO and the hypoxia incubator increased expression of several hypoxia target genes, only hMSCs exposed to PHE showed a dramatic increase in IL-8 expression. Although known to be regulated by hypoxia $[43,44]$ IL-8 can also be increased by hypoxia-independent mechanisms. One hypothesis for the increase of IL-8 solely in PHE-treated cells could be that PHE activates another signaling pathway that in turn activates IL-8 transcription. A candidate pathway is the NF- $\kappa$ B pathway, which activation leads to IL-8 expression $[45,46]$ and indeed, our microarray data shows that expression of RelA - a NF- $\kappa B$ target gene - is higher in the presence of PHE than in hypoxia or DFO-treated cells. Alternatively, increased stability of the heterodimeric complex in the nuclei can explain the stronger activation of HIF target genes, as we also observed a higher expression of P300, a known co-activator of HIF, in PHE-treated cells [21, 47].

We chose to impinge on the hypoxia pathway and explore the potential to manipulate this pathway in hMSCs. Although some of the core components of the hypoxia pathway are conserved between cell types, variations occur between different cell types and species, which can result in a distinct activation pattern of HIF target genes [21, 48, 49]. Several screens for HIF activation/inhibition have been performed, but, to the best of our knowledge, this is the first screen using hMSCs. Due to their heterogeneity, primary hMSCs pose additional issues for screening assays and therefore, we used a clonally expanded immortalized cell line reasoning that, although some metabolic pathways can be altered, the cellular components of the hypoxia pathway will closely resemble those in primary hMSCs [50]. Surprisingly, of the 12 previously identified hypoxia mimics [28], only 1 was able to activate the HRE reporter in hMSCs, thus clearly demonstrating the cell type specificity for mechanisms regulating hypoxia. After exclusion of hits that have detrimental effects on proliferation, our screen using a library of 1280 compounds revealed one compound, PHE, which was also the only hit from the previously described 12 compounds. Similar to DFO, PHE can act as a chelator and form a complex with iron [51], but even though most molecules have a described molecular target, the lack of specificity should not be ignored [52]. 
We tested the response to the above-mentioned treatments in hMSCs from two different donors. Despite the fact that the expression profile was highly reproducible, one cannot exclude the fact that cells from other donors will respond differently [53]. In fact, when we confirmed the expression of certain proteins known to be involved in angiogenesis and stem cell mobilization at a protein level, we observed a different response between the donors for G-CSF and bFGF and these observations warrant a larger set of donors to be evaluated.

Our main goal here was to identify compounds that increase HRE activity, but we also found compounds that can potentially inhibit its activity. This class of compounds can certainly be interesting for cancer therapies where hypoxia-driven neoangiogenesis is one of the mechanisms underlying tumor growth. Thus, the possibility to use small molecules to control the secretome of the cells will open new avenues in the treatment of several diseases.

\section{Acknowledgments}

We would like to thank Pasi Halonen for technical support and thoughtful discussions, and Bram Koopman for technical support. Furthermore, the authors gratefully acknowledge the support of the TeRM Smart Mix Program of the Netherlands Ministry of Economic Affairs and the Netherlands Ministry of Education, Culture and Science and the STW program.

\section{Disclosure statement}

All animal experiments were performed in compliance with Dutch government guidelines and approved by the Institutional Committee for Animal Welfare of the Leiden University Medical Center (LUMC). 


\section{References}

1. Haynesworth SE, Baber MA, Caplan AI. (1996) J Cell Physiol 166, 585-592

2. Le Blanc K, Frassoni F, Ball L, Locatelli F, et al. (2008) The Lancet 371, 1579-1586

3. Caplan AI. (2009) J Pathol 217, 318-324

4. Baker M. (2009) Nature News,

5. Garcia-Olmo D, Herreros D, Pascual I, Pascual JA, et al. (2009) Dis Colon Rectum 52, 79-86

6. Menasche P. (2010) J Mol Cell Cardiol 50, 258-265

7. Bartholomew A, Sturgeon C, Siatskas M, Ferrer K, et al. (2002) Exp Hematol 30, 42-48

8. Chabannes D, Hill M, Merieau E, Rossignol J, et al. (2007) Blood 110, 3691-3694

9. Falanga V, Iwamoto S, Chartier M, Yufit T, et al. (2007) Tissue Eng 13, 1299-1312

10. Orlic D, Kajstura J, Chimenti S, Bodine DM, et al. (2003) Pediatr Transplant 7 Suppl 3, 86-88

11. Quevedo HC, Hatzistergos KE, Oskouei BN, Feigenbaum GS, et al. (2009) Proc Natl Acad Sci U S A 106, 14022-14027

12. Nagaya N. (2005) Circulation 112, 1128-1135

13. Shabbir A, Zisa D, Suzuki G, Lee T. (2009) Am J Physiol Heart Circ Physiol 296, 1888-1897

14. Uemura R, Xu M, Ahmad N, Ashraf M. (2006) Circ Res 98, 1414-1421

15. Leiker M, Suzuki G, Iyer VS, Canty Jr. JM, et al. (2008) Cell Transplant 17, 911-922

16. Crisostomo P, Markel TA, Wang Y, Meldrum D. (2008) Surgery 143, 577-581

17. Lennon DP, Edmison JM, Caplan AI. (2001) J Cell Physiol 187, 345-355

18. Hu X, Yu SP, Fraser JL, Lu Z, et al. (2008) J Thorac Cardiovasc Surg 135, 799-808

19. Hung S-C, Pochampally RR, Chen S-C, Hsu S-C, et al. (2007) Stem Cells 25, 2363-2370

20. Hung SC, Pochampally RR, Hsu SC, Sanchez C, et al. (2007) PLoS ONE 2, e416

21. Lendahl U, Lee KL, Yang H, Poellinger L. (2009) Nature reviews 10, 821-832

22. Volkmer E, Kallukalam BC, Maertz J, Otto S, et al. (2010) Tissue Engineering Part A 16, 153164

23. Harris AL. (2002) Nat Rev Cancer 2, 38-47

24. Semenza GL. (2003) Nat Rev Cancer 3, 721-732

25. Jaakkola P, Mole DR, Tian Y-M, Wilson MI, et al. (2001) Science 292, 468-472

26. Doorn J, van de Peppel J, van Leeuwen JPTM, Groen N, et al. (2011) Biomaterials 32, 60896098

27. Siddappa R, Mulder W, Steeghs I, Klundert VD, et al. (2009) Tissue Eng Part A 15, 2135-2143

28. Xia M, Huang R, Sun Y, Semenza GL, et al. (2009) Toxicol Sci 112, 153-163

29. Chau NM, Rogers P, Aherne W, Carroll V, et al. (2005) Cancer Research 65, 4918-4928

30. Fernandes H, Mentink A, Bank R, Stoop R, et al. (2010) Tissue Eng Part A 16, 1693-1702

31. Shibata T, Akiyama N, Noda M, Sasai K, et al. (1998) Int J Radiat Oncol Biol Phys 42, 913-916

32. O’Brien J, Wilson I, Orton T, Pognan F. (2000) Eur J Biochem 267, 5421-5426

33. Livak KJ, Schmittgen TD. (2001) Methods 25, 402-408

34. Wettenhall JM, Smyth GK. (2004) Bioinformatics 20, 3705-3706

35. Roodhart JML, Daenen LGM, Stigter ECA, Prins H-J, et al. (2011) Cancer cell 20, 370-383 
36. Liu J, Barradas A, Fernandes H, Janssen F, et al. (2010) Tissue engineering Part C, Methods 16, 479-485

37. Wenger RH. (2005) Sci STKE 2005, re12-re12

38. Di Santo S YZ, Wyler von Ballmoos M, Voelzmann J, Diehm N, Baumgartner I, Kalka C. (2009) PLoS One 4, e5643

39. Amin AH, Abd Elmageed ZY, Nair D, Partyka MI, et al. (2010) Lab Invest 90, 985-996

40. Pola R, Ling LE, Silver M, Corbley MJ, et al. (2001) Nat Med 7, 706-711

41. Kusano KF, Pola R, Murayama T, Curry C, et al. (2005) Nature Medicine 11, 1197-1204

42. Li A, Dubey S, Varney ML, Dave BJ, et al. (2003) J Immunol 170, 3369-3376

43. Kim KS, Rajagopal V, Gonsalves C, Johnson C, et al. (2006) The Journal of Immunology 177, 7211-7224

44. Galindo M, Santiago B, Alcami J, Rivero M, et al. (2001) Clinical \& Experimental Immunology $123,36-41$

45. Karashima T, Sweeney P, Kamat A, Huang S, et al. (2003) Clin Cancer Res 9, 2786-2797

46. Chan DA, Kawahara TLA, Sutphin PD, Chang HY, et al. (2009) Cancer Cell 15, 527-538

47. Ruas JL, Berchner-Pfannschmidt U, Malik S, Gradin K, et al. (2010) The Journal of biological chemistry 285, 2601-2609

48. Kelly BD, Hackett SF, Hirota K, Oshima Y, et al. (2003) Circ Res 93, 1074-1081

49. Benita Y, Kikuchi H, Smith AD, Zhang MQ, et al. (2009) Nucleic Acids Res 37, 4587-4602

50. Ebert AD, Svendsen CN. (2010) Nat Rev Drug Discov 9, 367-372

51. Maxwell P, Salnikow K. (2004) Cancer Biol Ther 3, 29-35

52. Murray AJ. (2008) Sci Signal 1, re4

53. Siddappa R, Licht R, van Blitterswijk C, de Boer J. (2007) J Orthop Res 25, 1029-1041 


\section{CHAPTER 9.}

\section{General conclusions and discussion}

To know that we know what we know, and to know that we do not know what we do not know, that is true knowledge.

- Copernicus 


\section{General conclusions and discussion}

Worldwide, bone and joint diseases affect hundreds of millions of people and are the most common cause of severe long-term pain and physical disability. In the Netherlands alone, 46,000 bone fractures as a result of osteoporosis are registered each year and including non-registered cases, this number is thought to be as high as 85,000. In addition, $25 \%$ of people with long-term health-related absenteeism and $33 \%$ of people unfit for work have musculoskeletal problems. Therefore, the world health organization declared the 2000-2010 decade 'the bone and joint decade' and in the United States the bone and joint decade initiative (usbjd) was introduced to raise awareness and increase funding for musculoskeletal disorders.

Bone tissue engineering is expected to provide solutions for these problems, and since the introduction of the fields of regenerative medicine, and more specifically bone tissue engineering, around two decades ago, important steps have been made. For example, specific calcium phosphates have been identified as osteoinductive materials, inductive coatings are applied on metal implants, signaling pathways involved in proliferation and differentiation of stem cells have been (partly) unraveled and it is now recognized that mechanical stress, topographies and chemical treatment can enhance the performance, proliferation or differentiation of various cell types. Despite these improvements, the amounts of newly formed bone in vivo are still limited and therefore, bone tissue engineering is still not applied on a broad scale to date.

\section{Human mesenchymal stromal cells}

Throughout this thesis, primary human mesenchymal stromal cells (hMSCs) are the main topic of investigation. Although they display donor variation, senescence and decreased differentiation potential with increasing passage, these cells form the best model, since cell lines may display different responses and data from other species cannot be translated to humans $[1,2]$. MSCs show limited proliferation compared to embryonic stem cells, but they never demonstrated teratoma formation or malignant transformation. Even though malignant transformation has been reported [3], this was later identified as a contamination with another cell type [4]. MSCs have been applied in numerous clinical studies without adverse effects and consequently are generally considered safe. However, their trophic and immunomodulatory effects were recently linked with tumor growth and metastasis, which might limit their use in cancer patients and warrants long-term follow-up of non-cancer patients who received infusions of MSCs [5]. They are not considered true stem cells, but are capable of differentiation into a variety of cell types, not only of mesenchymal origin. This offers possibilities regarding vascularization or control of an immune response in tissue engineered constructs, since cells differentiated towards multiple lineages can easily be combined in one construct 
and the need to isolate different cell types from one patient is eliminated. However, the performance of these cells in in vivo bone tissue engineering applications is still limited and the quality of stem cells from each individual varies tremendously, which influences the success rate of a procedure. MSCs can also be obtained from various sources, including bone marrow and adipose tissue, but cells from different sources can show different responses to the same signal [6]. As of yet, we are not able to predict the quality of a stem cell and thus its performance. This calls for genetic and/or phenotypic analyses of cells from different donors and different tissues to identify underlying variations and to find the most suitable cell and source for a specific application.

\section{Allogeneic versus autologous cells}

Cells derived from the patient do not induce an immune response, which remains a major advantage of autologous implantations. However, as stated above, the quality of hMSCs varies between patients and cells may lack sufficient quality for a specific application. For example, in patients with osteoporosis, the release of toxic signals by adipocytes is thought to interfere with osteoblast function and survival [7], but hMSCs might be affected as well, which might hamper the bone forming ability of hMSCs from patients with osteoporosis. By using cells of an allogeneic source, cells of pre-defined quality can be obtained from donors and expanded into a ready-to-use product. In addition, this provides the possibility to implant/inject cells more quickly after the occurence of the defect. It is believed that MSCs do not evoke an immune response, even in an allogeneic setting, due to a lack of human leukocyte antigen class II (HLA class II) expression. Infusion of allogeneic HLA-mismatched cells was already applied for the treatment of graft-versus-host disease with no adverse effects and both cell types displayed equal efficiency. It was also shown that MSCs do not express HLA class II extracellularly, either in a differentiated or undifferentiated state and that differentiated cells do not induce lymphocyte alloreactivity, although HLA class I was increased upon differentiation [8]. These data suggest that differentiated MSCs can be safely used in an allogeneic bone tissue engineering setting, and for practical reasons this deserves further investigation.

\section{Activation of signaling pathways and downstream targets}

Although numerous signaling pathways, their functions and mechanisms have been identified and unraveled in MSCs, the biology of these cells is very complicated and numerous questions remain. In the first experimental part of this thesis, we investigated the role of the cAMP/PKA pathway in differentiation of hMSCs in more detail. Previously, we already showed that treatment with db-cAMP enhances osteogenic differentiation [2] but studies have also reported the role of this pathway in adipogenic differentiation $[9,10]$. In chapter 3 , we show that treatment with a second PKA activator, forskolin, 
has similar effects on osteogenic differentiation of hMSCs, thus confirming previous findings. In contrast, as demonstrated in chapter 4, activation of the PKA pathway with GPCR ligands did not affect differentiation of hMSCs and intermittent treatment with $\mathrm{db}$-cAMP resulted in decreased ALP expression. In line with these findings, Radio et al. showed that melatonin increases ALP expression of hMSCs, but only in osteogenic medium, and that PKA was not required for this effect. In addition, only continuous exposure for 21 days resulted in increased mineralization. These data show that the type, the duration, the activation level of a signal as well as interplay with other signaling pathways are of key importance and indeed, several pathways have been shown to differentially affect MSCs, based upon the type, strength or duration of the signal. Wnt signaling for example has mitogenic effects on MSCs depending on the concentration $[11,12]$, and BMPs play a role in both osteogenesis and adipogenesis, depending on the type of receptor activated [13].

Most defined signaling pathways can activate multiple downstream signal transduction pathways but people often only refer to the general pathway. Wnt signaling for example, consists of a canonical and a non-canonical pathway, which are both activated via binding of Wnts to the Fzd receptor, but downstream signaling occurs via $\beta$-catenin, $\mathrm{Ca}^{2+}$ or JNK [14]. For many pathways, downstream signaling mechanisms have been unraveled, but the exact signal activating one of several downstream pathways is in most cases still unknown. More specifically for the cAMP/PKA pathway, it has been demonstrated that cAMP does not only activate PKA, but also Epac [15] and recent studies suggest that Epac is the factor required for adipogenesis [16-18]. cAMP thus can not solely be considered a PKA activator. In chapter 5 we showed that two cAMPanalogues, which activate both PKA and Epac, have very distinct effects on long-term differentiation of hMSCs. We also show that 8-br-cAMP, which induces adipogenesis, activates a larger number of cAMP-responsive genes than db-cAMP and induces higher PKA activity, but its effect on Epac is unknown. These data suggest that depending on the stability and/or affinity of the used molecules, different downstream pathways are activated, which ultimately may direct the cells in completely opposing directions. In addition, activation of one single pathway is unlikely to induce differentiation into fully mature cells, but rather a combination of signals and/or pathways needs to be activated. Therefore, interplay between signaling pathways and examination of the downstream pathways, rather than generic signaling pathways, and the use of molecules that specifically activate a downstream pathway may provide better insight in cues that direct hMSCs towards a specific lineage.

\section{Activation triggers of MSCs at the in vivo wound site}

MSCs are now repeatedly used in clinical trials to examine their trophic and immunomodulatory effects, as reviewed in chapter 2. Several animal models as well 
as clinical studies have reported positive effects of these cells, and many of them have reported effects of conditioned medium alone. In addition, the low engraftment percentages and the short window in which effects are exerted provide evidence for trophic and immunomodulatory effects. However, some large studies reported no effect of infused MSCs, and their exact effects remain subject of debate.

The discrepancy between animal studies and clinical trials shows that data from other species cannot always be translated to humans. On the other hand, it is difficult to compare animal studies, in which infusions of stem cells are usually performed shortly after the introduction of a defect, whereas in clinical trials, patients are only recruited months to years after. It is hypothesized that infused MSCs are attracted and activated, or licensed, by inflammatory proteins at the wound site, and this inflammatory profile is likely to change with time, which could result in poor activation or migration of the infused cells. Therefore, research on the 'state' of the wound in time and its effects on infused cells are of key importance to determine optimal treatment protocols. It might be necessary to activate hMSCs prior to infusion. Similarly, in bone tissue engineering, numerous proteins and molecules are released shortly after a defect originates, which might positively or negatively affect bone formation. The implantation of a tissue engineered-construct itself creates a wound as well, and also in this case the optimal timing of implantation might be crucial and should be further investigated.

\section{Mechanisms of in vivo bone formation}

In cell-based bone tissue engineering applications it is generally believed that the direct differentiation of cells into osteoblasts accounts for new bone formation. However, in vitro pre-differentiation of hMSCs does not necessarily result in enhanced bone formation in vivo $[19,20]$, suggesting that other mechanisms are involved. We showed in chapter 6 that osteogenic differentiation of hMSCs can be accompanied by secretion of biologically active bone-specific growth factors. In addition, the osteogenic inducer in this case, db-cAMP, is one of the few molecules that not only induces osteogenic differentiation in vitro but also increases in vivo bone formation. This suggests that these secreted molecules may play a role in vivo, by enhancing proliferation and differentiation, not only of implanted cells but also of host cells. It is crucial that the underlying mechanisms of in vivo bone formation are revealed. Do implanted cells differentiate into osteoblasts, which then produce new bone, or do secreted growth factors activate host cells, which then deposit new bone? Do scaffolds induce osteogenic differentiation of seeded cells, do they induce differentiation of host cells, or do they induce secretion of growth factors and cytokines? Answers to these questions could help to optimize differentiation, scaffold design and ultimately help increase bone formation. 
One of the growth factors secreted in relatively high concentrations after treatment with db-cAMP is insulin-like growth factor-1 (IGF-1). In chapter 8, the effects of IGF-1 on proliferation, differentiation and in vivo bone formation of hMSCs were investigated. The rationale behind this study is that, with IGF-1 being one of the most abundant growth factor in bone, and its known involvement in bone formation during development, enhanced secretion of IGF-1 may have paracrine effects on in vivo bone formation. Although IGF-1 itself slightly increased bone formation, the synergistic effects of IGF-1 and BMP-2 were not completely clear. We found an increase in bone formation in this group, but rather than improving in vivo bone formation, IGF-1 seemed to facilitate adenoviral transduction of BMP-2 or to enhance BMP-2 secretion. Although overexpression of growth factors has been shown to enhance bone formation repeatedly, viral modification of cells for use in humans needs proper investigation before this can be applied safely and currently the incorporation of growth factors into scaffolds offers a better alternative. On the downside, high concentrations of growth factors are required for this approach, which is associated with high costs and release outside the defect area, thus resulting in excessive bone formation. In addition, concerns have been raised on BMP-2-induced inflammatory responses and carcinogenic or teratogenic effects [21]. Therefore, treatment of cells with small molecules or modifications of the scaffold to alter cell behavior are good alternatives, and we have shown that a single small molecule can induce production of multiple growth factors. However, so far only modest alterations to cells have been achieved, and the concentrations of secreted proteins are relatively low. It is currently unknown if these stimuli can induce a sufficiently strong response.

\section{Protocol consistency}

As mentioned, in chapter 8, the effects of IGF-1 on proliferation and differentiation of hMSCs was investigated. We show that in vitro results are highly dependent on the presence of serum as well as the used concentrations, which may explain previous inconsistent studies. [22-25]. Not only serum and concentration, but also the source of cells, isolation procedures and culture media vary widely between different laboratories and even within laboratories. To be able to truly compare individual studies, standardized culture protocols need to be implemented.

\section{In vitro markers to predict in vivo bone formation}

The fact that various in vitro osteoinducers do not affect in vivo bone formation, demonstrates the need for a proper in vitro marker for in vivo bone formation. ALP is generally used as a marker of early osteogenic differentiation in vitro, but does not correlate with in vivo bone formation [26]. In a large study using hMSCs from 62 donors, our lab recently demonstrated that expression of the cellular-adhesion molecule-1 
(CADM1) correlates with in vivo bone formation and it is currently investigated if this marker can also be used to predict or enhance in vivo bone formation. Most likely, the best prediction is not based on a single marker, but on a combination of markers. Besides genotyping of cells, the secretion of trophic factors could provide a new approach in determining the ideal state of hMSCs for bone tissue engineering. This is supported by the fact that scaffolds which induce high gene expression levels of BMP-2 induce relatively larger amounts of bone than non-BMP-2-inducing counterparts [27]. Another study, by He et al. similarly showed that secretion of osteopontin and VEGF was dependent on the hydroxyapatatite content of scaffolds and that this also correlated to in vivo bone formation [28]. Identification of proper markers (for example protein secretion) could aid in predicting the performance of cells and in optimizing differentiation protocols.

\section{Training of hMSCs}

Throughout this thesis we showed that it is possible to alter the secretome of hMSCs by treatment with small molecules. We have demonstrated this for bone tissue engineering (db-cAMP induces secretion of bone-specific growth factors) and for angiogenesis (phenanthroline induces secretion of angiogenic growth factors). Whether these secreted growth factors exert effects in vivo remains to be investigated, but this approach opens a window to improve the performance of hMSCs in numerous clinical applications. In chapter 8 , we used a screen on a cell line with an hypoxia responsive element, to identify activators of the hypoxia inducible factor-1 (HIF-1) pathway, and found a novel compound that induces secretion of angiogenic growth factors. Such a screen can thus be used to identify small molecules but also materials or topographies that stimulate or inhibit secretion of specific growth factors. Secretion of angiogenic factors could facilitate angiogenesis in a tissue engineered construct, but this principle can also be applied to myocardial infarcts and kidney failure or islet transplantation in diabetes, where the survival of, and vascularization around, the islets is crucial for successful implantation. Co-transplantation of islets with MSCs is currently under investigation, and properly designed scaffolds that induce secretion of pro-survival and pro-angiogenic factors by MSCs could improve function of implanted islets. On the other hand, in cartilage tissue engineering, vascularization leads to endochondral bone formation and thus should be prevented. In vitro, co-cultures of MSCs and chondrocytes displayed improved matrix formation and scaffolds or small molecules that reduce secretion of VEGF by MSCs may offer possibilities in this case. More specifically for bone tissue engineering, monitoring BMP-2 secretion in high throughput screens using cell lines with a BMP responsive element, can provide new hits when screening small molecules, materials or surface topographies. 


\section{Conclusions}

To conclude, hMSCs are still one of the most promising cell types for cell therapy and regenerative medicine applications, but donor variability and the quality of cells from patients with chronic diseases deserve more attention. Consistency in culture/ study protocols between laboratories and large, controlled clinical trials are crucial to define the true potential of hMSCs. A better understanding of activation patterns and downstream mechanisms of signaling pathways is required and then, to improve their performance, these cells can be treated with small molecules, or used on scaffolds with specific surface characteristics, which can be identified using high throughput screens. 


\section{References}

1. Siddappa R, Mulder W, Steeghs I, Klundert VD, et al. (2009) Tissue Eng Part A 15, 2135-2143

2. Siddappa R, Martens A, Doorn J, Leusink A, et al. (2008) Proc Natl Acad Sci U S A 105, 72817286

3. Rubio D, Garcia-Castro J, Martin M, de la Fuente R, et al. (2005) cancer research 65, 30353039

4. (2010) cancer research 70, 6682

5. $\quad$ Wong R. (2011) J Biomed Biotechnol 2011, 459510

6. $\quad$ Kim H-J, Im G-I. (2009) Journal of Orthopaedic Research 27, 612-619

7. Duque G. (2008) Curr Opin Rheumatol 20, 429-434

8. Le Blanc K, Tammik C, Rosendahl K, Zetterberg E, et al. (2003) Experimental Hematology 31, 890-896

9. Zhao Y, Ding S. (2007) Proc Natl Acad Sci U S A 104, 9673-9678

10. Yang D-c, Tsay H-j, Lin S-y, Chiou S-h, et al. (2008) PLoS ONE 3, e1540

11. De Boer J, Siddappa R, Gaspar C, Van Apeldoorn A, et al. (2004) Bone 34, 818 - 826

12. De Boer J, Wang HJ, Van Blitterswijk CA. (2004) Tissue Eng 10, 393-401

13. Muruganandan S, Roman AA, Sinal CJ. (2008) Cell Mol Life Sci 66, 236-253

14. Laudes M. (2011) J Mol Endocrinol 46, R65-R72

15. de Rooij J, Zwartkruis FJT, Verheijen MHG, Cool RH, et al. (1998) Nature 396, 474-477

16. Petersen RK, Madsen L, Pedersen LM, Hallenborg P, et al. (2008) Mol Cell Biol 28, 3804-3816

17. Ji Z, Mei FC, Cheng X. (2010) Front Biosci (Elite Ed) 2, 392-398

18. Martini C, Plaza M, Vila M. (2009) Mol Cell Endocrinol 298, 42-47

19. De Boer J, Licht R, Bongers M, Van Der Klundert T, et al. (2006) Tissue Eng 12, 2927-2937

20. De Kok IJ, Hicok KC, Padilla RJ, Young RG, et al. (2006) J Oral Implantol 32, 103-109

21. Johnson JS, Meliton V, Kim WK, Lee K-B, et al. (2011) Journal of Cellular Biochemistry 112, 1673-1684

22. Koch H, Jadlowiec JA, Campbell PG. (2005) Stem Cells Dev 14, 621-631

23. Walsh S. (2003) Bone 33, 80-89

24. Jeong W-K, Park S-W, Im G-I. (2008) J Biomed Mater Res A 86A, 1137-1144

25. Chen F-M, Chen R, Wang X-J, Sun H-H, et al. (2009) Biomaterials 30, 5215-5224

26. Siddappa R, Licht R, van Blitterswijk C, de Boer J. (2007) J Orthop Res 25, 1029-1041

27. Yuan H, Fernandes H, Habibovic P, de Boer J, et al. (2010) Proc Natl Acad Sci U S A 107, 1361413619

28. He J, Genetos DC, Leach JK. (2010) Tissue Eng Part A 16, 127-137 


\section{Summary}

Opportunity is missed by most people because it's dressed in overalls and looks like work.

- Thomas Edison 


\section{Summary}

The average life expectancy has increased dramatically over the past centuries and, as a consequence, people have to deal more and more with (typical elderly) diseases, which clearly postulates the need for tissue engineering and stem cell therapies. Tissue engineering aims to restore or replace a malfunctioning tissue completely, whereas stem cell therapy mainly utilizes single cells to improve function.

As reviewed in chapter 2 human mesenchymal stromal cells (hMSCs) are an interesting source for cell therapies and tissue engineering applications, because these cells are able to differentiate into various target tissues, such as bone, cartilage, fat and endothelial cells. In addition, these cells secrete a wide variety of growth factors and cytokines that exert effects on surrounding cells, including immunomodulatory, proangiogenic, pro-survival, anti-scarring and anti-apoptotic effects. A large number of clinical trials is currently employed to investigate the use of MSCs and their trophic effects in, amongst others, autoimmune diseases, myocardial infarcts and kidney failure. However, so far results are conflicting and more standardized protocols should be implemented to be able to compare studies and draw conclusions.

For bone tissue engineering applications, the differentiation of MSCs into bone (osteogenic) cells prior to implantation is believed to enhance their bone forming capacities, but not every compound that induces differentiation also induces bone formation in vivo. We have shown before that treatment with the small molecule dbcAMP, which activates the protein kinase A (PKA) pathway, enhances both in vitro differentiation and in vivo bone formation and in chapter 3 we have tried to optimize this differentiation protocol by examining other compounds that activate PKA. We found that forskolin, a more upstream activator of PKA also increases bone formation and, although the amounts of bone were not significantly higher than after treatment with db-cAMP, this confirms our previous findings.

Besides the type of PKA activator, the duration and/or strength of the signal also determines downstream effects. In chapter 4 we show that various GPCR ligands, which activate the PKA pathway upon binding to their receptor, have no effect on osteogenic differentiation, and that, whereas continuous stimulation of hMSCs with db-cAMP results in an increase in ALP expression, intermittent exposure to db-cAMP for 2-8 hours per day results in decreased ALP expression. This suggests that not the concentration, but the duration of the signal determines the downstream effects of PKA activation.

In addition to these findings, in chapter 5, we found that treatment with another cAMP-analogue (8-br-cAMP) induces adipogenic differentiation of hMSCs, an effect even stronger when combined with high concentrations of dexamethasone. This suggests that PKA is not only involved in osteogenic differentiation, but balances differentiation 
into the osteogenic or adipogenic lineage. Our data points to a stronger effect of 8-brcAMP on PKA and cAMP responsive genes and it has been suggested that, at higher concentrations of cAMP, additional effects are exerted via Epac, which is involved in adipogenic differentiation. Thus, higher PKA activity or activation of Epac may correlate with adipogenic differentiation.

In chapter 3 it was already demonstrated that insulin-like growth factor-1 (IGF-1) and bone-morphogenetic protein-2 (BMP-2) gene expression are increased upon activation of PKA in hMSCs. As discussed above, secreted growth factors can also exert effects on surrounding cells and in chapter 6 we found that treatment of hMSCs with db-cAMP indeed results in secretion of bone-specific growth factors and that these growth factors are biologically active. When fresh cells were cultured in conditioned medium from untreated MSCs or from cAMP-treated MSCs, cells demonstrated higher proliferation in medium from cAMP-treated MSCs. In addition, cAMP-conditioned medium increased expression of osteogenic genes, thus demonstrating the activity of bone specific growth factors in this medium and also suggesting that these growth factors can contribute to new bone formation upon implantation of the cells.

Since we found in chapter 6 that IGF-1 is highly induced upon treatment with dbcAMP, in chapter 8 we investigated the effects of this growth factor on hMSCs, since previous research has shown conflicting results. We found that recombinant human IGF-1 increases proliferation and differentiation of hMSCs, but their response was dependent on the use of serum and the concentration. To investigate the effects of overexpression of IGF-1, we adenovirally transduced MSCs with adIGF-1, adBMP-2 or both. We found that, compared to mock-transduction, bone formation was slightly increased in adIGF-1 samples whereas adBMP-2 induced high amounts of new bone formation. The combined transductions of adIGF-1 and adBMP-2 showed even larger amounts of bone. Interestingly, we found increased amounts of secreted BMP-2 after cotransductions, suggesting that adIGF-1 facilitated adBMP-2 transduction. However, due to the increased BMP-2 secretion, it is not possible to draw any conclusions regarding the effect of IGF-1 on bone formation.

Besides secretion of osteogenic growth factors, the secretion of angiogenic growth factors might facilitate vascularization of a bone tissue engineered construct, which is crucial for the survival of cells. In addition, the therapeutic effects of hMSCs in myocardial infarcts or kidney failure is thought to be largely due to angiogenic factors, and enhanced secretion might thus improve their therapeutic potential. Culture of cells in an hypoxia chamber increases secretion of angiogenic factors and this indeed enhances therapeutic potential. However, hypoxia cultures are labor-intensive and expensive and therefore, in chapter 8 we performed a high throughput screen on an immortalized MSC line containing an hypoxia responsive element to identify a small molecule that 
activates the hypoxia inducible factor-1 (HIF-1) signaling pathway. Phenanthroline was identified as the most promising hit and further investigation of the mechanisms revealed that this compound induces strong expression of HIF-1 target genes and, most interesting, induced expression and secretion of interleukin-8, whereas hypoxia and the well-known hypoxia mimic desferoxamine had no effect on interleukin-8. We showed that conditioned medium derived from phenanthroline-treated cells has similar effects as hypoxia-conditioned medium and this compound thus offers a good alternative. 


\section{Samenvatting}

Voetballen is simpel, maar het moeilijkste wat er is, is simpel voetballen.

- Johan Cruijff 


\section{Samenvatting}

De gemiddelde levensverwachting is de laatste jaren enorm gestegen, met als gevolg dat het aantal ouderdom-gerelateerde aandoeningen ook toeneemt. Weefseltechnologie en stamcel therapieën zijn dus hard nodig. Weefseltechnologie (of tissue engineering) heeft als doel het vervangen of repareren van een defect weefsel waarbij cellen worden gecombineerd met een dragermateriaal, terwijl in stamcel therapieën vaak gebruik wordt gemaakt van losse cellen.

Zoals samengevat in hoofdstuk 2, vormen humane mesenchymale stamcellen (hMSCs) een interessante bron van stamcellen voor cel therapieën en weefseltechnologie. Dit omdat deze cellen in staat zijn zich te vormen tot verschillende weefsels, zoals bot, kraakbeen, vet en endotheel. Ook scheiden deze cellen een groot aantal groeifactoren uit welke de omgeving kunnen beïnvloeden. Deze kunnen bijvoorbeeld een immunologische reactie reduceren, maar ook bijdragen aan neo-angiogenese, overleving van cellen en het voorkomen van littekenweefsel. Een groot aantal klinische onderzoeken is op dit moment bezig, of al afgerond, om deze immunologische en trophische effecten van MSCs te onderzoeken, voornamelijk voor autoimmuun ziekten, hartinfarcten en nierfalen. Hoewel soms veelbelovend, zijn de resultaten tot op heden echter nog niet erg consistent en de implementatie van gestandaardiseerde protocollen leidt er hopelijk toe dat verschillende studies onderling vergeleken kunnen worden en dat eenduidige conclusies kunnen worden getrokken.

Voor toepassingen in bot weefseltechnologie wordt er over het algemeen aangenomen dat de differentiatie van stamcellen naar botcellen de botformatie in vivo bevordert. Maar, niet elk molecuul dat differentiatie van hMSCs induceert, resulteert ook in een toename van de botformatie in vivo. We hebben al eerder aangetoond dat behandeling van hMSCs met het molecuul db-cAMP, waarmee de protein kinase A (PKA) signaal transductie route wordt geactiveerd, zowel de differentiatie als de botformatie verbetert. In hoofdstuk 3 hebben we deze differentiatie proberen te optimaliseren, door andere moleculen welke ook de PKA route activeren te onderzoeken, en we hebben hierbij aangetoond dat ook behandeling met forskolin een positief effect heeft op botformatie. Hoewel de hoeveelheden nieuw gevormd bot niet significant hoger waren dan met db-cAMP, bevestigt dit onze data dat activatie van PKA tot meer bot leidt.

Afgezien van het type PKA activator speelt ook de manier waarop PKA geactiveerd wordt een belangrijke rol, en dan vooral de lengte en de sterkte van het signaal. In hoofdstuk 4 laten we zien dat stimulatie van hMSCs met liganden voor de GPCR receptor, welke de PKA route zouden activeren, geen effect heeft op differentiatie van hMSCs. Ook had activatie van PKA met tussenpozen een tegengesteld effect vergeleken met continue stimulatie. Dit leidde tot een afname van de activiteit van alkalische phosphatase (een 
marker voor bot differentiatie), terwijl deze juist toenam door continue stimulatie. Dit suggereert dat niet alleen de sterkte, maar mede de lengte van het signaal bepaalt welk effect PKA activatie op de cellen heeft.

In hoofdstuk 5 zagen we dat stimulatie van hMSCs met een andere cAMP-analoog (8-br-cAMP) vet differentiatie induceert en dat dit effect nog sterker werd in combinatie met dexamethasone. Dit duidt erop dat PKA niet alleen betrokken is bij bot differentiatie, maar ook een rol speelt in de balans tussen vet en bot differentiatie. Onze data wijst er verder op dat behandeling met 8-br-cAMP leidt tot een sterkere activatie van PKA en cAMP-doelgenen. Ander onderzoek suggereert dat bij hoge concentraties niet alleen PKA, maar ook Epac, welke betrokken is bij vet differentiatie, wordt geactiveerd. Hogere PKA activiteit of activatie van Epac lijkt dus te correleren met vet differentiatie.

In hoofdstuk 3 lieten we zien dat de genexpressie van insulin-like growth factor (IGF1) en bone-morphogenetic protein-2 (BMP-2) toenemen na activatie van PKA in hMSCs. Wanneer deze groeifactoren door de cel worden uitgescheiden, kunnen ze de cellen in de omgeving beïnvloeden. In hoofdstuk 6 laten we zijn dat behandeling van hMSCs met $\mathrm{db}$-cAMP inderdaad leidt tot een toename van deze groeifactoren in het medium, en dat deze biologisch actief zijn. Geconditioneerd medium van db-cAMP-behandelde cellen verbeterde de groei en de bot differentiatie van hMSCs, vergeleken met medium van niet-behandelde cellen. Dit wijst erop dat deze uitgescheiden groeifactoren een rol kunnen spelen bij de botformatie in het lichaam.

Aangezien we in hoofdstuk 6 zagen dat IGF-1 in hoge concentraties wordt uitgescheiden na behandeling met db-cAMP, hebben we in hoofdstuk 8 gekeken welke effecten IGF-1 heeft op hMSCs. We vonden hierbij dat IGF-1 de groei en differentiatie van hMSCs bevordert, maar de aanwezigheid van serum en de gebruikte concentratie spelen hierbij een belangrijke rol. Vervolgens is het effect van IGF-1 overexpressie op botformatie onderzocht, door MSCs adenoviraal te transduceren met adIGF-1, adBMP-2 of beide. We vonden hierbij dat, vergeleken met een mock-transductie, de botformatie enigszins was verhoogd in de adIGF-1 groep, terwijl grote hoeveelheden bot waren gevormd in de adBMP-2 groep. Nog meer bot was gevormd in de co-transductie groep (adIGF-1 en adBMP-2). Opmerkelijk was dat de secretie van BMP-2 in deze groep hoger lag dan na transductie met BMP-2 alleen, wat erop duidt dat adIGF-1 de transductie met adBMP-2 bevordert. Echter, hierdoor kunnen geen conclusies worden getrokken over het effect van IGF-1 op BMP-2-geïnduceerde botformatie.

Naast de secretie van bot groeifactoren, zou de secretie van angiogene groeifactoren de formatie van bloedvaten in een construct kunnen bevorderen, wat cruciaal is voor het overleven van de cellen. Aangezien de therapeutische effecten van MSCs in hartinfarcten en nierfalen ook grotendeels worden toegedicht aan de secretie van 
dit soort groeifactoren, zou een toename van deze uitgescheiden factoren ook in de weefselregeneratie de effecten van hMSCs kunnen verbeteren. Wanneer cellen onder lage zuurstofconcentraties (hypoxia) worden gekweekt scheiden ze meer van deze angiogene groeifactoren uit en nemen de therapeutische effecten inderdaad toe. Het kweken van cellen op deze manier is echter lastig en relatief duur. Daarom hebben we in hoofdstuk 7 een grote screen gedaan op een geïmmortalizeerde MSC lijn. Deze cellijn bevat een hypoxia response element (HRE) en hiermee kunnen moleculen die de hypoxia-inducible factor-1 (HIF-1) signaal transductie route activeren geïdentificeerd worden. Phenanthroline was de meest veelbelovende hit en verder onderzoek naar de mechanismen van dit molecuul liet zien dat deze sterke expressie van HIF-1 doelgenen induceert. Opmerkelijk was dat phenanthroline de expressie en secretie van interleukine-8 verhoogde, terwijl hypoxia en de bekende hypoxia-mimiek desferoxamine geen effect hadden op interleukine-8. Verder laten we zien dat geconditioneerd medium van phenanthroline-behandelde cellen dezelfde effecten heeft als geconditioneerd medium van hypoxia cellen, en dit molecuul vormt dus een goed alternatief. 


\section{Dankwoord}

I get by with a little help from my friends.

- The Beatles 


\section{Dankwoord}

Tot slot het hoofdstuk dat de meeste mensen als eerste lezen, en velen misschien als enige... Zowel mijn wetenschappelijke als mijn persoonlijke ontwikkeling is ruwweg weer te geven in een zelfde soort signaal transductie route schema als die van de cAMP / PKA route in hoofdstuk 3. Er zijn mensen die veelal de wetenschappelijke ontwikkeling hebben gestimuleerd en daarmee mijn sociale leven hebben geremd, of andersom, maar velen hebben ook beiden weten te stimuleren. Over het algemeen denk ik dat er meer activatoren dan remmers actief waren, en dat ik me hierdoor op beide vlakken behoorlijk heb weten te ontwikkelen.

Ik zou een compleet tweede proefschrift kunnen schrijven met een persoonlijk woordje voor alle collega's, vrienden en familie die hebben geholpen bij experimenten, artikelen, het proefschrift of gewoon als alles even tegenzat, maar daar heeft niemand zin in (ik al zeker niet), en ik heb dus geprobeerd dit dankwoord enigszins beperkt te houden. Desondanks volgen er nu een stuk of wat pagina's met persoonlijke woorden voor een aantal mensen die mij bijzonder hebben geholpen bij dit proefschrift of die mij erg dierbaar zijn.

Geheel tegen de gewoonte in begin ik niet met het bedanken van mijn promotor. Simpelweg omdat mijn co-promoter een stuk bemoeizuchtiger was. Jan; zonder jouw visie, kritiek, motivatie en vooral tomeloze ideeën had dit proefschrift er niet zo uitgezien. Natuurlijk heb ik veel van je geleerd, maar belangrijker nog, je hebt jouw enthousiasme voor alles wat te maken heeft met biologie, signaal transductie routes, genetica en stamcellen op mij weten over te dragen. Bedankt voor de kans om te doen wat ik echt leuk vond, de vrijheid en voor je open manier van begeleiden. Als tweede dan toch, dank ook aan mijn promoter, Clemens, natuurlijk omdat je mij een kans gaf in jouw lab, maar ook voor je input en de kritische vragen en opmerkingen tijdens werkbesprekingen die mij aan het denken hebben gezet over dit onderzoek. Ook bedankt voor het beschikbaar stellen van de TR-shirts, waardoor het TR-futsal team eindelijk de professionele uitstraling kreeg die het verdiende.

Uiteraard ben ik ook grote dank verschuldigd aan mijn paranimfen, voor hulp tijdens en voorafgaand aan de promotie, maar vooral ook voor de goede gesprekken, de gezelligheid en een hoop afleiding tijdens koffie met muffins, champagne met toastjes en biertjes met falafel in voornamelijk dat laatste jaar. Nathalie, bedankt voor je hulp met de microarrays, ik kijk alweer uit naar 't volgende Science cafe met 'nog 1 biertje' bij de Xoun borrel na. Eelco, misschien over een paar jaar mijn aanvrager in 't UMCG? Hopelijk kunnen we daar onze koffie momentjes dan gewoon weer oppakken.

A number of people, from the University of Twente as well as from other laboratories, have helped me especially on the research part, although unfortunately not all the work 
has been included in this thesis. Allereerst, Maarten, mijn enige masterstudent in de afgelopen 4 jaar, maar ik heb het dan ook flink druk met je gehad. Even alle gekheid op een stokje, ik was erg blij met jouw keuze voor mij als afstudeerbegeleider. Het was een leerzame periode, maar wat mij betreft ook nog eens een hele leuke en gezellige, waar ik zeker een paar mooie herinneringen aan heb. Bedankt voor al je hulp; met de data, maar ook met 'ons' artikel. Alle succes met je eigen promotie! Grote dank ook aan Peter ten Dijke, Maarten van Dinther en Nils Visser, voor het beschikbaar stellen van de virussen en cellijnen en het verzorgen van mijn eerste kennismaking met (lentivirale) infecties. Eigenlijk was op dat moment alles nog nieuw voor mij en jullie geduld en behulpzaamheid waren zeer prettig. Dank ook aan Marco Harmsen en Guido Krenning, die zo vriendelijk waren om mij enkele dagen op hun lab te ontvangen en alle tips en trucs op het gebied van HUVECs bij te brengen. Een speciaal bedankje voor Jeroen, voor al zijn geduld, uitleg en hulp met de microarrays, de analyses en de artikelen, maar ook gewoon voor een paar hele leuke dagen in Rotterdam. Toch jammer van die d-map. Hans, bedankt voor het beschikbaar stellen van Jeroen en de microarray apparatuur, en natuurlijk voor het plaatsnemen in de commissie. Scott en Jan; thanks for letting me do the work that was not allowed in my own lab. And, of course, for teaching me how to do so. Extra thanks to Scott for the implantations, the stainings and his help with the manuscript. Leuven is a great place and not only to work! Paul, bedankt voor je ideeën, je input en de discussies. Zeen en Margreet bedankt voor het uitvoeren van de matrigel assays, en zeker ook voor de quantificering! Guido Moll and Katarina, thanks for your input and ideas regarding the review. Guido, thanks as well for your help with the figures and Katarina for taking place in my committee! Henk-Jan en Anton, bedankt voor het beschikbaar stellen van materialen, voor discussies, input en gezelligheid tijdens diverse congressen en vooral ook voor een paar hele leuke, gezellige dagen in Barcelona! Pim, Myrthe, Stefan en Stefan, bedankt voor een leerzame ervaring en een paar gezellige dagen op het lab. Tot slot, Johan, Koen en Joost; bedankt voor het lezen van dit hele proefschrift en het plaatsnemen in de commissie.

At this place I would also like to express my appreciation once more towards the people where I first started my 'career' in Tissue Engineering; Prof. Dietmar Hutmacher and Dr. Mia Woodruff. Thanks to you, as well as to the whole former department of tissue engineering at NUS, for making me feel very welcome and for giving me the great opportunity to work there.

Then, to the TR group in Enschede. With such a large department, where many people are both collegues and friends, I have a long list of people with whom I've shared more than medium;

Anouk, Ineke en Jacqueline; mijn eerste officiële kantoorgenoten. Ik heb altijd met veel plezier (soms misschien teveel?) een kantoor met jullie gedeeld. De gezelligheid, maar 
vooral ook het luisterend oor en de echte gesprekken tijdens de moeilijke momenten in dat eerste jaar waardeer ik enorm. Misschien nog eens een etentje? Speciale dank aan Anouk voor een paar leuke uitjes (bel je me als je weer eens een incubator op gaat halen?) en assistentie op het lab!

Andre (I don't think I will ever get used to calling you Hugo), obrigado; basically for everything. Our chats, our dinners, good conversations, you caring, your help in the lab, and your help in the lab again. I will never forget our cold trip to snowy Germany (or you making fun of me stressing out) or the warm welcome in Portugal. Hugo, this thesis would not have been the same without you. Thanks for sharing your work with me, for always joining futsal games and for having the courage to travel with me to Leiden (and back). Let's hope that Sporting (or any other Portugese team) never beats Twente again. Jun, thanks for the nice chats and the fun times in- and outside the office, the Wii parties and the Chinese specialties. Champions league final at your place this year? Ram, a special thanks to you. The one to introduce me to cAMP and all the CREB that came with it. I still don't understand why we laughed at that nerdy joke every time. I could not have asked for a nicer supervisor and I'm glad we also became friends. Thanks for all your help during my master but also with this thesis. All the best with your family, becoming a true Dutch and your career in science, management or something in between!

Paul. Thanks for all those tea-breaks in which I could ventilate my frustrations, irritations, disappointments and, sometimes, also triumphs. Although, of course, usually I listened and you did the talking. Thanks also for moving to Pisa and providing me with a holiday retreat, but it was better having you around in Enschede.

Audrey, bedankt voor al je praktische hulp met dit proefschrift en de promotie, maar ook voor allerlei kleine dingetjes in de afgelopen jaren. Jammer dat ons skeeler-clubje nooit echt van de grond is gekomen. Ana, thanks for bringing people together in many dinners and for good and funny conversations, both in and outside the lab. Looking forward to your thesis! Karolina, thanks for a very nice Polish wedding, the Polish cuisine (or actually, thanks Maciek for that) and for your help on the HUVECs. Hemant, thanks for the coffees, the Mars, Snickers and cigars and a great football session on the beach of Terschelling. We've also shared more serious conversations and I hope you will come to see that many people want the best in life for you. Nicolas, thanks for your humorous input during various get-togethers and a very nice trip in Granada. Gustavo, erg leuk om je bij de oranje-gekte van het nederlands elftal te hebben. $\mathrm{Nu}$ je genaturaliseerd bent.. het nederlands elftal kan nog steeds een goede keeper gebruiken. Heel veel geluk in de nabije toekomst voor Clara en jou! Pamela, bedankt dat je mijn 'date' wilde zijn tijdens het TERMIS galadiner, maar ook voor gezellige, serieuze of behulpzame lunches. Anand, thanks for being a friend and showing me around (badminton!) when I came to Singapore. I was happy to pick you up from the busstation one year later when you arrived in The Netherlands, but you didn't need much help. Lorenzo, de eerste promotie 
waar ik bij was, was de jouwe. En niet alleen daarmee heb je een heel goed voorbeeld gesteld. Anindita, I thought I was talking fast, but you easily win. Thanks for some nice discussions and some good laughs. Looking forward to your thesis in the near future! Jojanneke, bedankt voor je mentoring toen ik net begon en het introduceren van het foute uur. Wat was er van de TeRM terecht gekomen zonder jou? Anne, Mijke, Wim en Janneke; bedankt voor alle gezelligheid tijdens de TERMIS 2011, ik heb me enorm vermaakt! Janneke, ook heel erg bedankt voor alle tijd en moeite die je in de Raman en SEM hebt geïnvesteerd, het ging niet vanzelf. Verder heb ik ook een hele leuke tijd gehad met jou als buurvrouw, je goede gevoel voor humor, je vriendelijkheid en het feit dat je (bijna) altijd vrolijk bent maken jou een van de leukste mensen om een bureau naast te zetten! Anne, bedankt voor al je mooie verhalen en je kaartleestalent. De reis was het waard. Mijke, bedankt voor je enthousiasme, je iniatieven en je vrolijkheid! Wim, bedankt voor je hulp bij 't kopen van de buskaartje. Bij 't volgende Science Cafe drink je gewoon dat laatste biertje mee toch? Ellie en Nicole, altijd goed om even bij te kletsen en de laatste 'nieuwtjes' uit te wisselen! Tim and Parthiban; thanks for making those last stressful months in the office a little more bearable.

To everybody else.. thanks to all of you, for help in the lab, for making friday afternoon drinks a success and for joining sports events, dinners or other get-togethers, but mostly for making TR a great place to work!

Gelukkig had ik ook grote groepen mensen buiten de UT om me heen met een hele eigen, frisse kijk op de zaak. Allereerst natuurlijk grote dank aan alle (oud)WBW 3952-ers, voor alle gezelligheid tijdens stapavonden, Lowlands, verjaardagen, nachtenvan-Drienerlo, concerten, zeilweekenden, huisfeesten, campingfeesten, Twentekampioensfeesten, pre-skifeesten, apres-skifeesten, oud-en-nieuw feesten en alle andere thema-feesten. Maar vooral ook bedankt voor alle geweldige, prachtige, soms ietwat overdreven verhalen (ook als ik er zelf niet bij was) die hieruit zijn ontstaan. Ook InfusiX bedankt voor vele leuke avonden en uitjes zowel tijdens de studie als daarna, tijdens vakanties, borrels, kerstdiners, gala's en feestjes! De scouting-groep uit Twello; als slechts aanhang, zonder enige scouting-ervaring of affiniteit met motors voel ik me toch helemaal opgenomen in de groep. Bedankt voor de interesse, gezellige avonden, mooie voorstellingen en skivakanties! Ook dank aan de vrienden van collega-dispuut Xoun voor gezelligheid tijdens EK's, WK's, gala's, etentjes, Twente-wedstrijden, een weekendje Cabo Polonia, Mario Kart sessies en, gewoon, borrels.

Dan zijn er nog een aantal mensen uit Emmeloord en omstreken die hier niet mogen ontbreken. Meike, Mariëtte, Lisanne en Suzanne (en aanhang), altijd ouderwets gezellig en nog net als vroeger, alsof we elkaar nog wekelijks spreken! Ooms en tantes, Karin \& Johan en de schoonfamilie uit Twello en omstreken; ik waardeer jullie interesse in mijn werk en het onderzoek enorm. Heel erg leuk dat jullie zo betrokken zijn en heel 
bijzonder dat een aantal van jullie helemaal naar Twente is afgereisd om eens een dag in het lab te komen kijken. Voor jullie is dit misschien een speciale dag, maar het is ook voor mij heel bijzonder dat jullie er allemaal bij zijn.

Pap, mam, Remko, Sander \& Hilde; voor jullie geldt natuurlijk hetzelfde. Misschien zijn mijn artikelen niet altijd helemaal duidelijk maar het feit dat jullie er naar vragen, ze opzoeken, bekijken en er nog vragen over stellen ook, vind ik helemaal te gek. Bedankt voor de mogelijkheid om te gaan studeren, voor alle interesse, voor de onvoorwaardelijke steun, en natuurlijk voor alle hulp met mijn talloze verhuizingen, mijn nog tallozere computerproblemen en alle andere dingen de afgelopen jaren!

Lieve Bram. Wat jou betreft kan ik het waarschijnlijk houden bij een simpel 'Bedankt hè'. Toch wil ik je ook graag zeggen dat ik je hulp met de figuren, de heatmaps, de GUIs en de cellcounter enorm waardeer maar, veel meer nog, dat je deze met zoveel enthousiasme hebt gemaakt. Verder zijn er natuurlijk ook een hoop lieve vriendjevriendinnetje dingen die ik hier zou kunnen schrijven, maar die vertel ik je thuis wel. Dus, bedankt hè!

- Joyce 


\section{Curriculum Vitae}

Misschien moet je jezelf eerst tegenkomen voordat je het kunt zijn.

- Loesje 


\section{Curriculum Vitae}

Joyce Doorn was born on August 17th, 1983 in Emmeloord, The Netherlands. She grew up here and graduated high school (Zuyderzee College) in 2001. Then she moved to Enschede, where she started her study Biomedical Engineering at the University of Twente. She finished her Bachelor in 2005 at the department of Polymer chemistry and BioMaterials (prof. dr. Jan Feijen) under the supervision of dr. Bas Siebum and prof. dr. Dirk Grijpma. She continued her master in the direction of tissue engineering, and performed an internship at the National University of Singapore with prof. dr.

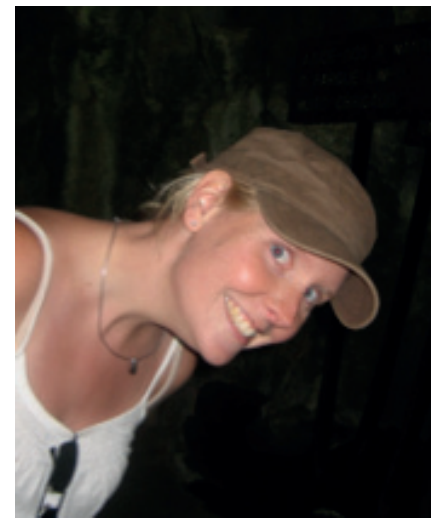
Dietmar Hutmacher. For her master assignment she went to the department of Tissue Regeneration (University of Twente) from prof. dr. Clemens van Blitterswijk, where she worked on protein kinase A signaling and osteogenic differentiation in human mesenchymal stromal cells under supervision of dr. Jan de Boer. After her graduation in 2007, she stayed at the MIRA institute to continue to work with dr. Jan de Boer on the research described in this thesis. Since november 2011 she has been working as an assistent clinical chemist at the department of Laboratory Medicine (University Medical Centre Groningen) under supervision of prof. dr. Ido Kema. 


\section{Publications and manuscripts}

Siddappa R, Martens A, Doorn J, Leusink A, Olivo C, Licht R, van Rijn L, Gaspar C, Fodde R, Janssen F, Van Blitterswijk CA, De Boer J. cAMP/PKA pathway activation in human mesenchymal stem cells in vitro results in robust bone formation in vivo. Proc Natl Acad Sci U S A. 2008 May 20;105(20):7281-6. Epub 2008 May 19.

Van Dinther M, Visser N, De Gorter DJ, Doorn J, Goumans MJ, De Boer J, Ten Dijke P, ALK2 R206H mutation linked to fibrodysplasia ossificans progressiva confers constitutive activity to the BMP type I receptor and sensitizes mesenchymal cells to BMP-induced osteoblast differentiation and bone formation J Bone Miner Res. 2010 Jun;25(6):120815.

Doorn J*, Siddappa R*, Liu J, Langerwerf E, Arends R, Van Blitterswijk CA, De Boer J. Timing, rather than the concentration of cyclic AMP, correlates to osteogenic differentiation of human mesenchymal stem cells. J Tissue Eng Regen Med. 2010 Jul;4(5):356-65.

Doorn J, Van de Peppel J, Van Leeuwen JPTM, Groen N, Van Blitterswijk CA, De Boer J, Pro-osteogenic trophic effects by PKA activation in human mesenchymal stromal cells, Biomaterials. 2011 Sep;32(26):6089-98

Doorn J, Siddappa R, Van Blitterswijk CA, De boer J, Forskolin enhances in vivo bone formation of human mesenchymal stromal cells, Tissue Engineering part A, sep 2011, accepted for publication

Doorn J, Moll G, Le Blanc K, Van Blitterswijk CA, De Boer J, Therapeutic applications of mesenchymal stromal cells; paracrine effects and potential improvements, Tissue engineering part B, oktober 2011, accepted for publication

Alves HA, Doorn J, Van Blitterswijk CA, De Boer J, Factors influencing the biological properties of mesenchymal stromal cell quality: implications for cell therapy, submitted

Doorn J, Leusink M, Groen N, Van de Peppel J, Van Leeuwen JPTM, Van Blitterswijk CA, De Boer J, Diverse effects of cyclic AMP variants on osteogenic and adipogenic differentiation of human mesenchymal stromal cells, submitted

Doorn J, Roberts SJ, Hilderink J, Van Apeldoorn AA, Van Blitterswijk CA, Schrooten J, De Boer J, Insulin-like growth factor-1 enhances proliferation and differentiation of human mesenchymal stromal cells, submitted 
Unadkat HV, Groen N, Doorn J, Fischer B, Barradas AMC, Hulsman M, Moroni L, Reinders MJT, Van Blitterswijk CA, De Boer J, High content imaging as a novel tool for automated analysis of biomaterial-induced cellular responses, submitted

Doorn J*, Fernandes HAM*, Van de Peppel J, Van Leeuwen JPTM, De Vries MR, Aref Z, Quax PHA, Van Blitterswijk CA, De Boer J, Hypoxia mimicing small molecules as a tool to train human mesenchymal stromal cells for revascularisation strategies, submitted

* Authors contributed equally 


\section{Abstracts selected for oral presentation}

J. Doorn, R. Siddappa, C.A. van Blitterswijk and J. de Boer, Optimizing protein kinase A activation to enhance osteogenic differentiation of human mesenchymal stem cells, Nederlandse vereniging voor Biomaterialen en Tissue Engineering, 2007, Lunteren, The Netherlands

J. Doorn, J. Plass, K. Janeczek, M. Karperien, O. Myklebost, C.A. van Blitterswijk and J. de Boer, Immortalized human mesenchymal stem cells as a biological model for bone tissue engineering applications, Nederlandse Vereniging voor Calcium en Bot, 2008, Zeist, The Netherlands

J. Doorn, C.A. van Blitterswijk and J. de Boer, Exploiting the secretome in regenerative medicine: a pro-osteogenic trophic effect by PKA activation in human mesenchymal stromal cells?, BMM-TeRM Annual meeting 2010, Ermelo, The Netherlands

J. Doorn, C.A. van Blitterswijk and J. de Boer, Exploiting the secretome in regenerative medicine: a pro-osteogenic trophic effect by PKA activation in human mesenchymal stromal cells? Dutch Biomedical Engineering Conference, 2011, Egmond aan Zee, The Netherlands

J. Doorn, C.A. van Blitterswijk and J. de Boer, Pre-treatment of human mesenchymal stromal cells for bone tissue engineering results in secretion of trophic, biologically active, growth factors, TERMIS-EU, 2011, Granada, Spain

\section{Abstracts selected for poster presentation}

J. Doorn, R. Siddappa, J. Liu, E. Langerwerf, R. Arends, C.A. van Blitterswijk and J. de Boer, Timing rather than the concentration of cyclic AMP correlates to osteogenic cell fate decision of human mesenchymal stem cells, Biology of stem cells, 2008, Paris, France

J. Doorn, R. Siddappa, J. Liu, E. Langerwerf, R. Arends, A. Renard, C.A. van Blitterswijk and J. de Boer, A role for Protein kinase A in osteogenic cell fate decision of human mesenchymal stem cells, International Society for Stem Cell Research, 2009, Barcelona, Spain

J. Doorn, C.A. van Blitterswijk and J. de Boer, Pre-treatment of human mesenchymal stromal cels for bone tissue engineering results in secretion of trophic, biologically active, growth factors, Nederlandse vereniging voor Biomaterialen en Tissue Engineering, 2010, Lunteren, The Netherlands 
J. Doorn, H. Fernandes, C.A. van Blitterswijk and J. de Boer, Hypoxia mimics as a tool to train human mesenchymal stromal cells for cell therapy applications, iSCT, 2011, Rotterdam, The Netherlands

J. Doorn, J. Hilderink, S.J. Roberts, J. Schrooten, C.A. van Blitterswijk and J. de Boer, Insulin-like growth factor-1 enhances proliferation and differentiation of human mesenchymal stromal cells, BMM-TeRM annual meeting, 2011, Ermelo, The Netherlands 
